\title{
WestVirginiaUniversity
}

THE RESEARCH REPOSITORY @ WVU

Graduate Theses, Dissertations, and Problem Reports

2010

\section{Enabling $\mathrm{HCCl}$ combustion of $\mathbf{n}$-heptane through thermo-chemical recuperation}

Francisco Posada Sanchez

West Virginia University

Follow this and additional works at: https://researchrepository.wvu.edu/etd

\section{Recommended Citation}

Posada Sanchez, Francisco, "Enabling HCCI combustion of n-heptane through thermo-chemical recuperation" (2010). Graduate Theses, Dissertations, and Problem Reports. 3011.

https://researchrepository.wvu.edu/etd/3011

This Dissertation is protected by copyright and/or related rights. It has been brought to you by the The Research Repository @ WVU with permission from the rights-holder(s). You are free to use this Dissertation in any way that is permitted by the copyright and related rights legislation that applies to your use. For other uses you must obtain permission from the rights-holder(s) directly, unless additional rights are indicated by a Creative Commons license in the record and/ or on the work itself. This Dissertation has been accepted for inclusion in WVU Graduate Theses, Dissertations, and Problem Reports collection by an authorized administrator of The Research Repository @ WVU.

For more information, please contact researchrepository@mail.wvu.edu. 
ENABLING HCCI COMBUSTION OF N-HEPTANE THROUGH THERMO-CHEMICAL RECUPERATION

by

Francisco Posada Sanchez

\author{
Dissertation submitted to the \\ College of Engineering and Mineral Resources \\ at West Virginia University \\ in partial fulfillment of the requirements \\ for the degree of
}

Doctor of Philosophy

in

Mechanical Engineering

\author{
Dr. Nigel N. Clark, Chair \\ Dr. Mridul Gautam \\ Dr. Hailin Li \\ Dr. Benjamin Shade \\ Dr. Kent Casleton
}

Department of Mechanical and Aerospace Engineering

Morgantown, West Virginia

2010

Keywords: HCCI Modeling, Thermo-Chemical Recuperation, Steam-Reforming, n-Heptane 


\section{ABSTRACT \\ Enabling HCCI Combustion of n-Heptane through Thermo-Chemical Recuperation}

\section{Francisco Posada Sanchez}

Concerns over air quality, environmental regulatory requirements and the need for reducing fuel consumption on conventional internal combustion engines (ICE) have motivated the development of alternative combustion processes for ICE. One alternative, homogeneous charge compression ignition (HCCI), has shown benefits of high efficiency with low $\mathrm{NO}_{\mathrm{x}}$ emissions, but suffers load range limitations and control issues. An increase in equivalence ratio at constant speed changes the combustion timing relative to top dead center (TDC), and also increases the pressure rise rate. The opposite occurs if the equivalence ratio is reduced, delaying the combustion timing with respect to TDC and reducing the peak pressure. Excessive heat release associated with richer mixtures drives the engine to ringing conditions, which sets the upper limit for HCCI operation. This thesis aims to investigate numerically the HCCI process under dual fuel operation. The secondary fuel stream bears different autoignition characteristics to regulate combustion timing and heat release at specific operational conditions. The secondary fuel stream is produced onboard as a reformed product of the primary fuel. The reforming process, which requires additional steam, takes advantage of the exhaust gases to convey the fuel reforming reactions, process that is called thermo-chemical recuperation (TCR). This thesis contributes to understanding the effects of different system conditions on the integrated HCCI-TCR system operational range and emissions of nitrogen oxides $\left(\mathrm{NO}_{\mathrm{X}}\right)$, and carbon monoxide $(\mathrm{CO})$.

Using n-heptane as the main fuel for HCCI combustion and fuel reforming, two different HCCI models are developed and validated. The single-zone model allows for studying the effect of the secondary fuel on combustion timing. A more complex model, the multi-zone model, allows for studying the effect of secondary fuel on overall engine performance and emissions. Both models operate under engine steady state assumptions (constant speed-load conditions). The combustion models were linked through a cycle simulation code to predict gas exchange processes, in particular the exhaust gas process which defines reforming conditions in the TCR. A model to predict the secondary fuel stream composition on the steam-fuel reformer, under steady state conditions, is developed and validated. Using $\mathrm{n}$-heptane and steam as reactants, the model is able to predict the reformed gas (RG) concentration at the reformer outlet as a function of reforming temperature and relative initial molar fractions of n-heptane and water. The model results are compared against experimental work on steam reforming of n-heptane. RG composition obtained is used to substitute n-heptane at the intake, which alters the HCCI combustion history and performance. Changes in combustion history concurrently affect the exhaust conditions, therefore affecting fuel reforming conditions. This interrelation between the HCCI and the TCR is studied with the integrated HCCI-TCR model. The effect of RG on HCCI combustion of n-heptane is to delay the combustion timing by affecting the concentration of combustion precursors. The effect on performance is highly dependent on overall HCCI-TCR conditions. Higher $\mathrm{H}_{2}$ output at the TCR improves calculated indicated mean effective pressure (IMEP) values and engine indicated thermal efficiency by delaying the combustion event while increasing the fuel-RG heating value. $\mathrm{NO}_{\mathrm{x}}$ predicted emissions are reduced with $\mathrm{RG}$ addition. CO predicted emissions increase with RG. 


\section{Acknowledgement}

I would like to acknowledge everyone who has contributed in my journey through engineering and graduate school. I specially thank my advisor Dr. Nigel Clark for the encouragement, guidance, lessons and support during the course of this research project, and for giving me the chance to work in the engines and emissions field. I want to thank also my other committee members Dr. Gautam, Dr. Li, Dr. Shade and Dr. Casleton for their guidance and for helping me shape this work. I want to thank the GTI team led by John Pratapas, and in special to Dr. Alexandr Koslov who was very helpful with the reforming modeling. Dr. Hailin Li of West Virginia University, and Dr. Vahid Hosseini of National Research Council Canada, deserve a special acknowledgment for providing the experimental data to validate the HCCI-TCR model. I want to thank Dr. Clint Bedick for being a wonderful partner in engineering work, and Dr. John Nuszkowski for introducing me to Cantera. I specially thank Dave McKain, for his openness in sharing the intricacies of emission data collection and analysis, and also thank Brad Ralston for his widely known patience teaching the ropes of emissions testing.

I want to thank my parents, Jaime and Trinidad for their constant support and for instilling in me the need for constantly doing the best since elementary school. I want to thank my sweet wife Elena for supporting me during these graduate student years, fueled by good food, love and humor. Finally, I would like to thank my brother, Camilo, and my good friends Manaseth and Ana Maria for the positive encouragement.

This project was sponsored by the US Department of Energy (DOE) under contract DE-FC2605NT42632. 


\section{Table of Contents}

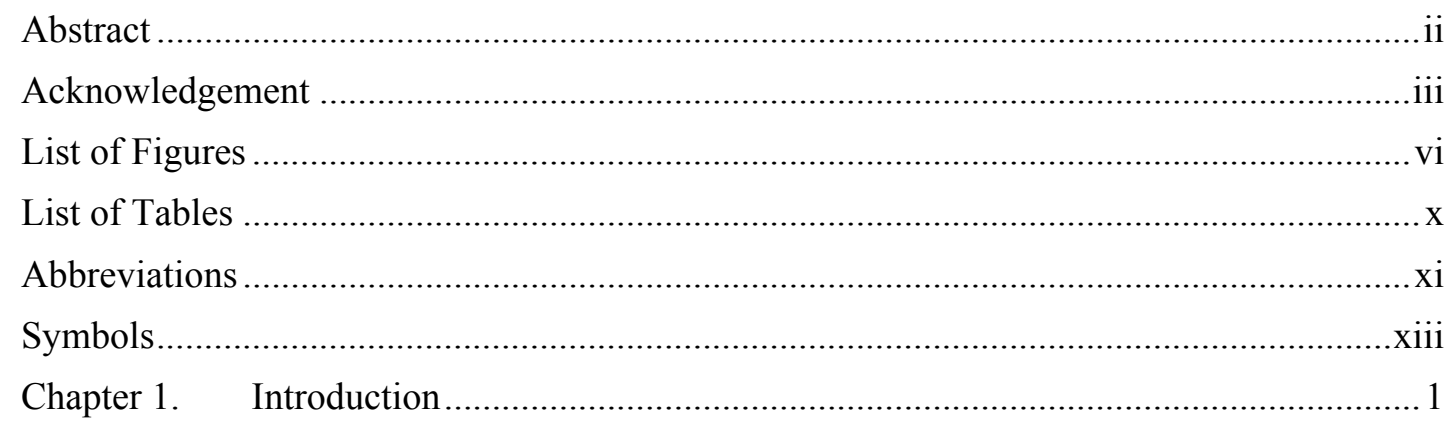

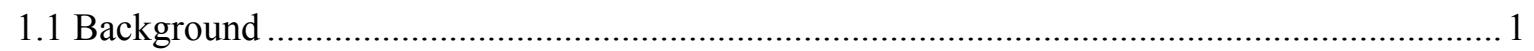

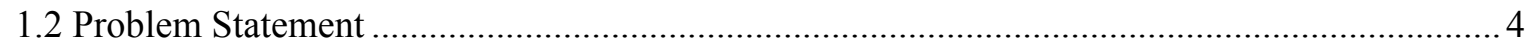

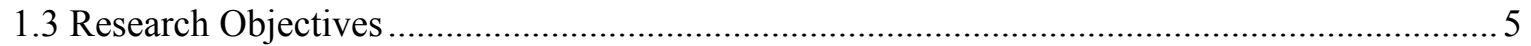

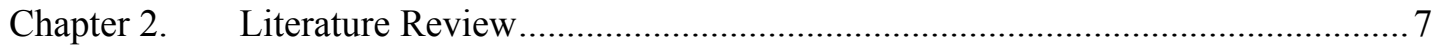

2.1 HCCI Combustion Characteristics ............................................................................. 7

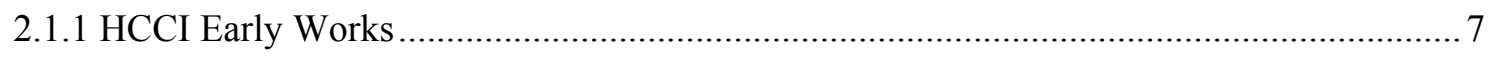

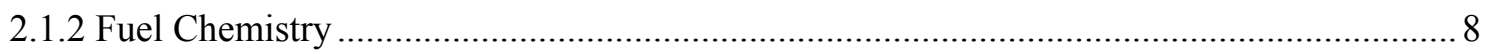

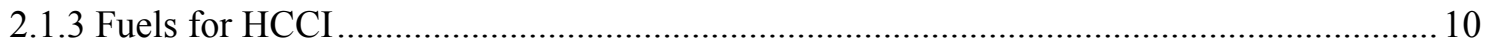

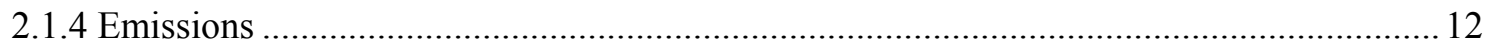

2.1.5 Efficiency, Operational Range and Combustion Stability ............................................ 13

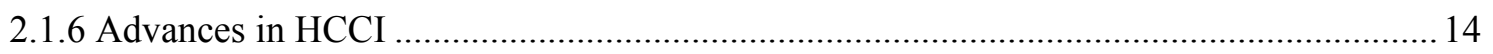

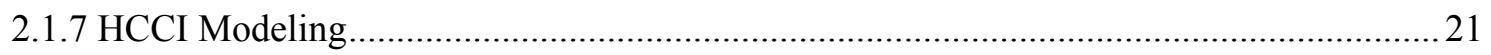

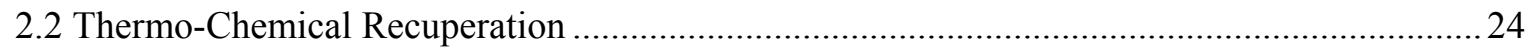

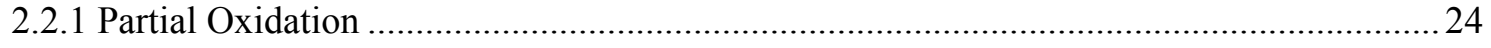

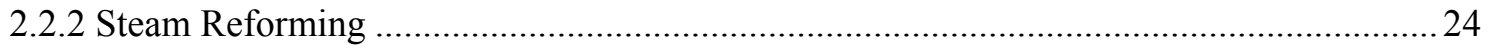

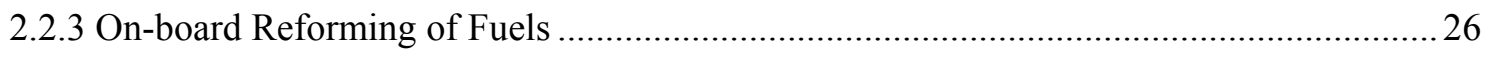

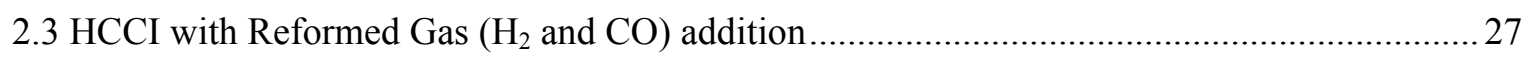

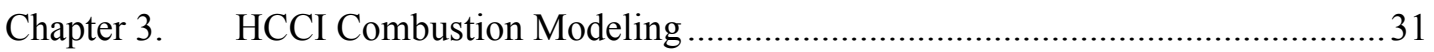

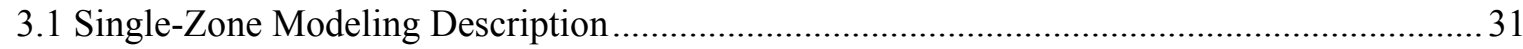

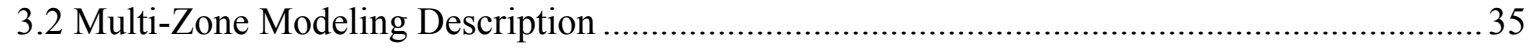

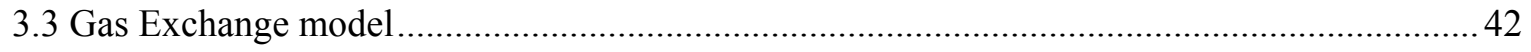

3.3.1 Exhaust Temperature Calculation for Thermo-Chemical Reforming .............................. 46

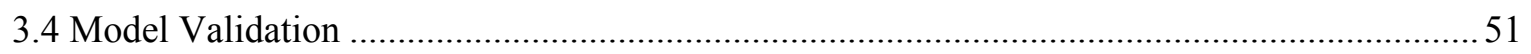

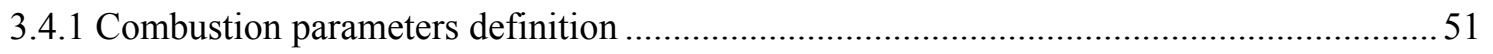

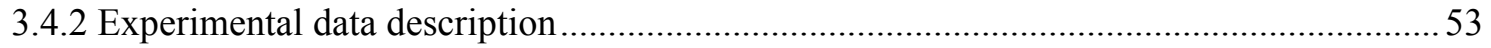

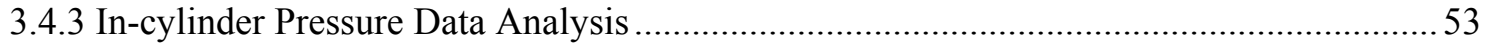

3.4.4 HCCI Model Validation. Adjustment of Chemical Kinetic Mechanism ...........................55

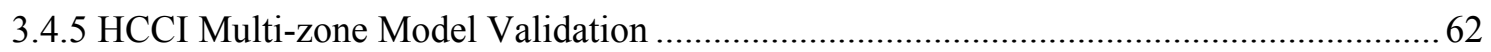


Chapter 4. Thermo-Chemical Recuperation

4.1 Comparative Analysis for Partial Oxidation and Steam Reforming ....................................... 71

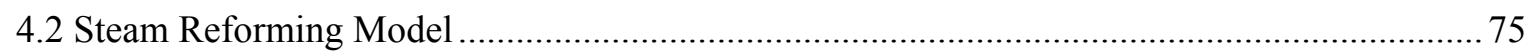

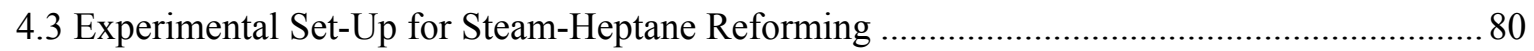

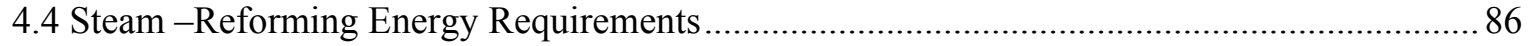

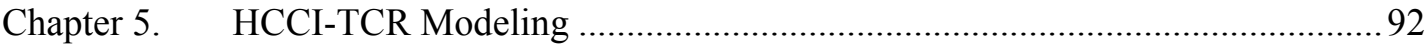

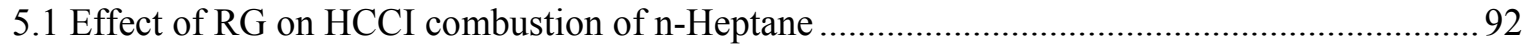

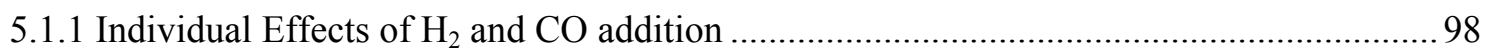

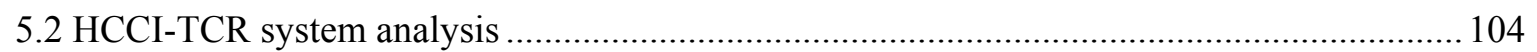

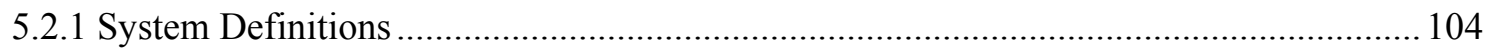

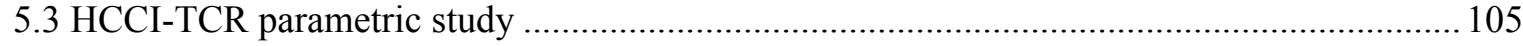

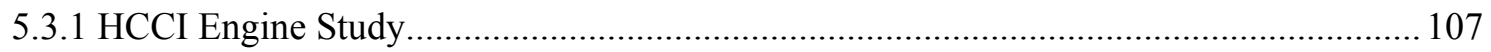

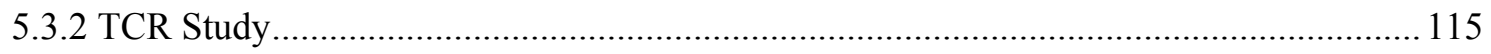

Chapter 6. Conclusions and Recommendations ........................................................ 118

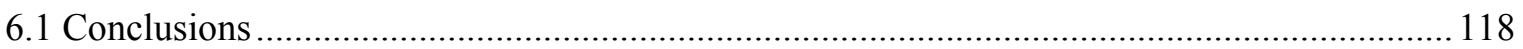

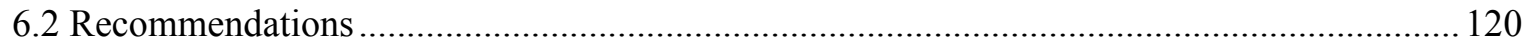

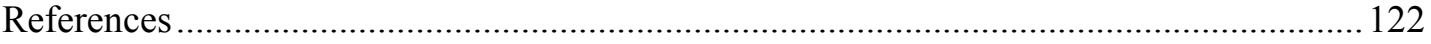

Appendix A. Experimental Data Variability ................................................................. 128 


\section{List of Figures}

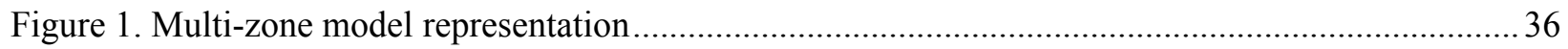

Figure 2. Multi-zone model flowchart for each crank angle degree .................................................... 41

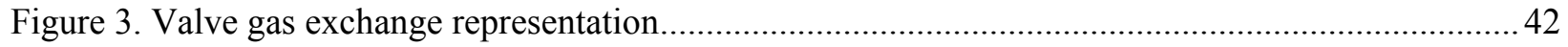

Figure 4. Effective open area $\left(A_{R}\right)$ profile for intake and exhaust valves............................................ 44

Figure 5. Calculated instantaneous mass flowrate of exhaust and intake gases, $\phi=0.35,900 \mathrm{rpm} \ldots \ldots \ldots \ldots . . . .46$

Figure 6. Calculated in-cylinder and exhaust gas temperature during the gas exchange period for two different equivalence ratios. EVC occurs at $5^{\circ}$ crank angle aTDC ................................................... 47

Figure 7. Instantaneous exhaust mass flowrate for a 4-cylinder model engine. $900 \mathrm{rpm}, \phi=0.35 \ldots \ldots \ldots \ldots . .48$

Figure 8. Instantaneous and time averaged exhaust temperature for a multi-cylinder (4-cyl) model engine.

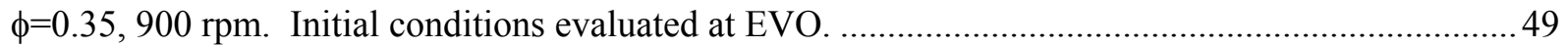

Figure 9. Calculated and experimental in-cylinder pressure during gas exchange processes. The main valve events are indicated. $\phi=0.35,900 \mathrm{rpm}$. Experimental in-cylinder pressure data from Guo et al.(2009) 50

Figure 10. In-cylinder mass history during gas exchange process at two different equivalence ratios and no EGR, and engine speed of 900rpm. Extreme left shows mass at EVO and extreme right at IVC.

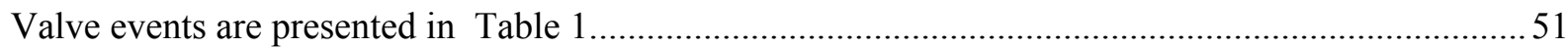

Figure 11. Definition of combustion parameters and its nomenclature .52

Figure 12. Comparison of experimental values and calculated pressure history during a complete cycle for HCCI combustion of $n$-heptane. $\phi=0.35,900 \mathrm{rpm}, \mathrm{P}_{\mathrm{int}}=1 \mathrm{~atm}, \mathrm{~T}_{\mathrm{int}}=310 \mathrm{~K}$

Figure 13. Experimental (dotted line) and calculated (continuous line) in-cylinder pressure history for different Air-fuel conditions. $\mathrm{P}_{\text {int }}=95 \mathrm{kPa}, \mathrm{T}_{\mathrm{int}}=310 \mathrm{~K}, \mathrm{CR}=10, \mathrm{P}_{\mathrm{exh}}=104 \mathrm{kPa}, 900 \mathrm{rpm}$. .58

Figure 14. Combustion parameters CA10 and CA50 calculated from model results and experimental data. $\mathrm{P}_{\text {int }}=95 \mathrm{kPa}, \mathrm{T}_{\text {int }}=310 \mathrm{~K}, \mathrm{CR}=10, \mathrm{P}_{\mathrm{exh}}=104 \mathrm{kPa}, 900 \mathrm{rpm}$. .59

Figure 15. Experimental (dotted line) and calculated (continuous line) in-cylinder pressure history for different engine speed conditions. $\mathrm{P}_{\text {int }}=95 \mathrm{kPa}, \mathrm{T}_{\mathrm{int}}=310 \mathrm{~K}, \mathrm{CR}=10, \mathrm{P}_{\mathrm{exh}}=104 \mathrm{kPa}, \phi=0.3$. 60

Figure 16. Combustion parameters CA10 and CA50 calculated from model results and experimental data. $\mathrm{P}_{\text {int }}=95 \mathrm{kPa}, \mathrm{T}_{\text {int }}=310 \mathrm{~K}, \mathrm{CR}=10, \mathrm{P}_{\mathrm{exh}}=104 \mathrm{kPa} . \phi=0.3$.

Figure 17. Experimental and $\mathrm{MZ}$ model calculated pressure and rate of heat release for three different $\mathrm{A} / \mathrm{F}$ values, $A F=43, A F=50$ and $A F=55 . P_{\text {int }}=95 \mathrm{kPa}, T_{\text {int }}=310 \mathrm{~K}, \mathrm{CR}=10, \mathrm{P}_{\text {exh }}=104 \mathrm{kPa}, 900 \mathrm{rpm}$. 
Figure 18. Calculated temperature and zone mass (as fraction of total mass) for three different $\mathrm{A} / \mathrm{F}$ values,

$$
\mathrm{AF}=43, \mathrm{AF}=50 \text { and } \mathrm{AF}=55 . \mathrm{P}_{\text {int }}=95 \mathrm{kPa}, \mathrm{T}_{\text {int }}=310 \mathrm{~K}, \mathrm{CR}=10, \mathrm{P}_{\text {exh }}=104 \mathrm{kPa}, 900 \mathrm{rpm} .
$$

Figure 19. Comparison of $\mathrm{MZ}$ and $\mathrm{SZ}$ calculated pressure data. $\mathrm{AF}=43, \mathrm{P}_{\mathrm{int}}=95 \mathrm{kPa}, \mathrm{T}_{\mathrm{int}}=310 \mathrm{~K}, \mathrm{CR}=10$, $\mathrm{P}_{\mathrm{exh}}=104 \mathrm{kPa}, 900 \mathrm{rpm}$. Experimental data from Guo et al. (2009)

Figure 20. Calculated mass fraction of fuel in each zone for $A F=43$ and $A F=55 . P_{\text {int }}=95 \mathrm{kPa}, \mathrm{T}_{\mathrm{int}}=310 \mathrm{~K}$,

$$
\mathrm{CR}=10, \mathrm{P}_{\mathrm{exh}}=104 \mathrm{kPa}, 900 \mathrm{rpm} \text {. }
$$

Figure 21. Calculated $\mathrm{CO}$ mass fraction in each zone for $\mathrm{AF}=43$ and $\mathrm{AF}=55 . \mathrm{P}_{\mathrm{int}}=95 \mathrm{kPa}, \mathrm{T}_{\mathrm{int}}=310 \mathrm{~K}$,

$$
\mathrm{CR}=10, \mathrm{P}_{\mathrm{exh}}=104 \mathrm{kPa}, 900 \mathrm{rpm} \text {. }
$$

Figure 22. Calculated mass fraction history for $\mathrm{NO}_{\mathrm{x}}$ (solid lines), and $\mathrm{NO}$ (dotted lines)...................... 70

Figure 23. RG composition calculated by equilibrium as a function of reforming temperature $\mathrm{T}_{\text {ref }}$ for a) Partial Oxidation and b) Steam reforming. Both analysis performed at $\mathrm{P}=1 \mathrm{~atm} . . \ldots \ldots \ldots \ldots \ldots \ldots \ldots \ldots \ldots . . . . . . . . . . . . . . . .74$

Figure 24. Lower Heating Value of RG for a) Partial Oxidation and b) Steam reforming....................... 75

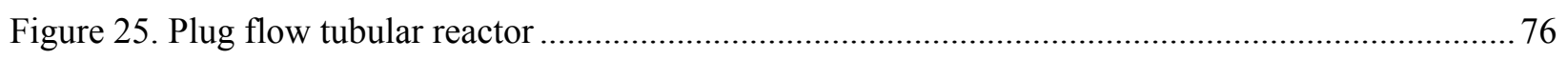

Figure 26. Calculated molar flowrate for $\mathrm{H}_{2}$ corresponding to $\mathrm{SR}$ of $\mathrm{n}$-heptane compared with results from (Nah and Palanki 2009). S:C=1:1, P=1 atm and $\mathrm{T}_{\mathrm{w}}=1200 \mathrm{~K}$. 80

Figure 27. Calculated temperature profile for the SR of $n$-heptane compared with results from (Nah and Palanki 2009). $\mathrm{S}: \mathrm{C}=1: 1, \mathrm{P}=1 \mathrm{~atm}$ and $\mathrm{T}_{\mathrm{w}}=1200 \mathrm{~K}$ 80

Figure 28. Experimental Setup for Steam -Heptane Reforming. TC: Thermocouple, F: flowmeter. .81

Figure 29. Experimental reformed gas composition for different reforming temperatures. $\mathrm{S}: \mathrm{C} \approx 2: 1, \mathrm{P}=1$ atm. 83

Figure 30. Species composition under equilibrium conditions for steam reforming of $n$-heptane compared to experimental data. $\mathrm{S}: \mathrm{C}=2: 1$, Pressure $=1 \mathrm{~atm}$. 83

Figure 31. $\mathrm{n}-H e p t a n e$ conversion compared to equilibrium values. $\mathrm{S}: \mathrm{C}=2: 1, \mathrm{P}=1 \mathrm{~atm}$. 84

Figure 32. Calculated exhaust temperature (continuous line) and reformed gas temperature profile inside the PFTR (dashed line) for different conditions of exhaust temperature (600 K-750 K). Reformed gas conditions at $\mathrm{L}=0$ are $\mathrm{T}=373 \mathrm{~K}, \mathrm{P}=1 \mathrm{~atm}$ and $\mathrm{S}: \mathrm{C}=1: 1$. .. 86

Figure 33. Section of the HCCI-TCR system showing the Recuperative Reformer (RR), the steam generator (SG) and the evaporator (EV)

Figure 34. Fraction of waste energy in the exhaust gases recuperated by fuel reforming (a), and the fuel reforming thermal efficiency (b). Results presented here are for the model engine running at $\phi=0.35$ and $1200 \mathrm{rpm}$, assuming $\mathrm{T}_{\text {ref }}=\mathrm{T}_{\mathrm{exh}}$

Figure 35. Fraction of waste energy in the exhaust gases recuperated by the whole TCR system (a), and TCR thermal efficiency (b). Results are for the model engine running at $\phi=0.35$ and $1200 \mathrm{rpm}$. .90 
Figure 36. Experimental and $\mathrm{MZ}$ model calculated in-cylinder pressure history under RG effects $\left(\mathrm{H}_{2}: \mathrm{CO}=3: 1\right) . \mathrm{P}_{\text {int }}=144 \mathrm{kPa}, \mathrm{T}_{\text {int }}=383 \mathrm{~K}, \mathrm{CR}=11.5, \mathrm{P}_{\mathrm{exh}}=104 \mathrm{kPa}, 800 \mathrm{rpm}, \phi \sim 0.26$. $\mathrm{RG}$ is presented as percentage .

Figure 37. Experimental (gray) and core-zone calculated (black) rate of heat release under RG effects $\left(\mathrm{H}_{2}: \mathrm{CO}=3: 1\right) . \mathrm{P}_{\text {int }}=144 \mathrm{kPa}, \mathrm{T}_{\text {int }}=383 \mathrm{~K}, \mathrm{CR}=11.5, \mathrm{P}_{\text {exh }}=104 \mathrm{kPa}, 800 \mathrm{rpm}, \phi \sim 0.26 . \mathrm{RG}$ is presented as percentage

Figure 38. Effect of RG addition on CA10 and CA50 calculated from model results and experimental data. $\mathrm{P}_{\text {int }}=144 \mathrm{kPa}, \mathrm{T}_{\text {int }}=383 \mathrm{~K}, \mathrm{CR}=11.5, \mathrm{P}_{\mathrm{exh}}=104 \mathrm{kPa}, 800 \mathrm{rpm}, \phi \sim 0.26$ 95

Figure 39. Relationship between $H_{\mathrm{L}}$ as a fraction of total heat release $\mathrm{HR}$, and CA50 for different values of $\mathrm{RG}\left(\mathrm{H}_{2}: \mathrm{CO}=3: 1\right) . \mathrm{P}_{\text {int }}=144 \mathrm{kPa}, \mathrm{T}_{\text {int }}=383 \mathrm{~K}, \mathrm{CR}=11.5, \mathrm{P}_{\text {exh }}=104 \mathrm{kPa}, 800 \mathrm{rpm}, \phi \sim 0.26$. 96

Figure 40. Computed start of ignition temperatures as a function of RG at constant composition cases: (a) $\mathrm{T}_{-} \mathrm{SOI}_{\mathrm{L}}$ at LTHR regime and (b) $\mathrm{T}_{-} \mathrm{SOI}_{\mathrm{H}}$ at $\mathrm{HTHR}$ regime. $\mathrm{RG}$ composition $\mathrm{H}_{2}: \mathrm{CO}=3: 1, \mathrm{P}_{\mathrm{int}}=144$ $\mathrm{kPa}, \mathrm{T}_{\text {int }}=383 \mathrm{~K}, \mathrm{CR}=11.5, \mathrm{P}_{\text {exh }}=104 \mathrm{kPa}, 800 \mathrm{rpm}, \phi \sim 0.26$ 96

Figure 41. Temperature curves at different values of $\mathrm{H}_{2}$ addition (no $\mathrm{CO}$ or $\mathrm{H}_{2} \mathrm{O}$ ), Baseline $\varphi=0.4$, $\mathrm{T}_{\mathrm{int}}=310 \mathrm{~K}, 1200 \mathrm{rpm}$. 99

Figure 42. Temperature curves at different values of $\mathrm{CO}$ addition (no $\mathrm{H}_{2}$ or $\mathrm{H}_{2} \mathrm{O}$ ), Baseline $\varphi=0.4$, $\mathrm{T}_{\text {int }}=310 \mathrm{~K}, 1200 \mathrm{rpm}$ 99

Figure 43. Rate of heat release for different values of $\mathrm{H}_{2}$ addition (no $\mathrm{CO}$ or $\mathrm{H}_{2} \mathrm{O}$ ), Baseline $\varphi=0.4$, $\mathrm{T}_{\text {int }}=310 \mathrm{~K}, 1200 \mathrm{rpm}$ 100

Figure 44. Rate of heat release for different values of $\mathrm{CO}$ addition (no $\mathrm{H}_{2}$ or $\mathrm{H}_{2} \mathrm{O}$ ), Baseline $\varphi=0.4$, $\mathrm{T}_{\text {int }}=310 \mathrm{~K}, 1200 \mathrm{rpm}$ 101

Figure 45. Relation between $\mathrm{HR}_{\mathrm{L}}$ as a fraction of total heat release $\mathrm{HR}$, and the main ignition event timing, CA50, for different values of $\mathrm{H}_{2}$ and $\mathrm{CO}$ addition $\left(\right.$ no $\mathrm{H}_{2} \mathrm{O}$ ), Baseline $\varphi=0.4, \mathrm{~T}_{\text {int }}=310 \mathrm{~K}, 1200$ $\mathrm{rpm}$ 101

Figure 46. Rate of change of temperature along the temperature domain. (a) For different values of $\mathrm{H}_{2}$ addition (no $\mathrm{CO}, \mathrm{H}_{2} \mathrm{O}$ ), (b) For different values of $\mathrm{CO}$ addition (no $\mathrm{H}_{2}, \mathrm{H}_{2} \mathrm{O}$ ). Baseline $\varphi=0.8$, $\mathrm{T}_{\mathrm{INT}}=370 \mathrm{~K}, 1200 \mathrm{rpm}$ 102

Figure 47. Computed molar fraction of $\mathrm{H}_{2} \mathrm{O}_{2}$ and $\mathrm{OH}$ for $\mathrm{H}_{2}$ addition (a) and for $\mathrm{CO}$ addition (b).

Baseline $\varphi=0.4, \mathrm{~T}_{\text {intake }}=310 \mathrm{~K}, 1200 \mathrm{rpm}$...... 103

Figure 48. Integrated HCCI engine and TCR 104

Figure 49. HCCI-TCR Model flowchart. 107

Figure 50. Calculated pressure and heat release rates for different values of $A F$ and no $R G$. $P_{\text {int }}=101 \mathrm{kPa}$, $\mathrm{T}_{\text {int }}=310 \mathrm{~K}, \mathrm{CR}=10, \mathrm{P}_{\mathrm{exh}}=101 \mathrm{kPa}, 900 \mathrm{rpm}$. 108 
Figure 51. Contour plot of CA50 values (degrees aTDC) at different $\mathrm{AF}_{\text {syst }}$ and $\mathrm{RG}$ values. a)Engine speed $900 \mathrm{rpm}$ and b) $1500 \mathrm{rpm}$. TCR operating at $\mathrm{S}: \mathrm{C}=1: 1$ and $\mathrm{T}_{\mathrm{ref}}=\mathrm{T}_{\text {exh }}$. 109

Figure 52. IMEP values calculated at different $\mathrm{AF}_{\text {syst }}, \mathrm{RG}$ and engine speed conditions. a) Engine speed $900 \mathrm{rpm}$ and b) $1500 \mathrm{rpm}$. TCR operating at $\mathrm{S}: \mathrm{C}=1: 1$ and $\mathrm{T}_{\text {ref }}=\mathrm{T}_{\text {exh }}$.

Figure 53. Calculated $\eta_{\text {th,i }}$ values at different $A F_{\text {syst, }}, R G$ and engine speed conditions. a) Engine speed $900 \mathrm{rpm}$ and b) $1500 \mathrm{rpm}$. TCR operating at $\mathrm{S}: \mathrm{C}=1: 1$ and $\mathrm{T}_{\mathrm{ref}}=\mathrm{T}_{\mathrm{exh}}$.

Figure 54. Calculated $\mathrm{NO}_{\mathrm{x}}$ emissions at different $\mathrm{AF}_{\text {syst }}, \mathrm{RG}$ and engine speed conditions. a) Engine speed $900 \mathrm{rpm}$ and b) $1500 \mathrm{rpm}$. TCR operating at $\mathrm{S}: \mathrm{C}=1: 1$ and $\mathrm{T}_{\mathrm{ref}}=\mathrm{T}_{\mathrm{exh}}$.

Figure 55. Calculated $\mathrm{CO}$ emissions at different $\mathrm{AF}_{\text {syst }}, \mathrm{RG}$ and engine speed conditions. a) Engine speed $900 \mathrm{rpm}$ and b) $1500 \mathrm{rpm}$. TCR operating at $\mathrm{S}: \mathrm{C}=1: 1$ and $\mathrm{T}_{\text {ref }}=\mathrm{T}_{\text {exh }}$.

Figure 56. Calculated $\mathrm{RI}$ values at different $\mathrm{AF}_{\text {syst, }} \mathrm{RG}$ and engine speed conditions. a) Engine speed 900 rpm and b) $1500 \mathrm{rpm}$. TCR operating at $\mathrm{S}: \mathrm{C}=1: 1$ and $\mathrm{T}_{\text {ref }}=\mathrm{T}_{\text {exh }}$.

Figure 57. Calculated Exhaust temperature at different $\mathrm{AF}_{\text {syst, }} \mathrm{RG}$ and engine speed conditions. a) Engine speed $900 \mathrm{rpm}$ and b) $1500 \mathrm{rpm}$. TCR operating at $\mathrm{S}: \mathrm{C}=1: 1$ and $\mathrm{T}_{\mathrm{ref}}=\mathrm{T}_{\text {exh }}$ 116

Figure 58. Calculated thermal efficiency of RR and TCR at different $\mathrm{AF}_{\text {syst }}$, RG. Engine speed $900 \mathrm{rpm}$.

Figure 59. Calculated fraction of enthalpy recuperated at the RR (a) and at the TCR (b) at different $\mathrm{AF}_{\text {syst }}$, RG values. Engine speed $900 \mathrm{rpm}$ 


\section{List of Tables}

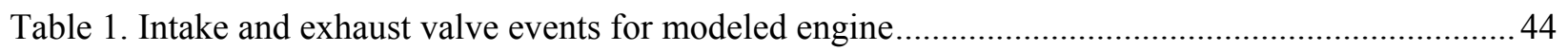

Table 2. Specifications of experimental engine used to validate the HCCI model...................................53

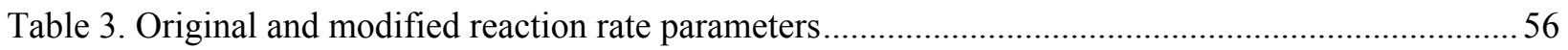

Table 4. Comparison of combustion and performance parameters between the experimental values and the

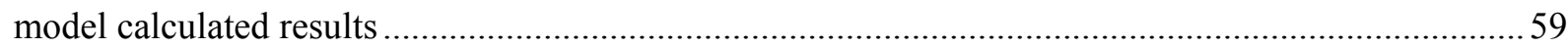

Table 5. Comparison of combustion and performance parameters between the experimental values and the

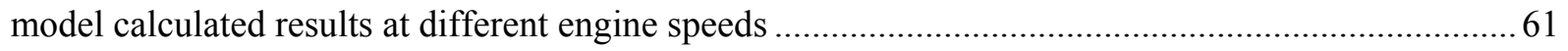

Table 6. Comparison of combustion and performance parameters between experimental values and MZ

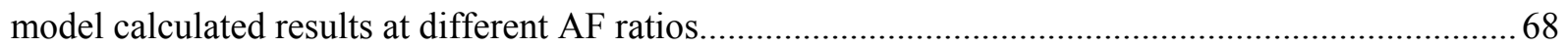

Table 7. Kinetic parameters used in the SR model. From Tottrup (1982) and Xu and Froment (1989) .... 78

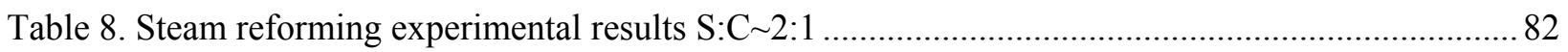

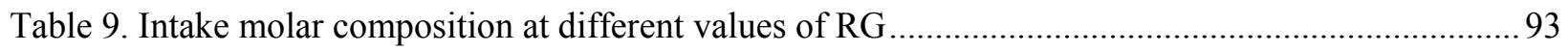

Table 10. Comparison of combustion and performance parameters between experimental values and MZ model calculated results at different RG percentage values .............................................................. 97

Table 11. Set of values used in the HCCI-TCR parametric study ...................................................... 106 


\section{Abbreviations}

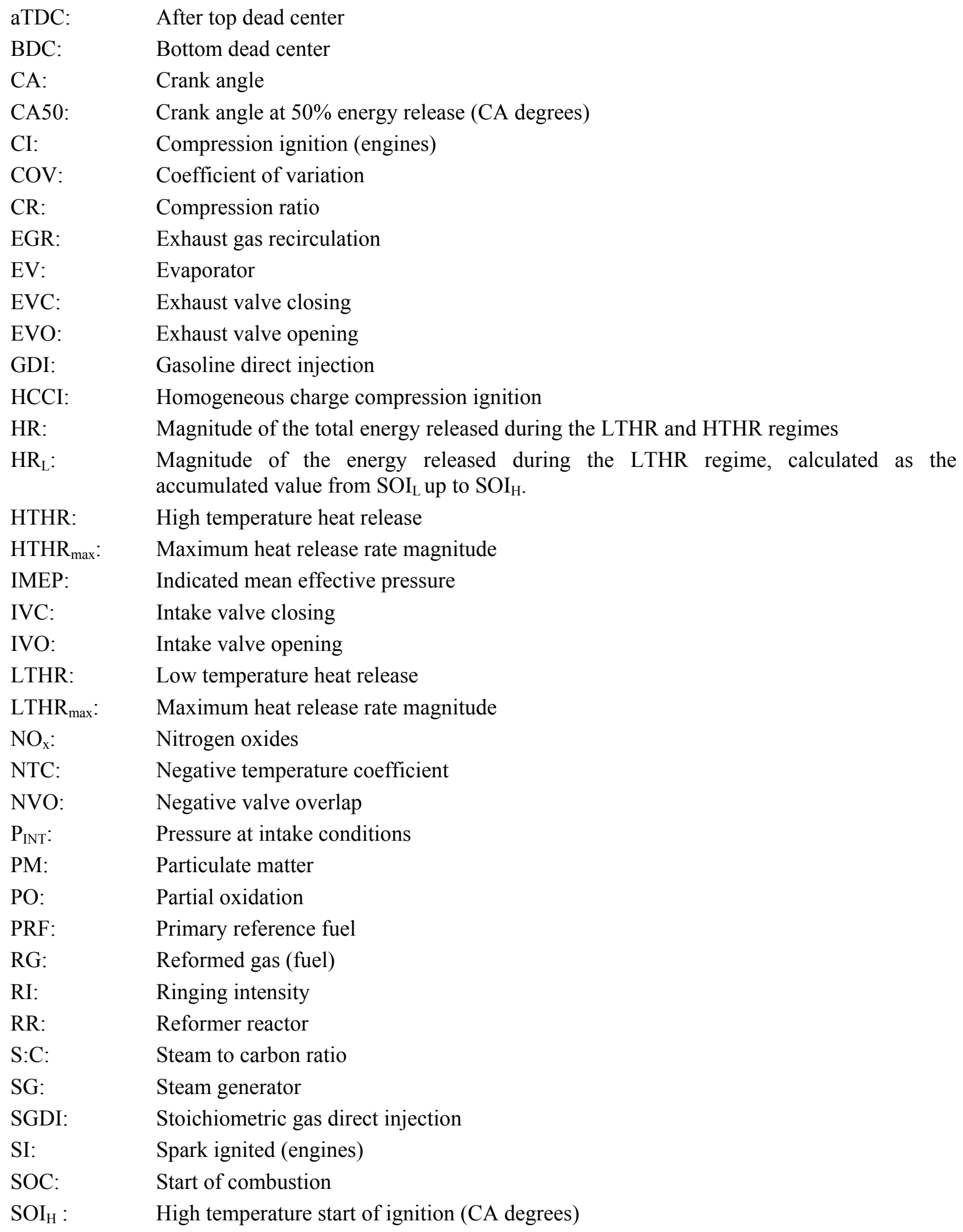


$\mathrm{SOI}_{\mathrm{L}}$ : $\quad$ Low temperature start of ignition (CA degrees)

T_SOI ${ }_{\mathrm{H}}$ : Gas mixture temperature corresponding to $\mathrm{SOI}_{\mathrm{H}}$

T_SOI ${ }_{\mathrm{L}}$ : Gas mixture temperature corresponding to $\mathrm{SOI}_{\mathrm{L}}$

$\mathrm{T}_{\text {INT: }} \quad$ Temperature at IVC (intake conditions)

VVA: Variable valve actuation

WGSR: Water gas shift reaction

$\mathrm{X}: \mathrm{C}: \quad$ Oxidant (Oxygen) to carbon ratio 


\section{Symbols}

\begin{tabular}{|c|c|}
\hline$A_{R}$ & Effective open area \\
\hline$A_{m}$ & Maximum valve opening area \\
\hline$a$ & Convective heat transfer adjustment factor \\
\hline$B$ & Bore \\
\hline$C_{D}$ & Discharge coefficient \\
\hline$C R$ & Compression ratio \\
\hline$c_{p}$ & Gas specific heat at constant pressure \\
\hline$c_{v}$ & Gas specific heat at constant volume \\
\hline$f$ & Fraction of core zone at TDC-Multi-zone model \\
\hline$f_{H_{R R}}$ & Fraction of exhaust enthalpy recovered in the reformer reactor \\
\hline$f_{H_{T C R}}$ & Fraction of exhaust enthalpy recovered in the whole TCR \\
\hline G & Gibb's function \\
\hline$H$ & Enthalpy \\
\hline$h$ & Specific enthalpy \\
\hline$h_{i}$ & Specific enthalpy of species $i$ \\
\hline$h_{\text {avg }}$ & Convective heat transfer-spatially averaged \\
\hline$k$ & Gases thermal conductivity \\
\hline$L$ & Chamber height \\
\hline$M W$ & Molecular weight \\
\hline$m$ & Mass \\
\hline$m_{c y l}$ & In-cylinder mass \\
\hline$m_{z}$ & Zone z mass \\
\hline$N_{i}$ & Number of moles of species $i$ \\
\hline$P$ & Pressure \\
\hline$Q$ & Heat transfer \\
\hline$Q_{w}$ & Heat transfer through walls \\
\hline$R$ & Rod length to stroke ratio \\
\hline$R_{u}$ & Universal gas constant \\
\hline$R_{z}$ & Zone z gas constant-mass based \\
\hline$S$ & Stroke \\
\hline$S_{T D C}$ & Stroke at TDC \\
\hline$t$ & Time \\
\hline$t_{i}$ & Wall thickness \\
\hline$T$ & Temperature \\
\hline$T_{w}$ & Wall temperature \\
\hline$T_{z}$ & Zone z temperature \\
\hline$U$ & Internal Energy \\
\hline
\end{tabular}




\begin{tabular}{|c|c|}
\hline$V$ & Volume \\
\hline$v$ & Specific Volume \\
\hline$W$ & Work \\
\hline$W_{i}$ & Indicated work \\
\hline$w_{i}$ & Rate of change of concentration of species $i$ \\
\hline$X i$ & Molar fraction of species $i$ \\
\hline$[X i]$ & Molar concentration of species $i$ \\
\hline$Y i$ & Mass fraction of species $i$ \\
\hline$Z$ & Number of zones in multi-zone model \\
\hline$\alpha$ & Fraction of fuel into reforming system \\
\hline$\beta$ & Ratio between pressure oscillation and amplitude \\
\hline$\Delta m$ & Change in the amount of mass \\
\hline$\Delta H$ & Change in the amount of enthalpy \\
\hline$\Delta \theta i$ & Duration of valve event in crank angle degrees \\
\hline$\phi$ & Equivalence ratio \\
\hline$\gamma$ & Specific heat ratio \\
\hline$\eta$ & Efficiency \\
\hline$\eta_{t h}$ & Thermal efficiency \\
\hline$\eta_{\text {th.ref }}$ & Reforming thermal efficiency \\
\hline$\kappa$ & Von-Karman constant \\
\hline$\mu$ & Gas viscosity \\
\hline$\theta$ & Crank angle degrees \\
\hline$\theta i$ & Valve event in crank angle degrees \\
\hline$\rho$ & Gas density \\
\hline$\tau$ & Reformer residence time \\
\hline$\omega$ & Crank shaft rotational speed \\
\hline
\end{tabular}




\section{Chapter 1. Introduction}

\subsection{Background}

Increasingly stringent emission standards have motivated engine manufacturers to develop internal combustion engine technologies that are able to achieve the required levels of compliance while providing similar or even better performance and fuel economy than previous engines. The industry and scientific community has approached the emission reduction problem by reducing engine-out emissions of conventional engines, and when required by emission regulations, by using aftertreatment devices.

Engine-out emissions of nitrogen oxides $\left(\mathrm{NO}_{\mathrm{x}}\right)$ in conventional compression ignition (CI) diesel engines were tackled by retarding injection timing and by using exhaust gas recirculation (EGR), which brought some fuel economy penalty. Higher fuel injection pressure, improved charge movement, and superior air handling -turbocharging- were employed to deal with the particulate matter (PM) that arises from diffusion combustion. After the implementation of 2007 emission regulations, the use of aftertreatment devices became important for PM control in heavy-duty vehicles when improvements in conventional diesel combustion were not enough to achieve the required emission limits. Heavy-duty 2010 emission regulations in the United States makes mandatory the use of selective catalytic reduction (SCR) systems for $\mathrm{NO}_{\mathrm{x}}$ control in diesel engines (Johnson 2009). $\mathrm{NO}_{\mathrm{x}}$ traps are required in light-duty diesel vehicles for compliance with Tier 2-Bin 5 emission regulations in the US (Johnson 2009).

In spark ignited (SI) gasoline engines the control of pollutants has been based on the use of threeway catalyst (TWC) systems, which require stoichiometric combustion at any given operational condition. Although the stoichiometric combustion with TWC has proven successful for pollution control purposes $\left(\mathrm{NO}_{\mathrm{x}}, \mathrm{HC}, \mathrm{CO}\right)$, the SI engine suffers lower efficiency due to its load control strategy by throttling at partial loads. Stoichiometric gas direct injection engines (SGDI) have been proposed to avoid the throttling problem, requiring high EGR and turbocharging.

In addition to improving conventional engines, engine manufacturers and the scientific community are working on advanced combustion technologies intended to achieve even more stringent emission limits, while avoiding the use of aftertreatment devices. Homogeneous charge compression ignition (HCCI) is an advanced internal combustion engine technology that offers lower engine-out $\mathrm{NO}_{\mathrm{x}}$ and $\mathrm{PM}$ than conventional diesel engines and has also demonstrated better engine thermal efficiency than SI engines. 
HCCI engines share similarities with both CI and SI engines. Air and fuel are premixed at a lean equivalence ratio $(\varphi<1)$ before the mixture reaches the cylinder, where the combustion process is initiated by fuel autoignition due to the increase in temperature associated with the compression stroke (Najt and Foster 1983). This process is characterized by the absence of flame propagation, the almost simultaneous reaction of the entire cylinder charge, rapid heat release rates, and small coefficient of variation (COV) between combustion events (Thring 1989). The absence of fuel rich mixture zones explains the low soot values experimentally observed for HCCI. This quasi-homogeneous combustion can be achieved using leaner air/fuel mixtures than diesel engines, generating lower peak temperatures during combustion. The low temperature combustion resulted from lean mixture operation reduce the formation of thermal $\mathrm{NO}_{\mathrm{x}}$. Higher thermal efficiency for HCCI, when compared to SI engines, is obtained benefiting from higher compression ratios (CR) required to ignite the mixture in the HCCI engine, in addition to lean operation (Thring 1989).

The benefits obtained with HCCI combustion in emissions and thermal efficiency are constrained by the operational range where those benefits are attainable. The operational range is limited due to the difficulties in controlling this combustion process when changes in load and speed are required. For SI engines the ignition timing is controlled by the spark timing, and for $\mathrm{CI}$ engines this is indirectly done by the fuel injection timing. The rate of heat release is controlled in SI engines by finite flame propagation and in CI engines by air and fuel mixing rates (Heywood 1988). In the case of HCCI, the combustion process is controlled by chemical kinetics, which is a function of charge composition and temperaturepressure history (Westbrook 2000).

In order to present a clear picture of the difficulties for HCCI control, let us present the case of load change by changing equivalence ratio at constant speed. At constant speed an increase in load demand, and its consequent increase in equivalence ratio, changes the combustion timing relative to top dead center (TDC) and the pressure rise rate. If the combustion timing is advanced before TDC the compression stroke work increases, adding pumping work losses. If the combustion timing is delayed, the peak pressure occurs later and its magnitude is reduced. In addition to timing difficulties, the rate of heat release also increases with richer mixtures, driving the engine to ringing ${ }^{1}$ conditions, which sets the upper limit for HCCI operation.

To extend the benefits of HCCI engines to a broader operational range and to achieve the required control of the combustion process, the composition and/or temperature history of the in-cylinder charge

${ }^{1}$ According to Eng (2002), the pressure waves generated during combustion in HCCI engines behave differently than those obtained in a SI engine (knocking). Eng suggests using the concept of ringing when referring to HCCI generated pressure waves. 
should be controlled on a cycle-by-cycle basis. A review of literature shows that two general directions have been proposed in an effort to extend the operational range of HCCI and to improve its controllability: modifying engine operation and design parameters, and modifying air/fuel mixture conditions (Milovanovic and Chen 2001). The final purpose of each of these strategies is to modify the composition and/or temperature history of the in-cylinder charge. Among the techniques used for controllability through engine operation and design parameters, the main technique is variable valve actuation (VVA). Air/Fuel mixture conditions modification is mostly based on EGR and dual fuel operation.

EGR is used as a diluting agent to control charge composition and temperature (Olsson et al. 2003). EGR can be obtained internally, as trapped gas, or through an external EGR loop. The internal EGR is obtained through valve timing strategies, including negative valve overlap (Urushihara 2003). Dual fuel operation, which is the focus of this work, is based on the use of two different fuel streams with different autoignition characteristics.

The autoignition characteristics of fuels depend on their composition, molecular size and structure (Westbrook 2000). Experimental data published on HCCI has presented evidence on the use of blends of fuel with different autoignition characteristics to improve controllability and expand the operational range of HCCI. A fuel with high resistance to autoignition, such as natural gas, can be ignited by using a secondary fuel with relative lower autoignition resistance, like iso-octane or $\mathrm{H}_{2}$ for natural gas (Olsson et al. 2001). A secondary fuel can also be used as an ignition inhibitor. Experiments on HCCI have demonstrated stable operation at medium and low loads for easily ignited fuels when a secondary fuel is used as inhibitor of the main combustion event (Ogawa et al. 2003). Combustion stability and increased performance is achieved in cases where the use of autoignition inhibitors allows for using high values of compression ratio. Ignition timing control and ringing inhibition has also been reported as benefits of dual fuel operation (Ogawa et al. 2003).

Controlling the combustion event by dual fuel operation may imply the use of separated fuel supplies. To overcome the need for dual storage, a secondary fuel, with different autoignition characteristics, may be produced on-board employing the steam-fuel reforming process. The steam and fuel mixture is heated by sensible heat from the engine exhaust gases in a catalyzed reformer reactor, where the original hydrocarbon reacts with water to produce a hydrogen rich gas mixture. The use of waste heat from the exhaust gases to reform the original fuel into a hydrogen-rich stream is known as thermo-chemical Recuperation (TCR). 
As presented in the literature (Olsson et al. 2001, Ogawa et al. 2003, Wilhemssonet al. 2007), the combustion process of a dual fuel HCCI engine is defined by the in-cylinder charge temperature and pressure, and by the specific charge composition, which depends on air/fuel ratio and the ratio between primary and secondary fuel flow rates. In the case of on-board fuel reforming, the reformed gas (RG) mixture composition is a function of base fuel and reformer reactor conditions (temperature, pressure, steam to carbon ratio), adding new variables that need to be addressed in order to generate a better picture of the system parameters to be controlled.

It is the purpose of this research project to investigate the operational range of an ideal HCCI engine by using dual fuel operation, where the secondary fuel is a reformed gas of the primary fuel. In order to achieve this goal, a model of the HCCI combustion process and the reforming process is developed and the effects of RG on the HCCI engine model are studied. This research extends the knowledge on HCCI combustion by studying the effects of reformed gases produced by TCR and the interaction between the HCCI engine and the TCR, which, so far, has not been explored.

\subsection{Problem Statement}

It has been shown that the benefits of the HCCI engine on performance and emissions are achieved at engine operational conditions comparable to low speed and low load of conventional CI or SI engines. The implicit inability of HCCI to exert a precise control on both ignition timing and rate of heat release is the main reason for a narrow operational range. The operational range at certain engine speed is constrained by misfiring at lean conditions and ringing phenomena at high load. It has been suggested by literature that the HCCI combustion process can be controlled with dual fuel operation, and second, that fuel reforming can be achieved on-board by using waste heat from the exhaust gases, i.e. by TCR. However, the integrated HCCI engine and fuel reforming system, operating as a unit, has not been studied yet.

Each system, the HCCI engine and the fuel reformer, has its own set of governing parameters and operational range. HCCI is governed by mixture composition, temperature and pressure. These conditions define the exhaust gas composition and temperature, which is employed by the fuel reformer for thermochemical recuperation. The conversion efficiency of the reforming process and the reformed gases composition are dependent variables of the operating conditions, i.e. temperature and flow rate, provided by the exhaust gases. The addition of reformed gases, composed mainly of $\mathrm{H}_{2}$ and $\mathrm{CO}$, in turn affects the $\mathrm{HCCI}$ engine equivalence ratio and intake conditions (composition and temperature), which changes the combustion history and therefore the exhaust gas conditions. 
There is no available information in the literature about the output composition of the fuel reforming process when driven by the exhaust gases of an HCCI engine. Even though the effects of a synthetic formulation of $\mathrm{RG}\left(\mathrm{H}_{2}\right.$ and $\left.\mathrm{CO}\right)$ on the HCCI combustion of n-heptane has been examined (Kongsereeparp and Checkel 2007, Hosseini and Checkel 2007-b), a more realistic scenario has not been approached. The effects of this real case scenario reformed gas composition, where the n-heptane reforming process is driven by the HCCI engine exhaust gases, has not been studied in terms of operating range and emissions.

The problem rests in assessing the set of operational conditions required by the integrated HCCITCR system in order to achieve a wider operational range ${ }^{2}$ than the baseline HCCI engine. At certain speed the operational range where improved engine performance is achieved is constrained in terms of load by ringing and misfire, and by emissions levels of $\mathrm{NO}_{\mathrm{x}}, \mathrm{HC}$ and $\mathrm{CO}$. The fuel reformer operational range is defined by its fuel conversion efficiency, which is limited by reforming temperature.

\subsection{Research Objectives}

The main objective of this research work is to numerically evaluate the set of conditions in the integrated HCCI - TCR system model through a parametric study to examine the possibility of extending the operational range of the baseline HCCI engine model fueled with n-heptane. The baseline HCCI engine model and the HCCI-TCR system model are numerically evaluated within the limits defined by suitable engine and TCR performance. The HCCI engine performance is evaluated based on IMEP values at constant speed, with limits defined by ringing and misfiring conditions. The performance of the TCR, which is function of the HCCI model engine exhaust gas temperature and steam to carbon ratio (S:C), is evaluated and reported. Specific objectives to accomplish the main objective are:

1. To develop a model for studying the HCCI process using n-heptane as the fuel. The model represents with reasonable accuracy the HCCI combustion process under different conditions defined by equivalence ratio, engine speed and intake pressure. Combustion parameters are defined to evaluate the effect of parameter variations in the HCCI engine performance, based on IMEP, and emissions $\left(\mathrm{NO}_{\mathrm{x}}\right.$ and $\mathrm{CO}$ and $\left.\mathrm{HC}\right)$. The model includes the gas exchange process for exhaust valve opening aiming to predict exhaust temperature and flowrate for reforming.

2. To develop a model for analyzing the fuel reforming process of n-heptane aiming to predict the reformed gases $(\mathrm{RG})$ composition. The model is based on experimental data obtained at different reforming temperatures. Reforming efficiency parameters are defined.

\footnotetext{
${ }^{2}$ At certain engine speed the operational range is defined by the indicated mean effective pressure (IMEP)
} 
3. To investigate the effect of RG on the combustion process of $n$-heptane under different engine conditions defined by $\mathrm{RG}$ ratio and $\mathrm{A} / \mathrm{F}$ ratio at constant speed values. The effects of $\mathrm{RG}$ on HCCI combustion is measured by combustion timing and heat release rates. The overall effects on engine performance, evaluated through IMEP values, and emissions $\left(\mathrm{NO}_{\mathrm{x}}\right.$ and $\mathrm{CO}$ and $\left.\mathrm{HC}\right)$ is used to draw the limits where RG addition may benefit the HCCI combustion of n-heptane.

4. To develop a system model, integrating the HCCI engine model and the fuel reforming process model, for analyzing the effects of fuel reforming by using waste heat form the HCCI model engine i.e., by thermo-chemical recuperation. The system model should be able to predict the RG composition based on the exhaust heat from the HCCI engine and the effects of the RG composition in the HCCI combustion process. 


\section{Chapter 2. Literature Review}

The literature review chapter consists of three main sections. The first one describes the HCCI combustion characteristics, its advantages, disadvantages and advances in HCCI. The second one is devoted to describe the thermo-chemical reforming process, emphasizing steam-fuel reforming fundamentals. The third, and closing section, presents the most relevant research work on HCCI operation through dual fuel and $\mathrm{H}_{2}$ enrichment.

\subsection{HCCI Combustion Characteristics}

\subsubsection{HCCI Early Works}

The history of HCCI combustion can be traced back to the late 1970s, when Onishi et al. (1979) were able to achieve stable combustion by controlled autoignition in a two stroke gasoline engine at part load and lean air/fuel conditions. The term employed by these researchers was Active ThermoAtmosphere Combustion (ATAC) and was developed based on studying abnormal combustion phenomena and knocking. ATAC was successfully achieved by controlling the $\mathrm{A} / \mathrm{F}$ ratio, residual gas amount, and combustion chamber temperatures. In-cylinder pressure data and Schlieren photographs allowed for identifying the characteristics of this combustion process. The rate of heat release obtained from pressure traces showed little cycle-to-cycle variations and soft rate of heat release. Schlieren photographs were used to verify the absence of flame front propagation and, more significantly, the quasisimultaneous ignition of the charge was detected through small variations in density between adjacent areas of the air-fuel mixture. Lower $\mathrm{NO}_{\mathrm{x}}$ emissions and better fuel economy than conventional two-stroke SI engines were achieved by the researchers, as well as noise and vibration reductions (Onishi et al. 1979).

Najt and Foster (1983), working on a four stroke cooperative fuels research (CFR) engine, were able to identify the overall mechanism that governs the controlled autoignition process and the effect of engine operating conditions on it. The CFR engine experimental setup allowed for independent control of the amount and temperature of the EGR. Their experimental results on CR variation effects showed that an increase in $\mathrm{CR}$ advanced the ignition timing and increased the energy release rates due to higher temperatures and concentrations. Changes in equivalence ratio, from lean to rich, were reported to affect the ignition timing and energy release rates, by advancing the combustion event with higher rates of 
energy release. Changes in engine speed were reported to affect the ignition process due to changes in the absolute time that the mixture had to follow the combustion process. Increasing the engine speed reduced the available time for combustion to occur, forcing the researchers to increase the intake temperature to speed up the reaction rates. EGR was used by the researchers to provide the initial mixture temperature required by autoignition. However, the inert nature of the EGR also dilutes the mixture, which partially inhibits the initial thermal effect, and reduces the peak temperature during combustion. The EGR species composition had no significant role in the autoignition process. The researchers concluded that low temperature hydrocarbon kinetics, which occurs below $950 \mathrm{~K}$, is responsible for the ignition process of the primary reference fuels used in the project, namely PRF60 and PRF70 fuels (Najt and Foster 1983).

The term HCCI was first coined by Thring (1989) in the course of an experimental work to test the range of operation of parameters involved in the novel four-stroke engine. The potential of the HCCI engine at low load operation was recognized as providing power density comparable to gasoline engines. In the experiments conducted by Thring, a four stroke engine was tested with commercial gasoline and diesel fuels. The intake system was fitted with an electrical heater to achieve a stable air/fuel/EGR intake mixture temperature. Intake temperatures were kept around $400^{\circ} \mathrm{C}$ for stable and broad operation. Results reported by Thring show that the indicated specific fuel consumption (ISFC) under HCCI operation with gasoline fuel is similar to values attained by conventional diesel (ISFC around 180-200 g/kWh). Results with diesel fuel were limited due to fuel atomization and heating problems (Thring 1989).

Pioneer works on controlled autoignition combustion and HCCI by Onishi et al. (1979), Noguchi et al. (1979) and Najt and Foster (1983) agreed on describing the HCCI engine as a compression-ignited, stirred chemical reactor, where the chemical kinetics of the reacting air-fuel and residuals, defined by its composition and temperature, governs the combustion event. The HCCI combustion process can be defined as a combustion process governed by fuel autoignition. Research on primary reference fuels have concluded that the autoignition of fuels depends on its composition, molecular size and structure (Milovanovic and Chen 2001). Although it is possible to achieve HCCI with many different fuels, this research project is focused in paraffins, particularly on n-heptane.

\subsubsection{Fuel Chemistry}

n-Heptane $\left(\mathrm{C}_{7} \mathrm{H}_{16}\right)$ is a straight chain paraffin with a nominal octane number $(\mathrm{ON})$ of $\mathrm{ON}=0$, which means that this fuel has a relative very low resistance to autoignition. The temperature history of $n$ Heptane and other paraffinic fuels show two-stage ignition, as explained by Westbrook (2000). The first stage is related with low temperature heat release (LTHR) period, and the second, or main combustion, is associated with the high temperature heat release (HTHR) period. The low temperature combustion is 
also regarded as "cool flame", with negative temperature coefficient (NTC) (Westbrook 2000). As a comparison, iso-octane, with $\mathrm{ON}=100$, bears high resistance to autoignition and a single stage ignition behavior (Kelly-Zion and Dec 2000). The existence of the LTHR has important consequences on HCCI combustion control (Milovanovic and Chen 2001).

For alkane fuels, the literature divides the chain reaction paths in three main routes: below $750 \mathrm{~K}$ dominated by chain propagating steps including oxygen molecules and generation of partially oxidized species (Fish 1968, Pollard 1977). Between $800 \mathrm{~K}$ and $950 \mathrm{~K}$ the chain propagating steps involving $\mathrm{O}_{2}$ molecules yield conjugate alkenes and $\mathrm{HO}_{2}$ radicals (Pollard 1977). Above $1000 \mathrm{~K}$ the main fuel radical reactions are thermal decomposition by $\mathrm{C}$-C bond breakage forming alkenes and smaller radicals (Glassman 1996). Based on the previous description, Westbrook (2000) defined two different regions of chain reaction: a low temperature kinetics region or ignition process, below $950 \mathrm{~K}$, and the high temperature kinetics region where the bulk of the chemical energy is released.

The low temperature reaction kinetics is characterized by $\mathrm{H}$ atoms abstraction from fuel molecules to produce alkyl radicals $\mathrm{R}$. These fuel radicals react directly with $\mathrm{O}_{2}$ molecules,

$$
R+O_{2}+M \rightarrow R O_{2}+M
$$

Equation 1

where $\mathrm{M}$ is a non-reactive third body.

The $\mathrm{RO}_{2}$ radicals start to decompose by isomerisation into QOOH radical species. The isomerisation rate depends strongly on size and structure of the original fuel molecule. The isomerisation rate is faster in long linear alkane fuel molecules than in highly branched fuel molecules with primary $\mathrm{C}-\mathrm{H}$ bonds, which are difficult to break (Westbrook 2000).

The QOOH species react through different chain propagation steps, which starts with one radical and produces $\mathrm{HO}_{2}$ or $\mathrm{OH}$ radical.

$$
\begin{aligned}
& Q \mathrm{OOH} \rightarrow Q+\mathrm{HO}_{2} \\
& \text { Equation } 2 \\
& \mathrm{QOOH} \rightarrow \mathrm{QO}+\mathrm{OH} \\
& \text { Equation } 3
\end{aligned}
$$

In addition to these chain propagation steps, Westbrook (2000) proposes that the QOOH radicals can react with $\mathrm{O}_{2}$ molecules to produce another radical $\mathrm{O}_{2} \mathrm{QOOH}$ that can be also isomerised. The isomerized product decomposes into ketohydroperoxide and an $\mathrm{OH}$ radical. Upon reaching $800 \mathrm{~K}$, the ketohydroperoxide decomposes into several species and at least two radicals. At this stage chain branching is established. As a result, the decomposition of $\mathrm{RO}_{2}$ radicals drives an inverse temperature 
dependence on the overall reaction rate, which is known as NTC behavior, typical of two stage ignition fuels (Westbrook 2000).

The high temperature kinetics starts above $850 \mathrm{~K}$, where the main chain branching reactions are:

$$
\begin{array}{lr}
\mathrm{H}+\mathrm{O}_{2}+\mathrm{M} \rightarrow \mathrm{HO}_{2}+\mathrm{M} & \text { Equation 4 } \\
\mathrm{RH}+\mathrm{HO}_{2} \rightarrow \mathrm{R}+\mathrm{H}_{2} \mathrm{O}_{2} & \text { Equation 5 } \\
\mathrm{H}_{2} \mathrm{O}_{2}+\mathrm{M} \rightarrow \mathrm{OH}+\mathrm{OH}+\mathrm{M} & \text { Equation 6 }
\end{array}
$$

where RH is an alkane.

It has been experimentally proven in studies involving diesel ignition and knock phenomena that the dominant characteristic of autoignition is the accumulation of $\mathrm{H}_{2} \mathrm{O}_{2}$ until certain temperature is reached when it decomposes via Equation 6 to cause ignition (Westbrook 2000).

According to Westbrook (2000), the key of fuel autoignition representative of HCCI combustion systems lays on the $\mathrm{H}_{2} \mathrm{O}_{2}$ concentration history. $\mathrm{H}_{2} \mathrm{O}_{2}$ is produced below $900-1000 \mathrm{~K}$ by low and intermediate temperature pathways, as presented above. $\mathrm{H}_{2} \mathrm{O}_{2}$ concentration increases steadily, with $\mathrm{H}_{2} \mathrm{O}_{2}$ decomposition much slower than its production. $\mathrm{H}_{2} \mathrm{O}_{2}$ decomposes rapidly at temperatures around 1000 $\mathrm{K}$, yielding large numbers of $\mathrm{OH}$ radicals (Equation 6). The increase of $\mathrm{OH}$ radicals consumes any remaining fuel, resulting in ignition.

The ignition process of iso-octane (single stage ignition) and n-heptane (dual stage ignition) combustion characteristics can be summarized as follows. A modest heat release occurs at temperatures below $900 \mathrm{~K}$, depending on the cool flame reactivity of the specific fuel, which results in some temperature increase. $n$-Heptane shows this kind of behavior. The dual stage ignition of n-heptane can be explained by its long linear molecular structure that favors faster isomerisation rates than branched alkanes, as is the case for iso-octane. Ignition occurs at the time when the core mixture temperature reaches the $\mathrm{H}_{2} \mathrm{O}_{2}$ decomposition temperature, around $1000 \mathrm{~K}$. Any modification of the combustion environment that increases the rate of increase of the mixture temperature, such as heat derived from low temperature kinetics due to radical isomerisation, will advance the ignition timing (Westbrook 2000, Milovanovic and Chen 2001). The opposite also holds true, and explains the use of inert exhaust gases to retard the ignition.

\subsubsection{Fuels for HCCI}

Fuel flexibility is another characteristic of HCCI engines. The fuel flexibility of HCCI has been used to test an extremely broad range of fuels, from methane to diesel. Research work has been conducted by 
several organizations trying to define suitable fuels for commercial HCCI operation (Aroonsrisopon et al. 2002, Dec and Sjoberg 2004, Shibata et al. 2004, Kalghatgi et al. 2003).

Initial work trying to correlate the well known fuel octane number with the ability to produce a stable combustion under HCCI mode showed the necessity of developing a new index for HCCI fuels which included engine operating conditions. The fuel octane number, for SI engines, is a measure of the ability of the fuel to resist autoignition. The number is defined as an average of two numbers provided by two tests performed on a single cylinder CFR engine, under ASTM procedures. One of the numbers, the Research Octane Number (RON), is obtained at $600 \mathrm{rpm}, 52^{\circ} \mathrm{C}$ intake temperature and $13^{\circ}$ crank angle (CA) before TDC spark advance. The second one, the Motor Octane Number (MON), is obtained at 900 $\mathrm{rpm}, 149^{\circ} \mathrm{C}$ intake temperature and $19^{\circ}$ to $26^{\circ} \mathrm{CA}$ before TDC spark advance (Heywood 1988). The difference between RON and MON is defined as fuel sensitivity S.

Research work on fuel octane sensitivity of paraffins, olefins and aromatics by Leppard (1990) showed that under motor rating conditions the paraffins exhibited low sensitivity. Some olefins with long carbon chain structures also exhibited low sensitivity. Because paraffinic fuels present low temperature reactivity, i.e. cool flames, the sensitivity of a fuel can be seen a measure of NTC behavior. Aroonsrisopon et al. (2002) concluded that the NTC behavior confounds the autoignition process. To explain this situation experimental runs with PRF70 fuel show that the cool flame energy release is more significant at lower intake temperatures and is also associated with later combustion of the charge. As a result, the relationship between charge temperature history and fuel autoignition is non-linear for fuels that show NTC behavior. On the other hand, researchers concluded that fuels that do not show NTC behavior would behave proportionally to changes in the charge temperature (Aroonsrisopon et al. 2002).

Dec and Sjoberg (2004), while studying the effects of fuel chemistry on combustion phasing with iso-octane, gasoline and PRF80 concluded that fuels with little cool flame chemistry required no temperature compensation on combustion phasing when changes in A/F ratio occurred. In contrast, fuels such as PRF80, which show significant cool flame chemistry, required changes in intake temperature to compensate changes in fueling rate (Dec and Sjoberg 2004). This conclusion coincides with the results from Aroonsrisopon research team.

An extensive fuel suitability research was performed by Shibata et al. (2004) using fuels with different boiling point/RON characteristics. It was demonstrated that fuels that exhibit a substantial low temperature heat release (LTHR) behavior accelerate the chemical reactions occurring during the period between the low temperature heat release and the high temperature heat release (HTHR) (Shibata et al. 2004). For a fuel that exhibits LTHR behavior, the time -i.e. temperature history- required between LTHR 
and HTHR was found constant. When the speed was increased, the crank angle span between LTHR and HTHR became larger, so there was not enough time to ignite the charge at an appropriate timing and misfired occurred. This condition reduces the speed dominion where HCCI is viable. Shibata et al. concluded that a fuel with large value of LTHR is an "Easy knock, high speed, and low torque fuel", and the opposite holds true for low LTHR fuels (Shibata et al. 2004).

The relation between fuel composition, LTHR, HTHR and HCCI engine performance was studied by Shibata et al.(2005) The experiment included 12 different fuel mixtures with different hydrocarbon mixture composition. Performance of the engine based on knock intensity and the variation in mean effective pressure, was correlated with the HTHR-CA50 (crank angle at 50\% of total HTHR) at 1000 rpm, which basically defined the operational range for each fuel tested. According to this research, the relation between LTHR and HTHR for all fuels tested was confirmed. The chemical composition was also correlated with this LTHR-HTHR interaction. A tendency of hydrocarbon families to advance the HTHR was associated in the study with larger magnitudes of LTHR. The effect of LTHR on advancing HTHR was categorized from higher to lower for hydrocarbon families as: n-paraffins $>$ isoparafins $>$ olefins $>$ aromatics $=$ naphtalenes. Aromatics and some naphtalenes exhibit an inhibitor effect due to specific carbon bonding. It was concluded, as mentioned in during the HCCI combustion section, that the structure of hydrocarbons strongly defines the LTHR behavior of hydrocarbons (Shibata et al. 2005).

\subsubsection{Emissions}

One of the main advantages of HCCI combustion is its low $\mathrm{NO}_{\mathrm{x}}$ and PM engine-out emission levels. This is based on the HCCI almost simultaneous combustion, without flame propagation, allowing for stable combustion in the lean limit (Milovanovic and Chen 2001). This lean combustion also impacts positively the production of thermal $\mathrm{NO}_{\mathrm{x}}$, which can be significantly reduced due to lower peak temperatures during HCCI combustion (Thring 1989, Onishi et al. 1979). Experimental results with isooctane and ethanol in a 6 cylinder engine at $1000 \mathrm{rpm}$ show that at part load the $\mathrm{NO}_{\mathrm{x}}$ production of a HCCI engine may be at the same level as values reported after the three way catalyst on a SI engine (Christensen et al. 1998).

Experimental work using a 6 cylinder truck engine was performed to investigate the operational range of stable HCCI combustion with turbocharging and intercooling (Olsson et al. 2001). The engine was run with variable mixtures of $n$-heptane and ethanol to control the load. The use of ethanol allowed for high compression ratio values, $\mathrm{CR}=18$. It was confirmed by the researchers that the $\mathrm{NO}_{\mathrm{x}}$ emission values were kept below $0.1 \mathrm{~g} / \mathrm{kWh}$, not just under low load, but also under high load conditions (around 15 bar BMEP) . 
Gray and Ryan (1997) ran a series of experiments investigating the application of diesel fuel for HCCI combustion. A CFR one cylinder variable compression ratio engine modified with an intake fuel injector and air heater was used in this study. Results from this study show that the $\mathrm{A} / \mathrm{F}$ ratio operational range is inversely proportional to the EGR span. A compression ratio range of $\mathrm{CR}=9$ to $\mathrm{CR}=11$ was found as stable for HCCI diesel operation. Engine-out emission values of $\mathrm{NO}_{\mathrm{x}}$ was $98 \%$ below the levels obtained for diesel operation. PM emission values were reduced to around 26\% (Gray and Ryan 1997). These low PM levels were achieved due to the absence of fuel rich zones typical of HCCI combustion (Ryan 1996).

Cairns and Blaxhill (2005) were able to run a 4 cylinder 2 liter engine with a geometric compression ratio $\mathrm{CR}=11.2$ and fueled by gasoline $95 \mathrm{RON}$, using external and trapped exhaust gases and shifting from HCCI to SI mode when required. Direct fuel injection, variable valve timing system, an electronically controlled intake valve working as a swirls control device and electronic EGR valve were required in this project. $\mathrm{NO}_{\mathrm{x}}$ emission values were found at the same level of post catalytic converters in stoichiometric SI engines, but this benefit was only reported at low load. At moderate loads the engine required to be run under SI stoichiometric conditions. The relation between the swirl valve and $\mathrm{NO}_{\mathrm{x}}$ production was also investigated. The swirl valve proved to be effective in reducing the $\mathrm{NO}_{\mathrm{x}}$ emission, when the load was increased, due to improved mixing conditions (Cairns and Blaxhill 2005).

CO and HC emissions are also higher on HCCI combustion than in SI (Christensen et al. 1997) or CI (Ryan 1996). The boundary layer and crevices have been indicated as the source of HC emissions, which are not able to react close to the colder walls of the cylinder. The partial oxidation of some of the hydrocarbon chains, also close to the cylinder walls, is the cause of high CO emission levels. Residual gas trapping through valve timing has been shown to reduce $\mathrm{CO}$ and $\mathrm{HC}$ emissions as demonstrated by Olsson et al. (2003). This was caused by the availability of radicals from the previous cycle.

\subsubsection{Efficiency, Operational Range and Combustion Stability}

Higher thermal and volumetric efficiency can be achieved by HCCI at partial load operation. Better thermal efficiency can be achieved with higher compression ratios. Compression ratios in HCCI can be higher than in SI combustion because HCCI combustion is based on autoignition. Experimental results with natural gas show that stable combustion at part load was achieved with $C R=21.0$, while SI combustion tolerated no more than $\mathrm{CR}=12.0$ before knock was detected (Christensen et al. 1997). Pumping losses are reduced by volumetric efficiency improvements. At part load conditions the HCCI engine accepts un-throttled operation, which reduces the pumping losses associated with the intake stroke (Christensen et al. 1997). 
As can be observed from the list of advantages, most of the benefits of HCCI occur at partial load operation, and this has consequently limited the commercial application, which requires a stable solution over the whole operating envelope. The main difficulty of HCCI combustion is the controllability over ignition timing and the rate of heat release. As mentioned before, the HCCI combustion process is controlled by chemical kinetics, and no direct control, as in SI or CI combustion, is used. As a result, the operational limit is confined by knock, in the rich limit, and by misfire, in the lean limit.

HCCI combustion bears negligible cycle-to-cycle variations compared to SI combustion (Onishi et al. 1979, Thring 1989). This was explained by Milovanovic and Chen (2001) as a result of a geometry independent combustion ignition. In the case of SI combustion, the early flame development is affected by the changes of $\mathrm{A} / \mathrm{F}$ concentration in the vicinity of a spark plug.

\subsubsection{Advances in HCCI}

Two general directions have been investigated to extend the operational range of HCCI and provide the required control: modifying air/fuel mixture properties and modifying engine operation and design parameters (Milovanovic and Chen 2001). The final purpose of each one of these strategies is to modify the composition and/or temperature history of the in-cylinder charge.

\subsubsection{Air/Fuel Mixture Control Strategies}

\section{In-cylinder charge temperature}

It has been mentioned before in this document that the HCCI is a process governed by fuel autoignition, which depends on composition and temperature of the mixture. The charge temperature history can be modified by controlling air intake temperature, usually by means of electrical heaters or by controlling the amount of exhaust gas residuals. Heating of intake air has been used mostly during research projects. The control of in-cylinder charge by controlling the exhaust gas residual amount has been used frequently for HCCI control and is explained in detail in the following section.

Increasing the intake temperature tends to advance the onset of combustion, according to models proposed by several researchers, but the controllable range is limited due to high heat release rates that lead to ringing conditions. Parametric studies performed by Fiveland and Assanis (2000) on HCCI of methane and hydrogen show that increasing intake temperature advanced the ignition onset due to increased reaction rates. The values of calculated volumetric efficiency and trapped mass -mass into the cylinder- were also reduced at higher temperatures. The combination of lower volumetric efficiency and advanced ignition onset, which increases pump work, had an overall negative effect on power out. However, too low intake temperatures were found as source of misfire. These two limiting conditions 
were used to define autoignition limits at certain engine speed and EGR content (Fiveland and Assanis 2000).

Modeling work on HCCI of large chain hydrocarbons, i.e. iso-octane, n-heptane and gasoline, performed by Easley et al. (2001) show that the intake temperature required for ignition at TDC is around $100 \mathrm{~K}$ lower than the intake temperature required for methane. Their modeling work also predicts that for gasoline at constant engine speed of $2500 \mathrm{rpm}$, the intake temperature should be reduced around $60 \mathrm{~K}$ when the equivalence ratio is varied from 0.2 to 1.0 to achieve constant combustion timing around TDC. Changes in engine speed also required adjustments in intake temperature to keep a constant combustion phasing. This was explained as being caused by changes in the mixture residence time to achieve the required combustion temperature (Easley et al. 2001).

Experimental studies on thermal stratification for heat release smoothing, by Sjoberg et al.(2004), show that for iso-octane the combustion phasing changes as the intake temperature changes. This experimental work confirmed that an increase in equivalence ratio required reduction on intake temperature looking for a constant value on combustion phasing. This effect was attributed to shorter burn duration and increased residual and wall temperatures. It was reported that the autoignition timing is more sensitive to changes in intake temperature when the ignition occurs after top dead center (Sjoberg et al. 2004).

\section{Exhaust Gas Recirculation}

The idea behind the EGR use for control of the HCCI engine is based in the availability of an inert gas that can be used to change the thermo-chemical characteristics of the in-cylinder charge. The control over the temperature and amount of this gas has been based on internal trapping of hot residual gases, or on a cooling charge of external EGR.

The effect of cooled EGR on emissions and performance of a turbocharged, six cylinder 12 liter HCCI engine operated with a mixture of n-heptane and ethanol was studied by Olsson et al. (2003) . It was expressed by the team, based on previous studies on HCCI, that the main reason to use EGR was to slow down the combustion rate. This is critical at high loads. The reason behind this is that EGR has lower specific heat ratio, $\gamma=\mathrm{c}_{\mathrm{p}} / \mathrm{c}_{\mathrm{v}}$, which reduces the mixture temperature during the compression stroke. An additional effect was the reduction in $\mathrm{O}_{2}$ concentration and the increase in $\mathrm{CO}_{2}$ and $\mathrm{H}_{2} \mathrm{O}$ which slows down the oxidation rates. A drawback of using EGR at high loads was the reduction in thermal efficiency, which is defined by compression ratio and the specific heat ratio (Heywood 1988). Experimental results reported by the researchers show that at idle and mid-load the use of high EGR improves combustion efficiency by recirculating the unburned hydrocarbons (Olsson et al. 2003). EGR content was reported as 
having a very insignificant effect in burn duration at mid loads. $\mathrm{CO}$ emissions were reduced by almost a half with EGR values close to $50 \%$. The reason for this improvement was also due to recycling of radical species. The final effect of EGR on thermal efficiency, i.e. the ratio between work produced and heat added, was not clearly defined by the researchers. According to modeling results, the thermal efficiency was expected to be reduced with EGR addition. However, the experimental trend show that the thermal efficiency increased, and after some value of EGR, decreased. $\mathrm{NO}_{\mathrm{x}}$ emissions were reduced in direct proportion to EGR addition, as expected (Olsson et al. 2003).

The effect of EGR on HCCI of n-heptane was studied by Peng et al. (2003) on a single cylinder experimental engine at an engine speed of $1500 \mathrm{rpm}$, compression ratio $\mathrm{CR}=18$ and intake temperature of $300 \mathrm{~K}$. It was found that in those conditions the richest equivalence ratio without EGR for stable operation was around $\varphi=0.2$. The maximum IMEP value was obtained at $\varphi=0.66$ with an EGR rate of $65 \%$. It was reported, coinciding with previous studies in this topic, that the autoignition of cool flame region was delayed at high EGR rates. Combustion duration was not changed by changes in EGR, but

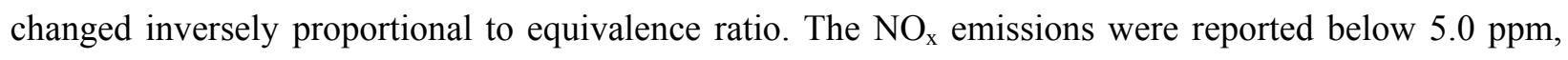
with maximum IMEP value around 4.0 bar. $\mathrm{HC}$ emissions were associated with equivalence ratio rather than low combustion temperatures due to EGR addition. The engine indicated fuel consumption was worst than values normally obtained for conventional diesel combustion. According to the researchers, the reason behind this negative behavior on fuel economy was that the test engine was not optimized for HCCI combustion. Its relation with EGR was not determined (Peng et al. 2003).

Persson et al. (2005) experimentally proved the internal trapping of EGR on a six-cylinder HCCI engine powered by gasoline. The amount of residuals was varied by a variable cam phasing mechanism. Additional spark timing was provided as part of the experimental setup. At high loads it was observed that rapid pressure rise was observed, which limited the load. By increasing the speed it was observed that the volumetric efficiency decreased due to increased amount of residuals. Reduction of the residuals to increase volumetric efficiency and reduce early ignition was limited by the occurrence of misfires (Persson et al. 2005).

Cairns and Blaxhill (2005) used a combination of external and trapped exhaust gases to run a 4 cylinder 2 liter engine fueled by gasoline 95 RON. Shifting between HCCI and SI mode was used to cover most operational conditions. Direct fuel injection, variable valve timing system, an electronically controlled intake valve working as a swirl control device, and electronic EGR valve were required in this project. Results show that at constant engine speed, without external EGR, the intake and exhaust valves had to be adjusted, while varying load, in order to avoid misfire or knock. The addition of external EGR 
allowed for achieving improvements of $65 \%$ in engine power output. The effect of increasing the amount of internal EGR was the over-advancing of ignition timing and increasing fuel consumption for stable operation at high loads. The highest benefits were obtained at low engine speeds and loads. In terms of fuel economy at low loads, the use of internal EGR alone proved to be beneficial (Cairns and Blaxhill 2005).

\section{Fuel blends}

The autoignition capacity of fuels depends on composition, molecular size and structure, as was previously stated. Blending of fuels with different autoignition properties has been studied by several researchers as a method to improve control and expand the operational range of actual HCCI system.

Olsson et al. (2001) modified a 6 cylinder turbo-charged engine for dual fuel operation. The system was designed to operate for $n$-heptane and ethanol. The addition of ethanol, with a high octane rating, allows for the combustion under a compression ratio of 18:1, which will be difficult to achieve under high load conditions. The relative amount of fuels is adjusted to perform load control without changing the

ignition timing. The control was effectuated using a controller with pressure sensor to adjust for the right timing (Olsson et al. 2001).

The control of ignition timing, rate of heat release and the expansion of the operating envelop for HCCI engines was studied by Ogawa et al. (2003). Experiments conducted at $1200 \mathrm{rpm}$, with a high ignitability light naphtha, cetane number $(\mathrm{CN})$ of $\mathrm{CN}=27$, and several low ignitability fuels (alcohols, non-alcohol oxygenates and benzene), demonstrated the control of ignition timing, and the suppression of excessive rapid combustion. The light naphtha was port injected to create a sufficiently homogenous charge. The low ignitability fuels were directly injected into the cylinder. Variable injection timing was investigated. It was reported in this study that low ignitability oxygenated fuels, such as alcohols, have an intense effect in inhibiting the low temperature reactions and, in consequence, were able to delay the onset of HTHR of the light naphtha. The reason of this effect is based on the affinity of methanol to react with $\mathrm{OH}$ radicals, reducing the availability for reacting with the naphtha fuel (Ogawa et al. 2003).

A different approach by using a fuel difficult to ignite, i.e. natural gas (NG), as the main fuel provider of the bulk of the chemical energy, and a secondary fuel, easy to ignite, i.e. n-heptane, as a pilot fuel required to ignite the main fuel, was employed by Wilhelmsson et al. (2007). In the experimental setup, the NG/n-heptane ratio was tailored to keep ignition timing at the maximum indicated efficiency. Boost was adjusted on a variable geometry turbocharger to obtain higher load conditions until certain $\mathrm{NO}_{\mathrm{x}}$ limit was reached. Overall net indicated efficiency -i.e. without taking pumping losses into accountat high load was around 45-50\% (Wilhelmsson et al. 2007). 


\subsubsection{Engine Operation and Design Parameters Modification for HCCI}

\section{Displacement}

The effect of displacement on gasoline fueled HCCI engines was studied by Hivonen et al. (2006) with three different multi-cylinder turbo-charged engines (1.6, 2.0 and 11.7 liters) modified to share similar values of compression ratio, around 14.5. Combustion phasing was assured by controlling the intake temperature in all three engines, at $1000 \mathrm{rpm}$ and using gasoline $91 \mathrm{RON}$. Maximum values of BMEP reported were around 6 bar. Results show maximum values of brake specific efficiencies at 4 bar BMEP for the largest engine and a proportional reduction for the medium and the smaller engine. The thermal efficiency was found to be similar for all three engines at the same BMEP.

\section{Compression ratio}

The proper selection and the influence of compression ratio for stable HCCI combustion has been a key topic in this field, and have been studied along with the choice of suitable fuels for HCCI. Initial studies performed by Gray and Ryan (1997) in HCCI of diesel fuel and blends of hexadecane and nheptane show that the effect of compression ratio in the A/F range where stable HCCI is achieved depends on the type of fuel. For commercial diesel fuel, the researchers concluded that as the CR increases (from 9 to 13) the $\mathrm{A} / \mathrm{F}$ ratio span of stable operation was increased. On the other hand, the $\mathrm{A} / \mathrm{F}$ ratio tended to narrow significantly when the $\mathrm{CR}$ ratio was increased for the fuel blends. The differences were attributed to particular temperature histories for each of the CR and fuel cases. As an additional observation, the tolerance of EGR was found also dependent on $\mathrm{CR}$ and $\mathrm{A} / \mathrm{F}$ ratio. The effect of compression ratio on combustion timing was similar for both fuels, and, as expected, higher compression ratios exhibited earlier combustion timing at the same engine speed for any A/F, and EGR composition (Gray and Ryan 1997).

Christensen and Johansson (2000), working with natural gas for HCCI, tested the influence of CR for two different boost conditions. At low boost, the compression ratio required for stable combustion was reached at $\mathrm{CR}=22$, at four different conditions of $\mathrm{A} / \mathrm{F}$ ratio. At boost of $1.5 \mathrm{bar}$, the compression ratio was reduced at $\mathrm{CR}=18$ to avoid rapid pressure rates leading to engine knock. It was observed that low $\mathrm{CR}$ would reduce the combustion duration in all cases studied. The highest $\mathrm{NO}_{\mathrm{x}}$ emissions were reported for the high CR and high boost case (Christensen and Johansson 2000).

\section{Variable fuel injection}

The use of variable injection timing has been widely investigated with promising results. Cao et al. (2006) using multi-cycle 3-D engine simulation of HCCI combustion on a gasoline engine compared the effects of two different fuel injection strategies: injection during the negative valve overlap (NVO) period 
and injection during the intake period. Results show that the cooling effect of injection on charge affects the volumetric efficiency and combustion phasing due to temperature changes. The volumetric efficiency was better with injection during the intake valve open period. It was found that the partial combustion during the compression period of the $\mathrm{NVO}^{3}$ a minor combustion event, or the release of radicals, takes place and this advances the combustion timing. This minor combustion during the NVO period and its advanced combustion show an increase in IMEP, but also in $\mathrm{NO}_{\mathrm{x}}$ emissions (Cao et al. 2006).

In a similar way Waldman et al. (2007) investigated the effects of fuel injection during the NVO period on a gasoline HCCI engine. Different modes were tested with an initial injection during the NVO period and a secondary injection. The secondary injection was applied either port-injected during intake stroke, or direct injected during the compression stroke. Different timings and relative amounts were tested. Results show that advancing the injection during the NVO period advances the HCCI combustion timing. This phenomenon was associated with fuel reformation during the NVO injection. The advance of the injection during the NVO period allowed the fuel to react with the remaining oxygen and, hence, creating an important radical pool, which advances combustion timing. Advances for up to $10^{\circ} \mathrm{CA}$ on combustion ignition were reported while varying fuel amounts during the NVO period, which agreed with numerical analysis by Urushihara et al.(2003). It was reported that retarding the NVO injection period show a positive effect in volumetric efficiency as a result of an increase of pressure at inlet valve opening (IVO). $\mathrm{NO}_{\mathrm{x}}$ emissions were reduced by retarding the $\mathrm{NVO}$ injection period. The study concluded that the ignition timing can be adjusted by tailoring the relative amount of NVO fuel injected and port/direct fuel injected. Earlier combustion was found when the amount of NVO injection was increased. Combustion efficiency improved as the percentage of NVO fuel injected increased (Waldman et al. 2007).

Partial fuel stratification, a technique that involves partial injections of fuel during the intake and compression stroke was studied by Sjoberg and Dec (2004) using primary reference fuels (PRF83) and iso-octane. Partial fuel stratification differs from the typical fuel stratification found in DISI engines. The early injection is meant to supply the charge with an almost homogeneous distribution of fuel to provide a base equivalence ratio around the cylinder. The second injection during the compression stroke should provide the required energy for load demand. Modeling work performed by the researchers on a multizone model showed that the rate of heat release in the stratified mixture was staged as it advanced from zone to zone. As a consequence, the rate of pressure rise was slowed down, which allowed the use of richer $\mathrm{A} / \mathrm{F}$ ratios without the risk of knock, expanding the operational range of the engine. The first fuel

\footnotetext{
${ }^{3}$ In NVO operation the exhaust valve closes well before top dead center, trapping a significant amount of hot exhaust gases. The trapped gases are then compressed during the remaining section of the exhaust stroke, and then expanded until late opening of the inlet valve. In a conventional SI engine, the intake valve is opened before the exhaust valve is closed.
} 
injection, during the intake stroke was experimentally determined to provide the higher IMEP values at the lowest $\mathrm{NO}_{\mathrm{x}}$ emissions level. The secondary injection was found to be optimal at $295^{\circ} \mathrm{CA}$. When comparing iso-octane, a single stage combustion fuel, with PRF83, a dual stage combustion fuel, the PRF blend showed lower cycle to cycle variations. This behavior was attributed to the steady release of heat after the LTHR region, before the main ignition occurs. The researchers concluded that fuel stratification was more successful with fuels bearing two-stage ignition behavior. This was attributed to the intensity of the LTHR stage in proportion to the local equivalence ratio. Because the local LTHR is staged, then the local HTHR is also staged, generating a globally staged heat release with lower pressure rise rates. Two stage ignition fuels are sensitive to local equivalence ratio values. In that paper, runs with PRF83 show IMEP gross increase from $537 \mathrm{kPa}$ to $597 \mathrm{kPa}$. An increase in $\mathrm{NO}_{\mathrm{x}}$ emissions was also reported.

\section{Dual HCCI-SI operation}

Due to the limited operational range where HCCI has proven stable combustion, the dual operation mode, switching between SI and HCCI operation, has become widely accepted among researchers, and some prototype engine has been tested and presented to the public. Kulzer et al. (2006) compared the thermal efficiency of several single and dual modes using gasoline 95RON. The use of VVA and gasoline direct-injection allowed for three different modes: dethrottled SI operation with early inlet valve closing, charge stratification with high EGR and HCCI operation. Fuel injection, all the valve events and ignition timing were modified for each combustion mode to achieve the best fuel consumption and emissions reductions. HCCI achieved the best emissions reduction and thermal efficiency, but was reported as more challenging to control. The effect of dethrottling was recognized as extremely favorable for reducing incylinder pressure and temperature curves. Compared to the other engines, HCCI achieved the best (42\%) indicated efficiency value and 94\% $\mathrm{NO}_{\mathrm{x}}$ emissions reduction at 5 bar NMEP, $2000 \mathrm{rpm}$ (Kulzer et al. 2006).

Another popular technique explored is the combination of SI and HCCI, which requires variable injection and valve timing. Experiments conducted on a 2 liter, 4 cylinder, GDI engine with $\mathrm{CR}=13$ by Wang et al. (2008) demonstrated the viability of dual mode operation. The HCCI/SI switch required the use of a fast cam. The two-stage variable valve timing mechanism from GM was used in this experiment. Two-stage refers to the profiles needed for SI and for HCCI combustion. HCCI under lean conditions was achieved using NVO and split injection, one during NVO and the other during compression. This technique reduced the sensibility of the charge to intake conditions. Combustion phase was tailored by changing the split ratio. Changes for SI to HCCI were difficult to achieve due to combustion fluctuation; it reported a reduction in $\mathrm{NO}_{\mathrm{x}}$ from $2500 \mathrm{ppm}$ to $300 \mathrm{ppm}$ and an increase in $\mathrm{HC}$ emissions and fuel economy penalties. The researchers reported a stable range of HCCI operation from $1500 \mathrm{rpm}$ to 4000 
rpm, and IMEP values from 1 bar to 4 bar. The level of $\mathrm{NO}_{\mathrm{x}}$ emissions was reduced beyond the $90 \%$ compared to conventional SI engines.

\subsubsection{HCCI Modeling}

Numerical modeling of the HCCI combustion process can be divided in two categories. The first, where the model is focused on predicting the ignition timing, is based on single-zone combustion modeling assuming homogeneous distribution of temperature and composition. The second category, besides covering the ignition timing, describes the combustion process based on a non-homogeneous temperature and composition volume. This secondary category covers multi-zone and CFD modeling. The main characteristics for HCCI modeling are presented below.

\subsubsection{Ignition prediction models: Single zone models}

Prediction of ignition can be accomplished by assuming a single zone with homogeneous distribution of species and temperature during the closed cylinder period covered form intake valve closing (IVC) to exhaust valve opening (EVO). The volume is defined by slider crack kinematics. Heat transfer is mostly based on Woschni type correlations with negligible radiation. Blow-by is usually neglected. Single zone models prediction of ignition timing is good due to the fact that the single zone is representative of the central core zone of the cylinder volume, where the mixture of gases is at higher temperature, with higher probability for ignition. Therefore these models can describe also phenomena associated with the central core, such as $\mathrm{NO}_{\mathrm{x}}$ emissions, and trends in peak pressure and indicated work. Methods to predict ignition are:

\section{Auto-ignition integral method}

This method is based on the Livengood-Wu (1955) which determines the onset of ignition (AI) based instantaneous ignition delay $(\tau)$ of the mixture $\tau=c P^{n} \exp (-b / T)$ where $\mathrm{P}$ and $\mathrm{T}$ are the instantaneous pressure and temperature, respectively; and $c, n$ and $b$ are fuel specific constants. This method is not suited for fuels that exhibit low temperature heat release (Shaver et al. 2003).

\section{Global reaction mechanism}

The global reaction mechanism method is based on calculating the autoignition of the mixture by using global reaction rates obtained in rapid firing machines for hydrocarbons available in literature (Shaver et al. 2003). The reaction rates had to be modified to account for IC engines conditions. The first HCCI model developed for this project was based on this kind of auto-ignition mechanism for n-heptane (Posada et al. 2007). 


\section{Detailed chemical kinetics mechanisms}

Detailed chemical kinetic mechanisms are able to simulate all of the documented chemical processes that occur during HCCI combustion leading to auto-ignition. Because HCCI combustion is governed by chemical kinetics, these detailed mechanisms are fundamental for single-zone and multi-zone. One of the advantages is that cool flame chemistry can be captured by this model. The drawback of this model lays on the amount of elementary reactions that are described, creating numerical difficulties for the set of differential equations to be solved (Aceves et al. 1999, Aceves et al. 2000). HCCI single zones model have been used to predict engine performance over a wide rage of operating conditions and has also been applied for control strategies (Shaver et al. 2003).

\subsubsection{HCCI detailed combustion: CFD and Multi-zone models}

Single-zone models are not able to predict burn duration, and the calculated rate of heat release, and pressure rise are extremely high (Aceves et al 1999). Boundary layer effects such as $\mathrm{HC}$ and $\mathrm{CO}$ emissions are also not covered by single-zone models (Easley et al. 2001). CFD and multi-zone models have been used to study the HCCI problem considering the auto-ignition chemistry and the chemical and thermal stratification between boundary layer and the mixture core.

\section{CFD Models}

In CFD models, the chemistry and fluid problems are solved simultaneously (Warnatz et al. 1999). CFD models are capable of predicting any engine combustion phenomena, with the appropriate grid resolution and setting of boundary conditions (Warnatz et al. 1999). However, the solution of combustion related problems is limited by the capability of the processor to handle large chemical kinetics mechanism. Reduction of mechanism is the simplest method to increase the speed of solution processing (Patel et al. 2004). However reduced mechanisms are applicable to a reduced set of engine conditions. Among the benefits observed in CFD modeling is the capability of describing turbulent mixing phenomena that occurs around the valve events. This is very important when the air and fuel mixture is not homogenous (Warnatz et al. 1999, Patel et al. 2004).

\section{Multi-zone models}

Multi-zone models can be described a simplified version of a CFD model, where many cells are grouped into a single zone. For problems were the auto-ignition chemistry is more significant than the fluid flow phenomena, a multi-zone model offers great computational advantage (Aceves et al. 2000). This approach also offers the benefit of describing boundary layer phenomena and accounting for stratification. Multi-zone models applied in HCCI combustion can be characterized by the number of zones, the type of zones and the interaction between zones. 
The number of zones goes from 2 zones, i.e. boundary layer (BL) and core zones (Fiveland and Assanis 2001), up to 30 zones (Noda and Foster 2001). Multi-zone models contain boundary layer zones that allow for better representing thermal stratification and crevices to describe unburned $\mathrm{HC}$ exchange with the core during expansion.

Easley et al. (2001) presented a model where the cylinder was divided in four types of zones: crevice, boundary layer, inner core and outer core. Mass exchange between zones was limited to crevice, boundary layer and outer core. The inner core was considered as an adiabatic zone, with no mass exchange, and zone interaction with the outer core due to work. The volume of each zone that exchange mass was defined as constant, depending on a specified boundary layer thickness for the BL zone, and a predefined crevice volume for said zone. The initial inner core volume depends on initial mass distribution for the inner core and on the volume balance for the outer core. As inputs, the model required boundary layer thickness, mass distribution and initial temperature and cylinder pressure (Easley et al. 2001).

Ogink and Golovitchev (2002) presented a multi-zone model with nine zones: a crevice zone of constant volume, a quench layer zone with a constant thickness of $0.1 \mathrm{~mm}$, a core zone that exchange mass with the quench layer and six core zones of constant mass. The volume of each core zone was derived from mass distribution obtained via in-cylinder pressure data analysis assuming normal distribution characteristics. Results demonstrated that the model properly predicts the pressure history and rate of heat release, but the emissions results were highly dependent on proper quantification of trapped mass and EGR.

Heat transfer between zones was first introduced by Komninos et al. (2004). In this approach, the volume of each zone was geometry dependant. The bounding geometry characteristic was defined by the percentage of core zone defined at TDC, usually 50\% of height at TDC. From this geometric condition, the remaining volume zones, or shells, were calculated by assuming a constant thickness and changing height. Mass and heat transfer was allowed from core to quench layer. Heat transfer to the walls was also accounted for.

Heat transfer to walls was considered in this investigation by using the correlation developed by Chang et al. (2004). No pressure-volume work interaction was considered because the model is geometry driven, as it was proposed by Komninos et al. (2004). All zones must share the same pressure. This model is based on the model developed by Komninos et al. (2004) Mass exchange between zones is considered because the mixing of cold gases from crevices and $\mathrm{BL}$ with hotter inner regions is the main reason for $\mathrm{HC}$ and CO emissions on HCCI engines (Easley et al. 2001). 


\subsection{Thermo-Chemical Recuperation}

The concept of thermo-chemical recuperation is based on the idea of storing heat energy by converting it to chemical energy. In practical terms, it means to take an energy-poor reactant, and reformed it through endothermic reactions into an energy enriched product.

TCR for reciprocating IC engines uses high efficiency heat exchangers to recover sensible heat from engine exhaust gases and convert it to chemical (fuel) energy. The main techniques for onboard reforming of automotive fuels are partial oxidation, also known as exhaust-gas reforming, and steam reforming. In the exhaust-gas reforming case, the fuel enters in direct contact with available water molecules in the exhaust gas stream after the combustion process (Kirk and Othmer 2000). Similarly, steam reforming is based on the interaction between fuel and water molecules, but in this case the water is provided by an independent source (on-board tank or exhaust gas condensate). The exhaust gas stream can be used as a heat source without being in direct contact with the fuel.

\subsubsection{Partial Oxidation}

Partial oxidation (PO) for hydrogen generation is a process used in industrial applications for $\mathrm{H}_{2}$ production. This process is mostly applied to heavier hydrocarbons or when there is a source of pure $\mathrm{O}_{2}$ available in the plant (Kirk and Othmer 2000). As the name implies, partial oxidation requires less than stoichiometric concentration of $\mathrm{O}_{2}$,

$$
C_{n} H_{m}+\frac{n}{2} O_{2} \rightarrow n C O+\frac{m}{2} H_{2}
$$

Equation 7

As an example, the partial oxidation of methane can be described by,

$$
\mathrm{CH}_{4}+\mathrm{O}_{2} \rightarrow \mathrm{CO}+2 \mathrm{H}_{2} \quad \Delta \mathrm{H}=-36 \mathrm{~kJ} / \mathrm{mol}
$$

Equation 8

where $\Delta \mathrm{H}$ represents the energy released during the partial oxidation. The negative sign means an exothermic reaction. This allows the PO process to be carried on without a source of heat, simplifying the final process design. The downside of the exothermic process is the waste of energy in conversion from chemical to heat energy (Jones and Wyszynski 1993). In the case of on-board partial oxidation, where there is no pure $\mathrm{O}_{2}$, Equation 7 includes the corresponding amount of $\mathrm{N}_{2}$ at both sides of the equation.

\subsubsection{Steam Reforming}

The steam reforming (SR) of a hydrocarbon fuel is a process in which steam is used to extract hydrogen from a hydrocarbon feedstock fuel in the presence of metal catalyst. Currently, the majority of the world's hydrogen is produced by steam reforming of fossil-fuels, primarily of natural gas, but it can 
also be obtained from naphtha, liquid petroleum gas (LPG) or refinery off-gas (Bennett 2007). The industrial production of hydrogen is accomplished through these general steps described below.

Gas pretreatment is the required first step to remove sulfur compounds that would poison the nickel based catalyst. The catalytic reforming process, where most of the $\mathrm{H}_{2}$ and the sub-product $\mathrm{CO}$ are produced, takes place at high temperatures $\left(650-900^{\circ} \mathrm{C}\right)$ and pressures $(3-25 \mathrm{bar})$. High pressures require high temperatures for a favorable equilibrium. For general hydrocarbon fuels, the following global reaction determines the ideal amount of hydrogen produced from the fuel (Kirk and Othmer 2000).

$$
\mathrm{C}_{n} \mathrm{H}_{2 n+2}+n \mathrm{H}_{2} \mathrm{O} \rightarrow n \mathrm{CO}+(2 n+1) \mathrm{H}_{2}
$$

Equation 9

The steam to carbon mole ratio is kept at values close to $\mathrm{S}: \mathrm{C}=3: 1$, for industrial applications, to avoid carbon deposition on the reactor catalytic walls.

Other reactions can also be promoted to obtain higher yield of $\mathrm{H}_{2}$. The water-gas shift reaction (WGSR) is exothermic and favored at low temperatures.

$$
\mathrm{CO}+\mathrm{H}_{2} \mathrm{O} \leftrightarrow \mathrm{CO}_{2}+\mathrm{H}_{2}
$$

Equation 10

As an example, the steam reforming of methane can be described by,

$$
\mathrm{CH}_{4}+\mathrm{H}_{2} \mathrm{O}(\mathrm{g}) \rightarrow \mathrm{CO}+3 \mathrm{H}_{2} \quad \Delta \mathrm{H}=206 \mathrm{~kJ} / \mathrm{mol} \quad \text { Equation } 11
$$

where $\Delta H$ represents the energy required to carry on the steam reforming reaction.

To compensate for low temperature processing at reduced kinetic speed, the process is usually implemented in two stages: high and low-temperature stages (Hoogers 2005). The high temperature WGSR occurs around $380^{\circ} \mathrm{C}$ using an iron oxide-chromium as catalyst. A second reduction of temperature at $250^{\circ} \mathrm{C}$ is carried out to increase the rate of reactions using copper, chromium and zinc oxides as catalysts (Hoogers 2005).

The steam reforming reaction is endothermic in the overall, and the required amount of energy depends on the stability of the base fuel to be reformed and the ability of the catalyst to activate and transform the base fuel into the products (Kirk and Othmer 2000). The process can be applied to many hydrocarbon fuels, requiring different catalyst materials and reforming temperatures. Methanol, for example, is reformed between $470 \mathrm{~K}$ and $570 \mathrm{~K}$, while methane is reformed between $1000 \mathrm{~K}$ and $1300 \mathrm{~K}$. Methanol reforming uses a copper catalyst supported by zinc oxide. The best catalyst for the hightemperature water-gas shift reaction is a mixture of iron and chromium oxides, while the low-temperature 
reaction implements a copper catalyst supported by zinc oxide. Methane reforming is usually catalyzed by nickel (Hoogers 2005).

\subsubsection{On-board Reforming of Fuels}

Partial oxidation and steam reforming are two processes to accomplish the thermo-chemical recuperation of fuels. Regarding mobile applications, these methods have been studied since World War II and only a handful of prototypes have been built.

Houseman and Cerini (1976) published a paper discussing the alternatives and trade-offs between both, PO and SR of a hydrocarbon fuel. Indolene, as a surrogate for gasoline, and methanol where used for the experimental work. Equilibrium calculations were performed to determine the theoretical behavior of both fuels and processes. For steam reforming, the model results showed that there is a trade off between the steam/fuel ratio and the operating temperature to reach certain $\mathrm{H}_{2} /$ fuel ratio. Theoretical thermal efficiencies, defined as the ratio between the LHV of products and reactants, were around $118 \%$. Steam reforming of methanol was reported successful at temperature higher than $260^{\circ} \mathrm{C}$. The heating value for the reformed product of methanol was increased by $8 \%$. The partial oxidation of gasoline was reported at equivalence ratios lower than $\varphi=0.37$. At this equivalence ratio, the PO thermal efficiency was around $80 \%$. Experimental results with partial oxidation of methanol, without catalyst, showed that at $496^{\circ} \mathrm{C}$ the thermal efficiency reached $50 \%$ and the product composition had $\mathrm{H}_{2}$ content of $20 \%$. Experimental results on steam reforming of gasoline showed that at $520^{\circ} \mathrm{C}$ the reformer reached a thermal efficiency of $112 \%$ and the $\mathrm{H}_{2}$ mole fraction was $51 \%$ (Houseman and Cerini 1976).

A direct contact reforming reactor capable of both steam reforming and partial oxidation was built and tested by Jones and Wyszynski (1993) for on-board reforming of n-heptane aiming at ultra-lean combustion through $\mathrm{H}_{2}$ addition. The exhaust gas reformer allowed for combining fuel, exhausts gases and steam, tailoring the reformate gas composition. Propane was used as the source of exhaust gases due to its similarity in composition with gasoline products. Four parameters were studied during the test: the temperature of the reformer gas inlet, the gas hourly space velocity (GHSV), exhaust gas composition and reforming oxidant to fuel ratio. Reactor Inlet temperatures were varied from $873 \mathrm{~K}$ to $1223 \mathrm{~K}$. GHSV was tested at $1000 \mathrm{~h}^{-1}$ and $3000 \mathrm{~h}^{-1}$. The oxidant composition was tested under standard (unmodified) combustion products, and under modified conditions by steam, also by $3 \%$ (by vol) excess oxygen in air and by both steam and oxygen. 
The reactor excess oxidant ratio ${ }^{4}$ was tested at two levels, $\lambda_{\mathrm{r}}=1$ and $\lambda_{\mathrm{r}}=2$. Results reported show that the highest temperature produced peak values of $\mathrm{H}_{2}$ concentration $(26 \%)$ and reformer thermal efficiency $(120 \%)$. Methane levels were significant at low temperatures and reduced with increase in temperature. Equilibrium levels of $\mathrm{H}_{2}$ and $\mathrm{CO}$ were not reached even at the lowest value of space velocity. $\mathrm{CH}_{4}$ and $\mathrm{CO}_{2}$ concentrations were higher than the corresponding equilibrium values. Test performed at $1000 \mathrm{~h}^{-1}$ and at higher temperature presented some carbon accumulation on the reactor walls. When the oxidant composition was compared, the highest values of $\mathrm{H}_{2}$ concentration $(32.2 \%)$ were reached with the fuel/steam reforming process, with $3 \%$ excess oxygen. $\mathrm{CO}$ yield was reduced with steam addition. The effect of oxidant ratio was to reduce the formation of solid carbon in the reformer (Jones and Wyszynski 1993).

The use of steam reforming of hydrocarbon fuels extends to other fields of applications such as fuel cells. Because fuel cells operation are based on hydrogen, the steam reforming of hydrocarbons technology is a potential supply of $\mathrm{H}_{2}$ based on commercial hydrocarbons. Hu et al. (2003) presented a paper on hydrogen production by steam reforming of hydrocarbons for use in PEM fuel cells, which require high $\mathrm{H}_{2}$ purity and small reactor volume. The catalyst selected for this research was based on $\mathrm{Pd}$ on ceria. Tests were conducted at a steam/methanol ratio of 1:1 by weight. Methanol, iso-octane and synthetic diesel fuel were tested. Results show that a very high GHSV (36000-144000 $\mathrm{h}^{-1}$ ) and at relative low temperature $(720-820 \mathrm{~K})$ the reformer achieved iso-octane and synthetic diesel conversion around $95 \%$. Methanol was reformed at temperatures around 570-620 K. It was also found that the commercial diesel fuel tested caused significant catalyst deactivation within 3 hours of tests (Hu et al. 2003).

\subsection{HCCI with Reformed Gas $\left(\mathrm{H}_{2}\right.$ and $\left.\mathrm{CO}\right)$ addition}

The effects of partial oxidation of hydrocarbons $\left(\mathrm{H}_{2}\right.$ and $\left.\mathrm{CO}\right)$ in HCCI combustion of n-heptane and iso-octane were investigated by Eng et al. (2002) in a single cylinder Ricardo Hydro engine with $\mathrm{CR}=12.5$. In order to achieve HCCI operation and, at the same time, avoid the use of high intake temperature to control combustion timing, the research team decided to use exhaust re-breathing techniques. The exhaust re-breathing technique is based on opening the exhaust valve during the intake stroke to re-breath some amount of hot exhaust gases to increase the in-cylinder mixture temperature. The PO gas was simulated with a predefined mixture of $\mathrm{H}_{2}, \mathrm{CO}$ and $\mathrm{N}_{2}$ with a relative composition that

\footnotetext{
${ }^{4}$ Reactor excess oxidant ratio was defined by Jones and Wyszynski (1993) as,

$$
\lambda_{r}=\frac{\text { Actual } O F}{\text { Stoich } O F}
$$
}
where OF is the oxidant to feedstock ratio 
reflected the hydrogen to carbon ratio of the fuel used in the experiment. Experimental results with nheptane at the base case, without rebreathing showed that the intake temperature had to be increased to keep COV of IMEP below 1\%. Even though the intake temperature was increased, the experimental results obtained in peak pressure location (CA degrees) showed that this event was retarded with increased amounts of PO gas. Analysis of the heat release data showed that the addition of PO to the nheptane combustion reduced the LTHR magnitude and increased the HTHR. The conclusion of these baseline runs was that the sensible energy required on increasing intake temperature was compensating the reduction on LTHR energy with PO addition. The researcher reported as very difficult to control HCCI with iso-octane. The use of re-breathing for HCCI operation was tested with both fuels. The effect of PO on HCCI with rebreathing was negligible for n-heptane. The effect on HCCI of iso-octane with rebreathing was to advance the ignition timing. Numerical simulation performed in a multi-zone model for $\mathrm{HCCI}$ of $n$-heptane was used to determine that $\mathrm{H}_{2}$ and $\mathrm{CO}$ addition lengthened the ignition delay time at low temperatures, but at high temperatures the delay time was augmented. It was concluded that at low temperatures the $\mathrm{H}_{2}$ and $\mathrm{CO}$ addition removed some of the $\mathrm{OH}$ radicals from the reaction chain and replaced them with $\mathrm{HO}_{2}$ and $\mathrm{H}_{2} \mathrm{O}_{2}$ which are relatively inert species. As a result, the low temperature chemistry was inhibited. The case of rebreathing was also analyzed. In this case, the high temperature history allowed for a quick travel to the HTHR region, avoiding the LTHR effects, resulting in an apparent no-effect in the HCCI combustion for n-heptane (Eng et al. 2002).

A HCCI engine fueled by dimethyl-ether (DME) and DME reformed gases (DRG) was studied by Shudo et al. (2003). The thermo-chemical recuperation system was studied for partial oxidation and steam reforming. The load was controlled by changing the ratio DME/DRG and its total amount delivered to the cylinder. The DRG composition for experiments with reforming through PO was assumed as $3 \mathrm{H}_{2}+2 \mathrm{CO}+2 \mathrm{~N}_{2}$. The DRG composition for steam reforming was assumed as $2 \mathrm{H}_{2}+1 \mathrm{CO}$. Lower heating values analysis performed by the researchers show that the reformed gases of DME from PO process had $2 \%$ lower LHV than the original DME; reformed gases from SR process had $15 \%$ higher LHV than DME. Experimental results on the four stroke engine with $\mathrm{CR}=9.7$ showed that the $\mathrm{DRG}$ addition from both reforming processes had similar effects by increasing indicated mean effective pressure and thermal efficiency. The reason for this benefit was found in a delay of the combustion event with DRG addition. The delay was increased in proportion with DRG content. The operational range defined by equivalence ratio, was extended from $\phi=0.28$ to $\phi=0.44$. Kinetics effects of the addition of $\mathrm{H}_{2}$ and $\mathrm{CO}$ were studied by the researchers. The addition of DRG extended the duration of the LTHR event and made the rate of LTHR slower, which had a delaying effect on the main HRHR event. The effect of $\mathrm{H}_{2}$ was observed to have a stronger effect on ignition delay than $\mathrm{CO}$. The researchers concluded that the additional $\mathrm{H}_{2}$ 
consumed $\mathrm{OH}$ radicals, and in consequence reduced it concentration and its rate of consumption from branched chains for $\mathrm{H}$ abstraction. Because $\mathrm{H}$ abstraction of dimethyl ether is the chain dominating path for LTHR, the whole process gets delayed (Shudo et al. 2003).

Kongsereeparp and Checkel (2007) developed a multi-zone model to study the effects of different concentration of reformed fuel on the LTC behavior. The reformed gas considered in this study consisted of a mixture of $75 \% \mathrm{H}_{2}$ and $25 \% \mathrm{CO}$ with a corresponding amount of diluents proportional to the residual exhaust gas. The effect of different blending levels of reformed fuel ( $0 \%-40 \%$ by mass) was studied for compressed natural gas (CNG), which is a high octane base fuel, and n-heptane, a low octane base fuel. Initial conditions where held the same for each type of fuel at different blending concentrations. The multi-zone model showed that the start of combustion can be modified by increasing the amount of reformed fuel in both type of fuels. For the CNG-reformed fuel model, the addition of the reformed fuel had relatively little effect on the SOC, and the advance on ignition timing was attributed to variations in mixture thermal properties. The researchers found that addition of n-heptane reformed fuel affects the low temperature heat release stage by changing the chemical state during the cool flame reaction stage, and therefore, delays the auto-ignition process (Kongsereeparp and Checkel 2007).

Experimental studies were developed on a CFR engine for both low and high octane fuels, and the effects on HCCI operational range, in-cylinder pressure history, heat release rates, engine performance and emissions were studied (Hosseini and Checkel 2007-a) and (Hosseini and Checkel 2007-b). During those studies the ratio of reformed fuel to base fuel was varied while $\mathrm{A} / \mathrm{F}$ ratio, intake temperature and EGR fraction were kept constant.

Results on low octane fuels (PRF0 and PRF20) evidenced that the addition of reformed fuel extended the operational range towards richer mixtures, and hence higher peak IMEP and wider IMEP range was achieved while keeping constant all other operational parameters. Peak cylinder pressure and pressure rise rate was reduced as the reformed fuel ratio was increased due to retarding effect on SOC. Replacement of base fuel for diatomic molecules $\left(\mathrm{H}_{2}\right.$ and $\left.\mathrm{CO}\right)$ increases the mixture specific heat ratio, consequently increasing the compression temperature. According to Hosseini and Checkel (2007-b), analysis of heat release data showed that the first stage of heat release, or LTHR, was reduced by an amount higher than the reduction expected from a lower amount of fuel on the mixture. The authors concluded that this excessive reduction in LTHR must be attributed to chemical kinetic effects. A lower LTHR implies less energy released and less radicals available to promote the main or HTHR stage. Experiments showed that the HTHR was retarded even after TDC with increased values of fuel reformed and the combustion duration became longer. As an example, $20 \%$ of fuel reformed addition delayed SOC 
by approximately $14^{\circ} \mathrm{CA}$ and increased the combustion duration by $50 \%$. A better combustion phasing compared with the short combustion duration for n-heptane generates a higher indicated power. An increase of $17 \%$ on indicated power was achieved on the previous example. Authors pointed out that the same combustion timing can be obtained by adjusting the intake temperature or the dilution using EGR or $\mathrm{A} / \mathrm{F}$ ratio. However, the thermal option is not adequate for control purposes and the dilution strategy implies a power loss, instead of the chemical energy contribution of the reformed fuel addition. As a result, the thermal efficiency is also increased, as confirmed in the case of $20 \%$ reformed fuel addition where the thermal efficiency was increased by $12 \%$. Regarding emissions reformed fuel addition did not show any significative change on $\mathrm{NO}_{\mathrm{x}}$ emissions respect to the almost zero resulting $\mathrm{NO}_{\mathrm{x}}$ emissions from the base HCCI engine. $\mathrm{CO}$ emissions were proportionally higher at higher reformed fuel ratios probably due to a higher initial concentration, but the HC emissions, which are higher for HCCI than for CI engines, did not show a stable tendency to derive definitive conclusions.

Results using high octane fuels (PRF80 and PRF100) were presented by Hosseini and Checkel (2007-a). The value of compression ratio used was between $C R=14.4$ and $C R=16.0$ and the intake temperature was increased $\left(140^{\circ} \mathrm{C}\right)$ compared to the one used for PRF0 $\left(100^{\circ} \mathrm{C}\right)$. Peak pressure and pressure rise rate were reduced by increasing the amount of reformed fuel, while keeping constant the $\mathrm{A} / \mathrm{F}$ ratio, EGR and intake temperature. The effects of reformed fuel ratio on heat release showed that the addition of reformed fuel delay the start of combustion and expand the combustion duration. A slight increase in indicated thermal efficiency was found with addition of fuel reformed due to the ability to control the SOC and shift the pressure peak after TDC. Addition of reformed fuel reported an increase in $\mathrm{HC}$ and $\mathrm{CO}$ emissions, as in the n-heptane case, proportionally to fuel reformed addition. Regarding $\mathrm{NO}_{\mathrm{x}}$ emissions, the results from the HCCI engine operation with baseline fuel were below $0.05 \mathrm{~g} / \mathrm{kWh}$, and the results of adding reformed fuel fall within the uncertainty measurement range (Hosseini and Checkel 2007-a). 


\section{Chapter 3. HCCI Combustion Modeling}

Modeling of HCCI combustion has been accomplished mainly through three different approaches depending on the specific process to be modeled and on information required by the researcher. It was mentioned earlier in section 2.4 that single-zone models, multi-zone models and CFD models have been developed to study this combustion process (Easley et al. 2001, Komninos et al. 2004). It is proposed in this research work to systematically proceed from a simple closed volume model, i.e. the single-zone model, which allows the study of the combustion phasing under different operational conditions, and then move towards a multi-zone model where the thermal stratification can be reproduced and therefore a picture of the heat release can be obtained more accurately.

Single-zone and multi-zone combustion models are designed to calculate in-cylinder mixture properties from IVC to EVO, describing compression, combustion and expansion processes. Initial conditions for these models i.e., average in-cylinder temperature, pressure and composition, require to be predefined at IVC. Instead, linking the closed volume combustion model to a gas exchange model, able to capture information on residual mass fraction $\left(\mathrm{m}_{\mathrm{R}}\right)$, composition and temperature before IVO, allows defining conditions at IVC. A gas exchange model was then developed and integrated with the combustion model into a cycle model aiming to provide a good approximation for exhaust gas temperature and conditions at IVC. Once the first IVC conditions are provided, the steady state solution is reached after a few iterations of the cycle model.

The exhaust gas temperature value provided by the model is later used in the TCR model to predict RG composition. The combustion model, gas exchange model and TCR model are later integrated into a HCCI-TCR cycle model where the interaction between the models is studied.

\subsection{Single-Zone Modeling Description}

A single-zone (SZ) model was developed in Matlab-Cantera to simulate the HCCI combustion of nheptane. The major assumptions and initial conditions applied in the single-zone model were as follows.

1. Closed system analysis from IVC to EVO. Blowby is neglected.

2. In-cylinder mixture composition and temperature are considered homogeneous at any given time.

3. Temperature and pressure at IVC, and composition of mixture of residual gas and fresh intake charge, are considered as the initial conditions for solving the set of differential equations. 
4. The homogeneous mixture is compressed and expanded following the slider-crank kinematics.

5. The compression of the in-cylinder charge provides the temperature conditions to initiate the autoignition process.

6. Convective heat transfer to walls is the only form of heat transfer considered. Constant walls temperature is assumed (Aceves et al. 1999, Aceves et al. 2000).

The chemical kinetic code that describes the oxidation of $n$-heptane in air was taken from the Lawrence Livermore National Laboratory ${ }^{5}$ based on the reaction rates for $n$-heptane oxidation proposed by Curran et al. (1998). Heat transfer to the walls was calculated using the correlation for convection proposed by Chang et al. (2004), which is a modification of the traditional Woschni's correlation for SI engines, while considering the combustion features of the HCCI engine; a constant wall temperature of $420 \mathrm{~K}$ was used for all cases in this simulation. The thermodynamic fundamentals of this model were previously described by the author (Posada et al. 2007) and described below.

The volume is function of the crank angle, compression ratio, bore, stroke and the connecting rod length.

$$
V(\theta)=V_{c}+(\pi / 4) B^{2} S\left(0.5+\frac{R}{2}+\frac{1}{c r-1}-\frac{\cos (\theta)}{2}-\frac{1}{2} \sqrt{R^{2}-\sin ^{2}(\theta)}\right)
$$

where $\theta$ is crank angle, $c r$ is compression ratio, $B$ is bore, $S$ is stroke and $R$ is connecting rod length to stroke ratio. For a constant rotational speed $\theta=\omega t$, where $\omega$ is the crankshaft rotational speed and $t$ is time.

The energy balance for a closed system and the ideal gas law are combined in order to derive a differential equation for the temperature of the gas inside the cylinder.

$$
\frac{d U}{d t}=\frac{d Q_{w}}{d t}-\frac{d W}{d t}
$$

Equation 13

Here $d Q_{w} d t$ is the rate of heat transferred to the wall, $d W / d t$ is the work done by the system by unit time, and $d U / d t$ is the rate of change of internal energy of the species involved in the combustion process .

The rate of change of total energy $U$ can be expressed as

$$
\frac{d U}{d t}=\frac{d(m h)}{d t}-p v \frac{d m}{d t}-V \frac{d p}{d t}-m p \frac{d v}{d t}
$$

\footnotetext{
${ }^{5} \mathrm{https}: / /$ www-pls.1lnl.gov/?url=science_and_technology-chemistry-combustion-nc7h16
} 
where the mass $m$ is calculated from ideal gas state equation and $v$ is the specific volume of gas in the cylinder.

The work is expressed as

$$
\frac{d W}{d t}=m p \frac{d v}{d t}
$$

The enthalpy term is expanded in terms of the contributions of the species in the cylinder as

$$
m h=H=\sum N_{i} \bar{h}_{i}
$$

Equation 16

where $N_{i}$ is the number of moles of species $i$ in the cylinder, $H$ is the total enthalpy of species and $\bar{h}_{l}$ is the enthalpy of species $i$ in a molar basis.

The rate of change of molar enthalpy is expressed in terms of the specific heat of species $C_{p, i}$ at temperature $T$.

$$
\frac{d \bar{h}_{i}}{d t}=C_{p, i}(T) \cdot \frac{d T}{d t}
$$

Differentiating the ideal gas law, changes in pressure, $p$, are related to temperature changes and molar concentration changes by,

$$
\frac{1}{p} \frac{d p}{d t}=\frac{1}{\sum\left[X_{i}\right]} \frac{d}{d t}\left[\sum\left[X_{i}\right]+\frac{1}{T} \frac{d T}{d t}\right.
$$

where $\left[X_{i}\right]$ is the concentration of species in the cylinder, defined as

$$
\left[X_{i}\right]=\frac{N_{i}}{V}
$$

Equation 19

where $N_{i}$ is the number of moles of species $i$ in the cylinder. The rate of change of concentration of species is obtained differentiating with respect to time

$$
\frac{d\left[X_{i}\right]}{d t}=\frac{1}{V} \frac{d N_{i}}{d t}-\frac{\left[X_{i}\right]}{V} \frac{d V}{d t}
$$

and

$$
w_{i}=\frac{\dot{N}_{i}}{V}
$$

where $w_{i}$ is the rate of change of species concentration obtained from chemical kinetics data. 
The rate of change of temperature can be determined by rearranging the previous equations:

$$
\frac{d T}{d t}=\frac{\left.\frac{\dot{Q}_{w}}{V}+\frac{\dot{V}}{V} P+P \frac{\sum\left[\dot{X}_{i}\right] M_{i}}{\sum\left[X_{i}\right] M_{i}}+P \frac{\sum\left[\dot{X}_{i}\right]}{\sum\left[X_{i}\right]}-\sum\left[X_{i}\right] \bar{h}_{i}-\frac{\dot{V}}{V} \sum\left[X_{i}\right] \bar{h}_{i}\right)}{\sum[X i] C_{p, i}(T)-(P / T)}
$$

Equation 22

Equations 20 and 22 are the set of non-linear differential equations to solve for temperature and compositions. Pressure values are obtained from Eq. 18. The rate of heat transfer required by Eq. 22 is defined as

$$
\frac{d Q_{w}}{d t}=-h_{\text {avg }} A\left(T-T_{\text {wall }}\right)
$$

where $h_{\text {avg }}$ is the spatially averaged convective heat transfer coefficient and $T_{\text {wall }}$ is the average temperature of the cylinder inside walls of area $A$. The value of $T_{\text {wall }}$ is considered constant during the cycle. The proposed correlation for the averaged convective heat transfer coefficient is (Chang et al. 2004),

$$
h_{\text {avg }}(t)=a \cdot L(t)^{-0.2} \cdot p(t)^{0.8} \cdot T(t)^{-0.73} \cdot v(t)^{0.8}
$$

Equation 24

where $L(t)$ is the instantaneous chamber height, and $s(t)$ represents the average cylinder gas velocity. The parameter $a$ is an adjustment factor used to reflect experimental conditions.

This oversimplified model does not account for the boundary layer mass, with lower temperature than the cylinder core. This overall higher in-cylinder temperature leads to faster combustion reactions, and higher peak pressure rise than the values reported by experiments. However, combustion phasing, or CA50, have been shown to be determined with good accuracy with this type of model (Aceves et al. 1999).

As it was explained in the literature review section, the SZ model does not properly describe the pressure and temperature history, and cannot predict BL phenomena. A multi-zone (MZ) model is required to better predict engine performance and emissions. Steps on this direction were taken and a multi-zone model with heat and mass interaction between zones was developed. The validation of both the single zone and multi-zone model were accomplished based on experimental data reported by Guo et al. (2009) on HCCI combustion of n-heptane. The model was run under different A/F values and speed values to verify its ability to reproduce the experimental data, and to study the effects on combustion phasing and heat release. 


\subsection{Multi-Zone Modeling Description}

The limitations of the SZ model on describing peak temperature and rate of pressure rise require the implementation of a multi-zone (MZ) model. The major assumptions made in the MZ model were as follows.

1. Closed system analysis from IVC to EVO. Blowby is neglected.

2. In-cylinder mixture composition and temperature stratification are simulated by dividing the cylinder volume in $Z$ number of zones. The temperature and composition of each zone is the same around the zone at any given time (Komninos et al. 2004).

3. Pressure across all zones is the same at any given time.

4. Every zone interacts with its neighboring zones by exchanging energy via heat conduction and mass (enthalpy). Mass exchange is required in order to keep pressure constant across all zones (Komninos et al. 2004).

5. The cylinder volume is compressed and expanded following the slider-crank kinematics. Each zone has its own volume and there is no volume interaction between zones associated with work (Komninos et al. 2004).

6. The crevice volume is considered as a fraction of the cylinder volume at TDC, and the temperature of the gas inside the crevice zone is always constant and equal to wall temperature (Komninos et al. 2004, Easley et al. 2001)

7. Convective heat transfer to walls is the only form of heat transfer considered. Constant walls temperature is assumed (Aceves et al. 2000, Chang et al. 2004, Fiveland and Assanis 2001).

Figure 1 shows a schematic of the multi-zone model. In this case, six zones are presented: four inner core zones, one boundary layer and a crevice volume. The number of zones was selected looking for a shell thickness similar to the boundary layer, which is usually around 1-3 mm in HCCI engines according to Hulkvist et al. (2001). 


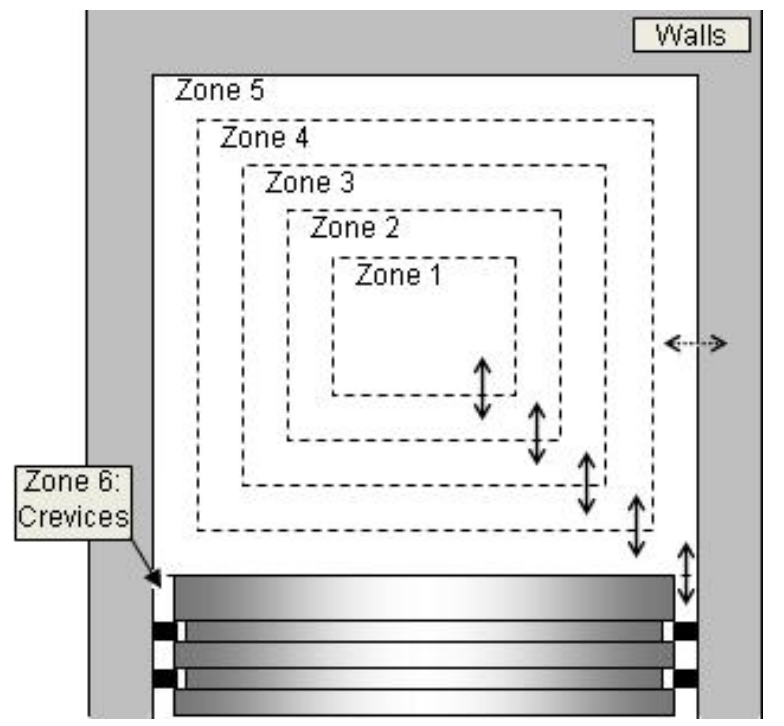

Figure 1. Multi-zone model representation

Each zone, but the inner core, is a cylindrical shell, with constant thickness in the radial and axial directions, and during the piston movement. The shell thickness is determined by the cylinder volume at TDC:

$$
2 \cdot(Z-2) \cdot t_{i}=f \cdot S_{T D C}
$$

Equation 25

where $Z$ is the number of zones, $t_{i}$ is the wall thickness, $S_{T D C}$ is the clearance volume height, and $f$ is the fraction of the $\mathrm{S}_{\mathrm{TDC}}$ devoted to the core zone at TDC.

This zone configuration is in agreement with experiments conducted in optical engines, where it was observed that the combustion is initiated at the core of the cylinder charge and it advances towards cylinder head and piston (Hulkvist et al. 2001). This thermal stratification is what differentiates the multizone model from previous single-zone models.

Heat transfer by conduction was assumed between neighboring zones,

$$
\dot{q}^{\prime \prime}=-k \frac{d T}{d x} \approx-k \frac{\Delta T_{i}}{t_{i}}
$$

where $\Delta T_{i}$ corresponds to the temperature difference between neighboring zones. The value of thermal conductivity, $k$, was calculated using the approach of Yang and Martin (1989). The thermal conductivity was calculated as composed of laminar and turbulent parts.

$$
k=k_{l}+k_{t}
$$

Equation 27 
where $\mathrm{k}_{1}$ and $\mathrm{k}_{\mathrm{t}}$ are the laminar and turbulent values respectively. The value of $\mathrm{k}_{1}$ was calculated from gas conductivity, as function of temperature; $k_{t}$ was calculated as (Yang and Martin 1989):

$$
\frac{k_{t}}{k_{l}}=\frac{\operatorname{Pr}_{l}}{\operatorname{Pr}_{t}} \frac{\mu_{t}}{\mu_{l}}
$$

This relationship holds for swirl dominated flows.

The viscosity ratio was calculated from the empirical expression fitting for incompressible turbulent flow (Yang and Martin 1989)

$$
\frac{\mu_{t}}{\mu_{l}}=\kappa y^{+}\left[1-\exp \left(-2 a \kappa y^{+}\right)\right]
$$

Equation 29

where $a=0.06, \kappa=0.41$ is the Von Karman constant, and $\mathrm{y}^{+}$was defined as (Yang and Martin 1989)

$$
y^{+}=\frac{u^{*}}{\mu_{w}} \int_{0}^{y} \rho d y
$$

where $\mu_{w}$ was the viscosity at wall conditions, $u^{*}$ is the friction velocity, proportional to engine speed, $\rho$ is the gas density as it changes from the wall towards the core (Yang and Martin 1989). This integral is easily solved because the gas density is constant along the zone.

Mass exchange between zones to keep a constant pressure around the cylinder requires a pressure difference between zones. This suggests that the energy equation needs to be solved initially without mass exchange. The resultant zone thermodynamic conditions of each zone are adjusted by exchanging mass, with its corresponding enthalpy value, until pressures values are equal for each of the zones.

For each zone $Z$, the energy balance for an open system and the ideal gas law are combined in order to derive a differential equation for the temperature of the gas inside the cylinder,

$$
\left.\left.\frac{d U_{z}}{d t}=\dot{Q}_{z, H T}-\dot{W}_{z}+\dot{m} h\right]_{z, \text { in }}-\dot{m} h\right]_{z, \text { out }}
$$

Equation 31

where $Q_{z, H T}$ is the rate of heat transferred by conduction, $W_{z}$ is the work done by the zone per unit time, and $d U_{z} / d t$ is the rate of change of internal energy of the species involved in the combustion process inside zone $Z$. 
Using the ideal gas law, and basic thermodynamic relationships, the energy equation becomes,

$$
\frac{d T_{z}}{d t}=\frac{\left.\left.\dot{Q}_{z, H T}+\dot{Q}_{Z, \text { react }}-\dot{W}_{z}+\dot{m} h\right]_{z, \text { in }}-\dot{m} h\right]_{z, \text { out }}}{\sum_{i=1}^{N} n_{i} c_{p},{ }_{i}-\sum_{i=1}^{N} n_{i} R_{u}}
$$

Equation 32

where $T_{z}$ is the zone temperature, $n_{i}$ is the molar composition of species $i$, and $R_{u}$ is the universal gas constant and

$$
\dot{Q}_{z, H T}=A_{z} \dot{q}^{\prime \prime}
$$

Equation 33

where $A_{z}$ is the zone $Z$ cylinder area. The rate of work developed by zone $Z$ is:

$$
\dot{W}_{z}=P_{z} \frac{d V_{z}}{d t}
$$

And the rate of heat addition due to species reaction is calculated as,

$$
\dot{Q}_{Z, \text { react }}=-\sum_{i=1}^{N} h_{i, Z} \frac{d n_{i, Z}}{d t}+R_{u} T_{z} \sum_{i=1}^{N} \frac{d n_{i, Z}}{d t}
$$

where $d n_{i, Z} / d t$ can be obtained from reaction rates defined by the chemical kinetics mechanism,

$$
\frac{d n_{i, z}}{d t}=\dot{n}_{i n, z}-\dot{n}_{o u t, z}+w_{i, z} \frac{d V_{z}}{d t}
$$

where $w_{i, Z}$ is the molar rate of production of species $i$ in the zone $Z$.

Solution of the set of equations Eq.32 and Eq.36 was performed for each crank angle, from inlet valve closing IVC to exhaust valve opening (EVO). Temperature, molar composition and volume of each zone define the state for each zone. A value of pressure for each zone $P_{z}$ can be calculated using ideal gas law. In order to equalize pressures for all zones a mass exchange is performed. 
Solving the mass exchange part of the equation is done in two stages. First, based on the results from the energy equation for closed volume, the cylinder pressure at the end of each crank angle period was calculated for both the whole cylinder, $P_{c y l}$, and for each zone $Z, P_{Z}$ as:

$$
P_{c y l}=\frac{m_{c y l} R_{u}}{\sum_{j=1}^{Z} \frac{V_{j} M W_{j}}{T_{j}}}
$$

and

$$
P_{Z}=\frac{m_{Z} R_{Z} T_{Z}}{V_{Z}}
$$

Equation 38

where $m_{Z}$ was the mass at zone $Z$, and $R_{z}$ is the gas constant for zone $R_{u} / M W_{z} \cdot M W_{z}$ was calculated using the average molar mass of the mixture according to composition in zone $\mathrm{Z}$. If the pressures in each zone were equal to in-cylider pressure $P_{c y l}$, then the energy equation was solved, and the energy and mass conservation equation solutions are saved and the process repeats in the next CA step. If the pressure of any zone was different to the in-cylinder pressure then mass is transferred between zones until each zone and the in-cylinder pressure are equal.

The second part of the solution involves the mass exchange between zones to equalize pressure in all zones. The mass flow from zone $Z$ to its adjacent zones $Z-1$ and $Z+1$ is determined based on the pressure differences, from higher to lower pressure zones. This was performed iteratively. Because mass carries energy via enthalpy, the energy conservation equation was solved along with mass conservation.

The mass present in each zone at the end of the closed system solution $m_{Z}$ was temporary renamed here as $m_{Z, 1}$, and was used as the initial condition to solve the mass exchange equation. The mass required at each zone to achieve $P_{z}=P_{c y l}$, at the end of the CA step, $m_{Z, 2}$ was calculated as

$$
m_{j, 2}=P_{c y l} \frac{V_{j} M W_{j}}{R_{u} T_{j}}, j=1 \ldots Z
$$

Second, the change of mass required to equalize pressures is found by

$$
m_{z, 2}=m_{z, 1}-\Delta m_{z}
$$

Equation 40

where $\Delta m_{z}$ can be obtained from the pressure difference by

$$
\Delta m_{z}=\frac{V_{z}}{R_{z} T_{z}}\left(P_{z}-P_{c y l}\right)
$$


With mass exchange also species are exchanged and its relative composition changed. The energy and mass conservation equation require a mass flowrate value to be applied in Equations 32 and 36 . The time differential comes from the duration of the CA step, $\Delta t_{C A}$. Mass flowrate or molar flowrate can be calculated for each zone. Conditions for mass (molar) exchange require that the core zone (Zone 1) only interacts with the adjacent Zone 2, and that the boundary layer zone interacts with the adjacent shell zone and with the crevice zone. The crevice zone only interacts with the BL zone. As mentioned before, the mass exchange implies changes in the internal energy of the affected zone. The energy equation for the zone receiving mass during the mass and enthalpy exchange is,

$$
U_{z, 2}=U_{z, 1}+H_{z^{\prime}}
$$

Equation 42

where $U_{z, 1}$ is the internal energy of zone $Z$ at the end of closed volume analysis, $U_{z, 2}$ is the internal energy of zone $Z$ at the end of the mass and energy exchange, and $H_{z}$, is the enthalpy of the zone that provides the mass $\Delta m$. In a more convenient way, the temperature change due to the mass exchange can be derived from the energy equation Eq. 42 and mass equation Eq. 41 as

$$
T_{z, 2}=\frac{T_{z, 1} m_{z, 1} c_{v_{z, 1}}+T_{z^{\prime}} \Delta m_{z^{\prime}} c_{p_{z^{\prime}}}}{\left(m_{z, 1}+\Delta m_{z}\right) c_{v_{z, 2}}}
$$

where $c p_{Z, 1}$ and $c p_{Z}$ are the specific heat of the receiving zone at the start of the iteration and the specific heat evaluated at the temperature corresponding to the zone providing $\Delta m_{Z}$. $C v_{Z, 2}$ is adjusted during the iterative process. The iterative process that involves mass and enthalpy exchange between zones is performed until $P_{z, 2}=P_{c y l}$, where $P$ was calculated by ideal gas law using $T_{z, 2}$ and $m_{z, 2}$ and its molar composition. As a result of this iterative process, the mass flow rate and its direction (from $Z_{i}$ to $Z_{i-1}$ and $Z_{i+1}$ ) were calculated.

Equations 32 and 36 are the set of differential equations to solve for temperature and concentration. The third thermodynamic property used to define the mixture state was density, which was calculated at each time step from mass and volume (Eq.12). Figure 2 shows the flowchart of the code developed in Matlab-Cantera. 


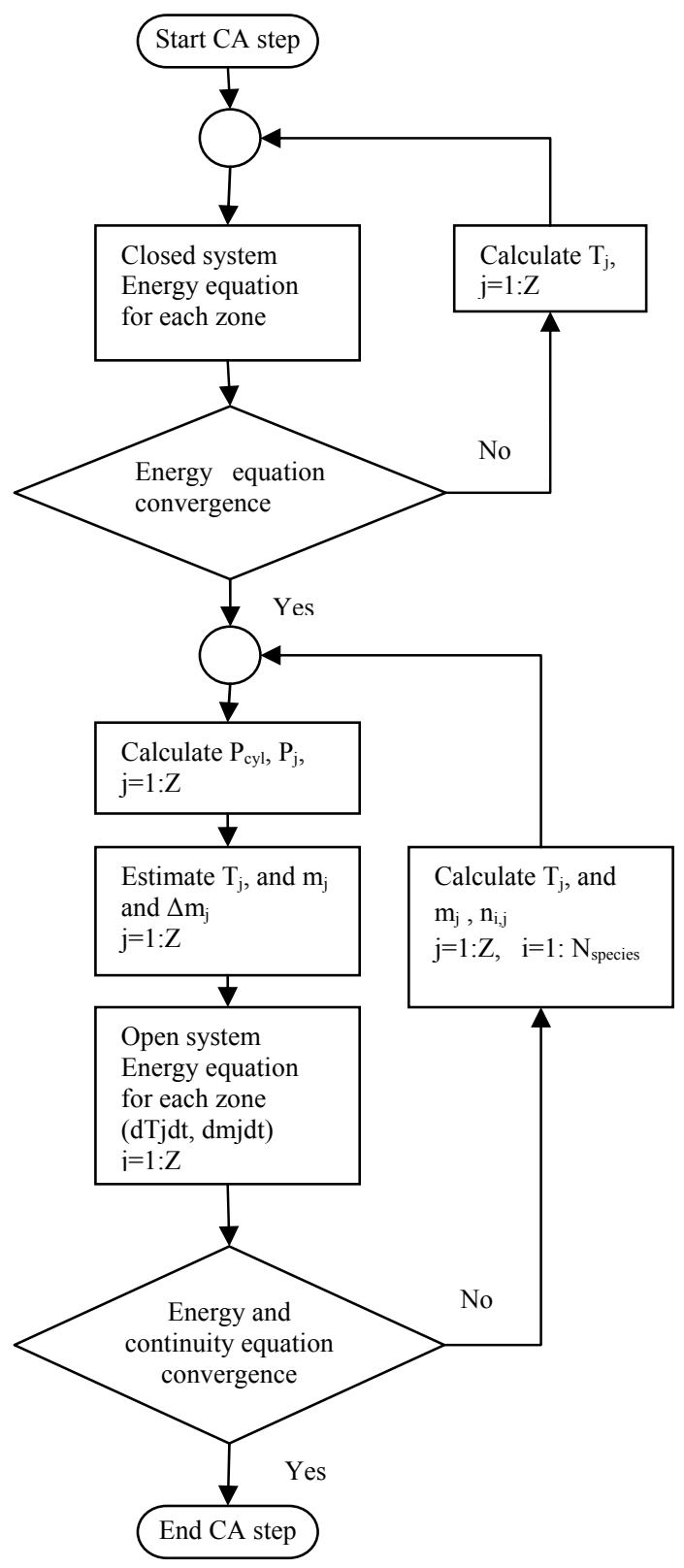

Figure 2. Multi-zone model flowchart for each crank angle degree

One of the reasons to use the Multi-zone model over the single-zone model is that the single-zone overshoots temperature at peak conditions, and this causes the gas mixture to expand at higher temperatures than obtained experimentally. The exhaust gas temperature and its enthalpy are highly important for determining the exhaust temperature and energy available for the steam-reforming process. In this regard, the multi-zone model allows for a better estimation of the in-cylinder gas conditions at 
EVO. From the instant the exhaust valves are open the exhaust blowdown model calculates the exhaust gas temperature while it is experiencing flow through the exhaust valves. The next section describes the exhaust blowdown model used to calculate the reforming temperature, $T_{r e f}$.

\subsection{Gas Exchange model}

The gas exchange model covers both the intake and exhaust process. It was mentioned before that the exhaust process is very important to accurately describe the exhaust gas temperature, and also to predict the residual gas composition and IVC conditions. An open system first law analysis coupled with steady state compressible flow equations was used to model the gas exchange processes. A description of the model is presented in Figure 3.
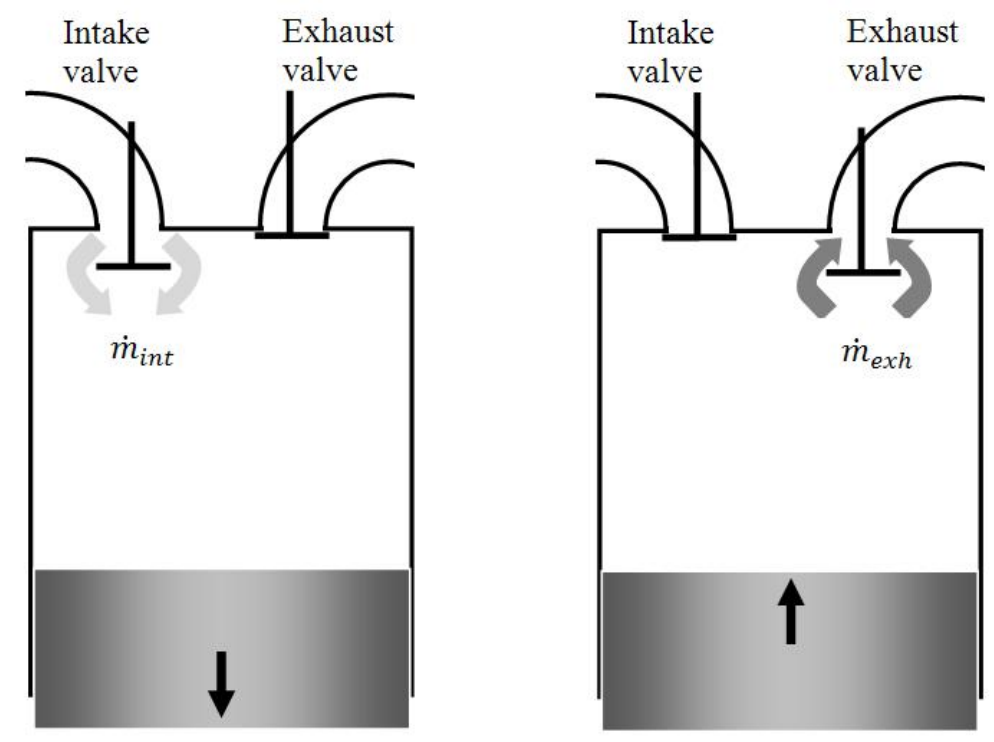

Figure 3. Valve gas exchange representation

In general, the in-cylinder thermodynamic state can be described by using a mass balance and energy balance for the system composed of the cylinder volume and the intake and exhaust port openings. It was assumed that there were no reactions inside the cylinder or during the exhaust or intake process (frozen species composition). The instantaneous in-cylinder mass is calculated as

$$
\frac{d m_{c y l}}{d t}=\dot{m}_{i n t}-\dot{m}_{e x h}
$$

Equation 44 
The energy balance can be established as

$$
\frac{d U_{c y l}}{d t}=\dot{Q}_{H T}-\dot{W}+\left.\dot{m} h\right|_{i n t}-\left.\dot{m} h\right|_{\text {exh }}
$$

Equation 45

where $d U_{c y l} / d t$ is the internal energy of the in-cylinder gas, $\dot{Q}_{H T}$ represents the heat transfer (negative) from Equation 23, and the last two terms represent the rate of change of absolute enthalpy in and out of the system. It should be noted that the case of exhaust gases coming into the cylinder or escaping through the intake port can be included by changing the valve lift function, as explained later.

Mass flowrate can be approximated using the steady state equations for compressible, isentropic flow through a restriction, where real gas flow effects are included by means of a discharge coefficient $C_{D}$. The equation for mass flowrate presented below was extracted from Heywood (1988),

$$
\dot{m}=\frac{C_{D} A_{R} P_{o}}{\sqrt{R T_{o}}}\left(\frac{P_{T}}{P_{o}}\right)^{\frac{1}{\gamma}}\left[\frac{2 \gamma}{\gamma-1}\left(1-\left(\frac{P_{T}}{P_{o}}\right)^{\frac{\gamma-1}{\gamma}}\right)\right]^{\frac{1}{2}}
$$

Equation 46

Equation 46 applies for subsonic (unchoked) flow, which is defined by the condition

$$
\left(\frac{P_{T}}{P_{O}}\right)>\left(\frac{2}{\gamma+1}\right)^{\frac{\gamma}{\gamma-1}}
$$

Equation 47

If the flow is sonic (choked) then the mass flowrate can be calculated by

$$
\dot{m}=\frac{C_{D} A_{R} P_{o}}{\sqrt{R T_{o}}} \sqrt{\gamma}\left(\frac{2}{\gamma+1}\right)^{\frac{\gamma+1}{2(\gamma-1)}}
$$

Equation 48

For flow into the cylinder $P_{o}=P_{\text {int }}$ and $P_{T}=P_{c y l}$, and for flow out of the cylinder $P_{o}=P_{c y l}$ and $P_{T}=P_{e x h}$. The value of $P_{e x h}$ was approximated as equal to one atmosphere $(1 \mathrm{~atm})$. The value of the specific heat ratio, $\gamma$, was calculated based on the molar composition and temperature at EVO. $A_{R}$ represents the effective open area which was estimated based on typical valve opening areas found in Heywood (1988). The shape of the $A_{R}$ profile is a simplified sinusoidal function derived from the valve profiles provided by Heywood (1988),

$$
A_{R}=\frac{1}{2} A_{m}\left(1 \pm \cos \left(\frac{\theta-\theta i}{2 \Delta \theta i}\right)\right)
$$

Equation 49 
where $A_{m}$ represents the maximum valve opening area calculated from the difference between head diameter and valve stem. The parameters $\theta i$ represents the valve event $i$, in degrees (CA), and $\Delta \theta i$ represents the duration of the valve lift associated with said event, also in crank angle degrees. The positive and negative signs are used depending if the valve is closing (negative) or opening (positive).

The intake and exhaust valve head diameters were assumed as 0.42 and 0.35 times the cylinder bore (Heywood 1988). Valve stem was assumed as $1 / 5$ of valve head diameter for both valves (Beard 1999). The value of $C_{D}$ was found independently for intake and exhaust by matching experimental in-cylinder pressure data with the calculated one. The general effective open area used in this model is presented in Figure 4. The valve events IVO, IVC, EVO, and EVC, presented in Table 1 were extracted from the engine where the experimental data was obtained (Guo et al. 2009). More information in the engine model is presented in the model validation section.

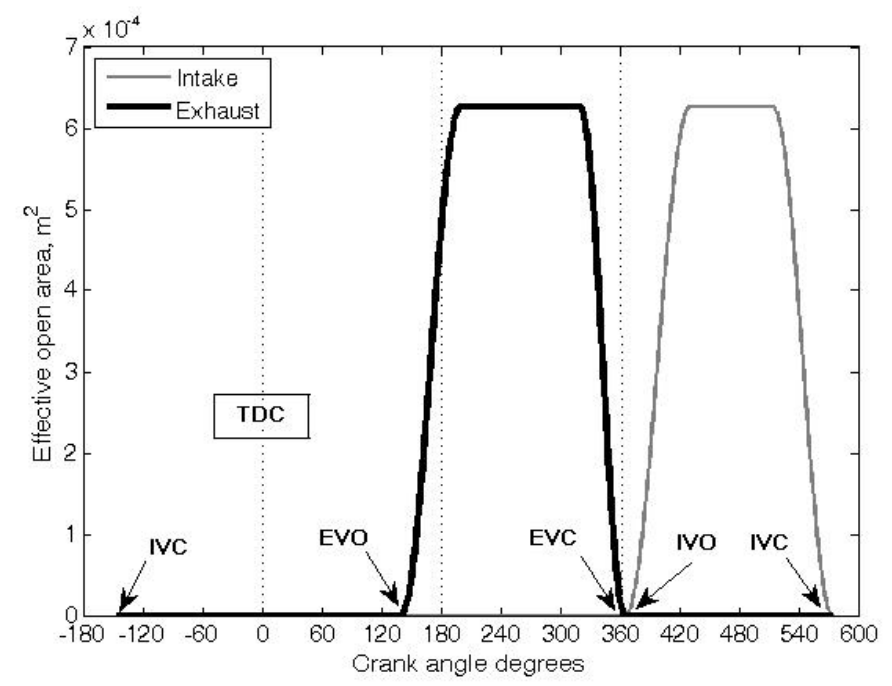

Figure 4. Effective open area $\left(A_{R}\right)$ profile for intake and exhaust valves

Table 1. Intake and exhaust valve events for modeled engine

\begin{tabular}{ccc}
\hline Event & Crank angle location (degrees aTDC) & Lift duration (CA degrees) \\
\hline$I V C$ & -146 & 60 \\
$E V O$ & 140 & 60 \\
$E V C$ & 5 & 45 \\
$I V O$ & 10 & 65 \\
\hline
\end{tabular}

Solving simultaneously the mass and energy conservation equations (Eq. 44 and 45) it is possible to calculate the in-cylinder temperature assuming quasi-steady conditions for mass flowrate calculations. Using a steady-state solution equation (Eq. 46-48) for this dynamic problem has been frequently used before for gas exchange calculations (Heywood 1988, AVL 2003). Exhaust gas temperature $\left(T_{e x h}\right)$ and 
mass flowrate $\left(\dot{m}_{\text {exh }}\right)$ can be obtained from the same assumption used in the solution of the equations for isentropic orifice flow.

The gas temperature downstream the exhaust port was calculated based on isentropic conditions. This is an approximation because the exhaust temperature after the port undergoes a process of heat transfer with the valves and the exhaust manifold. A number of exhaust port convective heat transfer correlations have been developed to properly describe this phenomenon. Those correlations usually are based on Nussel-Reynolds with the general form $N u=K R e_{j}^{n}$ for laminar flow and $N u=$ $K R e_{j}^{n} \operatorname{Pr}^{m}$ for turbulent flow. The geometric constant for $R e_{j}$ is evaluated depending on the flow (choked or not) for valve or port diameter (Caton and Heywood 1981, Fu et al. 2005). Although it is clear that in a vehicle the exhaust gas temperature varies with time and position along the exhaust pipe, in this model the effect of heat transfer is not considered. Isentropic conditions are applied here aiming to obtain the best conditions downstream for the thermo-chemical recuperation to take place. Thus, the exhaust gas temperature relates with the in-cylinder gas temperature by,

$$
T_{e x h}=\frac{T_{c y l}}{1+\frac{\gamma-1}{2} M^{2}}
$$

Equation 50

where $T_{c y l}$ represents the stagnation temperature and $M$ is the Mach number $\mathrm{M}=1$ for sonic flow or

$$
M=\left\{\frac{2}{\gamma-1}\left[\left(\frac{P_{o}}{P_{T}}\right)^{\frac{\gamma-1}{\gamma}}-1\right]\right\}^{0.5}
$$

Equation 51

for subsonic flow. Stagnation and $P_{o}$ and orifice pressure $P_{T}$ are set depending on intake or exhaust process, as explained before. Values for intake temperature were considered equal to the assumed constant intake temperature.

Results from the gas exchange model are presented here to illustrate the magnitude of mass flowrate and the in-cylinder and exhaust temperatures. Figure 5 presents the instantaneous mass flowrate at 900 rpm. In the exhaust process the first peak corresponds to the compressible flow, before the maximum is sonic and after the peak is subsonic. The incompressible flow due to cylinder displacement governs the mass flowrate after the in-cylinder pressure approximates the exhaust pressure. The intake process undergoes a similar process, where the first part is governed by compressible flow and the second is cylinder-displacement governed. 


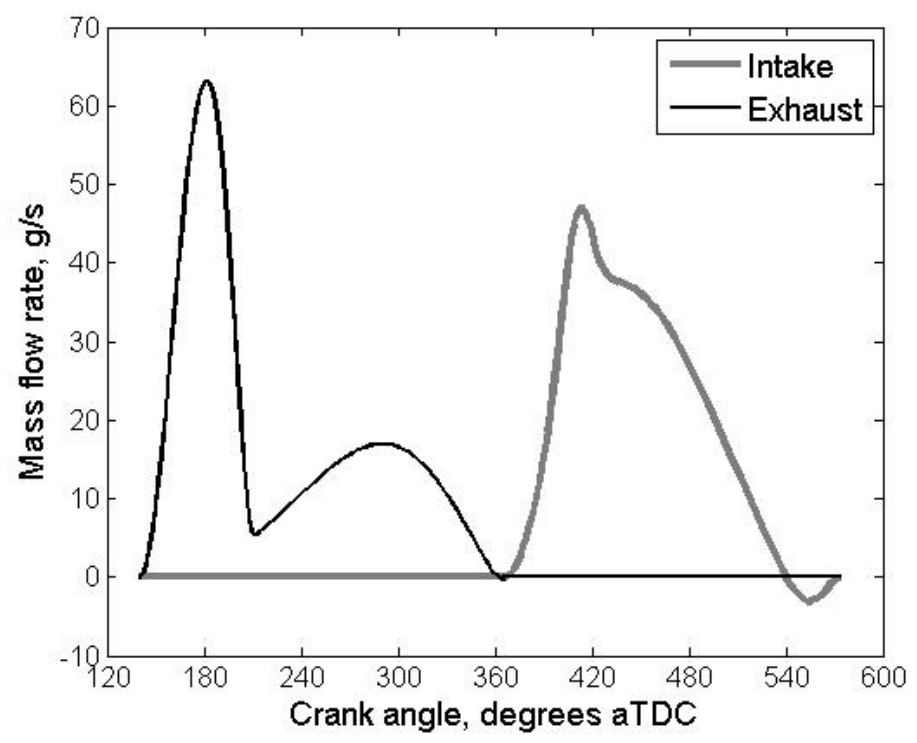

Figure 5. Calculated instantaneous mass flowrate of exhaust and intake gases, $\phi=0.35,900 \mathrm{rpm}$.

\subsubsection{Exhaust Temperature Calculation for Thermo-Chemical Reforming}

The solution of mass and energy balances during the gas exchange process allows for calculating an approximated exhaust temperature (Equation 50) for the exhaust gas flowing during the period of valve opening. Figure 6 shows both the in-cylinder temperature and the exhaust temperature at any given time during the gas exchange process for a single cylinder. It is clear that during the blowdown process, the exhaust gases temperature behaves under compressible, isentropic conditions, and that after BDC, when the gases are swept out the cylinder by the motion of the piston the exhaust temperature is close to the remaining in-cylinder gases.

Because this period is finite and this present research project is based on steady-state conditions, an approximation is required to obtain a steady exhaust temperature. Although a time-averaged temperature calculation may look appropriate for that purpose, it does not reflect the average energy of the exhaust gas due to the strong variations in mass flowrate. Thus, an enthalpy-based averaged calculation is needed. 


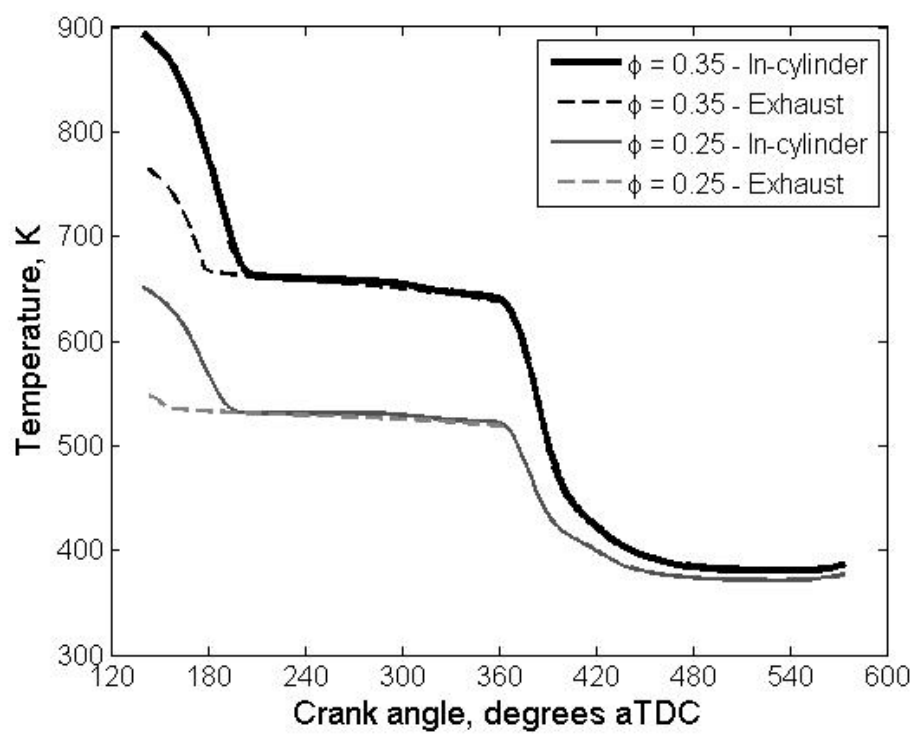

Figure 6. Calculated in-cylinder and exhaust gas temperature during the gas exchange period for two different equivalence ratios. EVC occurs at $5^{\circ}$ crank angle aTDC

Equation 52 presents the time averaged exhaust temperature, $\bar{T}_{\text {exh }}$, used as reforming temperature in the thermo-chemical reformer.

$$
\bar{T}_{e x h}=T_{r e f}=\frac{\int_{E V O}^{E V C} \dot{m}_{e x h, \theta} c_{p, \theta} T_{e x h, \theta} d \theta}{\int_{E V O}^{E V C} \dot{m}_{e x h, \theta} c_{p, \theta} d \theta}
$$

Equation 52

where the subscript $\theta$ represents any given crank angle. This methodology is widely used for evaluating the performance of turbochargers and catalytic converters (Heywood 1988).

Although the model is developed for a single cylinder engine, the exhaust mass flowrate under that assumption would be non steady-state due to large periods of null mass flowrate when the exhaust valve is closed. In order to circumvent this limitation, the flowrate corresponding to a 4-cylinder engine, which guarantees constant exhaust flowrate, is employed for calculating the average exhaust temperature used for reforming. The mass flowrate is then adjusted (divided by the number of cylinders) for calculating the enthalpy available for thermo-chemical recuperation. The exhaust mass flowrate of a multi-cylinder engine (4-cyl) is presented in Figure 7. It should be noted that the exhaust temperature calculation assumes that at EVO the exhaust mass flowrate is zero (note the mass flowrate value at $140^{\circ} \mathrm{CA}$ after TDC in Figure 7). 


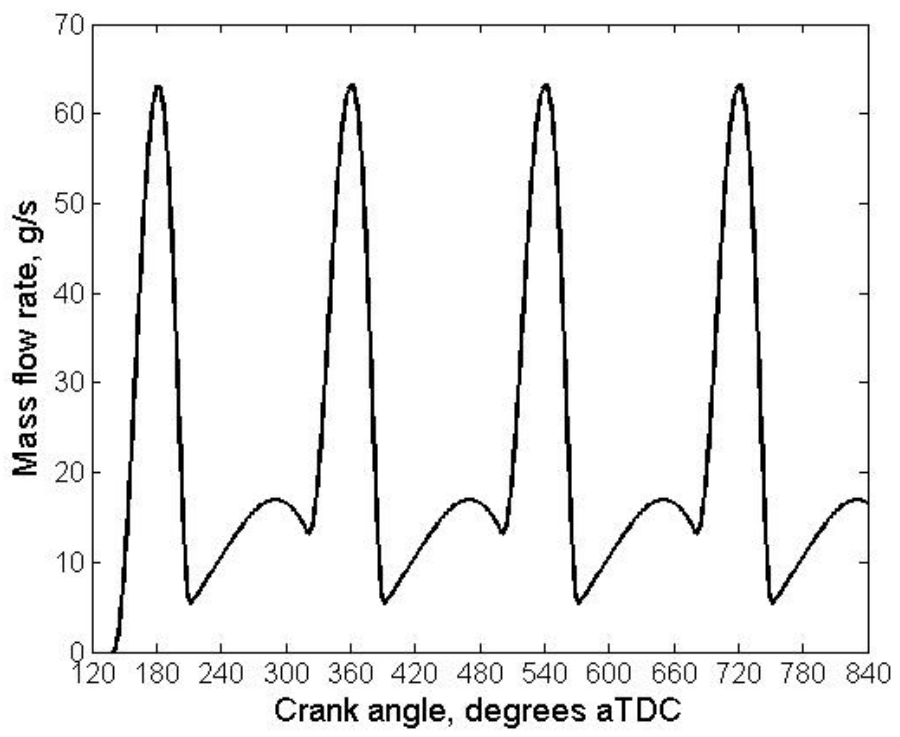

Figure 7. Instantaneous exhaust mass flowrate for a 4-cylinder model engine. $900 \mathrm{rpm}, \phi=0.35$.

The exhaust gas temperature can be calculated using the exhaust gas temperature history calculated with Equation 50, its corresponding specific heat value, and the mass flowrate for a multi-cylinder model engine. The instantaneous temperature of a multi-cylinder engine is calculated here using basic enthalpy calculations for mixing flows. Because specific enthalpy and mass flowrate change with time for each cylinder the instantaneous temperature of the combined flows $T_{e x h, \theta}$ was calculated before obtaining the time average.

$$
T_{e x h, \theta}=\frac{\sum_{k=1}^{n_{c y l}} \dot{m}_{\theta, k} c_{p \theta, k} T_{\theta, k}}{\sum_{k=1}^{n_{c y l}} \dot{m}_{\theta, k} c_{p \theta, k}}
$$

The subscript ' $\theta$ ' represents any given crank angle (or time), and ' $k$ ' represents the cylinder number for $n$-cylinders. The values obtained for the instantaneous exhaust temperature are used then to calculate the time-averaged values. Figure 8 shows the results of this method for calculating average exhaust gas temperatures. The continuous value of temperature (in bold color) corresponds to values of $T_{\text {exh, } \theta}$ and presents the pikes corresponding to EVO events for each of the cylinders in the multi-cylinder model. The time averaged exhaust gas temperature $\bar{T}_{\text {exh }}$ is presented in grey color. It should be noted that the initial conditions are evaluated at EVO for a model engine at $\phi=0.35$ and $900 \mathrm{rpm}$. This explains why the instantaneous temperature starts at high value at EVO and is later reduced. After several engine cycles the time averaged temperature tends to a steady value, which is used in the thermo-chemical recuperation model as exhaust temperature. Enthalpy values required in the thermo-chemical recuperation process to 
carry on the steam reforming reactions are based on the steady state temperature obtained with the timeaveraged calculation. Molar fraction of species is kept at the same values obtained at EVO conditions.

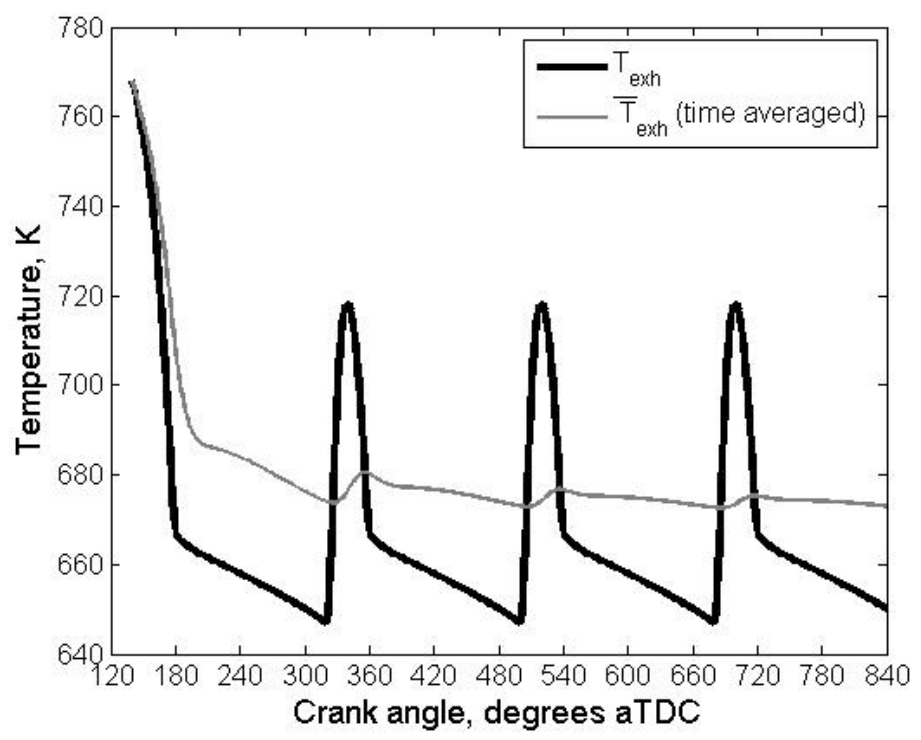

Figure 8. Instantaneous and time averaged exhaust temperature for a multi-cylinder (4-cyl) model engine. $\phi=0.35,900$ rpm. Initial conditions evaluated at EVO.

Experimental data to validate the gas exchange model was only available as in-cylinder pressure data. The values of $C_{d}$ and $A_{R}$ profiles were adjusted to approximate as much as possible the experimentally recorded in-cylinder pressure data.

Figure 9 shows experimental and model results for the gas exchange process. The value of intake (manifold) and exhaust pressure were set at $1.25 \mathrm{~atm}$ and $1.1 \mathrm{~atm}$, respectively, providing the closest results to the experimentally recorded data. Some dynamic details on the pressure history are not captured by the model because of the inability to capture pressure fluctuations and the dynamics proper of this transient phenomenon. The general trend of the model and the timing corresponding to main valve events are adequate enough to be used in this current research work. 


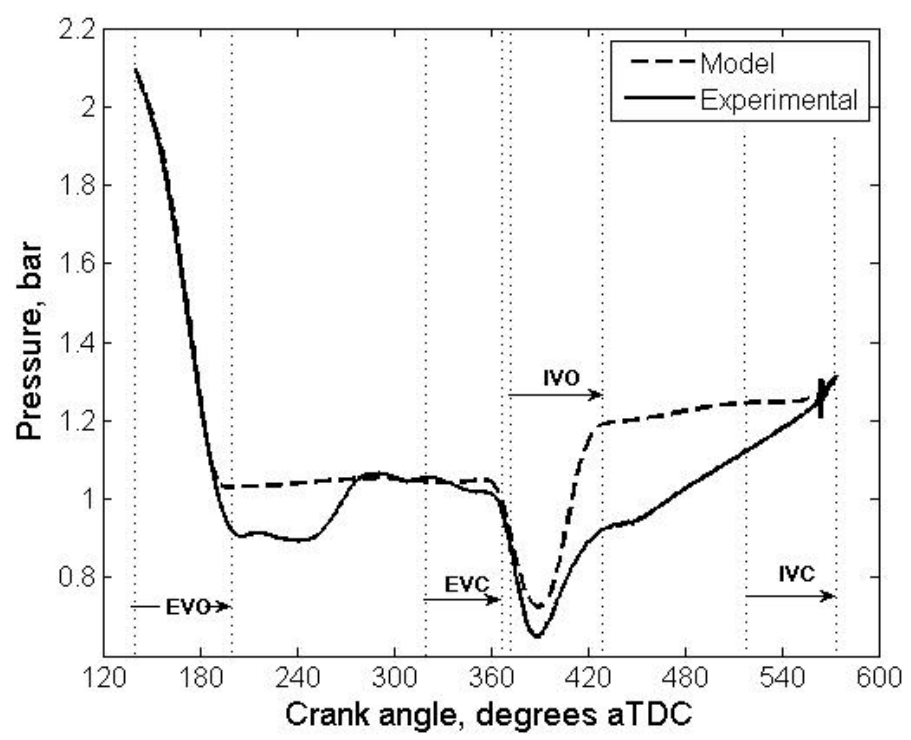

Figure 9. Calculated and experimental in-cylinder pressure during gas exchange processes. The main valve events are indicated. $\phi=0.35,900 \mathrm{rpm}$. Experimental in-cylinder pressure data from Guo et al.(2009)

The value of $\mathrm{Cd}$ was then estimated as $\mathrm{Cd}=0.5$ for exhaust valve and $\mathrm{Cd}=0.6$ for intake valve. These values were kept constant for all of the simulated conditions regardless of engine speed or load.

Another important quantity that can be estimated with the gas exchange model is the residual mass fraction. Residual mass fraction $m_{R}$ is defined here as the amount of mass at EVC divided by the mass at IVC or the constant mass during the closed volume process. Figure 10 shows the in-cylinder mass history during the gas exchange process. Note that the mass at EVO and IVC has to be equal. The figure shows that at $900 \mathrm{rpm}$ the residual mass fraction is

$$
m_{R}=\frac{m_{E V C}}{m_{I V C}}=\frac{m_{E V C}}{m_{c y l}}
$$

Residual gas fraction plays a significant role for calculating molar composition at IVC, which affects the combustion of a HCCI engine. Residual mass composition depends on the stoichiometric conditions, Air-fuel ratio and EGR at IVC conditions. The composition can be initially assumed as equal to EGR and then adjusted by solving the combustion cycle and comparing the initial assumption for $m_{R}$. In the example presented here the fraction $m_{R}$ is $6 \%$ and $8 \%$ for $\phi=0.35$ and $\phi=0.25$, respectively. 


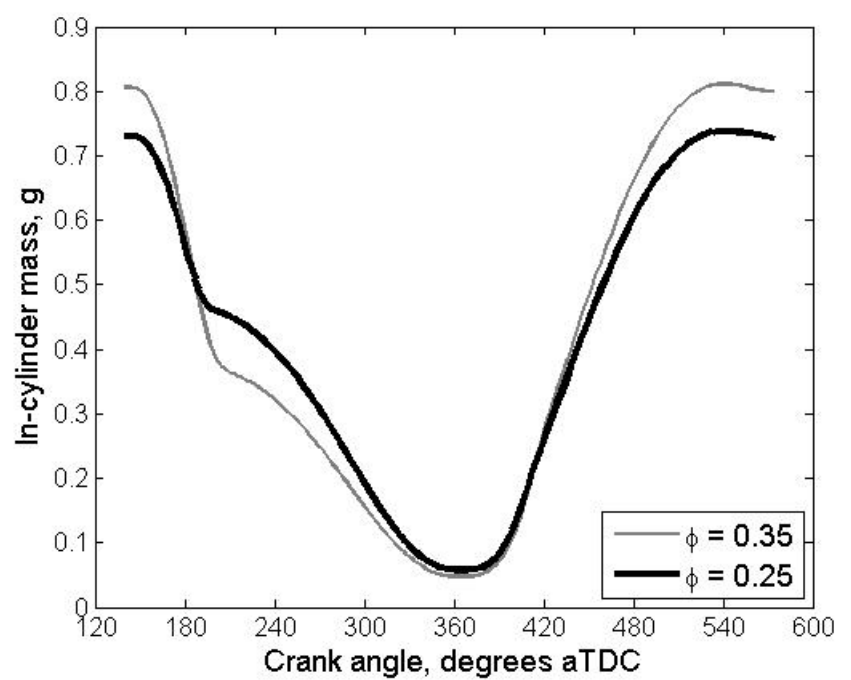

Figure 10. In-cylinder mass history during gas exchange process at two different equivalence ratios and no EGR, and engine speed of 900rpm. Extreme left shows mass at EVO and extreme right at IVC. Valve events are presented in Table 1.

\subsection{Model Validation}

Both of the HCCI engine models were validated with experimental data provided as in-cylinder pressure data of a HCCI engine fueled by n-heptane. Combustion parameters are presented first to define the basic criteria used during the analysis of the experimental in-cylinder data and the numeric data. Information about the engine used to obtain the experimental data for validation of the HCCI model is presented later. Then the experimental in-cylinder pressure data processing to obtain the heat release and its corresponding combustion characteristics is presented. The comparison between model and experimental data is presented at the end of this chapter, including the required modification in the original n-heptane chemical kinetic code.

\subsubsection{Combustion parameters definition}

The definition of combustion parameters required to analyze the combustion process is introduced here. Figure 11 presents the main combustion parameters commonly employed to study two stage combustion fuels, based on the work of Lu et al. (2005). LTHR and HTHR are clearly identified, with their corresponding maximum values $\mathrm{LTHR}_{\max }$ and $\mathrm{HTHR}_{\max }$ respectively. The crank angle corresponding to $50 \%$ of the total heat release is marked as $\mathrm{CA} 50 . \mathrm{SOI}_{\mathrm{L}}$ is defined as the start of ignition for the LTHR regime. It was calculated as the crank angle at $10 \%$ of the value corresponding to maximum $d T / d C A$. The start of ignition for HTHR $\left(\mathrm{SOI}_{\mathrm{H}}\right)$, in crank angles corresponds to the local minimum between $\mathrm{LTHR}_{\text {max }}$ and $\mathrm{HTHR}_{\text {max }}$. The magnitude of the energy released during the LTHR regime, 
identified here as $\mathrm{HR}_{\mathrm{L}}$, is calculated as the accumulated value from $\mathrm{SOI}_{\mathrm{L}}$ up to $\mathrm{SOI}_{\mathrm{H}}$. T_SOI $\mathrm{L}_{\mathrm{L}}$ and $\mathrm{T} \_\mathrm{SOI}_{\mathrm{H}}$ are the gas mixture temperature values corresponding to $\mathrm{SOI}_{\mathrm{L}}$ and $\mathrm{SOI}_{\mathrm{H}}$ respectively (Lu et al. 2005).

The HCCI engine performance limits are defined in the lean limit by misfire, and by ringing in the rich limit. The rich limit is defined following the ringing model for HCCI engines proposed by Eng (2002). The ringing intensity $(R I)$ correlates the in-cylinder pressure history with the ringing intensity $\left(\mathrm{MW} / \mathrm{m}^{2}\right)$ according to equation

$$
R I=\frac{\frac{1}{2 \gamma}\left(\beta\left(\frac{d p}{d t}\right)_{\max }\right)^{2}}{P_{\max }} \sqrt{\gamma R T_{\max }}
$$

Equation 55

where $(d p / d t)_{\max }$ is maximum rate of pressure rise, $P_{\max }$ and $T_{\max }$ are the peak pressure temperature, and $\gamma$ is the mixture specific heat ratio. The parameter $\beta$ is the ratio between the pressure oscillation amplitude after combustion and the maximum rate of pressure rise, usually around 0.05 . Typical experimental values for $\mathrm{RI}$ are in the range $2-6 \mathrm{MW} / \mathrm{m}^{2}$ (Eng 2002).

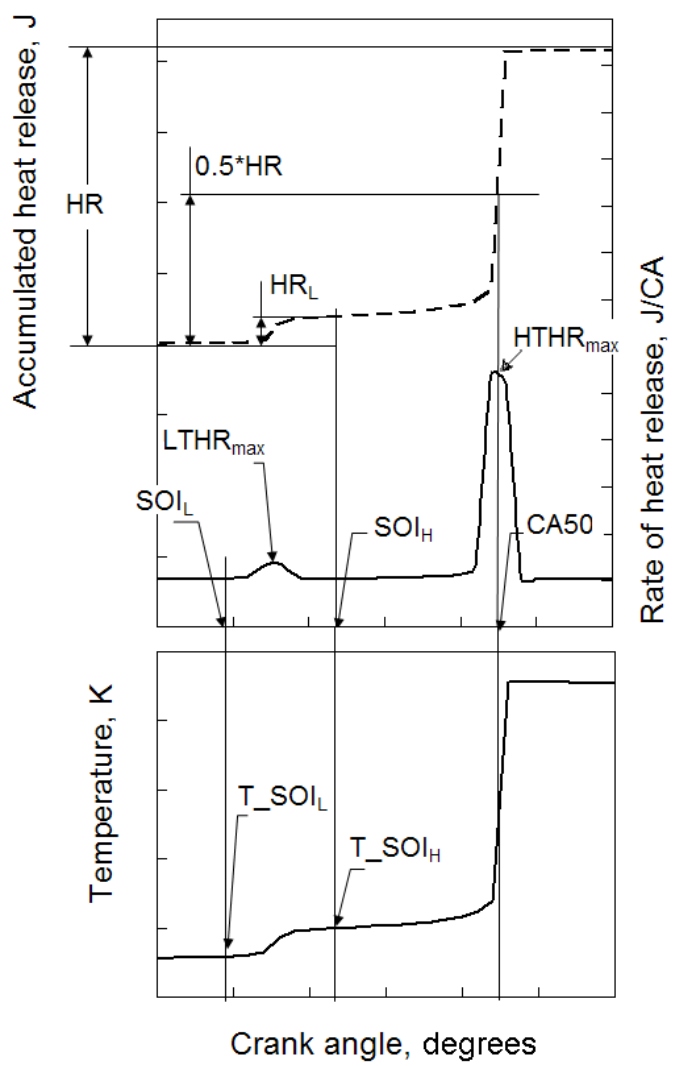

Figure 11. Definition of combustion parameters and its nomenclature 


\subsubsection{Experimental data description}

The HCCI engine characteristics required by the HCCI combustion and used in this validation correspond to CFR engine used in previously published data on HCCI combustion of n-heptane by Guo et al. (2009). The CFR engine is a single-cylinder four-stroke engine with variable compression ratio. Table 2 presents the main geometric characteristics and specifications of the engine.

\begin{tabular}{ccc} 
Table 2. Specifications of experimental engine used to validate the HCCI model \\
\hline Parameter & Units & Value \\
\hline Cylinder Bore & $\mathrm{mm}$ & 82.55 \\
Stroke & $\mathrm{mm}$ & 114.3 \\
Displacement Volume & $\mathrm{cc}$ & 611.7 \\
Connection Rod Length & $\mathrm{mm}$ & 254 \\
Compression Ratio & - & $10-11.5$ \\
Intake valve open & & 370 \\
Intake valve close & CA deg. aTDC & -146 \\
Exhaust valve open & & 140 \\
Exhaust valve close & & 365 \\
\hline
\end{tabular}

\subsubsection{In-cylinder Pressure Data Analysis}

The in-cylinder pressure data for different engine load, represented by air-fuel ratio, and engine speed was employed to obtain combustion and performance characteristics of HCCI of n-heptane under steady state conditions. The set of pressure data used for validating the model, at each of the engine conditions studied, is the average of 75 cycles run at each condition. Appendix 1 describes the variability of the in-cylinder pressure data used for validation.

Combustion parameters such as CA10, CA50, combustion duration and ringing intensity, and performance parameters such as IMEP and indicated thermal efficiency were calculated using a heat release analysis methodology.

\subsubsection{Heat release}

The method implemented was based on the well known heat release rate analysis that assumes closed volume, ideal gas composition and homogenous pressure and temperature (Heywood 1988). The model includes a variable specific heat ratio $(\gamma)$ representing changes in mixture gas composition between compression, combustion and expansion. The heat release is differentiated in chemical or reaction heat release rate $d Q_{c h} / d \theta$ and net heat release $d Q_{n e t} / d \theta$. 
The net heat release rate (Equation 56) represents the sensible energy change and work transfer to the piston (Heywood 1988). The chemical heat release rate is composed of net heat release rate and heat losses to the walls (Equation 57).

$$
\frac{d Q_{n e t}}{d \theta}=\left(\frac{\gamma}{\gamma-1}\right) P \frac{d V}{d \theta}+\left(\frac{1}{\gamma-1}\right) V \frac{d P}{d \theta}
$$

Equation 56

and

$$
\frac{d Q_{c h}}{d \theta}=\frac{d Q_{n e t}}{d \theta}+\frac{d Q_{h t}}{d \theta}
$$

Equation 57

The heat transfer to the walls $d Q_{h t} / d \theta$ was calculated using the same correlation for convective heat transfer to the walls presented in the single zone modeling description section (Equations 23 and 24). Solution of the heat transfer rate requires an estimate of in-cylinder temperature. Average in-cylinder temperature was obtained for each crank angle by manipulating the ideal gas equation (Equation 58). It was assumed that the average mixture molecular weight did not change during the compression, combustion and expansion process. Assuming that pressure and temperature at IVC were known (Equation 59) the temperature at each crank angle was obtained (Equation 60).

$$
\begin{array}{ll}
T(\theta)=P(\theta) V(\theta)\left(\frac{1}{n R_{u}}\right) & \text { Equation } 58 \\
\frac{T(I V C)}{P(I V C) V(I V C)}=\left(\frac{1}{n R_{u}}\right) & \text { Equation } 59 \\
T(\theta)=P(\theta) V(\theta)\left(\frac{T(I V C)}{P(I V C) V(I V C)}\right) & \text { Equation } 60
\end{array}
$$

The temperature at each crank angle is used to calculate the heat transfer, which combined with solution of the net heat transfer provides the final heat of reaction values. The heat release problem is solved first and then the pressure trace is reconstructed to match measured pressure values. The difference is corrected by adjusting the convective heat transfer value factor " $a$ " in Equation 24.

\subsubsection{Indicated Work, IMEP and Thermal Efficiency}

Indicated work covers the work done during the closed cylinder period. It is defined as

$$
W_{i}=\int_{I V C}^{E V O} P d V
$$

Equation 61

where pressure and volume are function of crank angle.

Indicated mean effective pressure is derived from work by dividing it by engine displacement, $V d$, as $I M E P=W_{i} / V d$. Engine indicated thermal efficiency is calculated as the ratio of energy input $Q_{i n}$ and the 
indicated work $W_{i}$. Along these pages, the terms engine thermal efficiency and work make reference to indicated calculated values.

\subsubsection{HCCI Model Validation. Adjustment of Chemical Kinetic Mechanism}

As was mentioned previously in the literature review section, the HCCI combustion process is controlled by chemical kinetics, which is a function of charge composition and in-cylinder temperaturepressure history (Westbrook 2000). The HCCI combustion model employed in this thesis was developed to predict the effects of RG gases on the HCCI combustion of n-heptane.

The chemical kinetics of n-heptane has been relatively well studied and there are a handful of mechanisms compatible with Chemkin and Matlab-Cantera. The chemical kinetic code that describes the combustion of $n$-heptane in air was taken from the Lawrence Livermore National Laboratory ${ }^{6}$ (LLNL) based on the reaction rates for n-heptane oxidation proposed by Curran et al. (1998). This chemical kinetic mechanism was elaborated based on a study of n-heptane oxidation in flow reactors, shock tubes and rapid compression machines. The original LLNL mechanism, containing 561 species and 2539 reactions, was validated by the researchers over a range of pressures from 1 bar to 42 bar, temperatures covering the $550 \mathrm{~K}$ to $1700 \mathrm{~K}$ range and equivalence ratios from 0.3 to 1.5 (Curran 1998).

The validation of the HCCI combustion model was focused on predicting the main combustion event during the HTHR period, which is described by CA50, or the crank angle when $50 \%$ of total chemical energy is released. Other options for validation criteria include the use of CA10, or $10 \%$ of total energy release and CA at $\mathrm{P}_{\max }$, or crank angle at peak pressure. CA50 was selected because it has been commonly used in fuel characterization for HCCI applications (Kalghatgi et al. 2003) and HCCI combustion prediction (Ogawa et al. 2003), and to keep continuity on previous work published by the author. CA10 has been used by other authors (Hosseini and Checkel 2007-b), and was also used as a secondary criteria to study the LTHR behavior.

Initial model results compared against n-heptane combustion data from Guo et al.(2009), show that the LLNL kinetic mechanism for n-heptane oxidation predicted the combustion events late at different engine load-speed conditions, and therefore the LLNL mechanism had to be tuned. The chemical kinetic mechanism tuning was carried on in two steps. First, the main species involved in defining the occurrence of the tow ignition events, the LTHR and the HTHR was studied. Second, reaction rates identified in the previous step were modified and run in the single-zone cycle model for comparison with experimental data.

\footnotetext{
${ }^{6} \mathrm{https}: / /$ www-pls.1lnl.gov/?url=science_and_technology-chemistry-combustion-nc7h16
} 
Tuning of species involved in the LTHR and HTHR process was defined based on literature. The LTHR process is governed initially by heat released associated with $\mathrm{H}_{2} \mathrm{O}$ production, according to Kongsereeparp and Checkel (2008). The set of reactions modified to tune the LTHR section were $\mathrm{nC}_{7} \mathrm{H}_{16}$ $+\mathrm{OH}=>\mathrm{C}_{7} \mathrm{H}_{15} *+\mathrm{H}_{2} \mathrm{O}$ and $\mathrm{H}_{2} \mathrm{O}_{2}+\mathrm{OH}<=>\mathrm{H}_{2} \mathrm{O}+\mathrm{HO}_{2}$. According to Curran et al. (1998) the main reactions defining the HTHR process, at the end of the NTC region is the reaction $\mathrm{H}_{2} \mathrm{O}_{2}+\mathrm{M}<\Rightarrow \mathrm{OH}+$ $\mathrm{OH}+\mathrm{M}$. The same reaction rate was modified also by Guo et al. (2009) and Kongsereeparp and Checkel (2008) in related studies for n-heptane combustion applied to HCCI engines. Once the reaction rates candidates for modification were identified a series of single-zone cycle model runs were performed and one by one the reaction constants were adjusted. The reaction rates are expressed through a threeparameter Arrhenius equation as presented by Equation 62 .

$$
k=A T^{B} \exp \left(-\frac{E}{R T}\right)
$$

Equation 62

where $k$ is the reaction rate for a reaction, $A$ is the pre-exponential factor, $B$ is the temperature exponent and $E$ is the activation energy. Table 3 shows the reactions with original and modified reaction rate parameters.

Table 3. Original and modified reaction rate parameters

\begin{tabular}{cllll}
\hline Reaction & A (original) & B (original) & A (modified) & B (modified) \\
\hline$n \mathrm{C}_{7} \mathrm{H}_{16}+\mathrm{OH}=>\mathrm{C}_{7} \mathrm{H}_{15}-1+\mathrm{H}_{2} \mathrm{O}$ & $9.4375 E 09$ & 1.1 & $1.05000 E 10$ & 1.1 \\
$n \mathrm{C}_{7} \mathrm{H}_{16}+\mathrm{OH}=>\mathrm{C}_{7} \mathrm{H}_{15}-2+\mathrm{H}_{2} \mathrm{O}$ & $4.7500 E 09$ & 1.13 & $5.02500 E 09$ & 1.13 \\
$\mathrm{H}_{2} \mathrm{O}_{2}+\mathrm{OH}<=>\mathrm{H}_{2} \mathrm{O}+\mathrm{HO}_{2}$ & $1.0000 E 13$ & 0 & $1.70000 E 13$ & 0 \\
$\mathrm{H}_{2} \mathrm{O}_{2}+\mathrm{M}<=>\mathrm{OH}+\mathrm{OH}+\mathrm{M}$ & $7.0600 \mathrm{E} 13$ & 0 & $9.6255 E 13$ & 0.15 \\
\hline
\end{tabular}

Several trials on the HCCI engine cycle model were required to find acceptable A and B parameters for a broad range of equivalence ratio and speed conditions from available experimental data.

An example of the model results obtained with the single-zone compared with experimental data is presented in Figure 12. Although the combustion timing is good, the difference in pressure after reaching combustion is higher than the reported by the experiments. A closer look into the results validation at different equivalence ratio and engine speed conditions is presented below. 


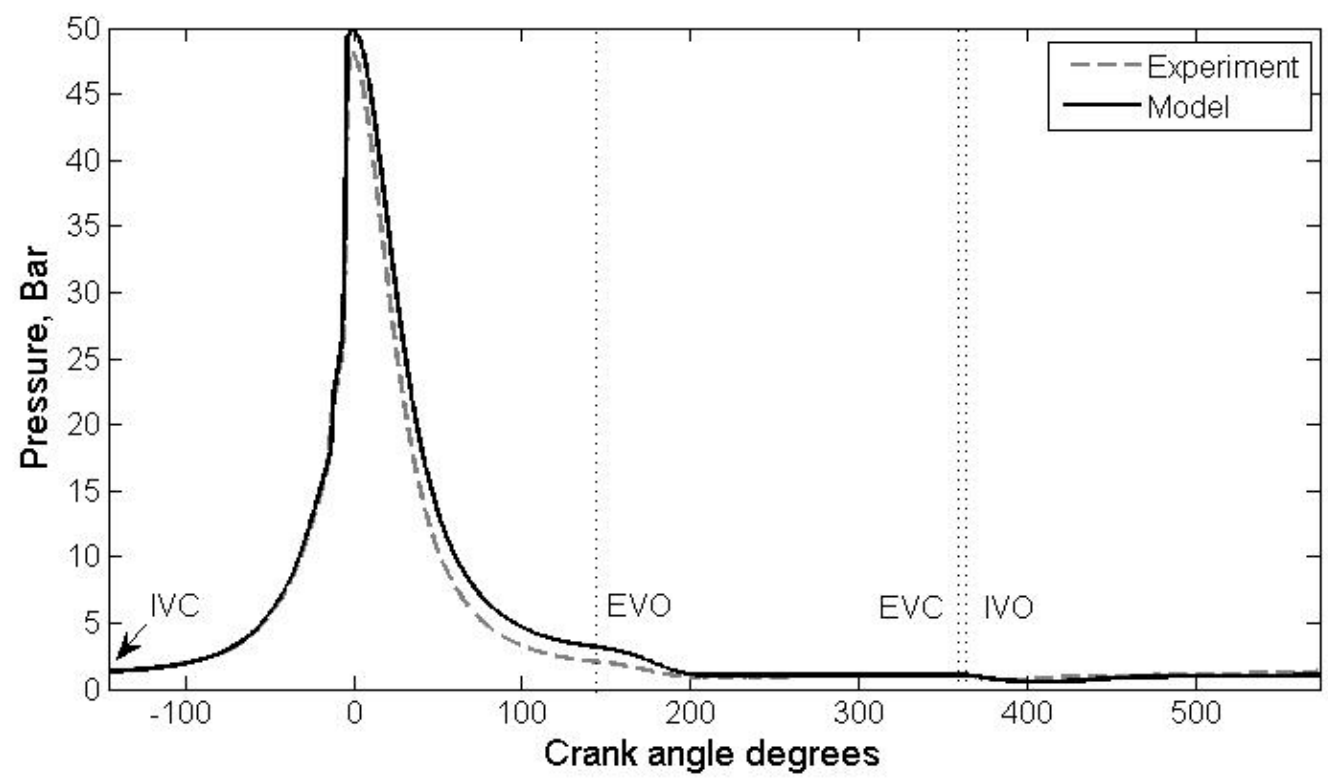

Figure 12. Comparison of experimental values and calculated pressure history during a complete cycle for HCCI combustion of $n$-heptane. $\phi=0.35,900 \mathrm{rpm}, P_{\text {int }}=1 \mathrm{~atm}, T_{\text {int }}=310 \mathrm{~K}$

Figure 13 shows the calculated in-cylinder pressure history results obtained at different conditions of equivalence ratio, at constant engine speed $(900 \mathrm{rpm})$ and constant intake and exhaust conditions $\left(\mathrm{P}_{\text {int }}=95 \mathrm{kPa}, \mathrm{T}_{\mathrm{int}}=310 \mathrm{~K}, \mathrm{P}_{\mathrm{exh}}=104 \mathrm{kPa}\right)$. As it was expected from $\mathrm{SZ}$ models, the calculated pressure history overshoots the experimentally obtained in every single case of AF ratio. At higher concentrations of fuel ( $\mathrm{AF}=43,45$ and 50$)$ at $\mathrm{IVC}$, the combustion is extremely fast and the overshoot is significant. This overshoot during combustion is carried on during the expansion period, leading to higher calculated pressures than experienced during the experiments. At lower fuel concentrations $(\mathrm{AF}=55,59$ and 60$)$ the combustion slows down, as it is controlled by its thermochemistry, and the overshoot in calculated pressure is smaller. It is important to recall that the n-heptane chemical kinetics mechanism used in this model was originally validated at equivalence ratios ranging from $\phi=0.3(\mathrm{AF}=50)$ up to $\phi=1.5(\mathrm{AF}=10)$ (Curran 1998), meaning that the model's ability to reproduce the experimental data is reduced for air-fuel ratios above $\mathrm{AF}=50$. Another reason behind the differences between numerical results and the experimental data is the variability of the experimental data. As an example, at $\mathrm{AF}=55$, the standard deviation of experimental in-cylinder pressure is around 2 bar at maximum pressure. Further details on the variability of the experimental data used to validate the model are presented in Appendix 1.

The HCCI single-zone cycle model correctly predicts the compression and combustion events during the LTHR and HTHR periods. The capacity of the model to describe the process as close as possible to experiments is evaluated with the crank angle where $10 \%$ and $50 \%$ of total net energy is released during 
combustion (CA10 and CA50, respectively). Figure 14 shows calculated and experimental CA10 and CA50 values. The LTHR prediction is close to the experimentally obtained values, as can also be observed in the LTHR region in Figure 13, where the calculated pressure increase occurs later than in the experiment. It has been observed in before that the LTHR period, or cool flame combustion, is dependent on the temperature history during compression, with little effect expressed by changes on equivalence ratio (Gray and Ryan 1997, Guo et al. 2009, Hosseini and Checkel 2007-b).

The HTHR event is followed closely by the model, as can be inferred from the ability of the model to closely reproduce the experimentally obtained CA50 values. The effect of increasing air-fuel ratio is to delay the main combustion event. This is due to changes in the mixture specific heat and fuel concentration. The change in mixture specific heat changes the temperature history during compression, and the change in fuel concentration affects the evolution of the cool flame chemistry (Dec and Sjoberg 2004). It is important to note that fuels with little or no cool flame chemistry, like isooctane, would not show significant changes in combustion onset CA50 with variations in AF ratio (Dec and Sjoberg 2004, Shibata et al. 2004).

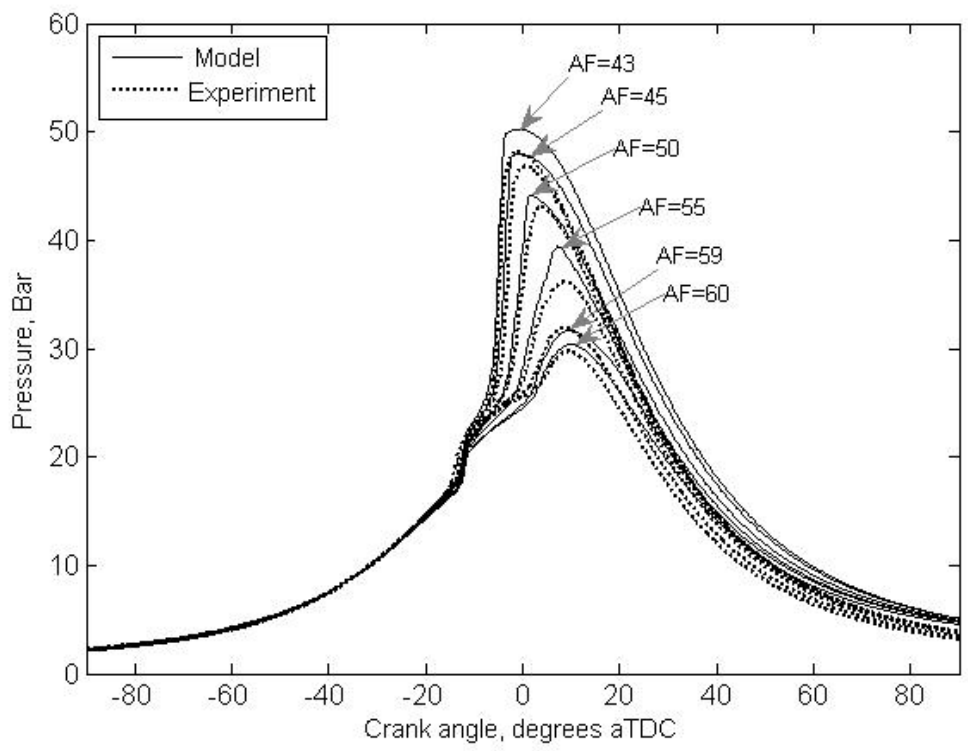

Figure 13. Experimental (dotted line) and calculated (continuous line) in-cylinder pressure history for different Air-fuel conditions. $P_{\text {int }}=95 \mathrm{kPa}, \mathrm{T}_{\text {int }}=310 \mathrm{~K}, \mathrm{CR}=10, P_{\text {exh }}=104 \mathrm{kPa}, 900 \mathrm{rpm}$. 

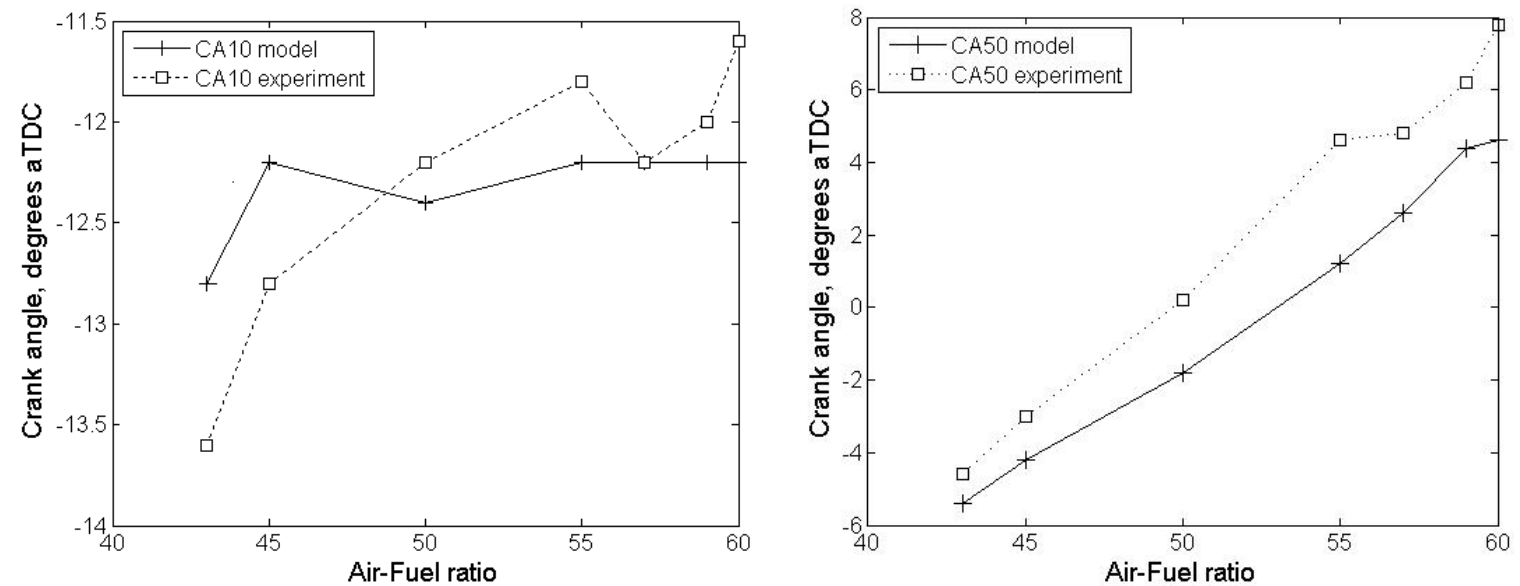

Figure 14. Combustion parameters $C A 10$ and CA50 calculated from model results and experimental data. $P_{\text {int }}=95 \mathrm{kPa}, T_{\text {int }}=310 \mathrm{~K}, \mathrm{CR}=10, P_{\text {exh }}=104 \mathrm{kPa}, 900 \mathrm{rpm}$.

In addition to combustion parameters CA10 and CA50, the ringing intensity (RI) and indicated mean effective pressure were also calculated. A summary of the main combustion parameters obtained from experimental data and calculated with the model is presented in Table 4. Error values as crank angle degrees (CA deg.) and as percentage with respect to experimental data are also included. The reduction in IMEP values is expected at reduced values of fuel addition for combustion, as this is the source of chemical energy to be transformed into piston work and sensible energy inside the cylinder. The increased fuel dilution at higher AF ratios reduces the peak pressure and rate of pressure increase. The significant increase in RI values with equivalence ratio corresponds to operational limits observed with HCCI combustion for different kinds of hydrocarbons, which is usually 2-6 MW/m² (Eng 2002). The error with respect to experimental data is due to the fast heat release typical of single-zone calculations.

Table 4. Comparison of combustion and performance parameters between the experimental values and the model calculated results

\begin{tabular}{|c|c|c|c|c|c|c|}
\hline Parameter & & $A F=43$ & $A F=45$ & $A F=50$ & $A F=55$ & $A F=60$ \\
\hline \multirow[t]{3}{*}{ CA10, CA deg. } & Experiment & -13.6 & -12.8 & -12.2 & -11.8 & -11.6 \\
\hline & Model & -12.8 & -12.2 & -12.4 & -12.2 & -12.2 \\
\hline & Error, $C A$ deg. & 0.80 & 0.60 & -0.20 & -0.40 & -0.60 \\
\hline \multirow[t]{3}{*}{ CA50, CA deg. } & Experiment & -4.6 & -3.0 & 0.2 & 4.6 & 7.8 \\
\hline & Model & -5.4 & -4.2 & -1.8 & 1.2 & 4.6 \\
\hline & Error, CA deg. & -0.80 & -1.20 & -2.00 & -3.40 & -3.20 \\
\hline \multirow[t]{3}{*}{$I M E P, k P A$} & Experiment & 371.94 & 378.34 & 369.73 & 335.46 & 234.10 \\
\hline & Model & 477.57 & 462.14 & 426.48 & 385.44 & 289.11 \\
\hline & Error, \% & 28.4 & 22.15 & 15.35 & 14.9 & 23.5 \\
\hline \multirow[t]{3}{*}{$R I, M W / m^{2}$} & Experiment & 4.78 & 2.86 & 0.74 & 0.19 & 0.15 \\
\hline & Model & 5.95 & 4.11 & 1.25 & 0.26 & 0.25 \\
\hline & Error, \% & 24.5 & 43.7 & 68.9 & 36.8 & 66.7 \\
\hline
\end{tabular}


The ability of the single-zone model and adjusted LLNL kinetic mechanism to reproduce experimental data under different engine speed conditions is presented in Figure 15. Equivalence ratio, intake and exhaust conditions were held constant $\left(\varphi=0.3, \mathrm{P}_{\mathrm{int}}=1 \mathrm{~atm}, \mathrm{~T}_{\mathrm{int}}=310 \mathrm{~K}, \mathrm{P}_{\mathrm{exh}}=104 \mathrm{kPa}\right)$. The calculated pressure history is able to represent the experimental data for engine speeds below $1000 \mathrm{rpm}$. The calculated peak pressure overshoots the experimental one for each case simulated, as is expected from single-zone models.

Analysis of combustion parameters CA10 and CA50 for the experimental data (Figure 16) show that the LTHR is progressively delayed with engine speed. This behavior can be attributed to the fact that it takes the same amount of time to reach the temperature required for cool flames and later, for the combustion onset. In consequence, with higher speed the events occur at a later crank angle. Calculated values for CA10 are clustered around $-13.5^{\circ} \mathrm{CA}$ after TDC, meaning that the calculated temperature at IVC was slightly increased with engine speed. A maximum of $2^{\circ} \mathrm{CA}$ difference between calculated and experimental CA10 data is considered well with the desired error for this research work. Obtained values for CA50 follow the same trend as the experiments, but the error increases above $100 \mathrm{rpm}$.

For engine speed higher than $1000 \mathrm{rpm}$ the calculated LTHR stage seems to release less chemical energy than is obtained during the experiment. During this stage the calculated pressure remained between 3-4 bar below the experimentally obtained pressure. The reduction in the amount of heat released during the cool flame stage forces the HTHR to occur at a later stage, which can be observed in the CA50 behavior.

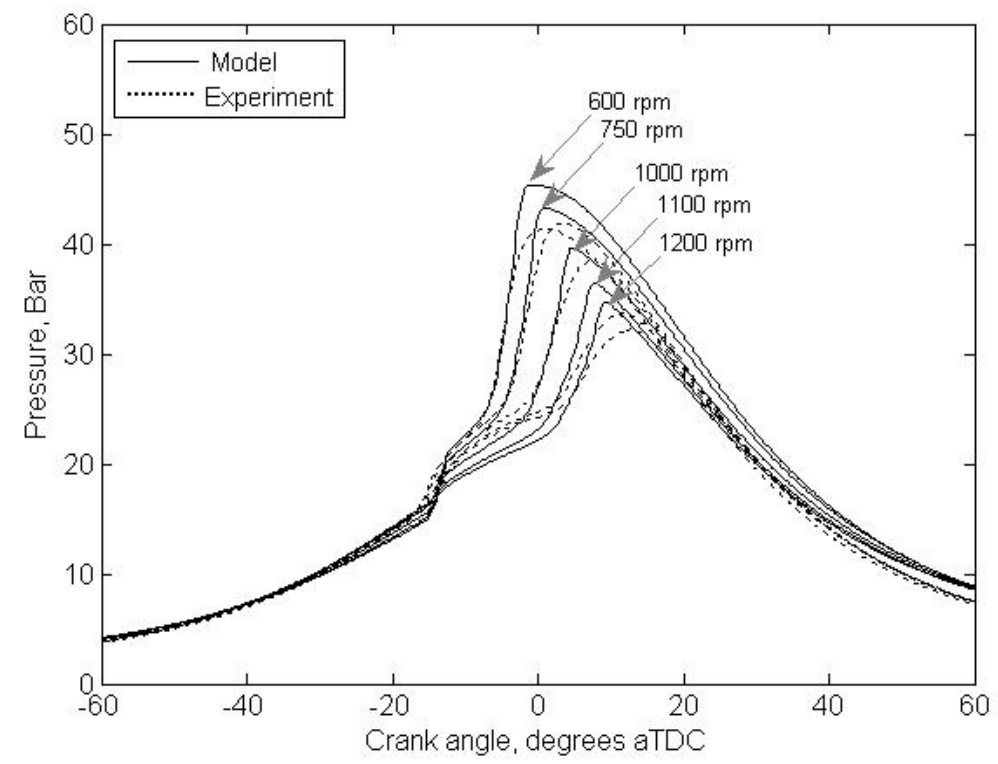

Figure 15. Experimental (dotted line) and calculated (continuous line) in-cylinder pressure history for different engine speed conditions. $P_{\text {int }}=95 \mathrm{kPa}, \mathrm{T}_{\text {int }}=310 \mathrm{~K}, \mathrm{CR}=10, P_{\text {exh }}=104 \mathrm{kPa}, \phi=0.3$. 

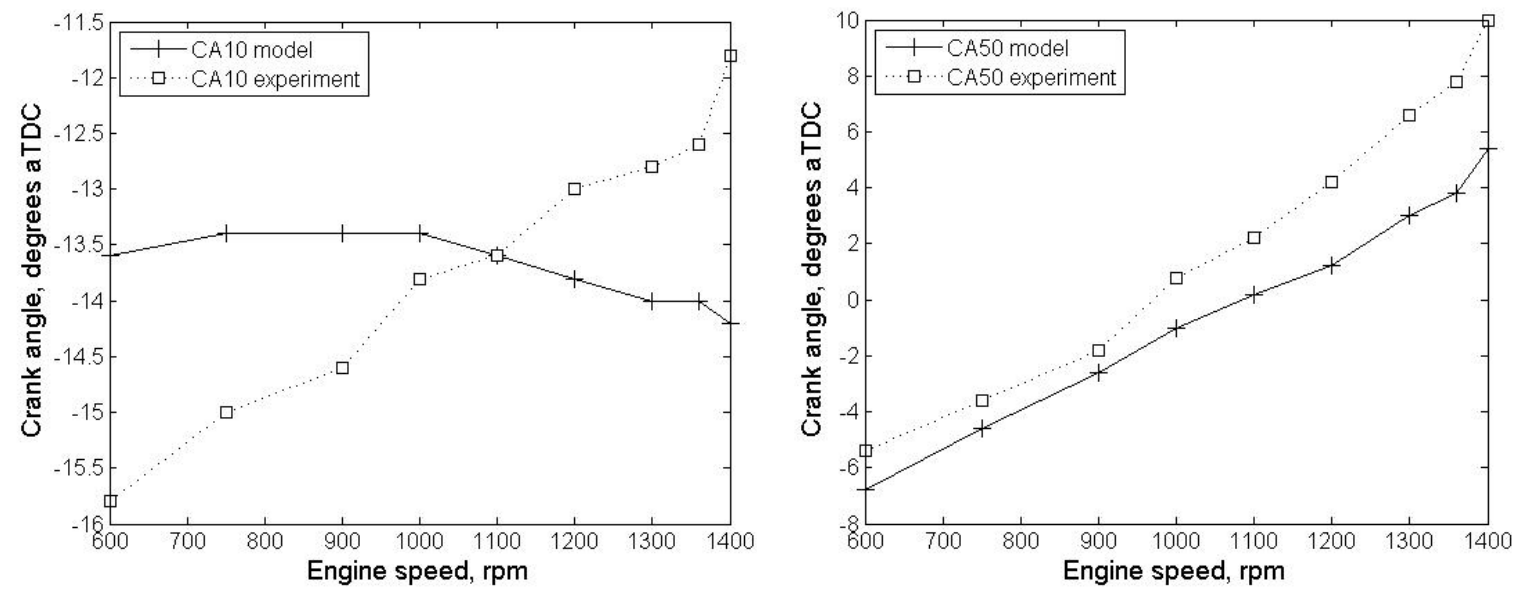

Figure 16. Combustion parameters $C A 10$ and $C A 50$ calculated from model results and experimental data. $P_{\text {int }}=95 \mathrm{kPa}, T_{\text {int }}=310 \mathrm{~K}, \mathrm{CR}=10, P_{\text {exh }}=104 \mathrm{kPa} . \phi=0.3$.

The combustion parameters discussed before and performance parameters such as IMEP and ringing intensity are presented in Table 5. Calculated IMEP values are higher than measured in experimental data because of higher pressure histories on all model results. Ringing intensity obtained from model results followed the estimated values for experimental data. The error increases with speed as the rate of change of pressure $(d P / d t)$ from the single-zone model overpredicts this value.

Table 5. Comparison of combustion and performance parameters between the experimental values and the model calculated results at different engine speeds

\begin{tabular}{|c|c|c|c|c|c|c|}
\hline \multirow{2}{*}{ Parameter } & & \multicolumn{5}{|c|}{ Engine speed } \\
\hline & & $600 \mathrm{rpm}$ & $750 \mathrm{rpm}$ & $1000 \mathrm{rpm}$ & $1100 \mathrm{rpm}$ & $1200 \mathrm{rpm}$ \\
\hline \multirow[t]{3}{*}{ CA10, CA deg. } & Experiment & -15.8 & -15.0 & -13.8 & -13.6 & -13.0 \\
\hline & Model & -13.6 & -13.4 & -13.4 & -13.6 & -13.8 \\
\hline & Error, CA deg. & 2.2 & -1.6 & -0.4 & 0.0 & 0.8 \\
\hline \multirow[t]{3}{*}{ CA50, CA deg. } & Experiment & -5.4 & -3.6 & 0.8 & 2.2 & 4.2 \\
\hline & Model & -6.8 & -4.6 & -1.0 & 0.2 & 1.2 \\
\hline & Error, CA deg. & -1.4 & 1.0 & 1.8 & 2.0 & 3.0 \\
\hline \multirow[t]{3}{*}{$I M E P, k P A$} & Experiment & 340.12 & 344.03 & 362.74 & 366.32 & 367.91 \\
\hline & Model & 427.19 & 417.99 & 406.99 & 402.58 & 402.12 \\
\hline & Error, \% & 25.6 & 21.5 & 12.2 & 9.9 & 9.3 \\
\hline \multirow[t]{3}{*}{$R I, M W / m 2$} & Experiment & 0.52 & 0.46 & 0.60 & 0.45 & 0.38 \\
\hline & Model & 0.99 & 1.08 & 1.45 & 1.30 & 1.27 \\
\hline & Error, \% & 90.4 & 134.8 & 141.7 & 188.9 & 234.2 \\
\hline
\end{tabular}




\subsubsection{HCCI Multi-zone Model Validation}

The multi-zone model validation was accomplished by comparing the simulated pressure with experimentally obtained in-cylinder pressure data. The conditions used for validation correspond to the same conditions used for validating the single-zone and kinetic mechanism for variations in air-fuel ratio. It should be recalled that the main reason for using MZ models is the ability to properly represent the overall performance of the HCCI engine. This allows for better estimation of IMEP and RI values, in addition to lower peak pressures and temperatures, which affects the $\mathrm{NO}_{\mathrm{x}}$ emission prediction. $\mathrm{HC}$ and $\mathrm{CO}$ are also predicted with the MZ model, but the accuracy of $\mathrm{HC}$ and $\mathrm{CO}$ predictions reported in literature is usually small (Aceves et al. 2000, Komninos et al. 2004, Easley et al. 2001).

\subsubsection{MZ Model Pressure and Heat Release Comparison with Experimental Data}

Figure 17 shows experimental and calculated in-cylinder pressure and corresponding rate of heat release for three AF ratio values. The multi-zone model was set with six (6) zones: zone 1, or core zone; zone 2 through 4 are intermediate zones; zone 5 is the boundary layer zone; and zone 6 represents the engine crevices. The engine characteristics correspond to the one described in Table 2. The AF cases presented here are $\mathrm{AF}=43,50$ and 55, the engine speed is $900 \mathrm{rpm}$ and there is no EGR.

The calculated pressure traces agree well with the experimental data during the compression and combustion period. At higher loads the calculated pressure during expansion was usually 2-3 bar above the experimental data. This difference may be explained by blowby in the experiment, which reduces the in-cylinder pressure. At low loads the difference was minimum, which confirms high blowby at high load. The MZ calculated peak pressure traces do not overshoot the experimentally obtained ones, which suggest that the average temperature inside the cylinder reaches lower peak temperatures.

The heat release curves for each zone are presented in Figure 17. The method for calculating heat release from experimental data, assumes uniform temperature and composition, while the zone heat release comes from calculated heat release due to chemical reactions in each zone. It should be noted that each zone combusts according to its own temperature-composition history, showing a series of spikes corresponding to combustion events in each zone. The overall calculated heat release represents the summation of each zone heat release. The LTHR zone is present and occurs at almost the same position, $\left(-13^{\circ}\right.$ crank angle aTDC) in all three cases, which correspond with the experiments. The HTHR stage for each zone occurs in a sequence commanded by the core zone. Timing for combustion is better explained by analyzing the temperature and mass history as presented in Figure 18. 

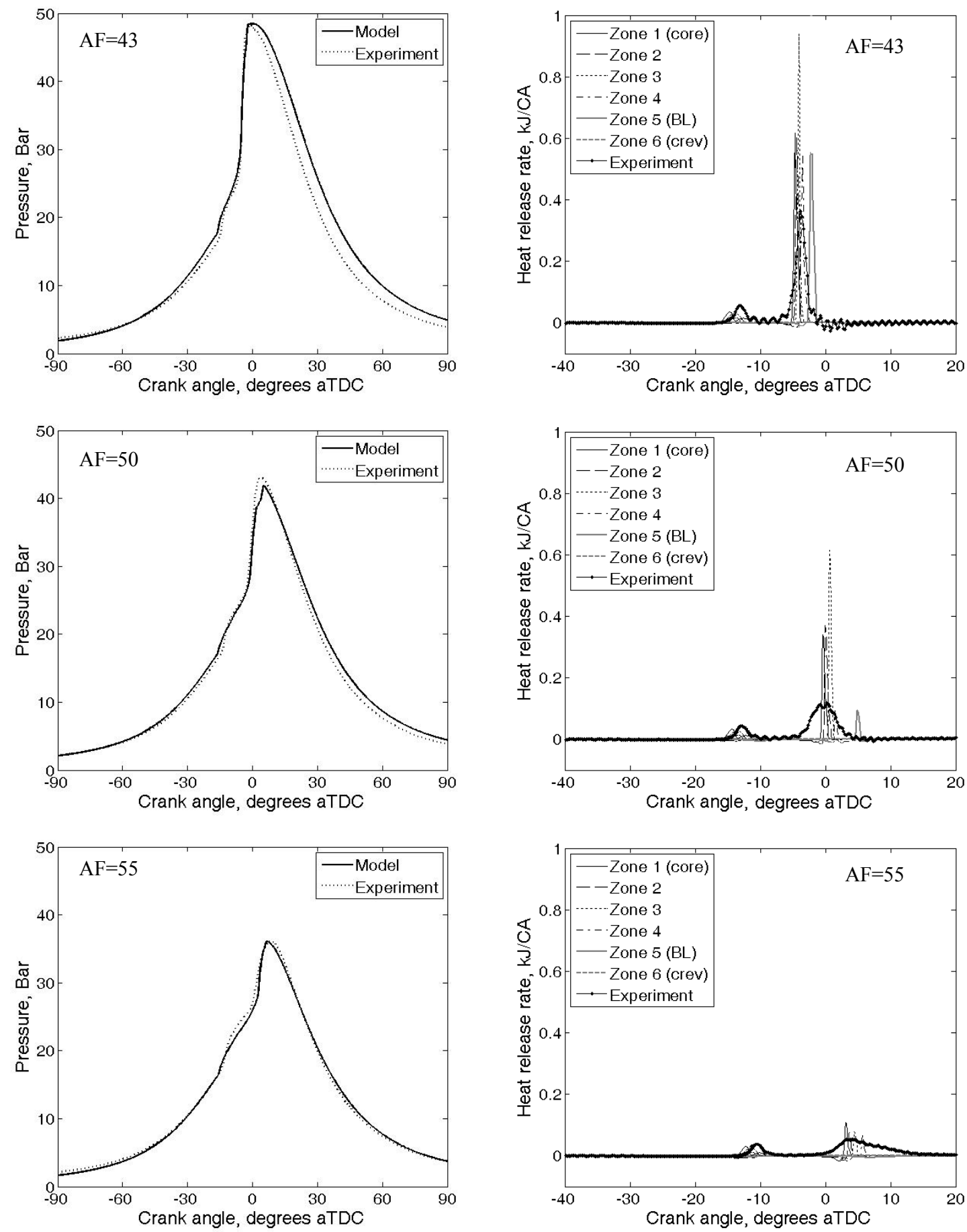

Figure 17. Experimental and $M Z$ model calculated pressure and rate of heat release for three different $A / F$ values, $A F=43, A F=50$ and $A F=55 . P_{\text {int }}=95 \mathrm{kPa}, T_{\text {int }}=310 \mathrm{~K}, C R=10, P_{\text {exh }}=104 \mathrm{kPa}, 900 \mathrm{rpm}$. 


\subsubsection{MZ Model Temperature Stratification and Mass Exchange}

Figure 18 shows the temperature (a) and mass distribution (b) considering a cylinder divided in six zones. An average calculated in-cylinder bulk temperature is also presented. Before the NTC zone, the temperature of each zone is very similar, about 5-8 K difference between zones 1-4 depending on load conditions. At higher load the difference is higher. The behavior of zones 5 and 6 , the boundary layer zone and crevices is different. The calculated temperature history of the BL zone was $40-50 \mathrm{~K}$ below the core temperature (zone 1) due to convective heat transfer with the walls. This difference is reduced at lower loads. Wall temperature was kept at $400 \mathrm{~K}$ for all the cases studied in this research work. The definition of the MZ model specified that the crevices were kept at wall temperature along the whole process. The implications of having a zone that does not ignite gives the $\mathrm{MZ}$ model the ability to predict $\mathrm{CO}, \mathrm{HC}$ and unburned fuel better than a SZ model. The LTHR stage starts at about the same temperature in each zone, with earlier combustion in core zones and later combustion in the BL zone. Once the LTHR starts, the temperature difference between zones increases. The temperature stratification during the LTHR stage is extended along the HTHR stage, allowing for longer combustion duration. Figure 17 shows that the sequential heat release is responsible for this extended combustion duration, which is a significant benefit of MZ models. It should be noted that by increasing the number of zones the heat release sequence would be smoother, resembling the experimental one.

Peak temperatures reached by each zone varied significantly and were highly dependent on load (AF). Difference between core and $\mathrm{BL}$ zones varied from $170 \mathrm{~K}$, at $\mathrm{AF}=43$, up to $600 \mathrm{~K}$ at $\mathrm{AF}=55$. In the later case the BL zone was close to misfire. During the expansion process the temperature stratification accentuates, with differences between core and BL zone varying from $400 \mathrm{~K}$ up to $600 \mathrm{~K}$. For a given number of zones, the thermal stratification during the compression and combustion stages is dominated by the initial temperature at IVC, chemical kinetics and the mass exchange between zones; the stratification during expansion is dominated by heat transfer between zones and by the convective heat transfer at the BL zone. Chemical kinetics is defined with the $\mathrm{SZ}$ model, which provides consistence with CA10 and CA50 values in all cases previously tested and explained. The mass exchange is required for the model to adjust pressure and is not suitable for adjustments. The convective heat transfer can be adjusted during the MZ model tuning but was left constant in all cases. The temperature at IVC and the heat transfer between zones are the only parameters that cannot be fully defined without more sophisticated temperature-sensing tools. Initial temperature at IVC can be circumvented by forcing a gradient temperature at IVC, based on CFD calculations or available literature. In this model the zone temperature distribution at IVC was based on CFD based calculations performed by Aceves et al. (2000) while studying modeling of HCCI combustion of methane. 

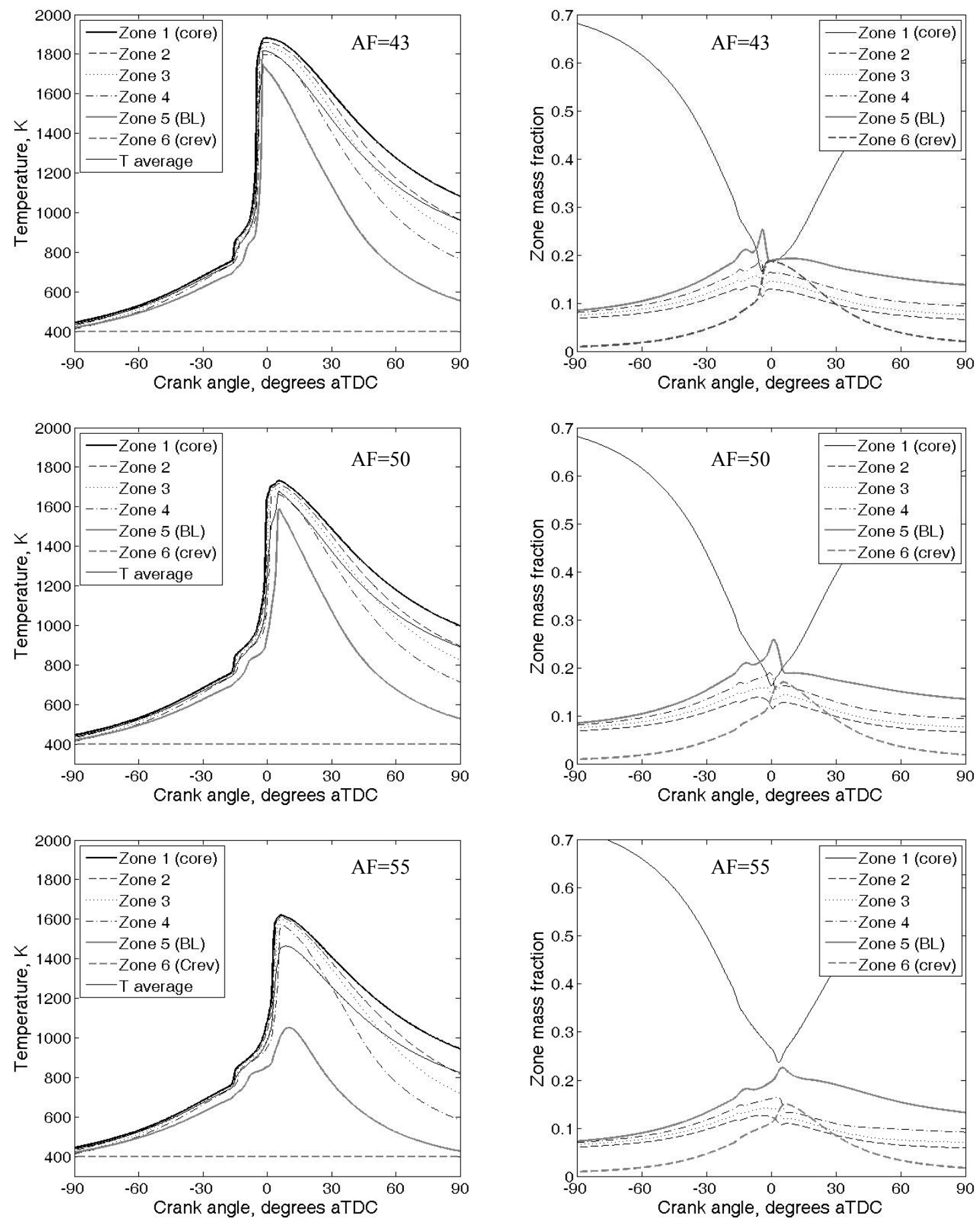

Figure 18. Calculated temperature and zone mass (as fraction of total mass) for three different $A / F$ values, $A F=43, A F=50$ and $A F=55 . P_{\text {int }}=95 \mathrm{kPa}, T_{\text {int }}=310 \mathrm{~K}, C R=10, P_{\text {exh }}=104 \mathrm{kPa}, 900 \mathrm{rpm}$.

The heat transfer between zones was studied during the model development. It was noted that changes in order of magnitude of thermal conductivity, $k$, did not affect the compression-combustion part, 
but changed the temperature history of the expansion stroke. Although the difference was significant between zones, the average value was very similar and its effect on pressure history negligible.

The calculated mass distribution for each zone, presented in Figure 18 as zone mass fraction, shows the interaction between adjacent zones. During the compression stroke the core zone reduces its fraction of in-cylinder mass to compensate for a reduction in volume and increase in temperature. During the LTHR and HTHR stages, the mass is quickly exchanged between zones, resulting in a significant mass increase for the crevices. Around TDC the crevice zone contains around $15 \%$ of the total in-cylinder mass. Although it seems excessive, it should be noted that around TDC, zones 1 through 5 have much higher temperature than the crevice (3-4 times more), which reduces their density. The calculated mass on the $\mathrm{BL}$ zone was the second largest after the core zone, which is due to its low temperature compared to zones 1 through 4 . It should be noted that the exchange of mass between zones also convey enthalpy, and that affects significantly the temperature history of each zone.

\subsubsection{MZ Model Evaluation}

The overall performance of the MZ model is evaluated following the same method used for the SZ model. The rate of heat release curves are analyzed for determining CA10 and CA50 values. Calculated CA10 and CA50 values are presented in Table 6. Results obtained from the single-zone and the multizone models are very similar regarding CA10 and CA50 values. The reason is that these events are governed by the chemical kinetic model, which was properly tuned with the SZ model. Comparing Table 4 and Table 6 shows that the MZ model tends to slightly advance both LTHR and HTHR events. This might be caused because the MZ model combustion is governed by the core zone temperature and composition history. During the MZ model set up it was observed that changes in the zone volume distribution affect the core temperature and composition history. In all three AF cases presented here the core zone was kept at $40 \%$ of clearance volume. It can be concluded that both SZ and MZ models are capable of predicting combustion events with adequate accuracy. Figure 19 presents a comparison for SZ and MZ model results against experimental in-cylinder pressure data. It is evident that the MZ model captures the compression and combustion process more closely to the experiment than the SZ model. The SZ model overshoots the calculated pressure values compared to experimental data. This behavior is typical of SZ models (Aceves et a. 1999, Fiveland and Assanis 2001). As a result of this pressure overestimation, IMEP calculated values from the SZ model are higher than calculations from MZ models. This makes relevant the use of MZ models for numerical IMEP calculation. Calculated RI values from the MZ model are closer than the ones obtained with the SZ model. This is caused by the improved ability of $\mathrm{MZ}$ model to predict the heat release process, as presented in previous sections, reducing the calculated rate of pressure rise with respect to the values obtained with the SZ model. HCCI performance 
parameters IMEP and RI were considerably improved over results obtained from the SZ model as can be concluded from Tables 4 and 6.

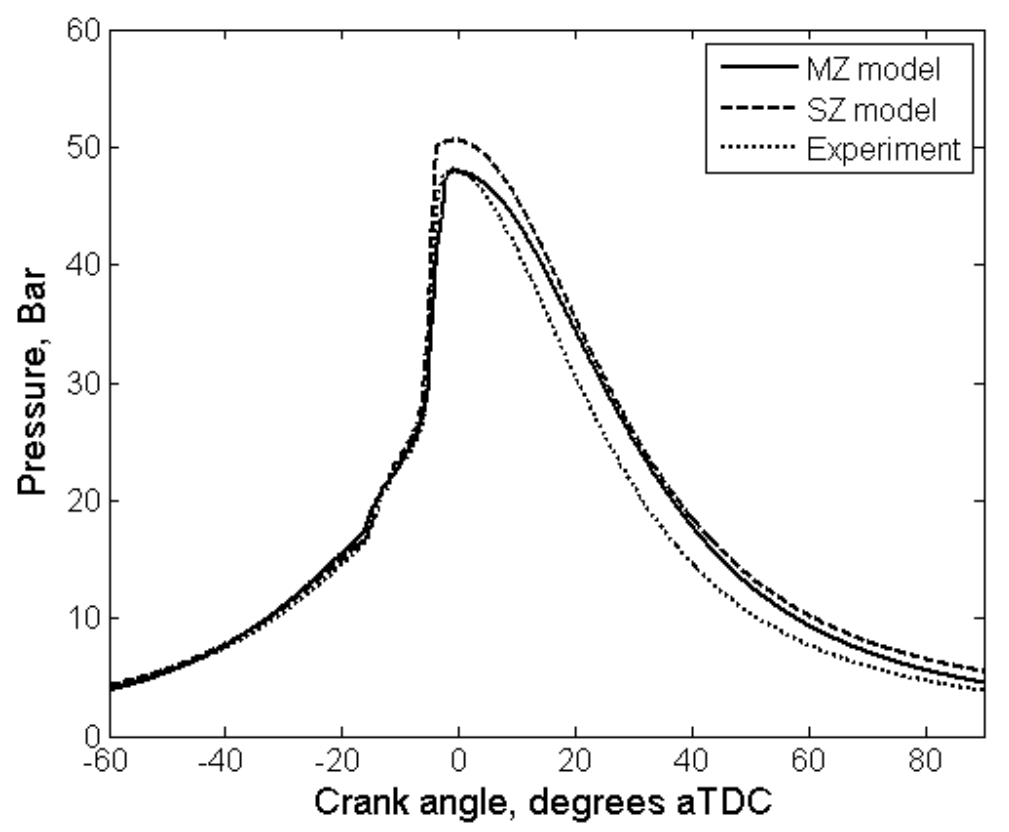

Figure 19. Comparison of $M Z$ and $S Z$ calculated pressure data. $A F=43, P_{\text {int }}=95 \mathrm{kPa}, T_{\text {int }}=310 \mathrm{~K}, \mathrm{CR}=10$, $P_{\text {exh }}=104 \mathrm{kPa}, 900 \mathrm{rpm}$. Experimental data from Guo et al. (2009)

The largest error in IMEP MZ calculated values came from the high load case, where calculated pressure was above experimental pressure along expansion process. The difference was considerably reduced at low load values (higher AF). Ringing calculated values were the most difficult to predict with accuracy. This is due to the fact that the rate of change of pressure governs the calculation as it is the largest numeric value involved in the RI calculation. Values of $d P / d t$ calculated from pressure data derived from the $\mathrm{MZ}$ results are directly affected by zone heat release behavior. In the case of $\mathrm{AF}=50$, late combustion of zone 5 led to a sudden increase in pressure, which affected the RI value obtained from the MZ model. In conclusion, the MZ model predicts IMEP values with accuracy, but RI values are dependent on zone distribution. 
Table 6. Comparison of combustion and performance parameters between experimental values and MZ model calculated results at different $A F$ ratios.

\begin{tabular}{|c|c|c|c|c|}
\hline Parameter & & $A F=43$ & $A F=50$ & $A F=55$ \\
\hline \multirow[t]{3}{*}{ CA10, CA deg. } & Experiment & -13.6 & -12.2 & -11.8 \\
\hline & Model & -14.0 & -13.4 & -12.4 \\
\hline & Error, CA deg. & 0.4 & 1.2 & 0.60 \\
\hline \multirow[t]{3}{*}{ CA50, CA deg. } & Experiment & -4.6 & 0.2 & 4.6 \\
\hline & Model & -5.8 & -2.0 & 3.8 \\
\hline & Error, CA deg. & 1.2 & 2.2 & 0.8 \\
\hline \multirow[t]{3}{*}{$I M E P, k P A$} & Experiment & 371.94 & 369.73 & 335.46 \\
\hline & Model & 427.22 & 391.39 & 341.50 \\
\hline & Error, \% & 14.8 & 5.9 & 1.8 \\
\hline \multirow[t]{3}{*}{$R I, M W / m^{2}$} & Experiment & 4.78 & 0.74 & 0.19 \\
\hline & Model & 5.21 & 0.95 & 0.21 \\
\hline & Error, \% & 8.8 & $29.0^{i}$ & 10.5 \\
\hline
\end{tabular}

i. Large error caused by late combustion of BL zone.

\subsubsection{MZ Model Emissions Prediction}

An interesting feature of the MZ model is its ability to account for species that are relevant to emissions and are associated with boundary layers and crevices, like unburnt fuel, $\mathrm{HC}$ and $\mathrm{CO}$. HC is mostly composed, in terms of mass, of unburnt fuel. Figure 20 shows the history of fuel (and unburnt fuel) in the cylinder for two $\mathrm{AF}$ cases $(\mathrm{AF}=43$ and $\mathrm{AF}=55)$. Before combustion, part of the fuel is exchanged between zones, as explained before, from hotter to colder zones compensating for pressure differences between zones. The core zone (Z1) is the first to oxidize the fuel during the LTHR and HTHR as it is the first zone to reach the temperatures required for combustion. As predicted by large hydrocarbons oxidation theory, the original n-heptane suffers different reactions before the LTHR stage(Westbrook 2000), reducing its total mass in the core zone quickly. Some of the fuel that is not consumed is transferred to adjacent zones 2 through 5. Upon combustion of the core zone, the rise in temperature forces the consumption of fuel remaining in other zones. The model shows the combustion sequence from zone 2 to zone 5. During combustion and before TDC the fuel is fully consumed in all internal zones and BL. However, during the compression stroke the crevice zone accumulated some amount of fuel, which was not consumed due to the low temperature of the zone. After TDC and during the expansion stroke, the fuel accumulated in the crevice zone is exchanged with the BL zone. From the boundary layer, the unburnt fuel is exchanged with other zones along the expansion stroke. 

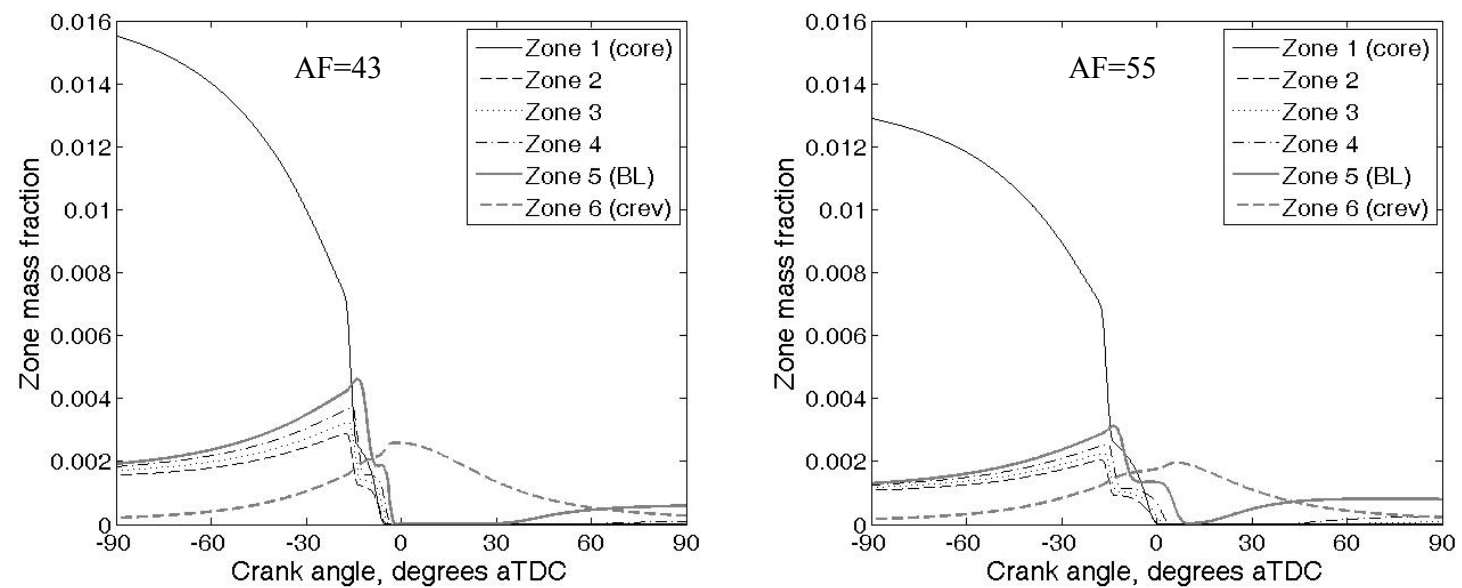

Figure 20. Calculated mass fraction of fuel in each zone for $A F=43$ and $A F=55 . P_{\text {int }}=95 \mathrm{kPa}, T_{\text {int }}=310 \mathrm{~K}$, $C R=10, P_{\text {exh }}=104 \mathrm{kPa}, 900 \mathrm{rpm}$

$\mathrm{CO}$ emissions mass fraction history by zone is presented in Figure 21. The model results show that most of the $\mathrm{CO}$ is produced in the internal zones (zone 1 through 5) during the early stage of the combustion and later is converted into $\mathrm{CO}_{2}$. After TDC the boundary layer zone increases the mass fraction of $\mathrm{CO}$ due to mass exchange with the crevice zone. The mass fraction of $\mathrm{CO}$ increases in the $\mathrm{BL}$ zone, as well as in adjacent zones, however some of the $\mathrm{CO}$ is also oxidized to form $\mathrm{CO}_{2}$. Because the temperature drops quickly in each of the internal zones, the $\mathrm{CO}$ and $\mathrm{HC}$ slowly oxidize into $\mathrm{CO}_{2}$, resulting in high $\mathrm{CO}$ and $\mathrm{HC}$ mass fractions at EVO. It is evident that $\mathrm{CO}$ mass fraction at $\mathrm{EVO}$ is higher at higher load, or equivalence ratio.
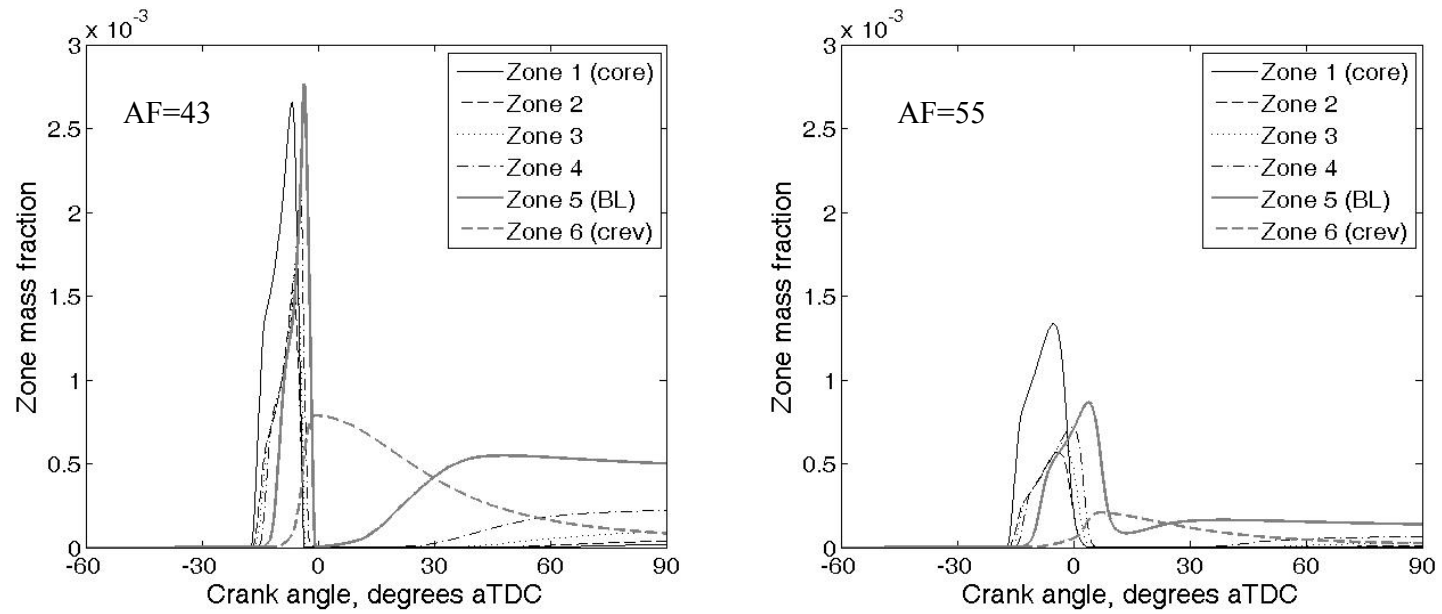

Figure 21. Calculated $C O$ mass fraction in each zone for $A F=43$ and $A F=55 . P_{\text {int }}=95 \mathrm{kPa}, T_{\text {int }}=310 \mathrm{~K}$, $C R=10, P_{\text {exh }}=104 \mathrm{kPa}, 900 \mathrm{rpm}$ 
The MZ model and the SZ model are both capable of predicting $\mathrm{NO}_{\mathrm{x}}$ emissions. The single-zone model tends to overpredict the NO formation because it predicts higher peak temperatures than what is estimated from experiments (Hulkvist et al. 2001). Figure 22 shows the $\mathrm{NO}$ and $\mathrm{NO}_{\mathrm{x}}$ history for $\mathrm{AF}=43$ $(\phi=0.35), \mathrm{AF}=50(\phi=0.30)$ and $\mathrm{AF}=55(\phi=0.27) . \mathrm{At} \mathrm{AF}=43$, it can be observed that the NO forms very rapidly when HTHR occurs, but it is later oxidized into $\mathrm{NO}_{2}$. This conversion of $\mathrm{NO}$ into $\mathrm{NO}_{2}$ is due to the low combustion temperature and high $\mathrm{O}_{2}$ availability. $\mathrm{NO}$ is oxidized into $\mathrm{NO}_{2}$ below the $1800 \mathrm{~K}$ threshold ( $\mathrm{Lu}$ et al. 2005). Above that temperature, directly linked to equivalence ratio, the NO formed during the HTHR period remains along the expansion stroke, which was also confirmed by Easley et al. (2001) while working with different fuels, including n-heptane. The $\mathrm{NO}$ and $\mathrm{NO}_{\mathrm{x}}$ formed mainly in the core zones, where it reach higher temperatures remains in the core and other internal zones during the expansion stroke. This behavior is the opposite of $\mathrm{HC}$ and $\mathrm{CO}$ emissions that are nested into the $\mathrm{BL}$ and crevice zones and alter convey to internal zones.

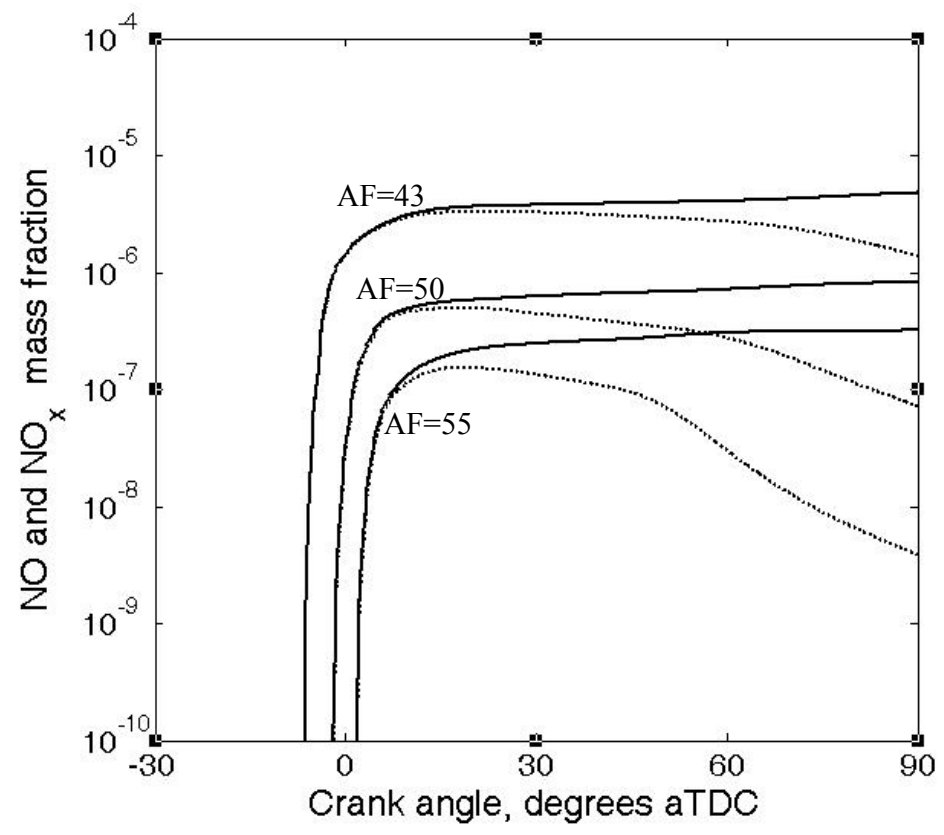

Figure 22. Calculated mass fraction history for $\mathrm{NO}_{x}$ (solid lines), and $\mathrm{NO}$ (dotted lines). 


\section{Chapter 4. Thermo-Chemical Recuperation}

The concept of thermo-chemical recuperation is based on the idea of storing heat energy by converting it to chemical energy. In practical terms, it means to take an energy-poor reactant and reformed it into an energy enriched product. It was presented in the literature review section that reforming of hydrocarbon fuels can be accomplished by two means, i.e., by partial oxidation (PO) and steam reforming (SR). This section is devoted to determine which of these two processes is the most suitable for thermo-chemical recuperation of n-heptane, and to define the reforming model and main assumptions.

\subsection{Comparative Analysis for Partial Oxidation and Steam Reforming}

The principal objective of the thermo-chemical recuperation process is to provide the HCCI engine with a secondary fuel with different auto-ignition characteristics. As an additional goal, the secondary fuel is expected to have the same or higher energy content per unit mass than the primary fuel. Applying these two goals into this current research work, the criteria for fuel reforming process selection were maximum $\mathrm{H}_{2}$ yield at the low reforming temperature, while minimizing the energy required for the reforming reactions. The method used for comparing PO and SR processes was a first law analysis and equilibrium calculations for reformed gas composition.

The first law analysis was performed to examine the net enthalpy change for each process, from reactants to products, assuming that the global reforming process achieves completion. Values of theoretical reforming thermal efficiency were obtained for different initial concentration of fuel $/ \mathrm{O}_{2}$ and fuel $/ \mathrm{H}_{2} \mathrm{O}$ for $\mathrm{PO}$ and SR respectively. Second, an equilibrium analysis of the reforming process was performed. This equilibrium analysis defines the species concentration of the main species involved in the reforming process as a function of reforming temperature.

The energy cost per mole of $\mathrm{H}_{2}$ produced was also assessed. As can be anticipated, the net enthalpy change analysis does not include the effect of reforming temperature and offers basically an upper limit value for thermal efficiency. In addition, the temperature and RG composition data is used to assess more accurately the energy cost of the reforming process.

The general idea of the thermodynamic analysis, based on the enthalpy change assumes a system composed of the reactant fuel and water for the SR process, and fuel and exhaust gases $\left(\mathrm{O}_{2}, \mathrm{CO}_{2}, \mathrm{H}_{2} \mathrm{O}\right.$ and $\mathrm{N}_{2}$ ) for PO process. 
For steam reforming of hydrocarbons $C_{n} H_{m}$, the net enthalpy change can be calculated from the global reaction balance

$$
C_{n} H_{m}+(S: C) n H_{2} O(l) \rightarrow n C O+\left(\frac{m}{2}+n\right) H_{2}+(S: C-1) n H_{2} O(g) \quad \text { Equation } 63
$$

as

$$
\Delta H_{R}=n h_{C O}^{0}+(S: C-1) n h_{H_{2} O(g)}^{0}-\left(h_{C_{n} H_{m}}^{0}+S: C n h_{H_{2} O(l)}^{0}\right) \quad \text { Equation } 64
$$

where $\mathrm{S}: \mathrm{C}$ is the steam to carbon ratio as defined in section 2.2 .

For partial oxidation, the enthalpy change based on the global fuel partial oxidation reaction (without inert and non-reactant gases)

$$
C_{n} H_{m}+\frac{n}{2} O_{2} \rightarrow n C O+\frac{m}{2} H_{2}
$$

can be calculated as

$$
\Delta H_{R}=n h_{C O}^{0}-h_{C_{n} H_{m}}^{0}
$$

Equation 66

where $h_{i}^{0}$ refers to enthalpy of formation for species $i$.

For n-heptane, the partial oxidation process enthalpy change can be estimated from the global reaction (Equation 65), with $n=7$ and $m=16$. The PO net enthalpy change is $\Delta H_{R}=-140 \mathrm{kcal} / \mathrm{kmol}_{\text {fuel }}$ or $17.5 \mathrm{kcal}$ per mol of $\mathrm{H}_{2}$ yield. The negative sign implies that the reaction releases to the environment 140 cal per mol of fuel reformed.

On the other hand the steam reforming process can be estimated from Equation 63, substituting $n$ and $m$ with 7 and 16, respectively, and assuming $\mathrm{S}: \mathrm{C}=1: 1$. This steam reforming reaction net enthalpy change is $\Delta H_{R}=382 \mathrm{kcal} / \mathrm{kmol}_{\text {fuel }}$, or $25 \mathrm{kcal}$ per mol of $\mathrm{H}_{2}$ yield. $\mathrm{SR}$ is an endothermic reaction. The exhaust gas waste heat could provide the heat required for driving the steam reforming reaction, which implies a recuperation of energy. However, the previous enthalpy calculations were based on assuming total fuel reforming. Equilibrium calculations provide a better insight into the composition of RG for each case in question.

The chemical equilibrium model was used to estimate species concentration as a function of reforming temperature for each of the process, SR and PO. For a system undergoing a reaction process at constant pressure, as is the case in the reforming process, chemical equilibrium is attained when the Gibbs energy reaches a minimum value. 
The Gibbs function is defined as

$$
G=\sum_{i=1}^{K} \hat{g}_{i} N_{i}
$$

Equation 67

Where $\hat{\mathrm{g}}_{\mathrm{i}}$ is the partial molar Gibb's function, and $N_{i}$ is the number of moles of species $i . K$ is the total number of species.

The partial molar Gibbs function is defined as

$$
\hat{g}_{i}=\hat{g}_{i}(T, P)+R T \ln X_{i}
$$

Equation 68

The minimization of the Gibb's function, which provides values of $N_{i}$, is constrained by the number of atoms of each element and by the condition $N_{i} \geq 0$. The solution of the non-linear system is accomplished through manipulation of the species Gibbs energy into an atomic formulation. Instead of dealing with solving the system for $K$ species, the element potential method, transforms the problem into a linear system for the number of atoms and total mole count. The element potential method was developed by Reynolds (1986) and uses thermodynamic data from JANNAF tables. It is already available in CHEMKIN $^{\circledR}$ as a subroutine called equil (Reaction Design 2007). The program requires defining all of the expected species involved during the reaction process and the thermodynamic state parameters to keep constant.

In the case of the reforming process the system was composed by the set of species considered, as defined in Equations 63 and $65\left(\mathrm{nC}_{7} \mathrm{H}_{16}, \mathrm{H}_{2} \mathrm{O}, \mathrm{O}_{2}, \mathrm{H}_{2}\right.$, and $\left.\mathrm{CO}\right)$. The thermodynamic parameter held constant was pressure (1 atm).

The equilibrium modeling of each process, PO and SR, at different reforming temperatures was used to calculate RG composition. The calculated RG composition was used to evaluate the RG lower heating value. Figure 23 shows the equilibrium composition of reformed gases for both PO and SR. PO process was studied at different rates of oxygen to carbon ratio $X: C$; Figure 23 a shows $X: C=1: 1$. The SR process was studied at two different sets of steam to carbon ratio. Figure $23 \mathrm{~b}$ shows $\mathrm{S}: \mathrm{C}=1: 1$. For both cases the pressure was held at $1 \mathrm{~atm}$. It is clear that for partial oxidation (Figure 23a) the oxygen is consumed at low temperature and goes to CO. The SR process (Figure 23b) shows that the addition of water provides extra hydrogen atoms that help in increasing $\mathrm{H}_{2}$ yield. It is clear that the SR process yields a higher $\mathrm{H}_{2}$ molar fraction when compared to $\mathrm{PO}$ at the same reforming temperature. As an example, at $T_{\text {ref }}=600 \mathrm{~K}$ the $\mathrm{H}_{2}$ yield molar fraction is around 0.13 for PO versus 0.28 for SR. 

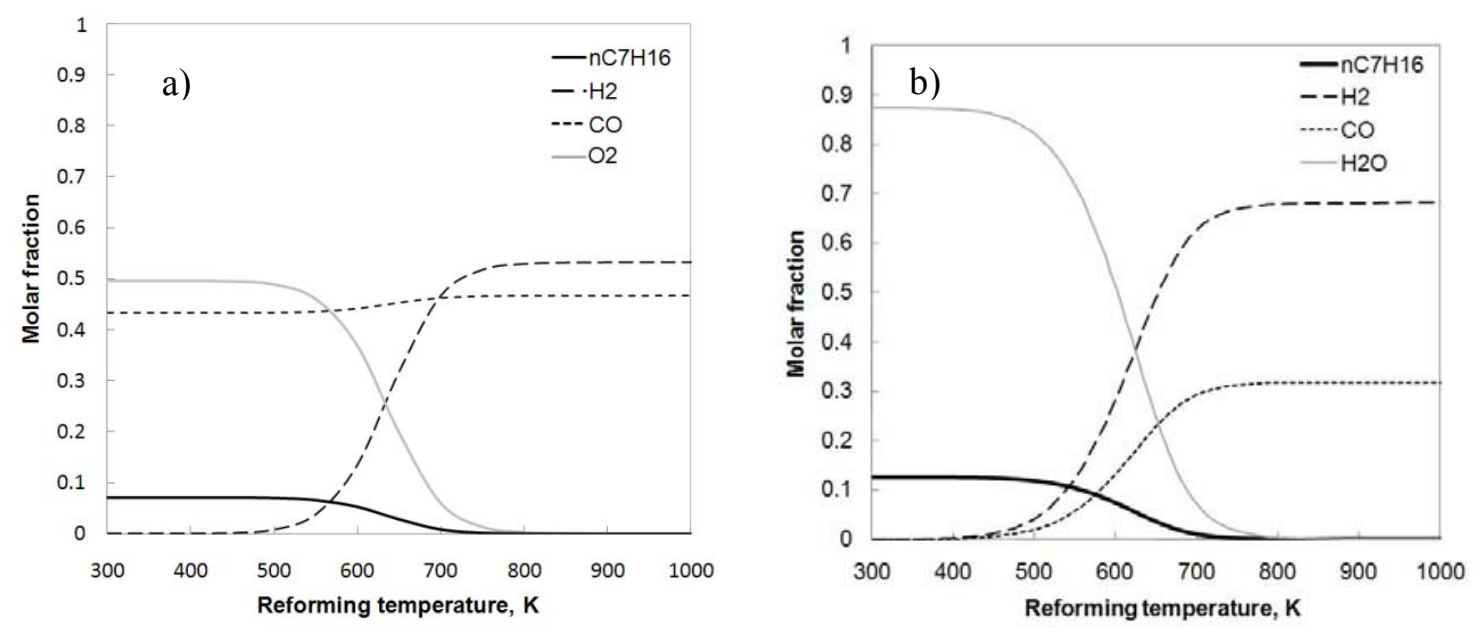

Figure 23. $R G$ composition calculated by equilibrium as a function of reforming temperature $T_{\text {ref }}$ for a) Partial Oxidation and b) Steam reforming. Both analysis performed at $P=1 \mathrm{~atm}$.

Figure 24 shows the RG lower heating values for both reforming processes based on composition from equilibrium calculations (Figure 23). Reforming thermal efficiency is defined in literature as the rate of LHV of products to LHV of baseline fuel (Jones and Wyszynski 1993):

$$
\eta_{\text {th.ref }}=\frac{L H V_{R G}}{L H V_{\text {fuel }}}
$$

Equation 69

This SR calculated efficiency does not account for the energy required to evaporate the water for the SR process, $h_{f g}$. This amount of energy per mol of fuel, as presented below, is proportional to S:C

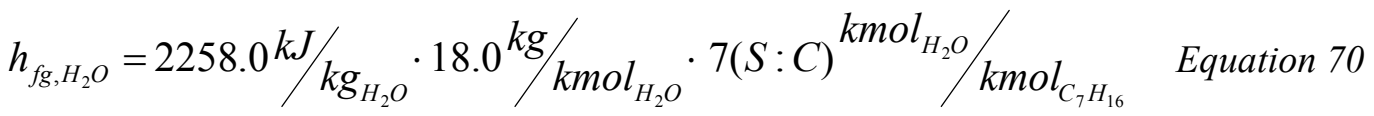

$$
\begin{aligned}
& h_{f g, H_{2} O}=0.285(S: C) M J / \mathrm{kmol}_{C_{7} H_{16}}
\end{aligned}
$$

The reforming thermal efficiency was defined in this research work as

$$
\eta_{\text {th.ref }}=\frac{L H V_{R G}}{L H V_{f u e l}+h_{f g, H_{2} O}}
$$

Partial oxidation RG products show an inferior value of LHV at any given reforming temperature under any given $\mathrm{X}: \mathrm{C}$ ratio. On the other hand, RG products of steam reforming show improved LHV at 
$T_{r e f}>476 \mathrm{~K}$. This shows that the reforming thermal efficiency SR is higher than PO. Calculated values of reforming thermal efficiency for reforming completion are $\eta_{\text {th.ref }}=0.87$ and $\eta_{\text {th.ref }}=1.24$ for PO (X:C=1:1) and SR respectively. The effect of S:C on LHV is positive and proportional to the amount of steam available. This benefit is due to the high $\mathrm{H}_{2}$ yield from steam reforming.
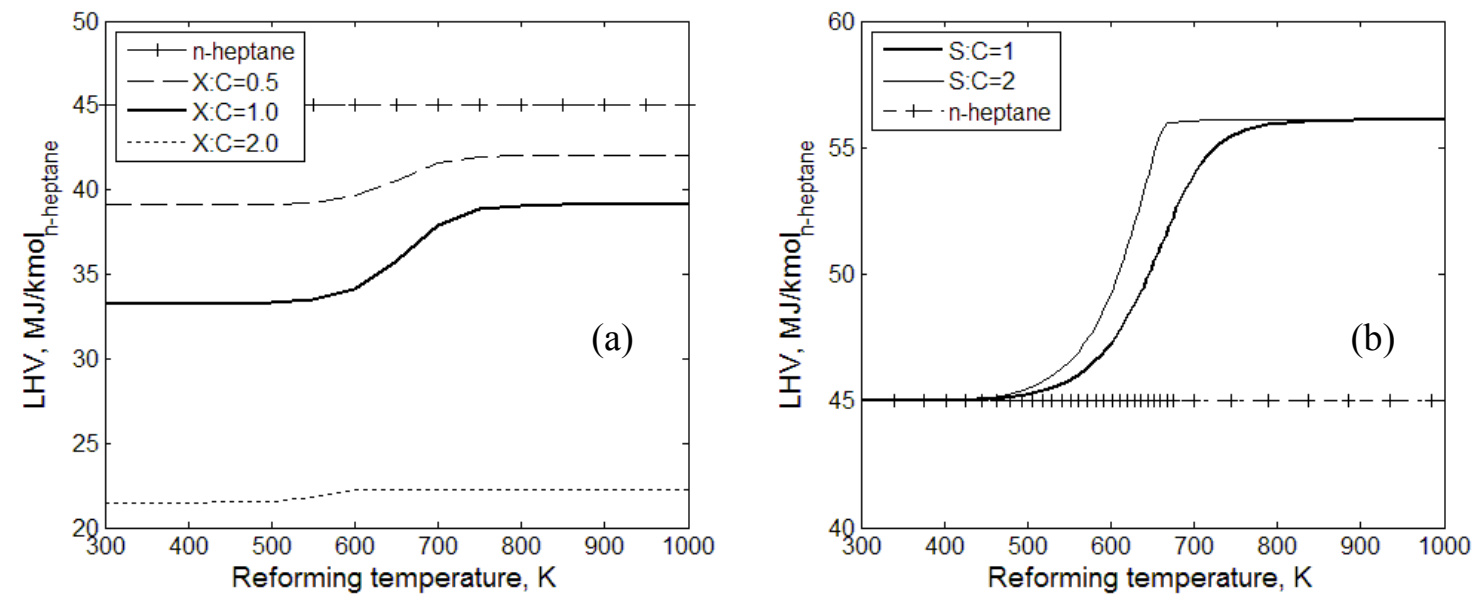

Figure 24. Lower Heating Value of RG for a) Partial Oxidation and b) Steam reforming

The study show that compared to PO, SR produces higher yield of $\mathrm{H}_{2}$ per mole of n-heptane; the molar ratio $\mathrm{H}_{2} / \mathrm{CO}$ is higher, which also increases its reforming thermal efficiency ( $\left.\eta_{\text {th.ref }}\right)$; and the SR process can recuperate the waste heat from the exhaust into chemical energy of the reformed gas, whereas PO generates more waste heat. Conclusion to these efforts carried on during the first stage of a DOEWVU research project (DE-FC26-05NT42632) for selecting the suitable reforming process for n-heptane on a HCCI model engine resulted in the selection of steam reforming as the most suitable technology for thermo-chemical recuperation.

\subsection{Steam Reforming Model}

The steam reforming model output provides the RG species composition required in the integrated HCCI-TCR model. The steam reformer model was developed for RG composition and also for performance, in order to account for the amount of energy required for the SR process to occur. The Ideal Case composition scenario aiming to obtain RG species composition was developed based on equilibrium assumptions, and the model was presented in the technology selection section. A secondary approach, aiming to obtain RG species composition and the reformer performance was developed based on kinetics reaction for steam reforming. 
The reformer was idealized as a plug flow tubular reactor (PFTR) with a jacket as the heat source for the endothermic reactions as shown in Figure 25.

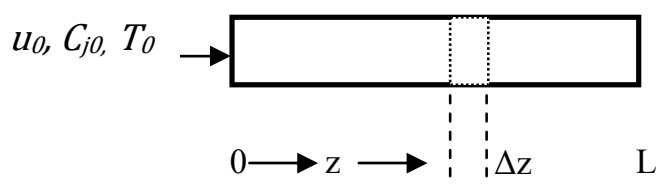

Figure 25. Plug flow tubular reactor

The basic mass and energy equations governing the steady state reaction in PFTR are, for mass conservation, assuming constant velocity along the reactor (Fogler 2006)

$$
u \frac{\partial C_{j}}{\partial z}=D_{j} \frac{\partial^{2} C_{j}}{\partial z^{2}}+\sum_{i=1}^{R} v_{i j} r_{i}
$$

Equation 73

where $C_{j}$ represents the molar concentration of species $j, u$ is velocity, $D_{j}$ is the diffusion coefficient, and $t$ and $z$ are the independent variables time and reactor axial direction respectively. The last term on the right accounts for changes in molar concentration of species $j$ due to reactions $R$ with other species $i$, which can be obtained from kinetic mechanisms data available in literature.

And for energy conservation (Fogler 2006),

$$
\rho c_{p} u \frac{\partial T}{\partial z}=k_{T} \frac{\partial^{2} T}{\partial z^{2}}+\sum_{i=1}^{R} \Delta H_{R i} r_{i}-Q_{w}^{\prime}
$$

Equation 74

where $T$ represents the unknown temperature and $k_{T}$ represents the heat conduction coefficient. The summation term accounts for enthalpy changes heat generated during the reaction. The term $Q^{\prime}{ }_{w}$ represents the heat transfer with the heating jacket per unit length.

These mass conservation equations was simplified considering that the effect of diffusivity can be neglected if $u L / D>100$, where $L$ represents the spatial scale (Hunt and Ewing 2009). The energy conservation equation was simplified by neglecting the effect of gas heat transfer. The SR model was developed based on these equations:

$$
\begin{array}{ll}
u \frac{\partial c_{j}}{\partial z}=\sum_{i=1}^{R} v_{i j} r_{i} & \text { Equation } 75 \\
\rho c_{p} u \frac{\partial T}{\partial z}=\sum_{i=1}^{R} \Delta H_{R i} r_{i}-Q_{w}^{\prime} & \text { Equation } 76
\end{array}
$$


The heat transfer term can be solved by assuming that the gases at any position $\mathrm{z}$ are at temperature $T$ while the jacket is at temperature $T_{w}$ and using a global heat transfer coefficient $U$ to obtain

$$
Q_{w}^{\prime}=p_{w} U\left(T(z)-T_{w}\right)
$$

where $p_{w}$ is the differential perimeter area.

The global heat transfer coefficient included convective heat transfer on the jacket surface and inside the reactor, and also the conductive heat transfer along the radial direction of the reactor pipe

$$
U=\frac{1}{\frac{1 D_{O}}{h_{i} D_{i}}+\frac{x_{W}}{k_{m_{(}}\left(D_{o}-D_{i}\right) / L n\left(\frac{D_{O}}{D_{i}}\right)}+\frac{1}{h_{O}}}
$$

Equation 78

where $D_{o}$ and $D_{i}$ are the external and internal reactor diameters, $x_{w}$ is the reactor wall radial thickness and $k_{m}$ its conductivity. The values for convective heat transfer coefficient were obtained from correlations for internal and external cylindrical annuli. Geometric factors were based on the experimental heat exchanger used during the experimental stage for steam reforming of n-heptane. The information available from GTI data was used to set this SR model.

The set of reactions for steam reforming of n-heptane on nickel catalyst, which corresponded to the catalyst used in the experimental work, has been defined as (Christensen 1996, Chen et al. 2003)

$$
\begin{array}{ll}
r_{1}: \mathrm{C}_{7} \mathrm{H}_{16}+7 \mathrm{H}_{2} \mathrm{O} \rightarrow 7 \mathrm{CO}+15 \mathrm{H}_{2} \mathrm{O} & \text { Equation } 79 \\
r_{2}: \mathrm{CO}+3 \mathrm{H}_{2} \rightleftharpoons \mathrm{CH}_{4}+\mathrm{H}_{2} \mathrm{O} & \text { Equation } 80 \\
r_{3}: \mathrm{CO}_{2}+4 \mathrm{H}_{2} \rightleftharpoons \mathrm{CH}_{4}+2 \mathrm{H}_{2} \mathrm{O} & \text { Equation } 81 \\
r_{4}: \mathrm{CO}+\mathrm{H}_{2} \mathrm{O} \rightleftharpoons \mathrm{CO}_{2}+\mathrm{H}_{2} & \text { Equation } 82
\end{array}
$$

The first reaction is irreversible and $\mathrm{C}_{1}$ components are formed with no intermediates (Chen et al. 2003). Methanation (reactions 2 and 3) and the water gas shift reaction (reaction 4) form $\mathrm{CH}_{4}, \mathrm{CO}_{2}$ and $\mathrm{CO}$.

The intrinsic reaction rate for n-heptane steam reforming over nickel $\left(r_{1}, C_{7} H_{16}\right)$ and the methanation reaction $r_{2}, C O$ were established by Tottrup (1982)

$$
r_{1, C 7 H 16}=\frac{k_{1} P_{C 7 H 16}}{\left(1+K_{A} \frac{\left.{ }^{P_{C 7 H 16} P_{H 2}}+K_{B} \frac{P_{H 2 O}}{P_{H 2}}\right)^{2}}{P_{H 2 O}}\right.}
$$




$$
r_{2, \mathrm{CO}}=\frac{\frac{k_{2}}{P_{\mathrm{H} 2}^{2.5}}\left(P_{\mathrm{C} 7 \mathrm{H} 16} P_{\mathrm{H} 2 \mathrm{O}}-\frac{P_{\mathrm{H} 2}^{3} P_{\mathrm{CO}}}{K_{1}}\right)}{\left(1+K_{\mathrm{CO}} P_{\mathrm{CO}}+K_{\mathrm{H} 2} P_{\mathrm{H} 2}+K_{\mathrm{CH} 4} P_{\mathrm{CH} 4}+K_{\mathrm{H} 2 \mathrm{O}} \frac{P_{\mathrm{H} 2 \mathrm{O}}}{P_{\mathrm{H} 2}}\right)^{2}}
$$

Steam reforming works performed on methane were used by $\mathrm{Xu}$ and Froment (1989) to establish additional methanation and water gas shift intrinsic reaction rates

$$
\begin{aligned}
& r_{3, \mathrm{CO}_{2}}=\frac{\frac{k_{3}}{P_{\mathrm{H} 2}}\left(P_{\mathrm{CO}} P_{\mathrm{H} 2 \mathrm{O}}-\frac{P_{\mathrm{H} 2} \mathrm{C}_{\mathrm{CO} 2}}{K_{2}}\right)}{\left(1+K_{\mathrm{CO}} P_{\mathrm{CO}}+K_{\mathrm{H} 2} P_{\mathrm{H} 2}+K_{\mathrm{CH} 4} P_{\mathrm{CH} 4}+K_{\mathrm{H} 2 \mathrm{O}} \frac{P_{\mathrm{H} 2 \mathrm{O}}}{P_{\mathrm{H} 2}}\right)^{2}} \quad \text { Equation } 85 \\
& r_{4, \mathrm{CO}_{2}}=\frac{\frac{k_{4}}{P_{\mathrm{H} 2}^{3.5}}\left(P_{\mathrm{CH} 4} P_{\mathrm{H} 2 \mathrm{O}}^{2}-\frac{P_{\mathrm{H} 2}^{4} \mathrm{CO}_{2}}{K_{3}}\right)}{\left(1+K_{\mathrm{CO}} P_{\mathrm{CO}}+K_{\mathrm{H} 2} P_{\mathrm{H} 2}+K_{C H 4} P_{\mathrm{CH} 4}+K_{\mathrm{H} 2 O} \frac{P_{\mathrm{H} 2 \mathrm{O}}}{P_{\mathrm{H} 2}}\right)^{2}} \quad \text { Equation } 86
\end{aligned}
$$

Table 7 present the values of the constants used in the previous equations. The operational conditions for the SR process are defined by reforming temperature, pressure and composition, namely, S:C ratio. The authors of the aforementioned reactions for SR of n-heptane defined that the those reactions are valid for reforming temperature of $600 \mathrm{~K}$ to $1000 \mathrm{~K}, \mathrm{~S}: \mathrm{C}$ ratio of 1 to 3 and reforming pressure of 1 to $10 \mathrm{~atm}$,

\begin{tabular}{|c|c|c|}
\hline Kinetic parameter & Value & Units \\
\hline$k_{l}$ & $3.906 \times 10^{8} \exp (-67800 /(R T))$ & $\mathrm{mol} / \mathrm{m}^{3} \mathrm{~s} \mathrm{~atm}$ \\
\hline$k_{2}$ & $9.886 \times 10^{16} \exp (-40100 /(R T))$ & mol atm $0.5 / m^{3} s$ \\
\hline$k_{3}$ & $4.665 \times 10^{7} \exp (-67130 /(R T))$ & $\mathrm{mol} / \mathrm{m}^{3} \mathrm{~s} \mathrm{~atm}$ \\
\hline$k_{4}$ & $2.386 \times 10^{16} \exp (-243900 /(R T))$ & mol atm $0.5 / \mathrm{m}^{3} \mathrm{~s}$ \\
\hline$K_{A}$ (adsorption constant) & 25.2 & $\mathrm{~atm}^{-1}$ \\
\hline$K_{B}($ adsorption constant) & 0.077 & - \\
\hline$K_{I}$ (equilibrium constant) & $\exp (29.3014-26248.4 / T)$ & - \\
\hline$K_{2}$ (equilibrium constant) & $\exp (-4.35369+4593.17 / T)$ & - \\
\hline$K_{3}$ (equilibrium constant) & $\exp (25.225-21825.28 / T)$ & - \\
\hline$K_{C O}($ adsorption constant) & $8.339 \times 10^{-5} \exp (70650 /(R T))$ & $\mathrm{atm}^{-1}$ \\
\hline$K_{H 2 O}($ adsorption constant) & $6.209 \times 10^{-9} \exp (82900 /(R T))$ & $\mathrm{atm}^{-1}$ \\
\hline$K_{\mathrm{CH} 4}($ adsorption constant) & $6.738 \times 10^{-4} \exp (38280 /(R T))$ & $\mathrm{atm}^{-1}$ \\
\hline$K_{H 2 O}($ adsorption constant) & $1.770 \times 10^{-5} \exp (-88680 /(R T))$ & - \\
\hline
\end{tabular}
(Tottrup 1982, Xu and Froment 1989).

Table 7. Kinetic parameters used in the SR model. From Tottrup (1982) and Xu and Froment (1989) 
The model was verified against results published by Nah and Palanky (2009) on hydrogen production via steam reforming of $n$-heptane. The conditions for verification were $T_{w}=1200 \mathrm{~K}, \mathrm{~S}: \mathrm{C}=1: 1$ and $1 \mathrm{~atm}$. The mass flowrate for steam reforming was set to $0.075 \mathrm{~g} / \mathrm{s}$ of $\mathrm{n}$-heptane. The geometric characteristics of the model were the same as the model $\mathrm{D}_{\mathrm{i}}=1$ ", $\mathrm{D}_{\mathrm{o}}=1-3 / 4$ ". With a defined geometry and flowrate values, the value for $R e$ was calculated in order to obtain proper values for convective heat transfer coefficient inside the pipe, $h_{i}$. Assuming that the reformer pipe is made of steel (steel alloy with chromium content $\mathrm{Cr} \approx 1 \%$ ), the global heat transfer coefficient was calculated, $U=45 \mathrm{~W} / \mathrm{m}^{2} \mathrm{~K}$. Based on that information the model built in Matlab-Cantera was run and results are presented in Figure 26 and Figure 27. The molar flowrate for hydrogen and the reformed gas temperature are presented and compared with results from Nah and Palanky (2009). The molar flowrate calculation provides information about the minimum residence time, $\tau$, required for full fuel reforming. Residence time is define here as

$$
\tau=L / u
$$

Equation 87

where $L$ is defined as the length and $u$ is the gas velocity.

It can be appreciated in Figure 26 that at the tested mass flowrate for reformed gases, process completeness is achieved around $L=0.18 \mathrm{~m}$ or $\tau=0.3 \mathrm{~s}$. The behavior of the reformed gas temperature $\mathrm{T}_{\mathrm{RG}}$ is presented in Figure 27. The temperature at the boundary condition $\mathrm{z}=0$ was set at $700 \mathrm{~K}$. The temperature increases before the reforming reaction takes place. The large drop in RG temperature is due to the occurrence of endothermic reactions associated with reforming reactions for $\mathrm{H}_{2}$ yield. Once nheptane started being consumed and the energy is absorbed in the process, the heat provided by the jacket $\left(\mathrm{T}_{\mathrm{w}}\right)$ increases the gas temperature. Differences between the model results and the results published by Nah and Palanky (2009) come mostly from differences in the catalyst bed configuration and its convective heat transfer mode. While Nah and Palanky's work was based on catalyst pellets, the model used in this research work was developed considering a straight passage as depicted in the experimental section on steam reforming. 


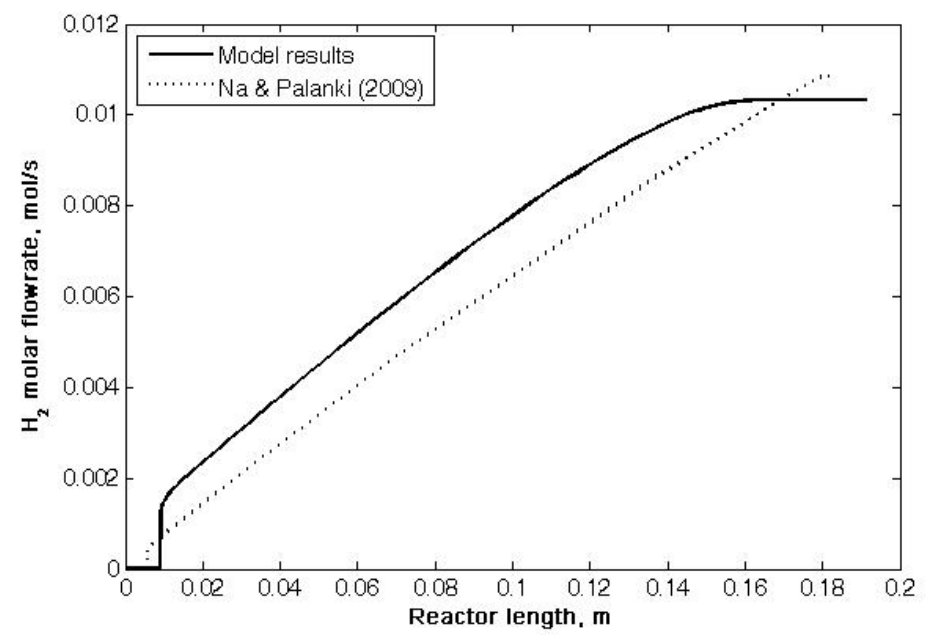

Figure 26. Calculated molar flowrate for $\mathrm{H}_{2}$ corresponding to $S R$ of $n$-heptane compared with results from (Nah and Palanki 2009). $S: C=1: 1, P=1$ atm and $T_{w}=1200 \mathrm{~K}$

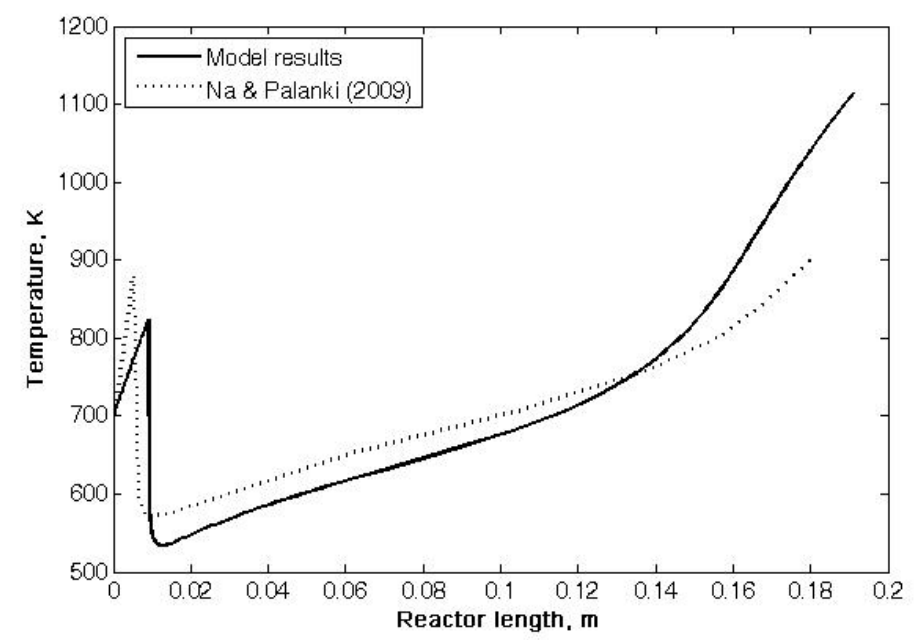

Figure 27. Calculated temperature profile for the SR of n-heptane compared with results from (Nah and Palanki 2009). $S: C=1: 1, P=1$ atm and $T_{w}=1200 \mathrm{~K}$

\subsection{Experimental Set-Up for Steam-Heptane Reforming}

Based on specifications provided by WVU, Gas Technology Institute (GTI) designed and built a steam reformer for $n$-heptane. The reformer was tested in order to estimate the reforming rate and process efficiency for non-catalytic and catalyzed reforming. Figure 28 shows a schematic of the bench-scale system that was designed and integrated with the TCR for conducting the laboratory tests. The system implemented a natural gas-fired furnace equipped with a radiant U-tube burner. The burner was used as a high temperature exhaust gas energy source. A pre-heater was installed to compensate for heat losses in 
the n-heptane/steam line. Both recuperators (preheater and reformer) are bayonet-style heat exchangers, with five heat exchange tubes. Each of the five tubes contains interior elements for heat exchange purposes. Catalytic pieces were strung on a stainless steel rod, and five rods were installed into the reformer heat exchange tubes. Nickel-potassium catalyst on ceramic substrate was used in the tests. The pipe connecting the pre-heater and reformer was heat taped and insulated. The thermostatically controlled heat tapes were used to reduce heat losses in the pipes.

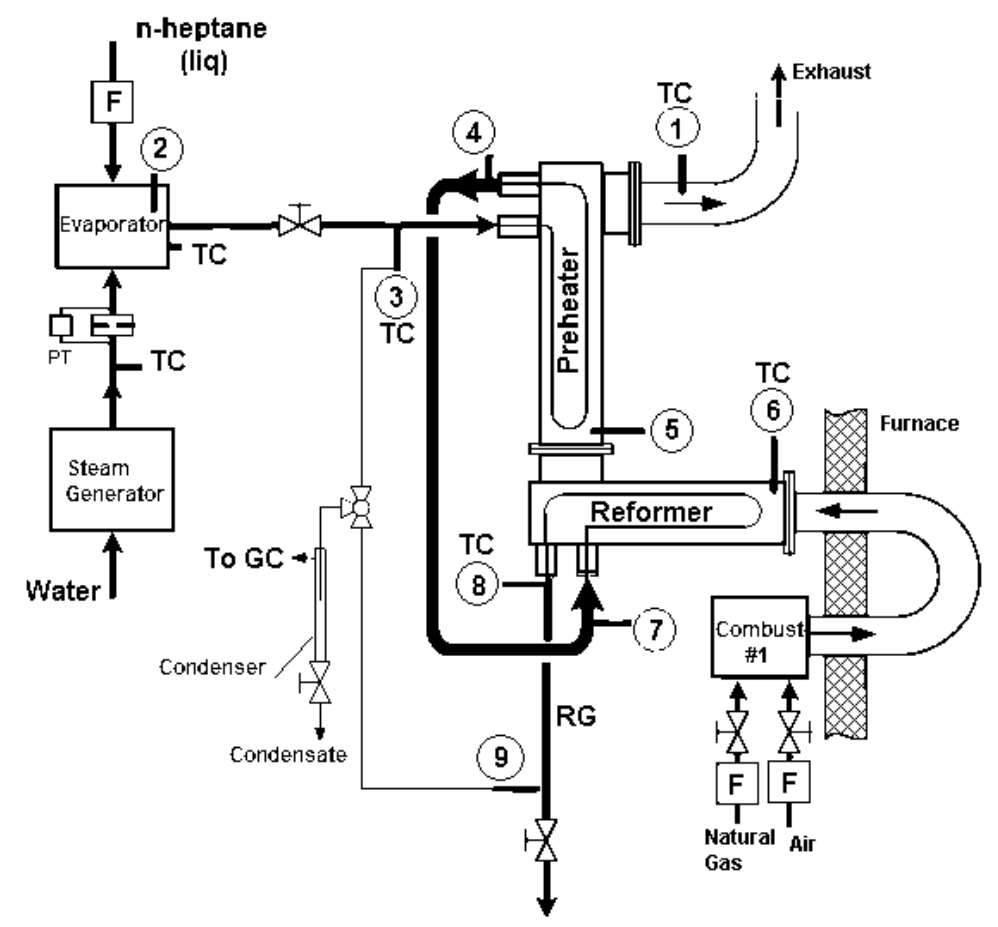

Figure 28. Experimental Setup for Steam -Heptane Reforming. TC: Thermocouple, F: flowmeter

Heptane is mixed with superheated steam at $\sim 1.3 \mathrm{~atm}$ and $400 \mathrm{~K}$ in the evaporator. The steam and fuel mixture, at a predefined molar ratio $(\mathrm{S}: \mathrm{C})$, enters the preheater where it increases its temperature without reaching fuel reforming conditions. The steam and fuel mixture reaches the reformer where the catalyst promotes the reforming of n-heptane. Fuel gas samples were taken from the reformer inlet and outlet through sample ports \#3 and \#9 respectively (Figure 28). Gas samples were passed through a specially designed water-cooled condenser to extract unprocessed water and heptane vapors. All collected hydrocarbons were assumed to be heptane. Fuel gas analysis was done using Varian CP 4900 gas chromatograph (GC). At least two samples were taken for each test. GC was calibrated to measure the following components: $\mathrm{H}_{2}, \mathrm{CH}_{4}, \mathrm{CO}, \mathrm{CO}_{2}, \mathrm{C}_{2} \mathrm{H}_{4}, \mathrm{C}_{2} \mathrm{H}_{6}, \mathrm{C}_{3} \mathrm{H}_{8}$, iso- $\mathrm{C}_{4} \mathrm{H}_{10}, \mathrm{n}-\mathrm{C}_{4} \mathrm{H}_{10}$, and $\mathrm{C}_{2} \mathrm{H}_{2}$.

Measured temperatures were in the following ranges. The exhaust gas temperature at the preheater outlet $T 1$ was $610 \mathrm{~K}-840 \mathrm{~K}$, the steam/n-heptane mixture temperature at the preheater inlet $T 3$ was $358 \mathrm{~K}$ $372 \mathrm{~K}$, the exhaust gas temperature at the reformer inlet $T 6$ was $646 \mathrm{~K}-795 \mathrm{~K}$, and the reformed fuel 
temperature at the reformer outlet $T 8$ was $628 \mathrm{~K}-693 \mathrm{~K}$. The steam flow rate was varied from 0.563 to $0.631 \mathrm{~g} / \mathrm{s}$. At these flow rates, the S:C molar ratio varied from 2 to 2.1. Experimental data for RG composition are presented in Table 8 . These data were used to tune a steam-reforming model that was applied to the integrated HCCI-TCR model.

Table 8. Steam reforming experimental results $S: C \sim 2: 1$

\begin{tabular}{|c|c|c|c|c|c|c|c|c|}
\hline $\begin{array}{l}\text { Steam } \\
\text { flow } \\
\tau\end{array}$ & $\begin{array}{l}\mathrm{kg} / \mathrm{s} \\
\mathrm{s}\end{array}$ & $\begin{array}{l}0.000593 \\
6.43\end{array}$ & $\begin{array}{l}0.000606 \\
6.21\end{array}$ & $\begin{array}{l}0.000606 \\
8.01\end{array}$ & $\begin{array}{l}0.000606 \\
9.63\end{array}$ & $\begin{array}{l}0.000631 \\
8.7\end{array}$ & $\begin{array}{l}0.000619 \\
4.86\end{array}$ & 0.000593 \\
\hline$T 5$ & & 629 & 741 & 667 & 670 & 635 & 795 & 852 \\
\hline T6 & & 648 & 743 & 681 & 691 & 646 & 795 & 853 \\
\hline$T 7$ & $\kappa$ & 628 & 623 & 593 & 581 & 568 & 653 & 688 \\
\hline$T 8$ & & 633 & 628 & 599 & 586 & 573 & 659 & 693 \\
\hline$T_{\text {ref }}$ & & 630 & 625 & 596 & 584 & 570 & 656 & 690 \\
\hline$H 2$ & & 0.3225 & 0.3147 & 0.1351 & 0.0171 & 0.0983 & 0.3854 & 0.4664 \\
\hline $\mathrm{CH} 4$ & & 0.0171 & 0.0282 & 0.0079 & 0.0001 & 0.0028 & 0.0279 & 0.0322 \\
\hline$C O$ & & 0.0112 & 0.0505 & 0.0074 & 0.0003 & 0.0050 & 0.0875 & 0.1272 \\
\hline $\mathrm{CO} 2$ & & 0.0986 & 0.0782 & 0.0418 & 0.0055 & 0.0307 & 0.0782 & 0.0791 \\
\hline $\mathrm{C} 2 \mathrm{H} 4$ & & 0.0001 & 0.0001 & 0.0000 & 0.0000 & 0.0000 & 0.0003 & 0.0009 \\
\hline $\mathrm{C} 2 \mathrm{H} 6$ & Molar & 0.0000 & 0.0000 & 0.0000 & 0.0001 & 0.0001 & 0.0013 & 0.0002 \\
\hline С $3 \mathrm{H} 8$ & fraction & 0.0003 & 0.0000 & 0.0000 & 0.0000 & 0.0000 & 0.0000 & 0.0006 \\
\hline$i-C 4 H 10$ & & 0.0000 & 0.0000 & 0.0000 & 0.0000 & 0.0000 & 0.0000 & 0.0019 \\
\hline$n-C 4 H 10$ & & 0.0000 & 0.0000 & 0.0000 & 0.0000 & 0.0000 & 0.0000 & 0.0027 \\
\hline $\mathrm{C} 2 \mathrm{H} 2$ & & 0.0000 & 0.0003 & 0.0000 & 0.0000 & 0.0000 & 0.0012 & 0.0030 \\
\hline $\mathrm{H} 2 \mathrm{O}$ & & 0.5161 & 0.5049 & 0.7518 & 0.9138 & 0.7968 & 0.4120 & 0.2828 \\
\hline $\mathrm{C} 7 \mathrm{H} 16$ & & 0.0340 & 0.0230 & 0.0560 & 0.0630 & 0.0663 & 0.0060 & 0.0030 \\
\hline
\end{tabular}

Figure 29 shows the main components of the reformed fuel composition (measured wet) for a steam/carbon molar ratio around 2:1 with catalyst and pressure $1 \mathrm{~atm}$.. There was up to $47 \% \mathrm{H}_{2}$ and $13 \%$ $\mathrm{CO}$ (by volume, wet) in the reformed fuel at a relatively low reforming temperature $(\approx 700 \mathrm{~K})$. The focus of this research work is to study the effects of the main reformed gases into the HCCI combustion of nheptane. The species $\mathrm{C}_{2} \mathrm{H}_{4}, \mathrm{C}_{2} \mathrm{H}_{6}, \mathrm{C}_{3} \mathrm{H}_{8}, \mathrm{i}-\mathrm{C}_{4} \mathrm{H}_{10}, \mathrm{n}-\mathrm{C}_{4} \mathrm{H}_{10}$ and $\mathrm{C}_{2} \mathrm{H}_{2}$, which appeared at the higher temperature range, are considered as minor species and were not included along the study for two reasons. First, the minor species are highly dependent on the catalyst selection and the catalyst used was not optimized for minimizing those minor species, and second, the effect of those minor species would require proper validation which is out of the scope of this research work. 


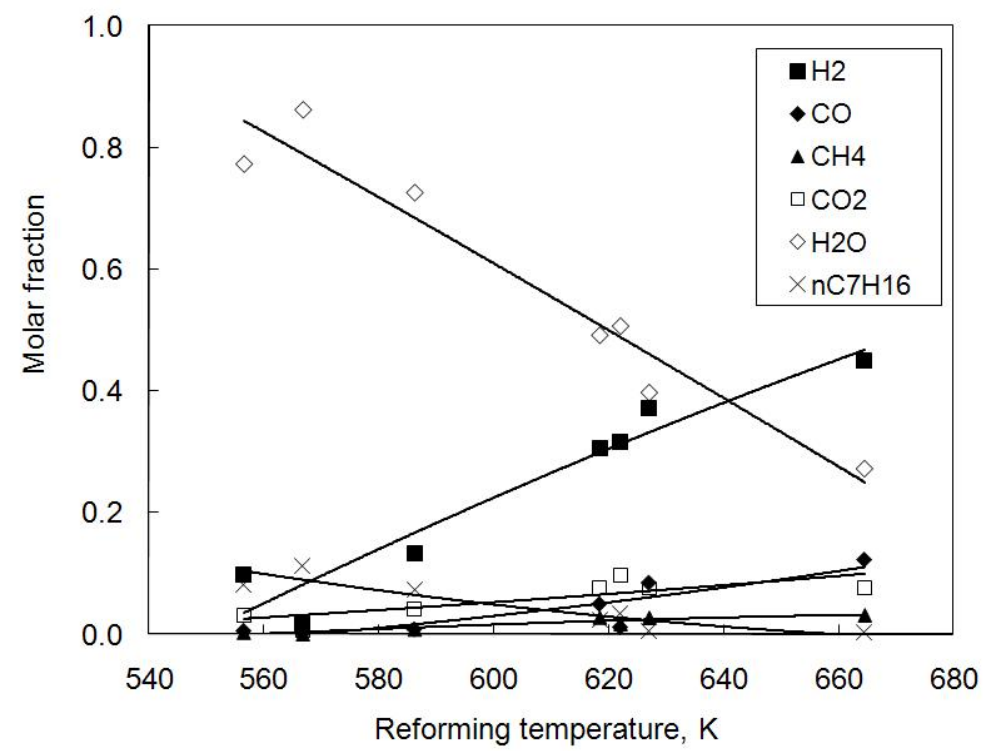

Figure 29. Experimental reformed gas composition for different reforming temperatures. $S: C \approx 2: 1, P=1 \mathrm{~atm}$.

The experimental RG composition results were compared against results from equilibrium calculations. The set of species considered in the equilibrium model were $\mathrm{C}_{7} \mathrm{H}_{16}, \mathrm{H}_{2} \mathrm{O}, \mathrm{H}_{2}, \mathrm{CO}$. The initial molar values corresponding to $\mathrm{S}: \mathrm{C}=2: 1$ were $\mathrm{n}_{\mathrm{C} 7 \mathrm{H} 16}=1$ and $\mathrm{n}_{\mathrm{H} 2 \mathrm{O}}=14$ and the pressure was held constant. Figure 30 presents the species equilibrium composition for this set of species at 1atm and experimental results for $\mathrm{H}_{2}$ and CO. High levels of $\mathrm{H}_{2}(28 \%-51.7 \%)$ and $\mathrm{CO}(13 \%-24 \%)$ content in the reformed fuel were calculated at relatively low reforming temperature $(550 \mathrm{~K}-700 \mathrm{~K})$.

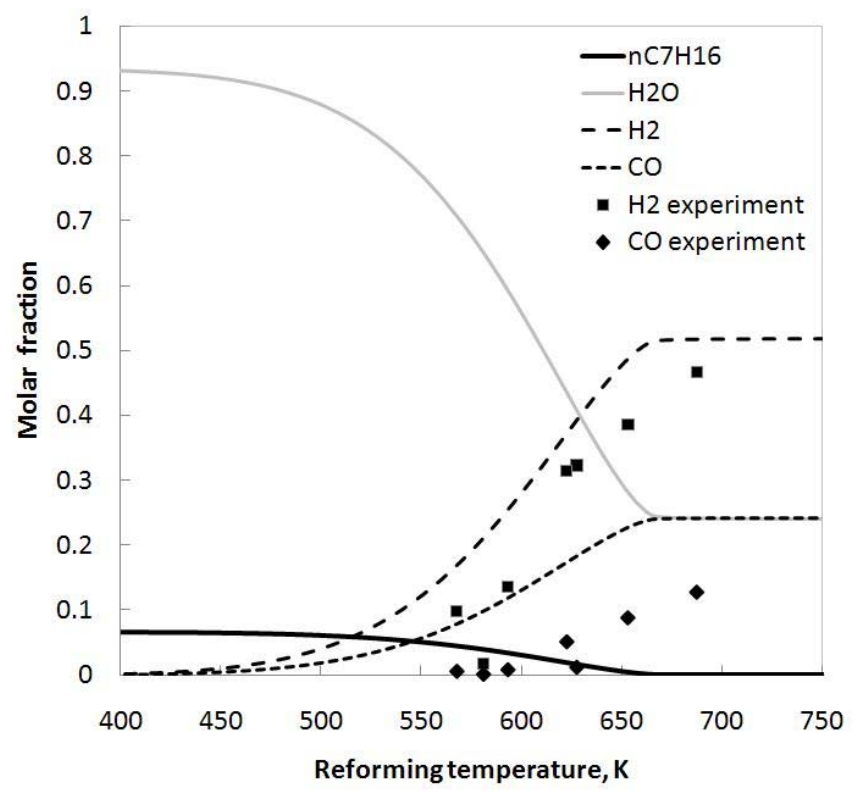

Figure 30. Species composition under equilibrium conditions for steam reforming of n-heptane compared to experimental data. $S: C=2: 1$, Pressure $=1$ atm 
A maximum of $51.7 \%$ of $\mathrm{H}_{2}$ yield was obtained at $676 \mathrm{~K}$, when the n-heptane was totally consumed and the amount of water reached the minimum equilibrium concentration. According to the literature, the steam reforming of $n$-heptane also involves the production of $\mathrm{CH}_{4}$ and $\mathrm{CO}_{2}$ due to water-gas shift reaction and methanation reactions (Christensen 1996, Chen et al. 2003). If $\mathrm{CH}_{4}$ is included into the set of species for equilibrium calculations the equilibrium results show that all the n-heptane is transformed into $\mathrm{CH}_{4}$ with no intermediate species. The experiments carried out show that the methanation process was not as strong as predicted in literature and that some amount of n-heptane was available at each reforming temperature tested. The experiment shows that the molar fraction of $\mathrm{CO}_{2}$ at the $\mathrm{SR}$ outlet was higher than $\mathrm{CO}$ when the residence time was longer than $4.9 \mathrm{~s}$.

The equilibrium model was also tested with $\mathrm{CO}_{2}$ as one of the species. In that case the prediction for $\mathrm{H}_{2}$ was very poor, but the prediction for $\mathrm{CO}$ and $\mathrm{CO}_{2}$ improved respect to the model containing only $\mathrm{nC}_{7} \mathrm{H}_{16}, \mathrm{H}_{2} \mathrm{O}, \mathrm{H}_{2}$ and $\mathrm{CO}$. Because the effect of $\mathrm{H}_{2}$ over the combustion of hydrocarbons has proven more significant than that from $\mathrm{CO}$, the ideal case composition in the model was based on the equilibrium composition defined by the following four species: $\mathrm{nC}_{7} \mathrm{H}_{16}, \mathrm{H}_{2} \mathrm{O}, \mathrm{H}_{2}$ and $\mathrm{CO}$.

Measured n-heptane conversion and calculated conversion based on equilibrium composition are shown in Figure 31 as a function of reforming temperature. According to the model, $90 \%$ conversion of $\mathrm{n}$-heptane occurs at reforming temperatures higher than $650 \mathrm{~K}$. Values obtained from experimental results show a similar trend, with $\mathrm{n}$-heptane conversions higher than $91 \%$ at $\mathrm{T}_{\text {ref }}=658 \mathrm{~K}$.

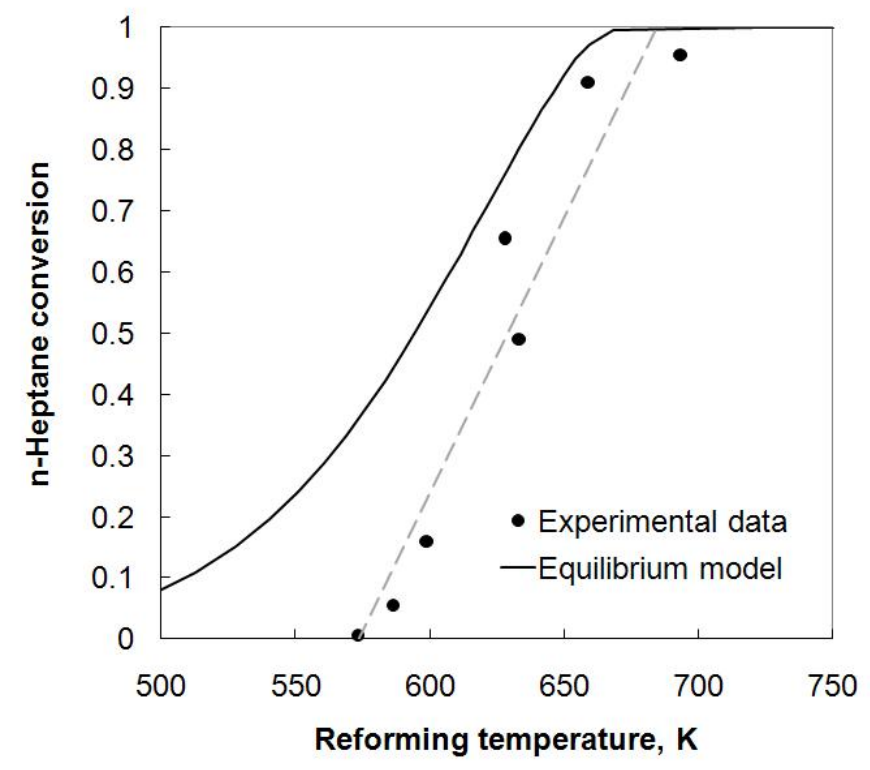

Figure 31. $n$-Heptane conversion compared to equilibrium values. $S: C=2: 1, P=1$ atm 
Summarizing, the equilibrium model allows for estimating the RG composition based on an ideal scenario, where the model inputs are reforming temperature, pressure and initial steam and n-heptane molar ratio (S:C), and the output is the equilibrium composition of $\mathrm{nC}_{7} \mathrm{H}_{16}, \mathrm{H}_{2} \mathrm{O}, \mathrm{H}_{2}$ and $\mathrm{CO}$.

The reforming temperature for the equilibrium model corresponds to a single value, which is not the case in experiments, where the temperature changes along the reactor. In the case of a reactor with a profile of temperature along its axis, the reforming temperature might be defined as the average temperature between inlet and outlet port of RG (T7 and T8 in Figure 28) or only the outlet port temperature T8. Moreover, for the application in question, i.e. the TCR, it would be desirable to associate the reforming temperature to the exhaust temperature, which was represented by the jacket temperature $\mathrm{T}_{\mathrm{w}}$ in the PFTR model (Equation 77). The equilibrium model by itself is incapable of providing any relationship with the exhaust gas temperature and flow that can be used to obtain the energy required for the SR process to occur. Therefore, the PFTR model is introduced here and a relationship between the exhaust temperature at steady state and the reforming process temperature is developed.

Figure 32 shows the temperature profile calculated along the PFTR model. In that case a uniform jacket temperature was used. Applying an energy balance to a differential area element $d A=\pi p d z$ in the reformed gas and the exhaust gases, where $p$ is reformer perimeter, the temperature profile can be obtained,

$$
\frac{d T_{w}(z)}{d z}=\frac{U d A}{\dot{m}_{\text {exh }} c_{p_{\text {exh }}}}\left(T_{w}(z)-T_{R G}\right)
$$

Equation 88

where the overall heat transfer coefficient $U$ is assumed constant for sake of simplicity. It is evident that the reforming gases changes along $\mathrm{z}$, so an artifice is done by integrating Equation 88 for small sections of length $z^{\prime}$, where $\mathrm{T}_{\mathrm{SR}}$ is assumed constant at the beginning of the small section $\mathrm{z}^{\prime}$. The solution is then,

$$
T_{w}\left(z^{\prime}\right)=T_{R G}-\left(T_{R G}-T_{w_{0}}\right) \exp \left(-\frac{U \pi D\left(z^{\prime}-z_{0}^{\prime}\right)}{C P_{\text {exh }}}\right)
$$

Equation 89

where $T w_{0}$ corresponds to wall the jacket temperature at the beginning of the $z^{\prime}$ section, $z_{0}^{\prime}{ }_{0} C P_{e x h}$ corresponds to the product of exhaust mass flowrate and its specific heat, $\dot{m}_{e x h} c_{p_{\text {exh }}}$.

Figure 32 shows the temperature for the reforming gases and the exhaust gases. The model results presented here correspond to low exhaust gas flow $(900 \mathrm{rpm})$ and a range of exhaust temperature from $600 \mathrm{~K}$ up to $750 \mathrm{~K}$. The reforming flowrate correspond to $10 \% \mathrm{RG}$ by volume and its temperature is 373 $\mathrm{K}$ which is the evaporation temperature of $\mathrm{n}$-heptane at $1 \mathrm{~atm}$. The flowrate for $10 \% \mathrm{RG}$ is calculated assuming a $10 \%$ of fuel into the engine is extracted for reforming. The amount of fuel into the engine is defined by the equivalence ratio, which in this exercise was assumed as $\phi=0.35$. Under these conditions 
the mass flowrate for exhaust gases was $\dot{m}_{\text {exh }}=6 \mathrm{~g} / \mathrm{s}$ and for reformed gas was $\dot{m}_{R G}=0.031 \mathrm{~g} / \mathrm{s}$. The specific heat of exhaust and reformed gases was $c p_{e x h}=1.1 \mathrm{~kJ} / \mathrm{kg}-\mathrm{K}$ and $c p_{R G}=2.5$ on average, respectively. After examination of the heat capacity rates for both streams, $C_{e x h}=\dot{m}_{e x h} c_{p_{e x h}}$ and $C_{R G}=\dot{m}_{R G} c_{p_{R G}}$, it can be observed that the large ratio of heat capacities, $C_{e x h} / C_{R G} \approx 85$, favors a low temperature reduction for the exhaust gas stream due to its relative large mass flowrate compared to the flowrate of the reformed gases.

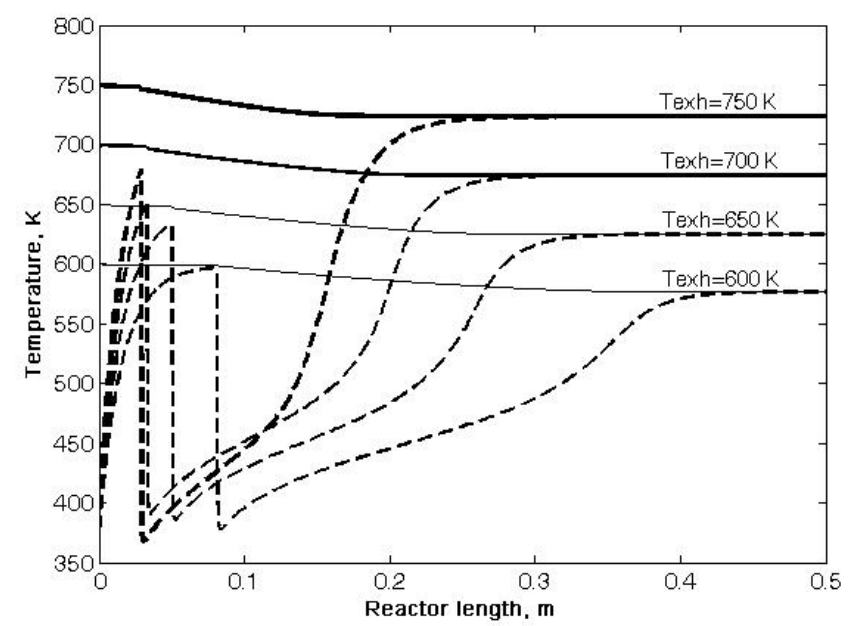

Figure 32. Calculated exhaust temperature (continuous line) and reformed gas temperature profile inside the PFTR (dashed line) for different conditions of exhaust temperature (600 K-750 K). Reformed gas conditions at $L=0$ are $T=373 \mathrm{~K}, P=1$ atm and $S: C=1: 1$.

Summarizing, the PFTR model is able to provide a relationship between the steady state value of exhaust gases temperature, which model was explained in the previous section, and the steam reforming model.

\subsection{Steam -Reforming Energy Requirements}

The concept of thermo-chemical recuperation is based on the premise that the energy in the exhaust gases can be converted into chemical energy, storing that energy into a higher heat content fuel and using that fuel in the combustion process. The energy required for TCR was accounted for by studying the energy consumed in the steam reforming process and in the generation of the steam-fuel mixture before the SR. 
The energy consumed in the steam reforming process was obtained from a first law analysis of the SR system. Figure 33 shows the reformer and the steam-fuel evaporation system.

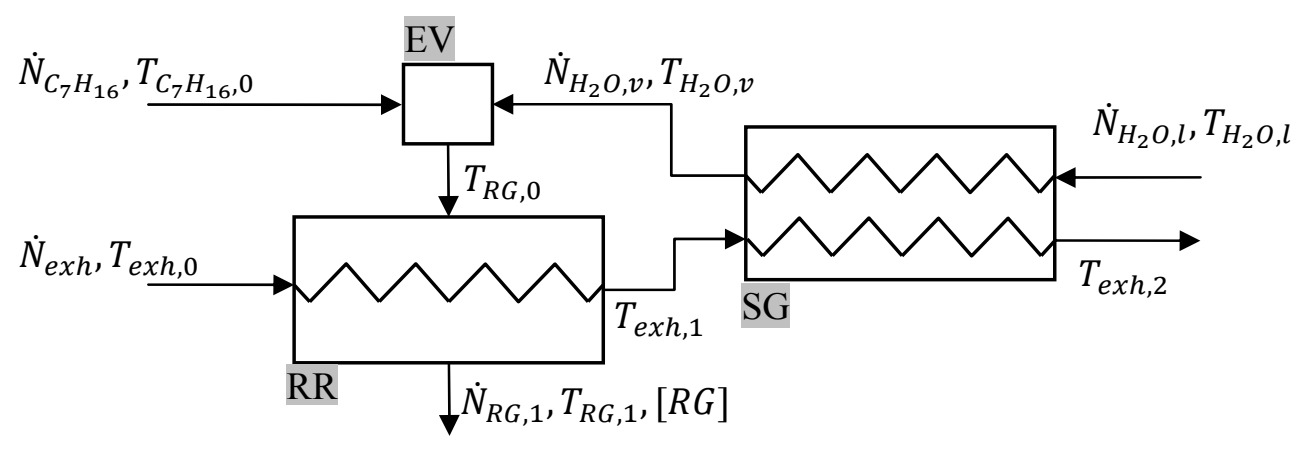

Figure 33. Section of the HCCI-TCR system showing the Recuperative Reformer (RR), the steam generator (SG) and the evaporator (EV)

The rate of energy required by the steam-reforming process to proceed can be calculated as,

$$
\frac{d Q_{S R}}{d t}=\dot{N}_{R G, 1} \hat{h}_{R G, 1}-\dot{N}_{R G, 0} \hat{h}_{R G, 0}
$$

Equation 90

where the subindex $R G, 1$ represents the conditions at the RR outlet port, defined by temperature, $T_{R G}$, and concentration $[R G]$, which is function of reforming temperature following the steam-reforming model. The subindex $R G, 0$ represents conditions at the inlet of the $\mathrm{RR}$, which is a mixture of steam and superheated $n$-heptane at temperature $T_{R G, 0}$. The value of $T_{R G, 0}$ depends on the partial pressure of steam and n-heptane such that both are at superheated conditions. The partial pressures of each one depends on the molar fractions defined by the $\mathrm{S}: \mathrm{C}$ ratio, and assuming that the reforming process pressure is $1 \mathrm{~atm}$, the partial pressures for both, n-heptane and steam are,

$$
\begin{gathered}
p_{C_{7} H_{16}}=\frac{1}{7(S: C)+1} \cdot 1 \mathrm{~atm} \\
p_{\mathrm{H}_{2} \mathrm{O}}=\frac{7(S: C)}{7(S: C)+1} \cdot 1 \mathrm{~atm}
\end{gathered}
$$

Equation 91

Equation 92

The corresponding saturation temperatures for both n-heptane and water were obtained from the NIST chemistry WebBook (Lemmon et al. 2010) and programmed into the Matlab-Cantera model for evaporation. As an example, at $\mathrm{S}: \mathrm{C}=1: 1$, the partial saturation temperatures of $\mathrm{n}$-heptane and water, at $\mathrm{P}=1 \mathrm{~atm}$, are $314.6 \mathrm{~K}$ and $361.7 \mathrm{~K}$, respectively; at $\mathrm{S}: \mathrm{C}=2$ the values of $\mathrm{T}_{\text {sat }}$ are $300.2 \mathrm{~K}$ and $363.6 \mathrm{~K}$. Thus, assuming that the temperature of $n$-heptane and water are fed at $T_{o}=300 \mathrm{~K}$, the steam produced by the steam generator (SG) should reach a temperature high enough to completely evaporate the flow of n- 
heptane into the RR. It is obvious that n-heptane present in the evaporator is in the superheated state at the water saturation temperature. Assuming also that the pressure along the fuel and vapor lines is atmospheric, the energy required by the steam generator (and evaporator) was calculated as,

$$
\frac{d Q_{S G}}{d t}=\dot{N}_{H 2 O}\left[\hat{h}_{H 2 O}\left(T_{H 2 O, v}\right)-\hat{h}_{H 2 O}\left(T_{H 2 O, l}\right)\right]
$$

Equation 93

where molar flowrate of water is defined by molar flowrate of fuel and the S:C ratio. The value of $T_{H 2 O, v}$ can be obtained from an energy balance in the evaporator by,

$$
\dot{N}_{R G} \hat{h}_{R G}\left(T_{R G, o}\right)=\dot{N}_{C 7 H 16} \hat{h}_{C 7 H 16}\left(T_{C 7 H 16,0}\right)+\dot{N}_{H 2 O} \hat{h}_{H 2 O}\left(T_{H 2 O, v}\right)
$$

Equation 94

and the left hand side of the previous equation can be expanded as,

$$
\dot{N}_{R G} \hat{h}_{R G}\left(T_{R G, O}\right)=\dot{N}_{C 7 H 16} \hat{h}_{C 7 H 16}\left(T_{R G, 0}\right)+\dot{N}_{H 2 O} \hat{h}_{H 2 O}\left(T_{R G, 0}\right)
$$

Equation 95

The value of $d Q_{S G} / d t$ depends on the temperature $T_{R G, 0}$. The minimum value acceptable for $T_{R G, 0}$ is the water saturation temperature corresponding to the partial pressure of water, $p_{H 2 O}$. As was presented before, the saturation temperature for $\mathrm{S}: \mathrm{C}=1: 1$ and $\mathrm{S}: \mathrm{C}=2: 1$ are $361.7 \mathrm{~K}$ and $363.6 \mathrm{~K}$ respectively. For sake of simplicity, the temperature at $\mathrm{RG}_{0}$ was set as $T_{R G, 0}=365.0 \mathrm{~K}$. It is evident that in a real application this temperature should be higher, accounting for heat losses along the pipes that take the mixture of $n$ heptane and steam to the RR inlet.

Just after the exhaust manifold, and assuming no heat loses, the exhaust condition $T_{\text {exh,l }}$ defines the enthalpy available for the recuperative process and the steam generation. During each step in the process of thermo-chemical recuperation some of the exhaust enthalpy, which otherwise would be wasted, is transferred to the reformed gases.

Let us introduce here two concepts relevant to the TCR. First, the fraction of enthalpy from the exhaust gases that is recovered in the recuperative reformer $\left(f_{H_{R R}}\right)$ and the fraction of enthalpy from the exhaust gases that is recovered in the whole TCR system $\left(f_{H C R}\right)$, at $T_{e x h, 1}\left(H_{e x h, 1}\right)$ and at $T_{e x h, 2}\left(H_{e x h, 2}\right)$ respectively, is calculated with respect to the enthalpy at $T_{\text {exh }, 0}\left(H_{\text {exh,0 }}\right)$ as,

$$
\begin{aligned}
& f_{H_{R R}}=\left(H_{e x h, 0}-H_{e x h, 1}\right) / H_{e x h, 0} \\
& f_{H_{T C R}}=\left(H_{e x h, 0}-H_{e x h, 2}\right) / H_{e x h, 0}
\end{aligned}
$$

Equation 96

Equation 97 
Second, the TCR thermal efficiency is introduced here as the ratio of the increase in LHV of the reformed gases with respect to the energy recovered from the exhaust gases' enthalpy.

$$
\eta_{T C R}=\frac{\dot{N}_{R G} L H V_{R G}-\dot{N}_{\text {fuel }} L H V_{\text {fuel }}}{H_{\text {exh }, 0}-H_{\text {exh }, 2}}
$$

Equation 98

Where the total enthalpies correspond to exhaust molar flowrate times the respective specific enthalpies at $T_{e x h, 0}$ and $T_{e x h, 2}$. The numerator corresponds to the difference LHV of the RG gas mixture, and the n-heptane LHV.

Figure 34a shows the fraction of energy (enthalpy) that was recovered from the exhaust gases and into the reformed gases for two different conditions of steam carbon ratio, $S: C$, and fraction of reformed fuel, $\alpha$. Figure 34b shows the thermal efficiency of reforming as defined by Equation 72 for all cases shown in Figure 34a. Exhaust temperature and reforming temperature are assumed equal. Recall that $\alpha$ is the fraction of heptane fed into the reformer to total heptane into the system.
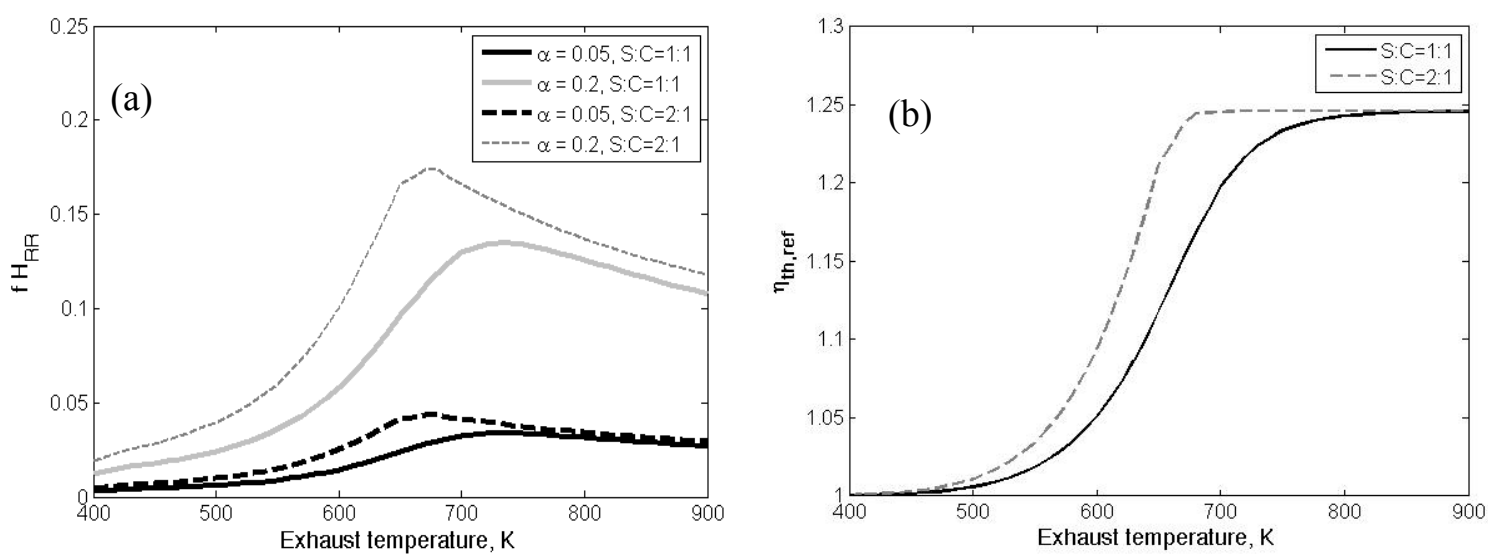

Figure 34. Fraction of waste energy in the exhaust gases recuperated by fuel reforming (a), and the fuel reforming thermal efficiency (b). Results presented here are for the model engine running at $\phi=0.35$ and 1200 rpm, assuming $\boldsymbol{T}_{\text {ref }}=\boldsymbol{T}_{\text {exh }}$.

The model results presented in Figure 34a show that energy is recovered from the exhaust gases. A maximum of exhaust heat recuperation is achieved below the reforming temperature where the $\mathrm{H}_{2}$ yield has reached its equilibrium maximum and the heptane conversion has ceased, $833 \mathrm{~K}$ and $719 \mathrm{~K}$ for $\mathrm{S}: \mathrm{C}=1: 1$ and $\mathrm{S}: \mathrm{C}=2: 1$, respectively. It is also clear that a higher fraction of fuel into the reformer, $\alpha$, requires higher amounts of water and the recuperation of waste exhaust energy is higher. Comparing $\alpha$ values for each case of $\mathrm{S}: \mathrm{C}$ show that the peak of exhaust heat recovery occurs at the same exhaust temperature. The effect of S:C show that more steam into RR recuperates more heat from the exhaust stream to accomplish the fuel reforming process. It should be noticed that the peak value for exhaust heat 
recuperation is shifted to lower exhaust temperatures when $\mathrm{S}: \mathrm{C}$ is increased, as the gas mixture specific heat changes according to its reforming composition.

Figure $34 \mathrm{~b}$ provides some insight into the reason for the shift in peak values of exhaust heat recuperation under different $\mathrm{S}: \mathrm{C}$ values. The fuel reforming thermal efficiency is defined as the ratio of lower heating values between reformed gas (RG) and the base fuel n-heptane. Higher reforming temperatures produce higher $\mathrm{H}_{2}$ yield and therefore the LHV of the RG increases with $\mathrm{T}_{\text {ref }}$ respect to the base fuel. The increase in S:C provides additional sources of $\mathrm{H}_{2}$, increasing the value of $\eta_{\text {th,eff }}$ at constant $T_{\text {ref. }}$ Therefore, the shift in temperature where peak fraction $f_{H R R}$ occurs at different $S: C$ values is related with the effect that $\mathrm{S}: \mathrm{C}$ has in $\mathrm{RG}$ composition. Additional $\mathrm{S}: \mathrm{C}$ reduces the reforming temperature where the energy recuperated from the exhaust gases is transformed into RG chemical energy. In summary, for temperatures below the peak, the energy provided by the exhaust gases is used in reforming the fuel via endothermic reactions; for reforming temperatures above the peak, the energy provided by the exhaust gases is consumed increasing the temperature of RG at the RR outlet, and does not increase the LHV of the RG.

Figure 35a shows the fraction of energy (enthalpy) that was recuperated from the exhaust gases and used in the whole TCR process, including fuel reforming and steam generation. Figure 35a presents the TCR thermal efficiency. Exhaust temperature and reforming temperature are assumed equal. The results correspond to the mass flowrates of the model engine at $\phi=0.35$ and $1200 \mathrm{rpm}$.
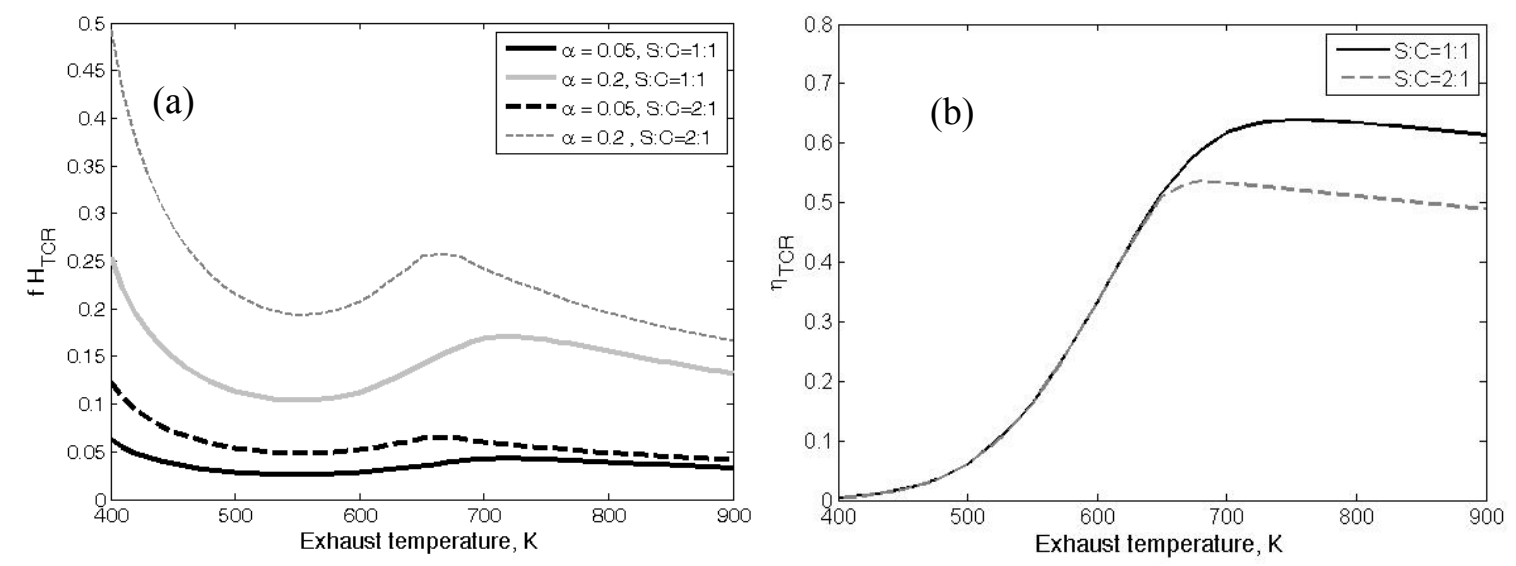

Figure 35. Fraction of waste energy in the exhaust gases recuperated by the whole TCR system (a), and TCR thermal efficiency (b). Results are for the model engine running at $\phi=0.35$ and $1200 \mathrm{rpm}$.

The results presented in Figure 35a show a significant fraction of exhaust heat recuperated in the whole TCR system. The results suggest that before the exhaust energy recuperated for reforming becomes significant, it is used principally in the steam generator. Higher values of $S: C$ require higher fractions of 
the exhaust enthalpy. At increased reforming temperature, the recuperated exhaust heat is used in the steam generation process and also for endothermic reforming reactions. The occurrence of peak value for recuperation beyond certain reforming temperature suggest that at that exhaust temperature the fuel reforming process reaches its maximum efficiency, as explained previously. Comparing peak values for $f_{H_{T C R}}$ and $f_{H_{R R}}$, the difference is based on the use of exhaust heat to produce the required vapor.

The TCR thermal efficiency results presented in Figure $35 \mathrm{~b}$ describes the fraction of chemical energy (LHV) that is added to the base fuel for each unit of energy recuperated in the TCR. The value of $\eta_{\text {TCR }}$ reaches a maximum at the same reforming temperature where the fuel reforming thermal efficiency $\left(\eta_{\text {th.eff }}\right)$ reaches its maximum. Increasing the exhaust temperature does not increases the LHV gained in the process, which remains equal, but increases the exhaust enthalpy, causing the $\eta_{\mathrm{TCR}}$ to reduce.

At its peak value the TCR thermal efficiency reaches $52 \%$ and $63 \%$ at $\mathrm{S}: \mathrm{C}=1: 1$ and $\mathrm{S}: \mathrm{C}=2: 1$, respectively. This implies that a fraction of the heat recuperated in the exhaust gases is available as chemical energy for the HCCI engine. The remaining fraction is consumed in increasing the temperature of the RG mixture of gases and generating steam. 


\section{Chapter 5. HCCI-TCR Modeling}

In previous chapters the models corresponding to the HCCI engine and the reformer where developed. In this section a system model, integrating both engine and reformer model is developed. The integrated model allows for analyzing the effects of reformed fuel on the HCCI model engine, while at the same time, predicts the RG composition based on the exhaust heat temperature and flowrate from the HCCI model engine. The first step to develop the integrated model was to study the effect of RG on HCCI combustion of $n$-heptane. The study was conducted on a model based on an engine used to obtain the experimental data for validation. The study included the effects of $\mathrm{RG}\left(\mathrm{H}_{2}\right.$ and $\left.\mathrm{CO}\right)$ on HCCI combustion of n-heptane.

Once the effect of RG on HCCI combustion was well understood, the integrated model was developed to investigate the HCCI-TCR system. The set of conditions defined by system equivalence ratio, engine speed and fraction of fuel to reformer was varied to numerically evaluate the integrated HCCI - TCR system model aiming to identify the operational range for suitable HCCI combustion and evaluate the TCR performance.

The HCCI engine performance was evaluated based on IMEP values at constant speed, with limits defined by ringing and misfiring conditions. The performance of the TCR, which is function of the HCCI engine exhaust gas temperature, was evaluated based on $\mathrm{H}_{2}$ yield and fuel conversion. In cases where the exhaust gases waste heat is not enough to drive the fuel reforming process, the additional fuel required was evaluated and accounted for in total engine energy input.

\subsection{Effect of RG on HCCI combustion of n-Heptane}

The ability of the HCCI model and the chemical kinetics mechanism to predict the behavior of HCCI combustion of $n$-heptane under the effects of reformed gases was studied in this section. The experimental data used to validate the model was obtained from Dr. Vahid Hosseini from NRC Canada, who studied the effects of $\mathrm{H}_{2}$ and $\mathrm{CO}$ on HCCI combustion of n-heptane. In that experiment a synthetic blend of $\mathrm{H}_{2}$ and $\mathrm{CO}$ at a molar ratio $\mathrm{H}_{2}: \mathrm{CO}=3: 1$ was used. This molar ratio represents the highest yield of steam-fuel reforming assuming that no excess water is used and the $\mathrm{H}_{2}$ yield is enhanced with the WGSR. 
The amount of reformed gas into the cylinder is defined by RG. RG was defined by Hosseini and Checkel (2007-b) and that definition is also used in this research work:

$$
R G=\frac{\dot{m}_{R G}}{\dot{m}_{R G}+\dot{m}_{f u e l}}
$$

Equation 99

RG was varied in the experiments from $0 \%$ up to $30 \%$. When the $R G$ fuel is included in the air-fuel calculation the equivalence ratio changes with RG addition. Therefore the equivalence ratio is redefined based on the atomic valence method following the approach suggested by Jain et al. (1981) for multispecies fuels,

$$
\varphi=\sum V^{+} / \sum \mid V^{-1}
$$

where $V^{+}$and $V$ represents the valence numbers of carbon (+4), hydrogen (+1), nitrogen $(0)$ and oxygen (-2). Table 9 presents the RG values, moles of species and equivalence ratio used for analyzing the effects of RG on HCCI combustion of n-heptane. These values correspond to values used experimentally and were used to validate the HCCI model and chemical kinetics mechanism.

Table 9. Intake molar composition at different values of $R G$

\begin{tabular}{ccccccccc}
\hline$R G$ & $C_{7} H_{16}$ & $\mathrm{O}_{2}$ & $N_{2}$ & $H_{2}$ & $C O$ & $\Sigma V^{+}$ & $2|V|$ & $\phi$ \\
$\%$ & $k m o l$ & $k m o l$ & $k m o l$ & $k m o l$ & $k m o l$ & - & - & - \\
\hline 0 & 1.00 & 41.86 & 157.38 & 0.00 & 0.00 & 44.00 & 167.42 & 0.26 \\
10 & 1.00 & 43.34 & 162.94 & 1.05 & 0.35 & 47.49 & 174.04 & 0.27 \\
20 & 1.00 & 50.63 & 190.39 & 2.23 & 0.74 & 51.43 & 204.03 & 0.25 \\
30 & 1.00 & 59.01 & 221.89 & 3.91 & 1.30 & 57.04 & 238.67 & 0.24 \\
\hline
\end{tabular}

Initial conditions defined by the species concentration of fuel, air and RG presented in Table 9 were used in the numerical MZ model to study the effects of RG on HCCI combustion of n-heptane. The experimental engine used was the CFR engine described in Table 2. Other conditions used were engine speed of $800 \mathrm{rpm}, \mathrm{CR}=11.5$ and intake conditions $\mathrm{P}_{\mathrm{int}}=144 \mathrm{kPa}$ and $\mathrm{T}_{\mathrm{int}}=110^{\circ} \mathrm{C}$. The effect of $\mathrm{RG}$ in the HCCI combustion of $n$-heptane is to delay the combustion onset as can be appreciated in Figure 36 . The model and kinetic mechanism correctly predicts the combustion onset change due to the effect of $\mathrm{H}_{2}$ and $\mathrm{CO}$ addition. It is evident that by increasing the amount of RG the combustion phasing is delayed, in agreement with experimental results. A better insight into the effects of RG addition can be obtained in Figure 37, which shows the rate of heat release from experimental results and the core zone heat release from model results, under the same conditions presented in Figure 36. The rate of heat release analysis shows clearly defined LTHR and HTHR stages and the effect of RG on both. 


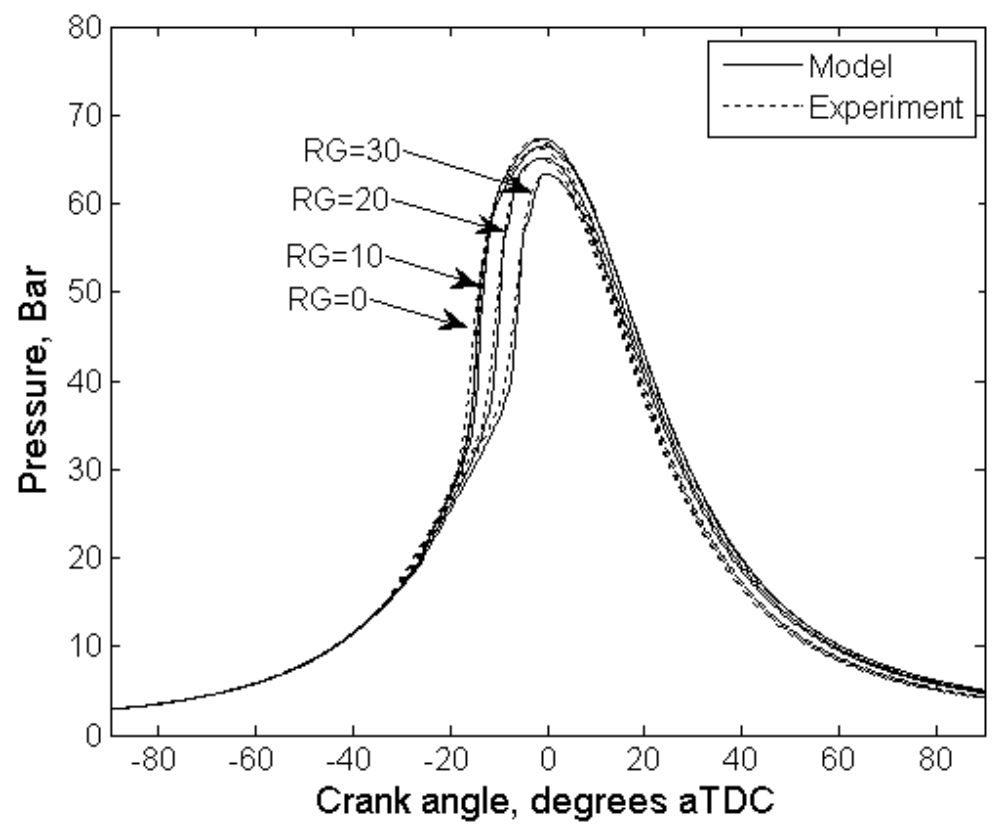

Figure 36. Experimental and MZ model calculated in-cylinder pressure history under RG effects $\left(\mathrm{H}_{2}: \mathrm{CO}=3: 1\right) . P_{\text {int }}=144 \mathrm{kPa}, \mathrm{T}_{\text {int }}=383 \mathrm{~K}, \mathrm{CR}=11.5, P_{\text {exh }}=104 \mathrm{kPa}, 800 \mathrm{rpm}, \phi-0.26 . \mathrm{RG}$ is presented as percentage

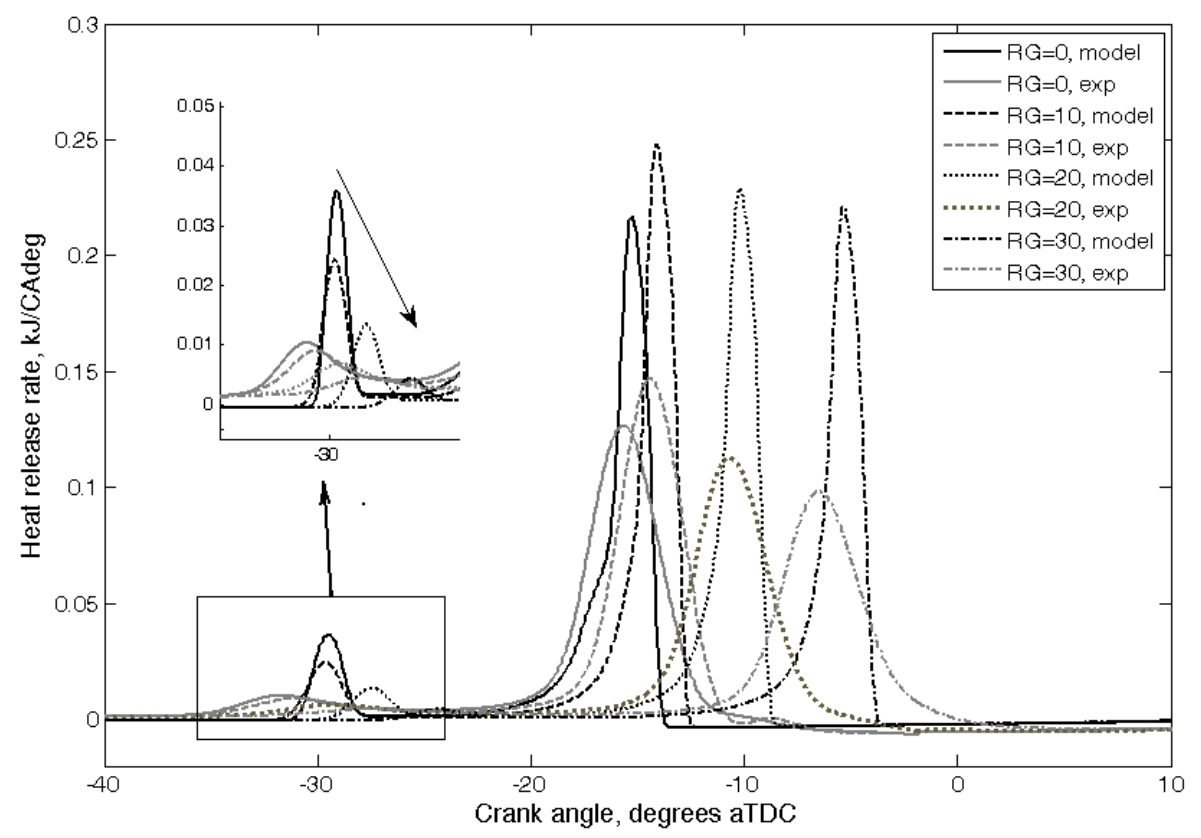

Figure 37. Experimental (gray) and core-zone calculated (black) rate of heat release under RG effects $\left(\mathrm{H}_{2}: \mathrm{CO}=3: 1\right) . P_{\text {int }}=144 \mathrm{kPa}, \mathrm{T}_{\text {int }}=383 \mathrm{~K}, \mathrm{CR}=11.5, P_{\text {exh }}=104 \mathrm{kPa}, 800 \mathrm{rpm}, \phi-0.26$. RG is presented as percentage 
It can be observed that at constant intake and engine operational conditions, the addition of RG delays and reduces the magnitude of the LTHR stage, as presented in the zoomed area, for both experimental and model results. The HTHR or main combustion event was delayed in proportion to the reduction on LTHR. Model results show that the kinetics mechanism is capable of predicting the LTHR with a few degrees of delay with respect of the experiments. Even though the model overshoots the rate of heat release values in all cases, the timing and the trend of the peak heat release correspond to experimental data.

Figure 38 shows calculated CA10 and CA50 values for experimental and model data. The ability of RG to affect both the LTHR and HTHR can be compared with the effect that changes on AF ratio has on the same parameters. AF ratio has a negligible effect on CA10 and a strong effect on CA50, as was presented in Figure 14. It can be inferred that the kinetic mechanism correctly predicts the main combustion event (CA50) within less than $2^{\circ} \mathrm{CA}$ difference with respect to the experimental data, but the low temperature combustion event presents $2-4^{\circ} \mathrm{CA}$ differences.
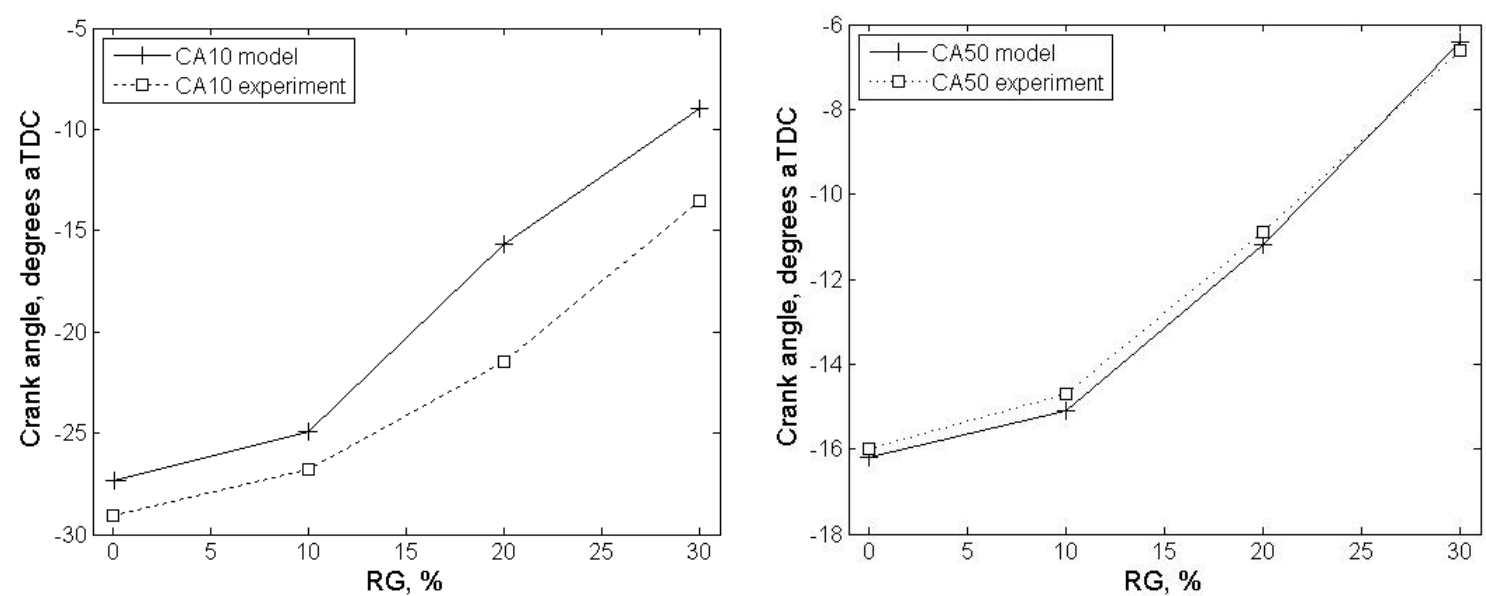

Figure 38. Effect of $R G$ addition on CA10 and CA50 calculated from model results and experimental data. $P_{\text {int }}=144 \mathrm{kPa}, T_{\text {int }}=383 \mathrm{~K}, \mathrm{CR}=11.5, P_{\text {exh }}=104 \mathrm{kPa}, 800 \mathrm{rpm}, \phi \sim 0.26$

The inhibiting effect on main ignition timing is attributed to the ability of RG to suppress LTHR reactions and can be observed in Figure 37, where the values of LTHR max $_{\text {w }}$ were reduced and delayed in direct proportion to RG. Values of heat released during the LTHR stage, indicated as $\mathrm{HR}_{\mathrm{L}}$, were integrated from $\mathrm{SOI}_{\mathrm{L}}$ up to $\mathrm{SOI}_{\mathrm{H}}$, as it was explained in the Combustion parameters description section (Figure 11). Figure 39 presents the relation between $\mathrm{HR}_{\mathrm{L}}$ normalized with respect to the total energy released (HR) and CA50 for both experimental and model data. The main ignition event was delayed at higher amounts of RG where the fraction of energy released during the LTHR regime was smaller. 


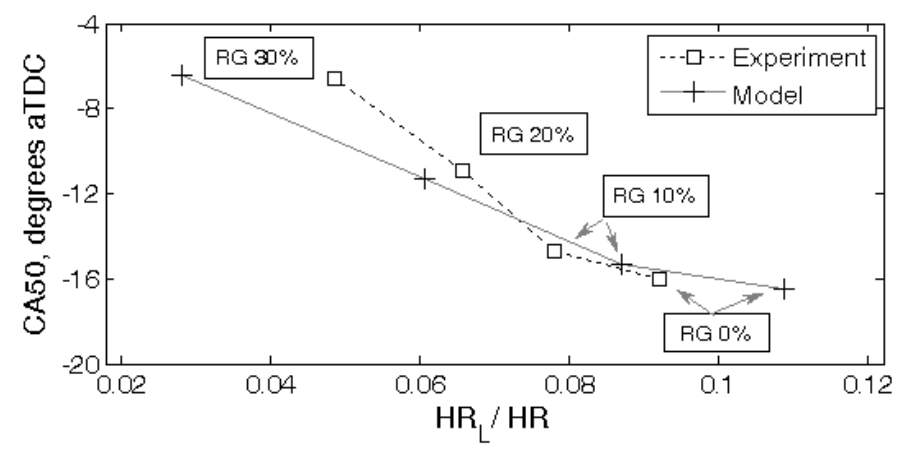

Figure 39. Relationship between $H R_{L}$ as a fraction of total heat release $H R$, and CA50 for different values of $R G\left(H_{2}: C O=3: 1\right) . P_{\text {int }}=144 \mathrm{kPa}, T_{\text {int }}=383 \mathrm{~K}, \mathrm{CR}=11.5, P_{\text {exh }}=104 \mathrm{kPa}, 800 \mathrm{rpm}, \phi-0.26$.

An insight into the effects of RG substitution on ignition temperature is revealed by Figure 40 . The LTHR start of ignition occurred at higher temperatures according to changes in the mixture specific heat and in-cylinder density due to the addition of RG. The synthetic composition did show high thermal effect (almost $0.7 \mathrm{~K}$ per \%RG). The change on $\mathrm{T}_{-} \mathrm{SOI}_{\mathrm{L}}$ was not as significant as the change occurred on the start of ignition for HTHR regime. The temperature at which high temperature reaction starts, or T_SOI , was reduced in proportion to RG, a clear evidence of kinetic effect derived from the presence of $\mathrm{H}_{2}$, which is explained below. Again, the strongest effect was produced by RG at the ideal case composition, where the $\mathrm{H}_{2}$ concentration was the highest, with a reduction of $1.725 \mathrm{~K}$ per $\%$ RG.
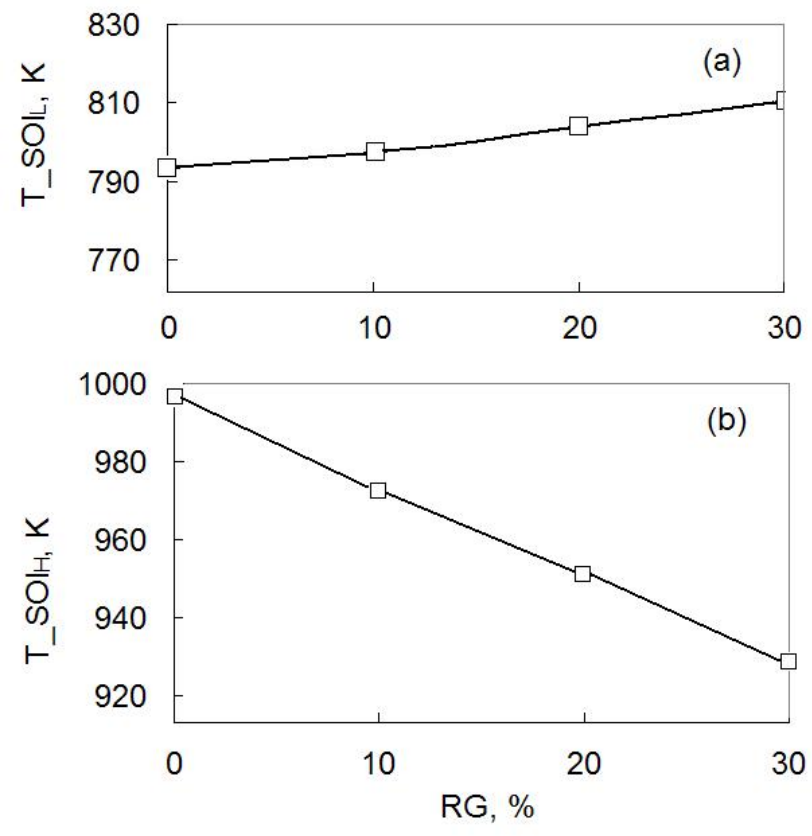

Figure 40. Computed start of ignition temperatures as a function of $R G$ at constant composition cases: (a) $T_{-} S O I_{L}$ at $L T H R$ regime and (b) $T_{-} S O I_{H}$ at $H T H R$ regime. $R G$ composition $H_{2}: C O=3: 1, P_{\text {int }}=144 \mathrm{kPa}, T_{\text {int }}=383$ $\mathrm{K}, \mathrm{CR}=11.5, P_{\text {exh }}=104 \mathrm{kPa}, 800 \mathrm{rpm}, \phi-0.26$ 
The effects on engine performance, defined by IMEP and RI are presented in Table 10, as well as calculated emissions of $\mathrm{NO}_{x}, \mathrm{CO}$ and HC. IMEP values obtained with the model are about $10 \%$ higher than experimental due to the pressure difference between model results and experiments during the expansion period, as seen in Figure 36. The trend of the model, however, is consistent with the experimentally obtained data. The calculated ringing index is about $20-30 \%$ higher than the experimental values, although the model calculated results follow the trend of experimental results. The results obtained with the MZ model on RI are larger than the experimental ones. This suggests the need for a larger number of zones, and to include BL regions that do not ignite to slow down the overall process, in a similar fashion as Aceves et al. (2000) proposed for their MZ model. The model and experimental results show that RG addition increases IMEP due to retarded CA50 values. The trend of the effect of RG on RI is non-linear, suggesting a positive correlation with fuel energy addition, which is larger in $\mathrm{RG}=0$ and $\mathrm{RG}=10 \%$. The dependence of RI on equivalence ratio was originally proposed by Eng (2002) in his work on HCCI ringing.

Table 10. Comparison of combustion and performance parameters between experimental values and MZ model calculated results at different $R G$ percentage values

\begin{tabular}{|c|c|c|c|c|c|}
\hline Parameter & & $R G=0$ & $R G=10 \%$ & $R G=20 \%$ & $R G=30 \%$ \\
\hline \multirow[t]{3}{*}{ CA10, CA deg. } & Experiment & -29.1 & -27.0 & -21.5 & -12.0 \\
\hline & Model & -26.6 & -24.9 & -17.7 & -11.0 \\
\hline & Error, CA deg. & 2.5 & 2.1 & 3.8 & 1.0 \\
\hline \multirow[t]{3}{*}{ CA50, CA deg. } & Experiment & -16.0 & -14.7 & -10.9 & -6.6 \\
\hline & Model & -16.5 & -15.3 & -11.3 & -6.4 \\
\hline & Error, $C A$ deg. & -0.5 & -0.6 & -0.4 & 0.2 \\
\hline \multirow[t]{3}{*}{$I M E P, k P A$} & Experiment & 233.27 & 252.28 & 248.83 & 252.96 \\
\hline & Model & 264.41 & 281.54 & 273.72 & 270.93 \\
\hline & Error, \% & 13.3 & 11.6 & 10.0 & 7.1 \\
\hline \multirow[t]{3}{*}{$R I, M W / m^{2}$} & Experiment & 0.99 & 1.28 & 0.92 & 0.73 \\
\hline & Model & 1.09 & 1.69 & 1.22 & 0.87 \\
\hline & Error, \% & 10.1 & 32.0 & 32.6 & 21.0 \\
\hline \multirow[t]{3}{*}{$N O_{x}, p p m$} & Experiment & 0.11 & 0.61 & 0.47 & 0.21 \\
\hline & Model & 0.11 & 0.51 & 0.35 & 0.13 \\
\hline & Error, \% & 0.0 & -16.4 & -25.5 & -38.1 \\
\hline \multirow[t]{3}{*}{ CO,ppm } & Experiment & 730 & 859 & 1188 & 1670 \\
\hline & Model & 750 & 833 & 992 & 1333 \\
\hline & Error, \% & 2.7 & -3.0 & -16.5 & -20.2 \\
\hline \multirow[t]{3}{*}{$H C, p p m$} & Experiment & 995 & 1027 & 1039 & 1029 \\
\hline & Model & 553 & 540 & 506 & 411 \\
\hline & Error, \% & -44.4 & -47.4 & -51.3 & -60.1 \\
\hline
\end{tabular}


From the results it can be observed that the $\mathrm{MZ}$ model is capable of predict $\mathrm{NO}_{\mathrm{x}}$ and $\mathrm{CO}$ values at zero RG addition. The addition of RG increases the error between measure and calculated values. The prediction trends for these two species follow the experimental values. In contrast, the HC predictions are well below the experimentally obtained values and the trend is the opposite of the experimental one. The ability of the MZ model to predict $\mathrm{HC}$ emission is very low, and therefore it is not used for calculating $\mathrm{HC}$ emissions in following sections.

\subsubsection{Individual Effects of $\mathrm{H}_{2}$ and $\mathrm{CO}$ addition}

In order to understand the ability of RG to reduce the LTHR magnitude and delay the ignition event, the independent effects of $\mathrm{H}_{2}$ and $\mathrm{CO}$ addition to the reactants mixture were also investigated. A numerical exercise was carried on in the single-zone model to study the independent effects of $\mathrm{H}_{2}$ and $\mathrm{CO}$ on the combustion process of $n$-heptane. Although no experimental data were available to study the effects of each species, the fact that the overall behavior of the model under addition of synthetic RG $\left(\mathrm{H}_{2}: \mathrm{CO}=3: 1\right)$ was consistent with the experimental data provides the basic support to investigate the reasons behind this behavior.

In this exercise a different set of engine conditions were used to differentiate it from previous validation analysis. Engine speed and load was selected as $1200 \mathrm{rpm}$ and intake conditions used in the closed-volume part of the single zone model were set at $\mathrm{T}_{\text {int }}=310 \mathrm{~K}$ and $\mathrm{P}_{\text {int }}=1$ atm. Figure 41 presents the in-cylinder temperature history performing a sweep of $\mathrm{H}_{2}$ composition (no $\mathrm{CO}$ or $\mathrm{H}_{2} \mathrm{O}$ added). For each case of $\mathrm{H}_{2}$ addition, the molar composition of n-heptane and air was kept at the baseline case $(\varphi=0.4)$. Two interesting characteristics were observed with the addition of $\mathrm{H}_{2}$. First, the replacement of fuel molecules by diatomic molecules leads to changes in the thermodynamic mixture properties such as the mixture specific heat, $c_{p}$, and the mixture specific heats ratio, $\gamma$. Such effect can be observed in the region a in Figure 41, where the temperature before the cool flame reaction region $(\mathrm{T}<780 \mathrm{~K})$ was higher at higher concentrations of $\mathrm{H}_{2}$. Second, despite the fact that pre-ignition temperature was higher at higher $\mathrm{H}_{2}$ content, CA50 was delayed in proportion to the amount of $\mathrm{H}_{2}$ added. This effect can only be explained

under chemical kinetic concepts as can be observed in the region $\mathbf{b}$ of Figure 41, where the LTHR process was proportionally delayed with $\mathrm{H}_{2}$ addition. 


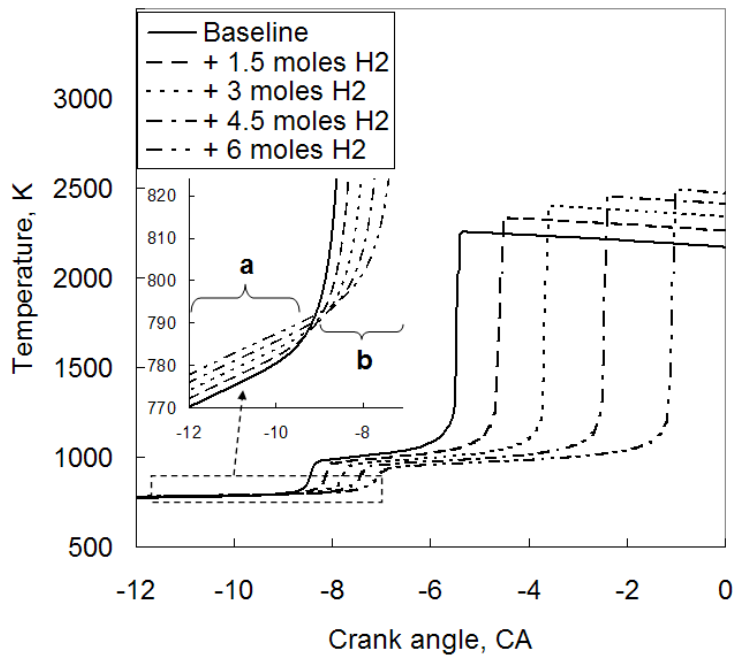

Figure 41. Temperature curves at different values of $\mathrm{H}_{2}$ addition (no $\mathrm{CO}$ or $\mathrm{H}_{2} \mathrm{O}$ ), Baseline $\varphi=0.4, T_{i n t}=310$ K, 1200 rpm

Figure 42 presents the in-cylinder temperature history performing a sweep of $\mathrm{CO}$ composition (no $\mathrm{H}_{2}$ or $\mathrm{H}_{2} \mathrm{O}$ added), where the number of $\mathrm{CO}$ moles added to the intake charge corresponded to molar values found in the RG mixture. For each case of $\mathrm{CO}$ addition, the molar composition of $\mathrm{n}$-heptane and air was kept at the baseline case $(\varphi=0.4)$. The addition of CO did encourage an earlier low temperature combustion regime, with a slight change in the onset of the main ignition event. The thermal effect of CO addition, expressed by changes in the mixture specific heat, was less than that of the effect produced by $\mathrm{H}_{2}$ addition, as can be observed in the amplified area in Figure 42.

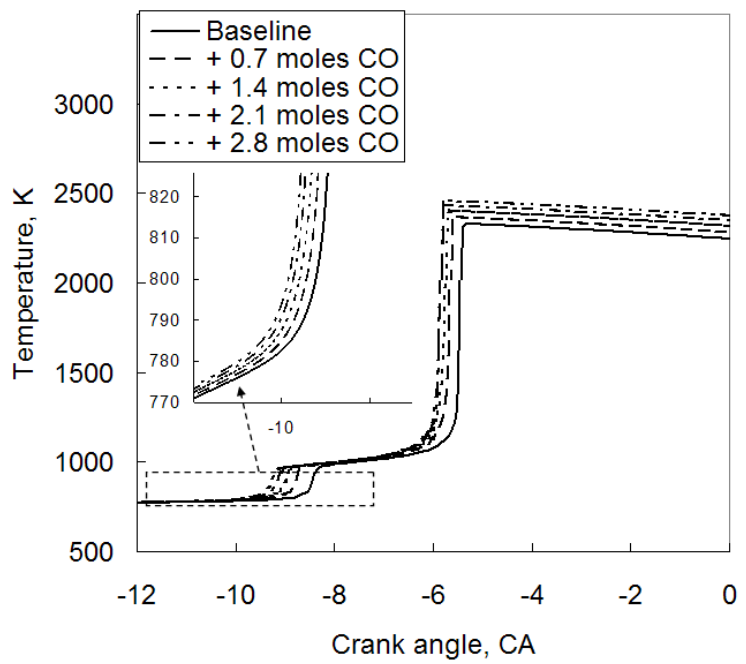

Figure 42. Temperature curves at different values of $\mathrm{CO}$ addition $\left(\right.$ no $\mathrm{H}_{2}$ or $\mathrm{H}_{2} \mathrm{O}$ ), Baseline $\varphi=0.4, T_{\text {int }}=310$ $\mathrm{K}, 1200 \mathrm{rpm}$

Fundamental studies of primary reference fuels (PRFs) have demonstrated that n-heptane has a clearly distinguishable two stage ignition. These are the cool flame region or LTHR with a negative 
temperature coefficient behavior, and the later main ignition stage or HTHR (Westbrook et al. 1988). Figure 43 shows the rate of heat release for $\mathrm{H}_{2}$ addition corresponding to Figure 41 . The two stage ignition process, LTHR and HTHR can be associated with fast changes in mixture temperature. The addition of $\mathrm{H}_{2}$ delayed the LTHR process proportionally. Any modification in the LTHR regime affects the behavior of the HTHR, as was previously acknowledged by Westbrook(2000). Numerical results show that the LTHR magnitude was reduced and that its occurrence was delayed by $1.3^{\circ} \mathrm{CA}$ at maximum $\mathrm{H}_{2}$ addition. The HTHR regime was then delayed from $-5.5^{\circ} \mathrm{CA}$ after TDC (baseline) to $-1.1^{\circ} \mathrm{CA}$ after TDC at the maximum $\mathrm{H}_{2}$ addition. It should be noted that SZ HCCI models generate shorter combustion duration with higher values of rate of heat release when compared to experimental results (Aceves et al. 1999).

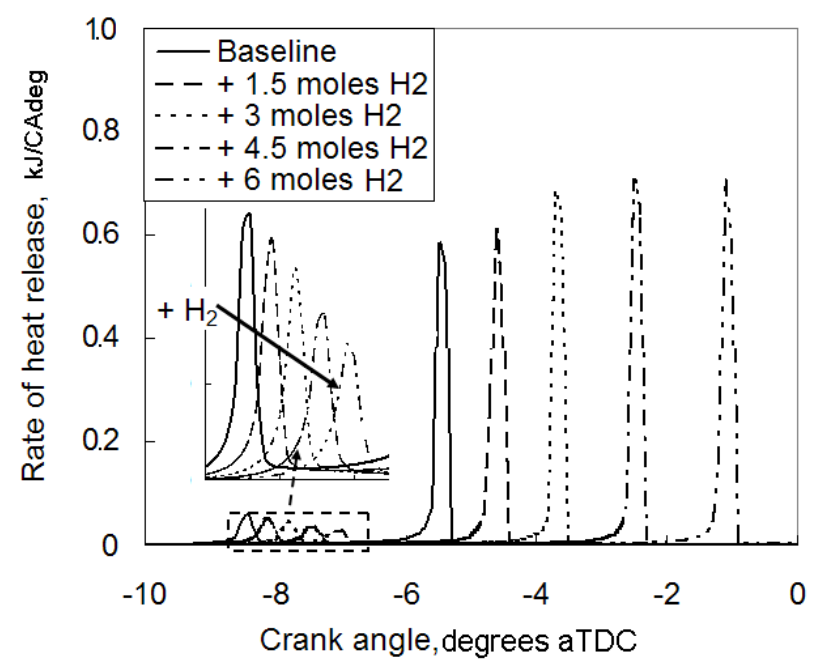

Figure 43. Rate of heat release for different values of $\mathrm{H}_{2}$ addition (no $\mathrm{CO}$ or $\mathrm{H}_{2} \mathrm{O}$ ), Baseline $\varphi=0.4, T_{\text {int }}=310$ $\mathrm{K}, 1200 \mathrm{rpm}$

The addition of $\mathrm{CO}$ produced the opposite effect on rate of heat release when compared to $\mathrm{H}_{2}$ addition. The numerical results are shown in Figure 44. In this case, the LTHR was advanced $1^{\circ} \mathrm{CA}$ at maximum CO concentration, inducing a HTHR stage slightly earlier than the baseline by $0.5^{\circ} \mathrm{CA}$. Figure 45 presents the effects of $\mathrm{H}_{2}$ and $\mathrm{CO}$ addition on the amount of energy released during the LTHR stage and its correlation with $\mathrm{CA} 50$. Values of $\mathrm{HR}_{\mathrm{L}}$ were normalized with respect to the total energy released (HR). For $\mathrm{H}_{2}$ addition, $\mathrm{HR}_{\mathrm{L}}$ is reduced as the concentration of $\mathrm{H}_{2}$ is increased, and the correlation between $\mathrm{HR}_{\mathrm{L}}$ and CA50 is remarkably linear. In contrast, the addition of $\mathrm{CO}$ shows no significant impact on the main ignition event, and a non-linear relationship exists between the amount of CO added and the fraction of $\mathrm{HR}_{\mathrm{L}}$. 


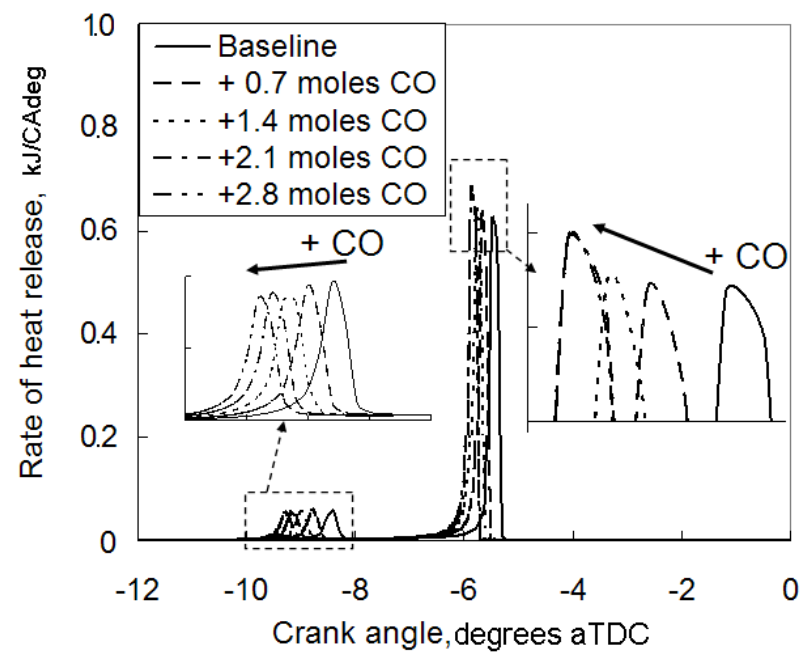

Figure 44. Rate of heat release for different values of $\mathrm{CO}$ addition (no $\mathrm{H}_{2}$ or $\mathrm{H}_{2} \mathrm{O}$ ), Baseline $\varphi=0.4, T_{i n t}=310$ $\mathrm{K}, 1200 \mathrm{rpm}$

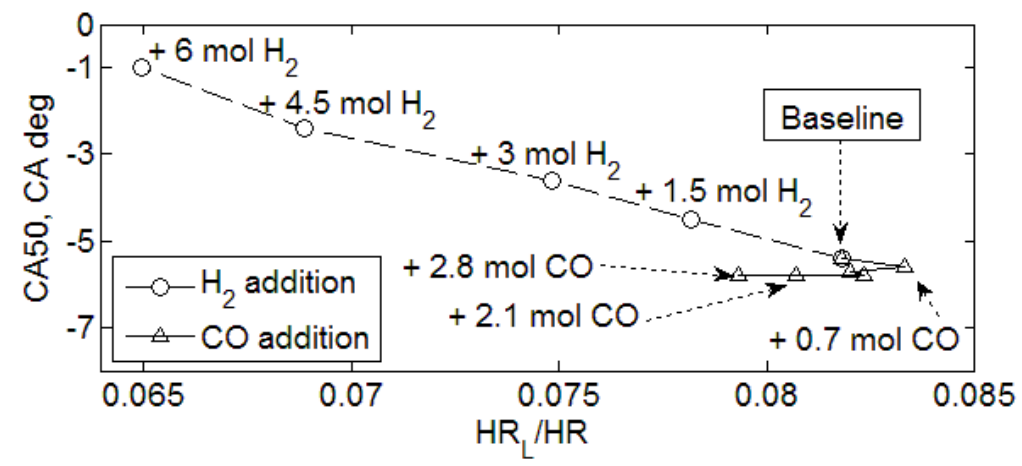

Figure 45. Relation between $H R_{L}$ as a fraction of total heat release $H R$, and the main ignition event timing, CA50, for different values of $\mathrm{H}_{2}$ and $\mathrm{CO}$ addition $\left(\right.$ no $\left.\mathrm{H}_{2} \mathrm{O}\right)$, Baseline $\varphi=0.4, T_{\text {int }}=310 \mathrm{~K}, 1200 \mathrm{rpm}$

The low temperature combustion regime characteristic of n-heptane and the effect of $\mathrm{H}_{2}$ and $\mathrm{CO}$ addition on this phenomenon can be appreciated better in Figure 46, where the rate of change of temperature is plotted against the mixture temperature. Section (a) on Figure 46 shows the rate of temperature change with $\mathrm{H}_{2}$ addition. For the baseline case $(\varphi=0.4)$, the LTHR regime was clearly present along the temperature range from $800 \mathrm{~K}$ to $850 \mathrm{~K}$, where the ignition is controlled by degenerative chain branching processes (Westbrook 2000). As explained by Warnatz et al. (1999), the $\mathrm{RO}_{2}$ radicals that are produced during this period decompose back to the reactants due to their instability manifested at high temperatures. The radical decomposition then leads the mixture temperature to the NTC region, between 950 and $1000 \mathrm{~K}$, where the rate of change of temperature is reduced at higher values of temperature until the chain branching stops. A subsequent series of chain branching reactions in the intermediate temperature range ( $900 \mathrm{~K}-1000 \mathrm{~K}$ ) leads to the buildup of $\mathrm{H}_{2} \mathrm{O}_{2}$ concentration. The $\mathrm{H}_{2} \mathrm{O}_{2}$ role during the combustion process is to provide the source for $\mathrm{OH}$ radicals required at the main ignition event. The 
HTHR was then identified to occur at temperatures higher than $1000 \mathrm{~K}$, as predicted by kinetic theory on large hydrocarbon combustion (Westbrook 2000).

The addition of $\mathrm{H}_{2}$ (Figure 46a) reduced the rate of temperature rise, $d T / d C A$, during the low temperature reaction stage, and shifted the NTC zone to lower temperatures. As a consequence, the HTHR zone was also shifted towards lower temperature ranges when compared to the baseline mixture, as can be appreciated in Figure 43. CO addition, in contrast, did not show such an important influence during the LTHR regime, as can be seen in Figure 46b, where the NTZ zones suffered a slight reduction. Its strongest effect was noticeable during the HTHR regime, where the rate of change of temperature, an indicator of rate of heat release, was moved towards higher temperature ranges.

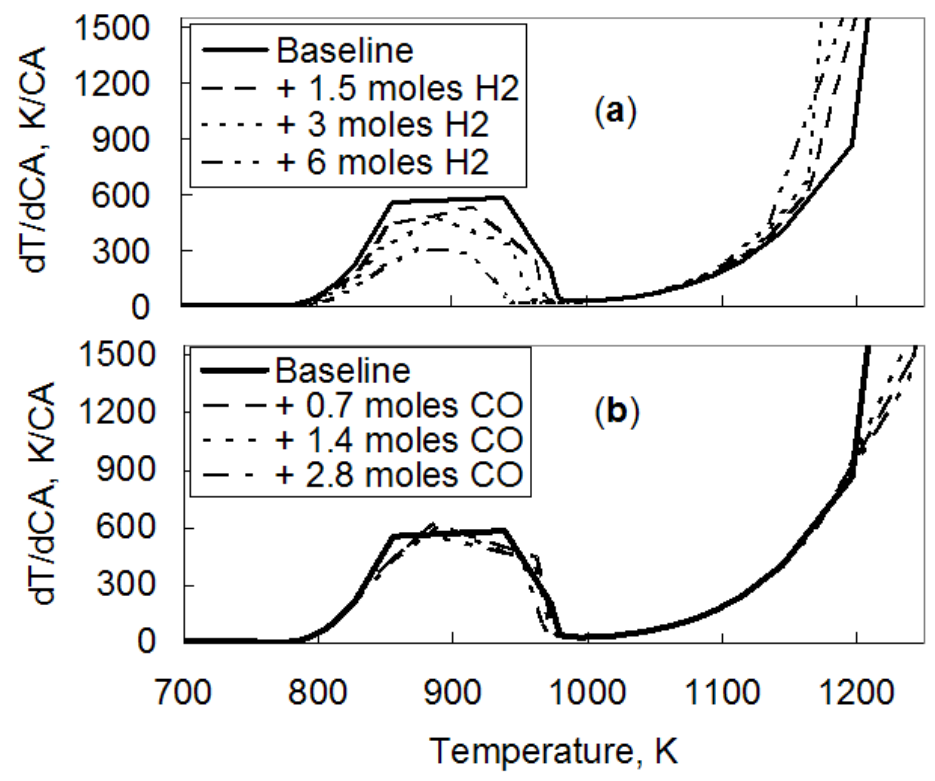

Figure 46. Rate of change of temperature along the temperature domain. (a) For different values of $\mathrm{H}_{2}$ addition (no CO, $\mathrm{H}_{2} \mathrm{O}$ ), (b) For different values of $\mathrm{CO}$ addition $\left(\right.$ no $\left.\mathrm{H}_{2}, \mathrm{H}_{2} \mathrm{O}\right)$. Baseline $\varphi=0.8, T_{I N T}=370 \mathrm{~K}, 1200$ rpm

The effect of modifying the low temperature reactions (cool flames) regime is to change the time at which $\mathrm{H}_{2} \mathrm{O}_{2}$ decomposition occurs, which is the key reaction for auto-ignition of hydrocarbons (Westbrook 2000). Numerical results show that ignition was observed when the mixture reached the $\mathrm{H}_{2} \mathrm{O}_{2}$ decomposition temperature, usually around $1100 \mathrm{~K}$. Even though the thermal effects of adding $\mathrm{H}_{2}$ tend to increase the temperature before the pre-ignition combustion regime, the ignition event was delayed. Figure 47 shows the effect of $\mathrm{H}_{2}$ and $\mathrm{CO}$ addition on $\mathrm{H}_{2} \mathrm{O}_{2}$ and $\mathrm{OH}$ molar fraction. 


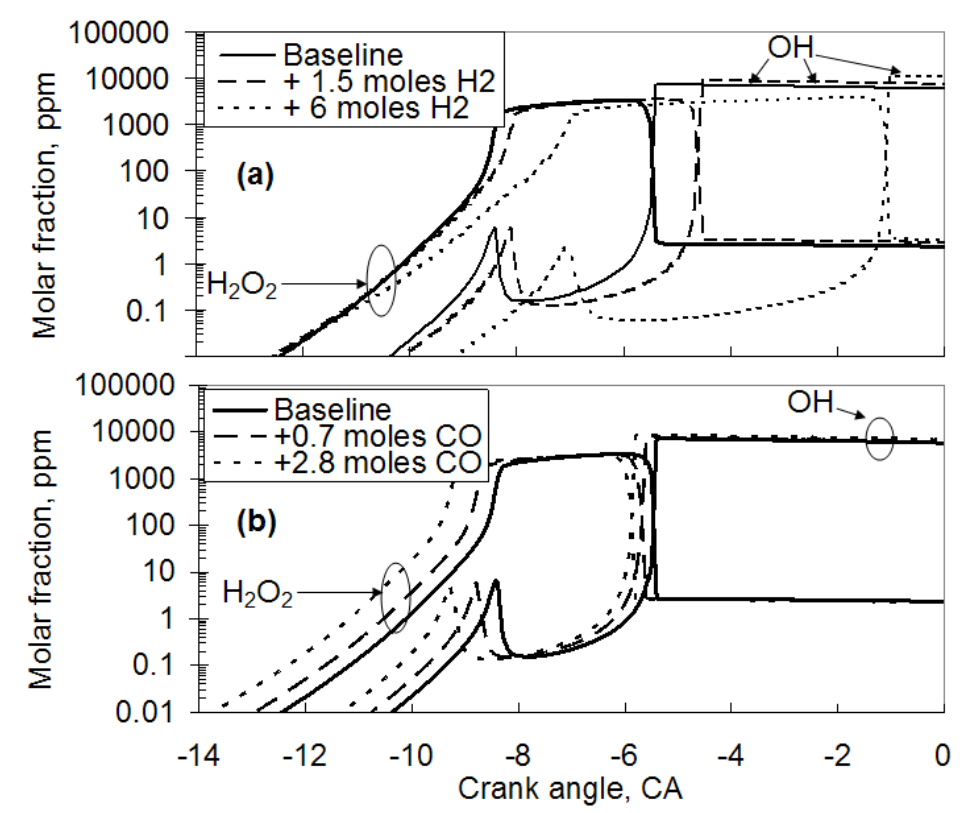

Figure 47. Computed molar fraction of $\mathrm{H}_{2} \mathrm{O}_{2}$ and $\mathrm{OH}$ for $\mathrm{H}_{2}$ addition (a) and for CO addition (b). Baseline $\varphi=0.4, T_{\text {intake }}=310 \mathrm{~K}, 1200 \mathrm{rpm}$

When the $\mathrm{H}_{2} \mathrm{O}_{2}$ molar fraction depicted in Figure 47 is compared to the rate of heat release for $\mathrm{H}_{2}$ and $\mathrm{CO}$ addition, Figure 43 and Figure 44 respectively, it can be observed that the main ignition event coincides with the $\mathrm{H}_{2} \mathrm{O}_{2}$ consumption. In Figure 43, at maximum $\mathrm{H}_{2}$ addition, the main ignition starts around $-1.1^{\circ} \mathrm{CA}$ after TDC, which corresponds to $\mathrm{H}_{2} \mathrm{O}_{2}$ depletion event in Figure 47a. Figure 44 shows that at maximum $\mathrm{CO}$ concentration the main ignition onset was started at $-5.9^{\circ} \mathrm{CA}$ after $\mathrm{TDC}, 0.5^{\circ} \mathrm{CA}$ earlier than the baseline ignition, which again corresponds to $\mathrm{H}_{2} \mathrm{O}_{2}$ depletion event in Figure $47 \mathrm{~b}$. The $\mathrm{H}_{2} \mathrm{O}_{2}$ buildup concentration process differs considerably in each case. For $\mathrm{CO}$ addition, the concentration trend of $\mathrm{H}_{2} \mathrm{O}_{2}$ was almost parallel for each case, suggesting a proportional change on species concentration due to changes on initial concentration of $\mathrm{CO}$. The addition of $\mathrm{H}_{2}$ changed the rate at which the $\mathrm{H}_{2} \mathrm{O}_{2}$ was generated, an indication of additional reactions involved during the cool flames regime. The spike on $\mathrm{OH}$ concentration was related with the LTHR period. The $\mathrm{OH}$ spike was retarded and reduced in magnitude in proportion to $\mathrm{H}_{2}$ addition, a feature that corresponded with the reduction on $\mathrm{HR}_{\mathrm{L}}$.

From this analysis, the separate effects of $\mathrm{H}_{2}$ and $\mathrm{CO}$ were clearly defined. The low temperature combustion regime was delayed by $\mathrm{H}_{2}$ addition and slightly advanced by $\mathrm{CO}$. As a result of the change of LTHR timing and magnitude, the HTHR regime was delayed by $\mathrm{H}_{2}$ addition. The thermal effect of CO addition promoted a slightly advance in both LTHR and HTHR. The magnitude of LTHR was $26 \%$ lower than the baseline case at the maximum $\mathrm{H}_{2}$ concentration $\left(+6\right.$ moles $\left.\mathrm{H}_{2}\right)$, while the $\mathrm{CO}$ addition reduced the LTHR magnitude by $6.5 \%$. 
Results obtained from the ideal case composition were useful to accept the model based on the LLNL kinetics code as a good approximation to experimental results found in literature regarding the effect of $\mathrm{H}_{2}$ and $\mathrm{CO}$ in HCCI combustion of n-heptane.

\subsection{HCCI-TCR system analysis}

Previous studies reported in literature have analyzed the effect of RG addition into HCCI combustion of different fuels (n-heptane, DME and methane) assuming a fixed composition for RG (Hosseini and Checkel 2007-a, Hosseini and Checkel 2007-b, Eng et al. 2002). A blend of $\mathrm{H}_{2}$ and $\mathrm{CO}$ in a fixed ratio is used in those studies, but the source of the RG blend is not specified. In this research work, the blend is produced through steam-fuel reforming, and the heat required for that process is obtained from the HCCI engine exhaust gases. Figure 48 describes the overall system. It is composed of HCCI engine, the steam reformer reactor (RR), the evaporator (EV), and the steam generator (SG).

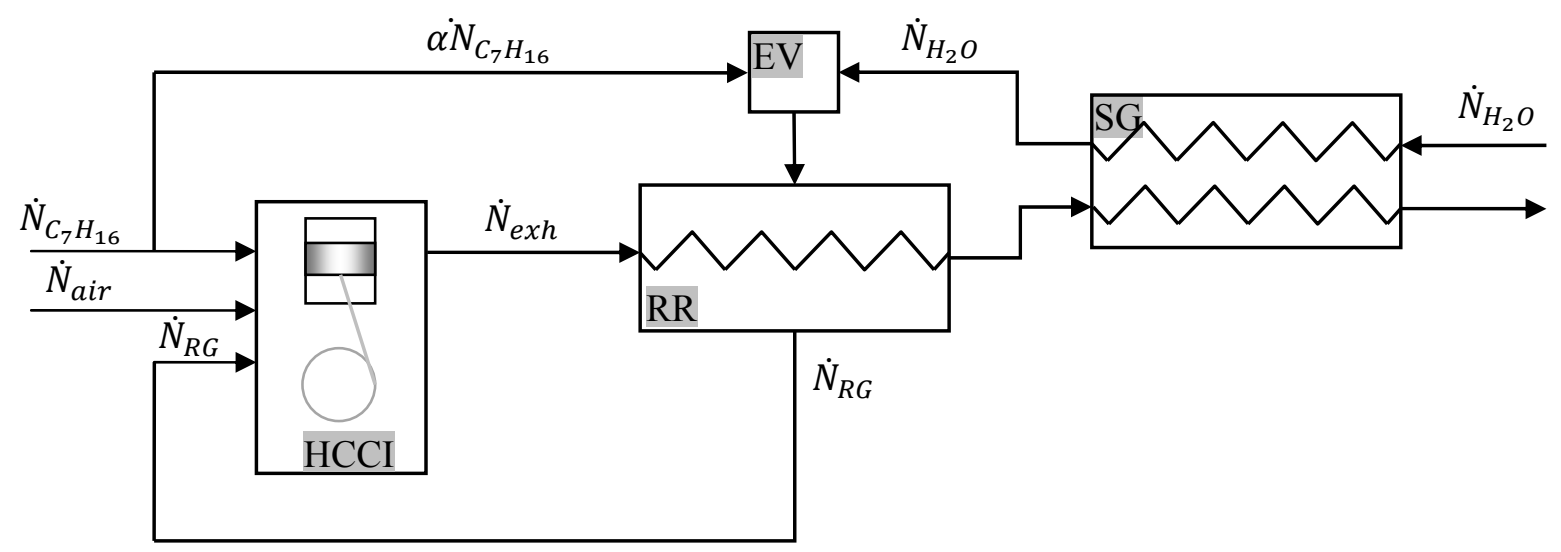

Figure 48. Integrated HCCI engine and TCR

\subsubsection{System Definitions}

Two of the concepts defined in the previous section still apply in the context of the overall HCCITCR system. The RG fraction and the equivalence ratio, defined by atomic valence method apply to the set of species that enter the cylinder at IVC. The concept of RG as the fraction of reformed gases to total fuel and reformed gases was presented in the previous section. From Figure 48, it can be inferred that for $\mathrm{RG}>0$, the equivalence ratio at the intake varies depending on the composition of RG. This indicates that equivalence ratio cannot be used as a control variable, but can be used to describe conditions at IVC. 
Let us introduce here the concept of system air-fuel ratio $\left(A F_{\text {syst }}\right)$,

$$
A F_{s y s t}=\frac{\dot{m}_{a i r, s y s t}}{\dot{m}_{C_{7} H_{16}, \text { syst }}}=\frac{\dot{N}_{a i r} M W_{a i r}}{\dot{N}_{C_{7} H_{16}} M W_{C_{7} H_{16}}}
$$

Equation 101

which is independent of RG. RG requires steam, which must be accounted for. The molar rate of water into the cylinder depends on $\mathrm{RG}$ and $\mathrm{S}: \mathrm{C}$,

$$
\dot{N}_{H_{2} O}=7(S: C) \alpha \dot{N}_{C_{7} H_{16}}
$$

Equation 102

which requires $\alpha$ to be defined. The fraction of fuel to reformer $(\alpha)$ was obtained by replacing the mass flowrates in the RG definition by its molar value, this led to a non-linear function of RG and $\alpha$ that is independent of fuel flowrate,

$$
R G=\frac{\alpha M W_{C_{7} H_{16}}+7(S: C) \alpha M W_{H_{2} O}}{M W_{C_{7} H_{16}}+7(S: C) \alpha M W_{H_{2} O}}
$$

Equation 103

which can be solved iteratively to find the value of $\alpha$.

The HCCI process is defined by composition, temperature and pressure at IVC. Assuming that temperature and pressure are known at IVC, the composition depends on $A F_{\text {syst }}$ and $\mathrm{RG}$. The value of $A F_{\text {syst }}$ can be set representing load. However, although the mass flowrate of RG can be inferred from $A F_{\text {syst }}$, and Equations 102 and 103, the composition depends on reforming temperature, which is defined by the exhaust temperature. Therefore, the interaction between HCCI and TCR can only be investigated via a parametric study covering changes in fuel input $\left(A F_{\text {syst }}\right), \mathrm{RG}$ amount and composition, and engine speed. The HCCI engine performance defined by IMEP and limited by RI can be investigated. Emissions trends can also be defined with the parametric study.

\subsection{HCCI-TCR parametric study}

The integrated HCCI-TCR system was investigated through a parametric study developed in the HCCI engine model assuming the same geometry presented in Table 2, and CR=10. The SZ HCCI model was used for the whole space of conditions required in the parametric study due to the time required for each simulation to converge. The MZ model was used for studying emissions at specific cases and to correct IMEP and RI obtained values from the SZ model. The parametric study covers the HCCI model engine speed and load (represented by $A F_{\text {syst }}$ ) under different conditions of RG addition and $\mathrm{S}: \mathrm{C}=1: 1$. Table 11 shows the set of values used for each parameter. 
Table 11. Set of values used in the HCCI-TCR parametric study

\begin{tabular}{cc}
\hline Parameter & Values \\
\hline Engine Speed, rpm & 900,1500 \\
Load $\left(A F_{\text {syst }}\right)$ & $55,50,40,35$ \\
$R G, \%$ & $0,10,20,30,40$ \\
\hline
\end{tabular}

The change in performance in the HCCI-TCR engine was compared in each case against the model engine without RG addition. The criteria used to evaluate the difference in performance were IMEP, thermal efficiency and indicated work. The TCR performance is evaluated through the reforming thermal efficiency, and the TCR thermal efficiency. The fraction of enthalpy recovered from the exhaust gases is also calculated for each case.

Due to the interaction of HCCI exhaust conditions on TCR performance and RG composition, which at the same time affects the HCCI combustion history, the numerical solution requires two sets of iterations to reach convergence. Figure 49shows the algorithm used to find the solution. Intake and exhaust pressure conditions were $1 \mathrm{~atm}$ in both cases. Besides the engine conditions presented in Table 11, the model initial conditions require RG composition, which is calculated with the TCR model, and conditions at IVC (pressure and temperature). The RG composition is obtained assuming an exhaust temperature value. Once the conditions at IVC are defined the model (either the SZ or the MZ) is run, including the gas exchange process which allow for better determination of temperature and residual composition ( $\sim 5 \%$ by mass) at IVC. The engine model cycle is run until temperature at IVC converges. The next step calculates the averaged steady state exhaust temperature used in the reforming process. If the temperature found with the model is different to the one initially used to calculate the RG composition, the new value of exhaust temperature is used to obtain RG composition and the whole model is run again until exhaust temperature converges. It should be noted that $\mathrm{T}_{\mathrm{exh}}$ is used as reforming temperature $\mathrm{T}_{\text {ref }}$ in the TCR model.

Engine performance, defined by CA50, IMEP, engine thermal efficiency and emissions are analyzed first for changes in RG fraction. The TCR system performance, defined by RR and TCR thermal efficiencies and fraction of enthalpy recuperated in both processes $\left(f_{H_{R R}}\right.$ and $f_{H_{T C R}}$, respectively). RI values are presented to define the rich operation conditions where the HCCI-CTR system can operate acceptably before severe ringing. 


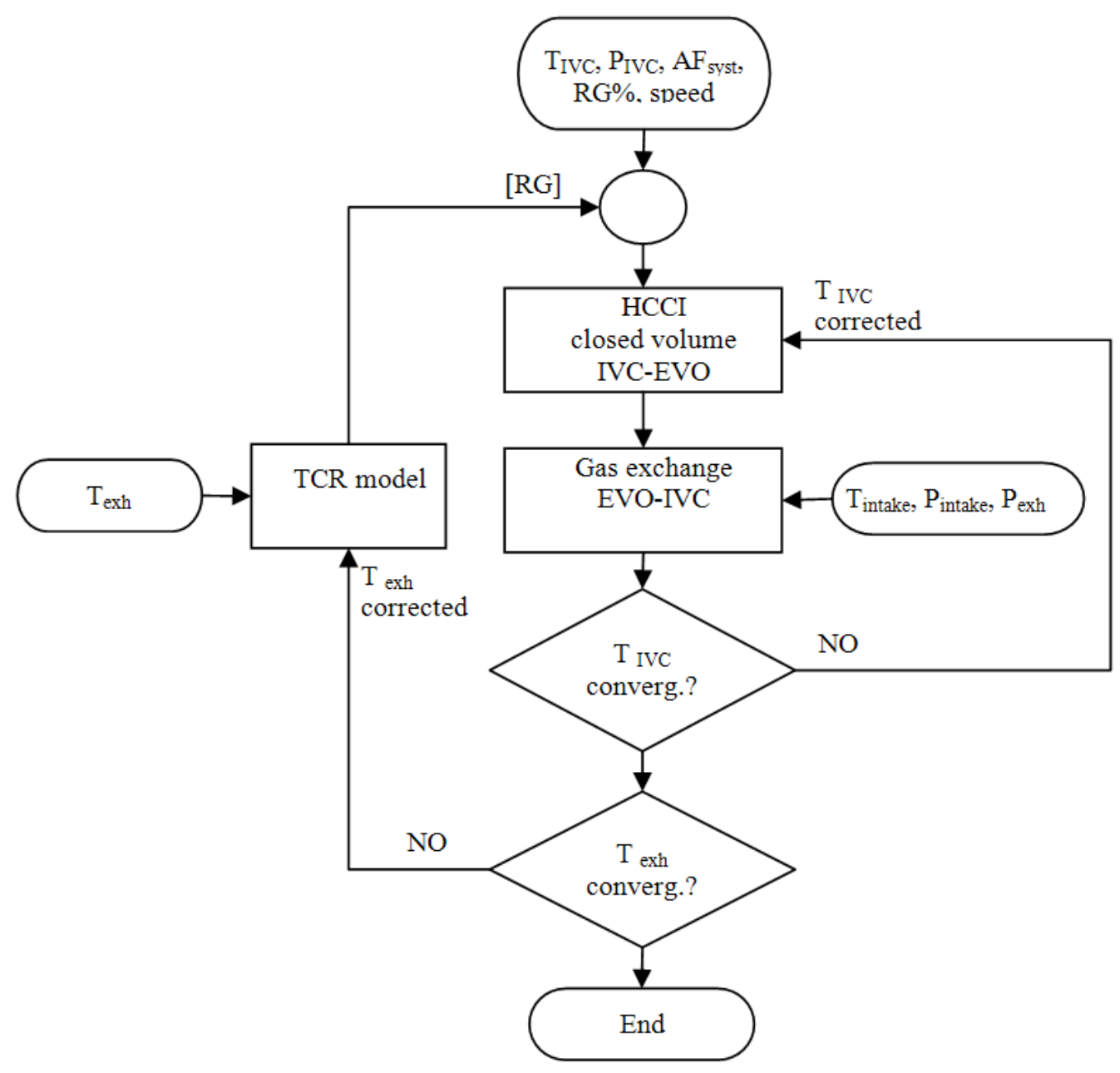

Figure 49. HCCI-TCR Model flowchart

\subsubsection{HCCI Engine Study}

Let us recall the difficulty of HCCI control when a load change (AF change) is demanded at constant speed. At constant speed, an increase in load demand changes the combustion timing relative to TDC and the pressure rise rate, as can be observed in Figure 50 at engine speed of $900 \mathrm{rpm}$. The combustion timing is advanced well before TDC, which implies that the compression stroke work increases, which reduces IMEP and thermal efficiency. The rate of heat release during HTHR increases considerably with reductions in AF values as is expected from higher fuel concentration cases. As can be observed in the figure LTHR does not change significantly with AF ratio, which was discussed in the HCCI model validation section. 

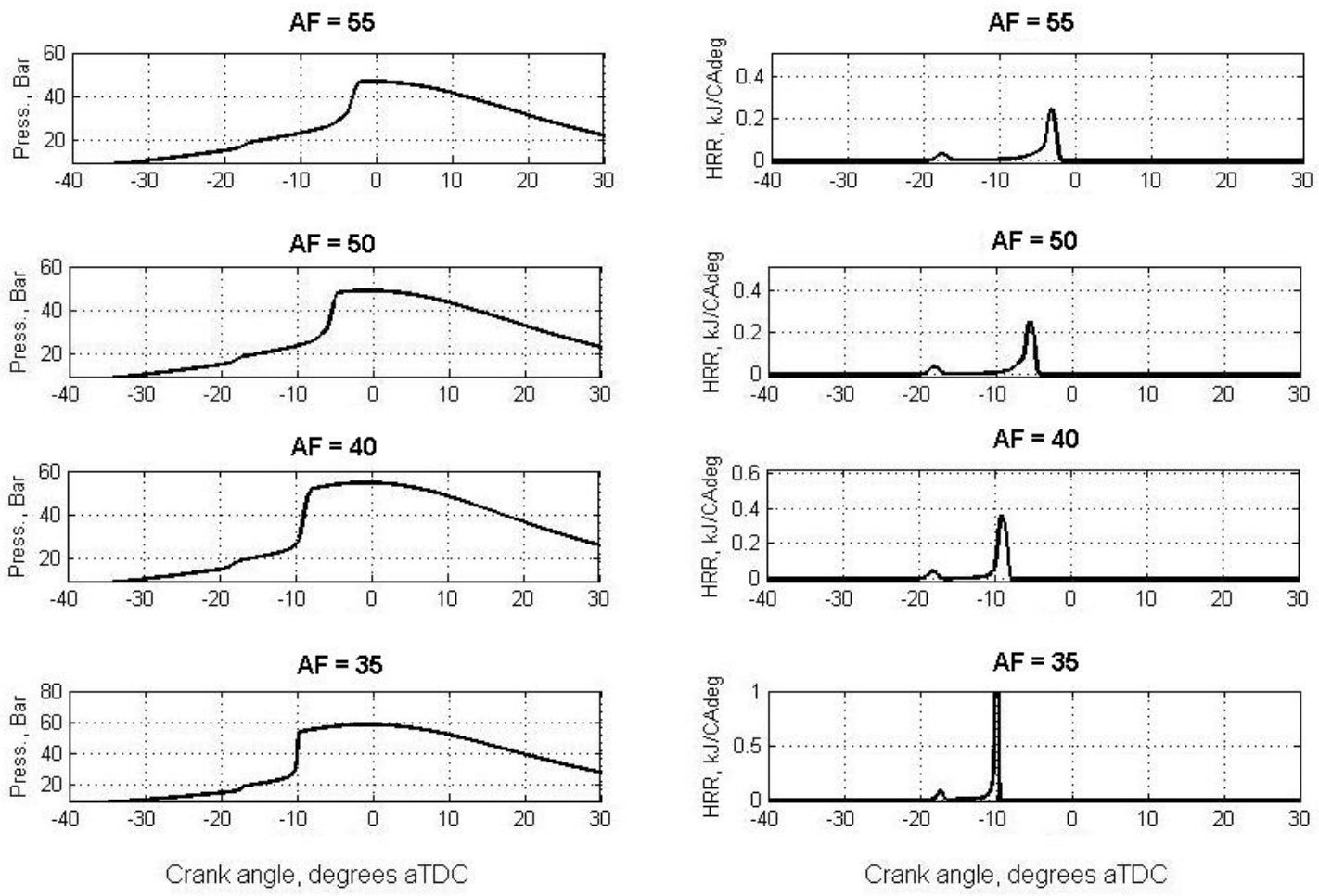

Figure 50. Calculated pressure and heat release rates for different values of $A F$ and no RG. $P_{\text {int }}=101 \mathrm{kPa}$, $T_{\text {int }}=310 \mathrm{~K}, \mathrm{CR}=10, P_{\text {exh }}=101 \mathrm{kPa}, 900 \mathrm{rpm}$.

\subsubsection{Effects on CA50}

The addition of $\mathrm{RG}$, thanks to its hydrogen content, allows for tuning the combustion timing, characterized by CA50 in this work. Using the HCCI-TCR model, mapping of CA50 values for different $\mathrm{RG}$ and $A F_{\text {syst }}$ values was performed. The TCR model was assumed at $\mathrm{S}: \mathrm{C}=1: 1$ and under reforming temperature equal to the calculated average exhaust temperature obtained from the gas exchange model. The mapping allows for determining the required addition of $\mathrm{RG}$ to achieve combustion at certain timing (CA degrees) for different values of load. Figure 51 presents the results of the CA50 mapping at $900 \mathrm{rpm}$. It can be observed that the effect of RG on CA50 at this engine speed depends on load $\left(A F_{\text {syst }}\right)$. At low load, the effect of RG is negligible, while at high load the effect is very significant. This could potentially be used as a look-up table by the engine control unit to regulate the timing at the best conditions for torque and thermal efficiency. 
a) Eng. speed $=900, S: C=1: 1$

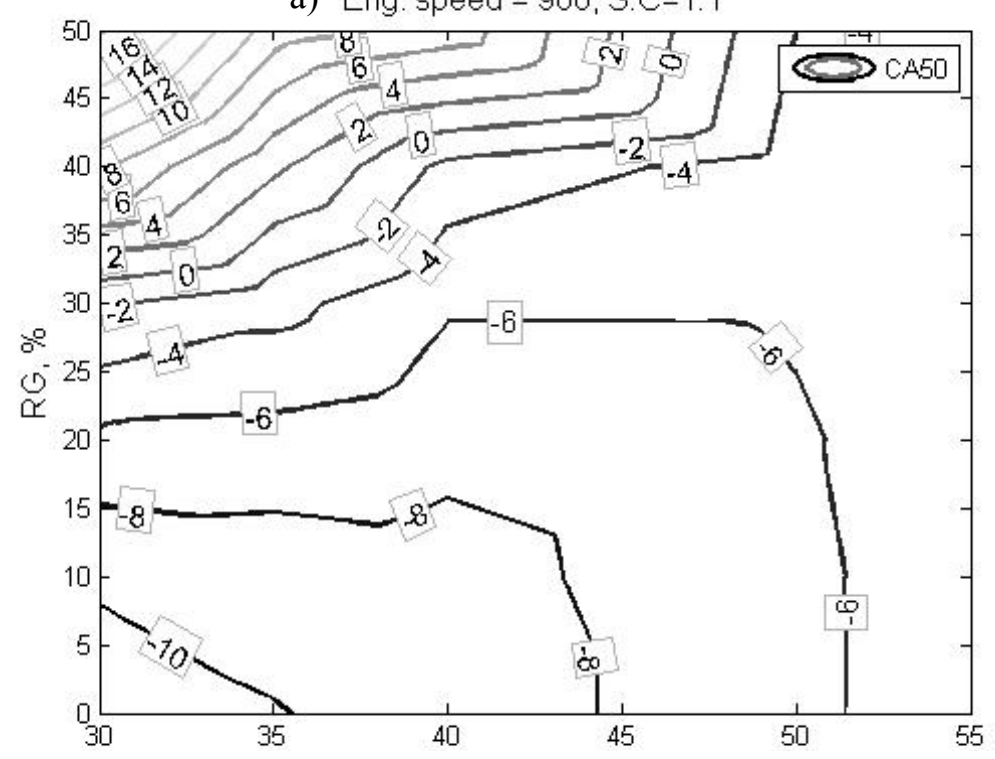

b) Eng. speed $=1500, S: C=1: 1$

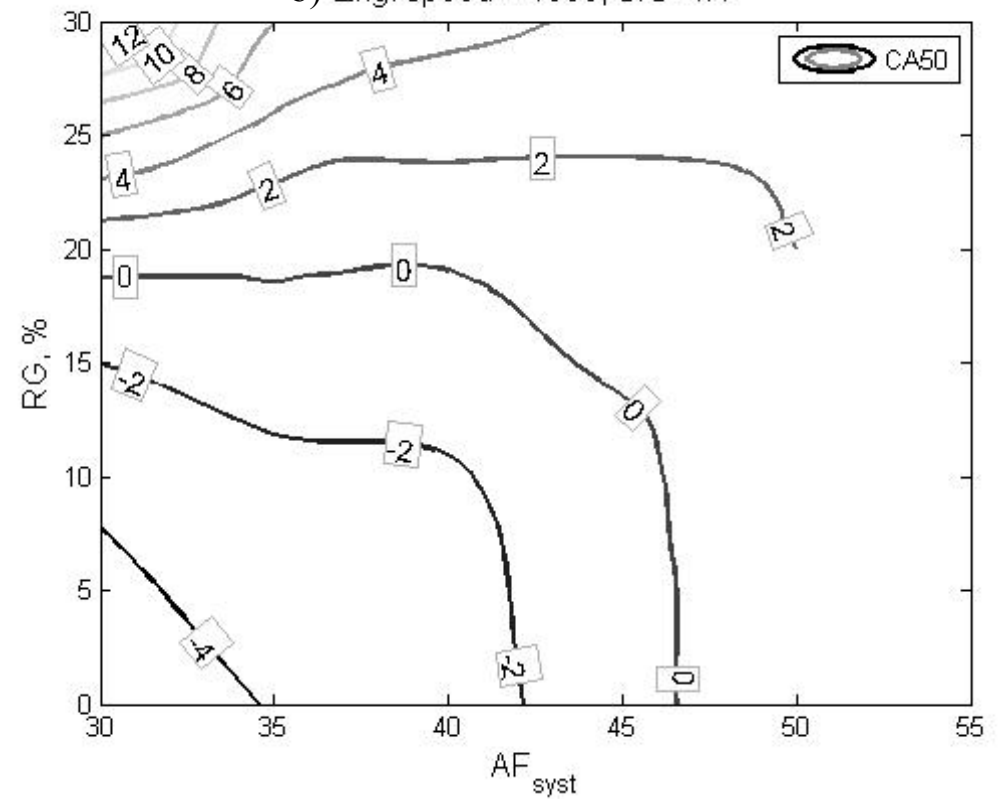

Figure 51. Contour plot of CA50 values (degrees aTDC) at different $A F_{\text {syst }}$ and $R G$ values. a)Engine speed $900 \mathrm{rpm}$ and b) $1500 \mathrm{rpm}$. TCR operating at $S: C=1: 1$ and $T_{r e f}=T_{e x h}$.

In low load cases, which correspond in this parametric study to $A F_{\text {syst }}=55$ and $A F_{\text {syst }}=50$, it was found that at any engine speed there was very little effect of RG on combustion timing (CA50). This is because the exhaust temperature is low and there is very little hydrogen yield in the fuel reformer. It should be noted that the effect of engine speed in CA50, for the same AF values, is related to the time required for the mixture to ignite. In both speed cases the time is essentially the same, but when observed 
in the crank angle domain, CA50 occurs earlier at low speeds and later at high speeds. At high loads the effect of RG addition is more pronounced, manifested in its ability to delay CA50 values by more than 20 $\mathrm{CA}$ degrees at the highest RG values. This CA50 maps allows for defining the control strategy at both speeds.

In order to understand the control strategy of an HCCI engine through RG addition, let us assume that for each case of engine speed (900 and $1500 \mathrm{rpm}$ ) in Figure 51 it is required to increase the load from $A F_{\text {syst }}=45$ up to $A F_{\text {syst }}=35$, while keeping CA50 at an arbitrary value of CA50=0 (TDC). At $900 \mathrm{rpm}$ and $A F_{\text {syst }}=45$ the ignition occurs at $-8.1^{\circ} \mathrm{CA}$ after TDC if no RG is added. In this condition the addition of $\mathrm{RG}=43 \%$ allows the mixture to ignite at TDC. Increasing the load from $A F_{\text {syst }}=45$ up to $A F_{\text {syst }}=50$ while keeping $\mathrm{RG}=43 \%$ advances the ignition event from TDC to $6^{\circ} \mathrm{CA}$ after TDC. It is required to reduce $\mathrm{RG}$ from $43 \%$ up to $35 \%$ in order to keep ignition at TDC. At high speed, ignition at TDC requires different values of $\mathrm{RG}$ at each $A F_{\text {syst }}$. At $A F_{\text {syst }}=45$ and $\mathrm{RG}=13 \%$ ignition occurs at TDC. In contrast to the low speed case, an increase in load to $A F_{\text {syst }}=35$ requires an increase in $\mathrm{RG}$ up to $18 \%$.

This non-linear behavior on CA50 under RG addition is caused by the combined effect of exhaust temperature variations and RG composition. It should be noticed that in this work the reforming temperature is assumed equal to the time averaged exhaust temperature. To better understand this let us recall that at constant load $\left(A F_{\text {syst }}\right)$, a delay in ignition generates an increase in exhaust temperature as combustion gases are left with less time to cool down during the expansion stroke. In the case of the HCCI-TCR system, the addition of RG delays the ignition, which increases the exhaust temperature, driving the TCR to higher levels of fuel conversion, which in turn increases the $\mathrm{H}_{2}$ concentration in the RG produced. Higher concentration of hydrogen would delay CA50 even more if RG addition is not reduced. The combined effect of RG, load and engine speed on exhaust temperature is presented in the next section.

\subsubsection{Effects on IMEP and Indicated Thermal Efficiency}

IMEP is interpreted by Heywood (1988) as a measure of the effectiveness with which the displaced engine volume produces work. Indicated thermal efficiency is universally defined as the fraction of energy input that is transformed into work during the closed volume period (IVC-EVO). It has been demonstrated by other researchers working on adding $\mathrm{H}_{2}$ and $\mathrm{CO}$ for $\mathrm{HCCI}$ control, that there is a positive effect on IMEP and thermal efficiency. Figure 52 presents the IMEP calculated in this investigation. In the present research work, the trend was also confirmed, although it depends not only on the amount of $\mathrm{RG}$ added but on the load and speed conditions that concomitantly define the RG composition. 
a) Eng. speed $900 \mathrm{rpm}, \mathrm{S}: \mathrm{C}=1: 1$

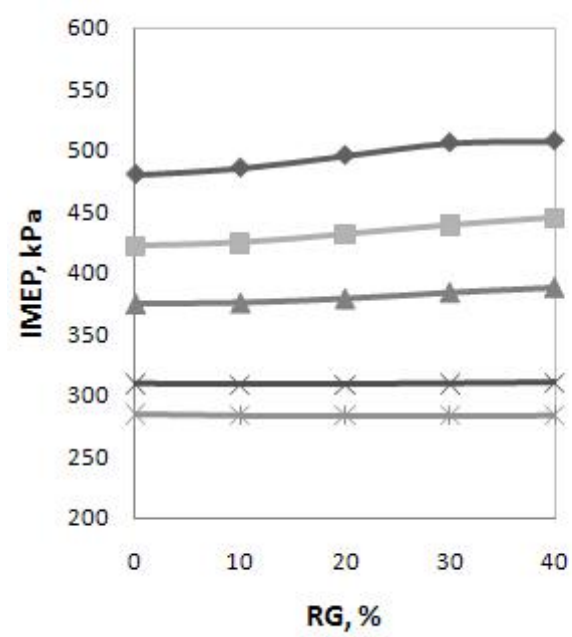

b) Eng. speed $1500 \mathrm{rpm}, \mathrm{s}: \mathrm{C}=1: 1$

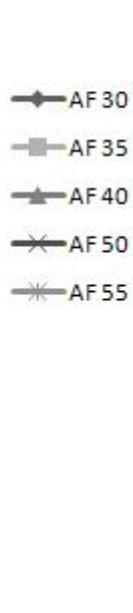

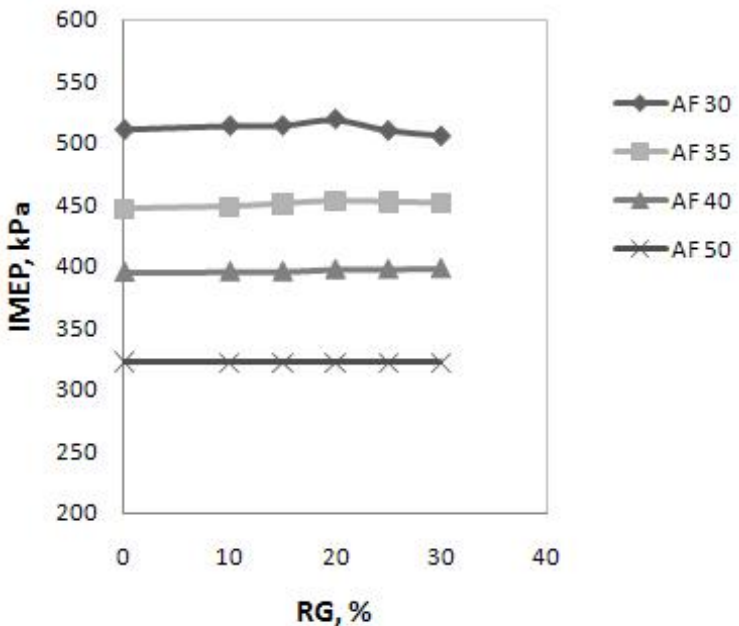

Figure 52. IMEP values calculated at different $A F_{\text {sys }}, R G$ and engine speed conditions. a) Engine speed 900 rpm and b) $1500 \mathrm{rpm}$. TCR operating at $S: C=1: 1$ and $T_{r e f}=T_{e x h}$.

At $\mathrm{RG}=0 \%$ the IMEP values obtained were higher at $1500 \mathrm{rpm}$ due to the fact that at this engine speed the CA50 is located closer to TDC, as can be observed in Figure 51. The effect of RG is more marked at low speeds where the retarding effect of RG on CA50 improves the IMEP values. At the higher load and $900 \mathrm{rpm}$, the benefit from RG addition was estimated as $6 \%$, while at mid-load $\left(A F_{\text {syst }}=40\right)$ the benefit in IMEP was found around 3.5\%. At $1500 \mathrm{rpm}$ the best benefit obtained with RG was calculated below $1.5 \%$, at $A F_{\text {syst }}=30$ and $\mathrm{RG}=20 \%$.

Calculated engine indicated thermal efficiency is presented in Figure 53 for two cases of engine speed and different $A F_{\text {syst }}$ and $\mathrm{RG}$ conditions. Indicated thermal efficiency varies depending on specific conditions on the HCCI-TCR system. At low speed, the indicated thermal efficiency increases with RG addition at high load, but it is slightly reduced at low loads. At high loads and in both cases of engine speed, the indicated thermal efficiency decays with RG addition upon reaching its maximum, which is associated with CA50 behavior (Figure 51). RG addition delays the CA50, affecting the amount of work it is able to produce during the expansion stroke. A similar behavior is observed in IMEP, where the maximum value tends to stabilize, at low speed, and to reduce, at high speed. It should be observed that the energy input at IVC is reduced with higher values of RG due to the fact that there is additional $\mathrm{CO}$ and water added into the system. Water enters into the cylinder if it is not consumed for $\mathrm{H}_{2}$ production at low reforming temperatures. $\mathrm{CO}$ has lower heating value per $\mathrm{kg}(10.1 \mathrm{MJ} / \mathrm{kg})$ compared to n-heptane (45 $\mathrm{MJ} / \mathrm{kg}$ ) and $\mathrm{H}_{2}(121 \mathrm{MJ} / \mathrm{kg})$. At high reforming temperatures the $\mathrm{CO}$ produced per unit mass is much higher than the $\mathrm{H}_{2}$ produced, reducing the energy content of the mixture. It should be noted that the 
mixture LHV in terms of energy per unit mass is higher with RG addition, as will be presented in the TCR analysis section.

a) Eng. speed $900 \mathrm{rpm}, \mathrm{S}: \mathrm{C}=1: 1$

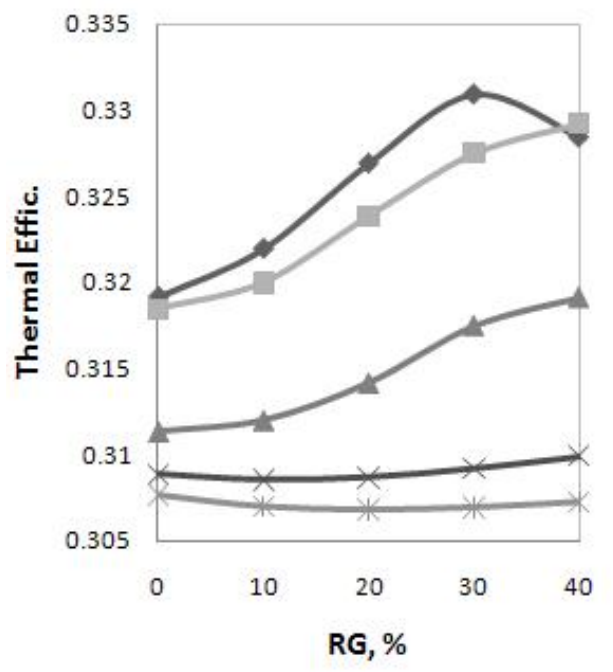

b) Eng. speed $1500 \mathrm{rpm}, \mathrm{s}: \mathrm{C}=1: 1$

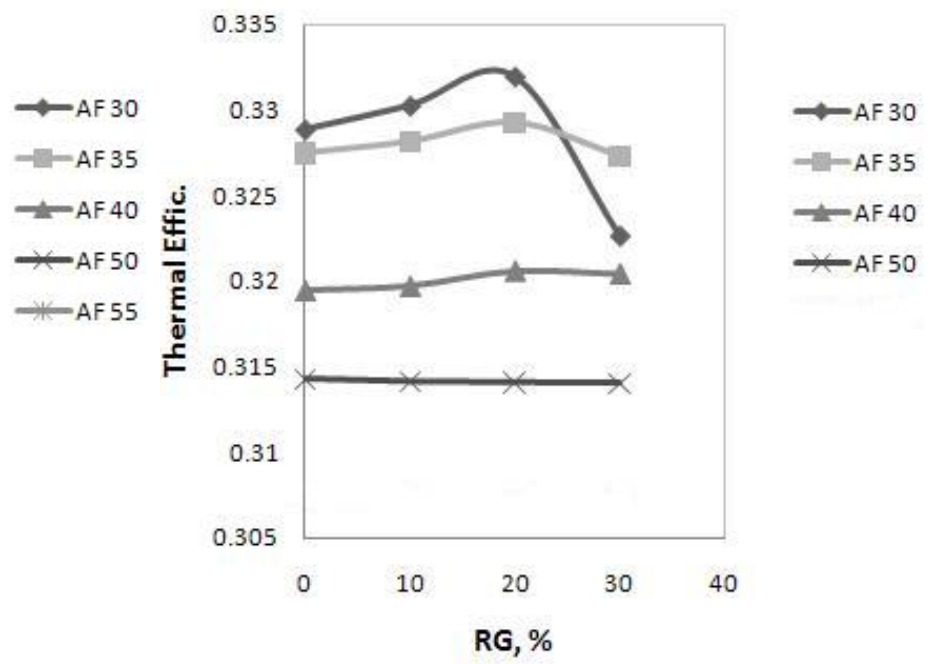

Figure 53. Calculated $\eta_{t h, i}$ values at different $A F_{\text {syst }}, R G$ and engine speed conditions. a) Engine speed 900 rpm and b) $1500 \mathrm{rpm}$. TCR operating at $S: C=1: 1$ and $T_{\text {ref }}=T_{\text {exh }}$.

It can be concluded that the effect of RG on indicated engine thermal efficiency is twofold. The first effect is a reduction in the energy input at IVC, and the second is an increase in work during the expansion stroke due to the delaying effect of RG on n-heptane combustion.

\subsubsection{Effects on Emissions of $\mathrm{NO}_{\mathrm{x}}$ and $\mathrm{CO}$}

Emissions were calculated with the $\mathrm{MZ}$ model. The effect of $\mathrm{RG}$ addition on calculated $\mathrm{NO}_{\mathrm{x}}$ production is highly dependent on engine load conditions, as can be observed in Figure 54. At high load the addition of $\mathrm{RG}$ reduces the amount of $\mathrm{NO}_{\mathrm{x}}$ emitted. This can be explained by the ability of $\mathrm{RG}$ to reduce peak pressure and temperature, in addition to delaying CA50. This reduces the severity of heat release, suggesting lower temperatures during combustion. At low load calculated $\mathrm{NO}_{\mathrm{x}}$ emissions reduce slightly with RG. The appearance of $\mathrm{NO}_{\mathrm{x}}$ at low load might be explained as a manifestation of the nitrous oxide mechanism. The $\mathrm{N}_{2} \mathrm{O}$ mechanism is promoted by high pressure and is not affected by low temperatures found in lean premixed systems. This makes the $\mathrm{N}_{2} \mathrm{O}$ route the major source of $\mathrm{NO}_{\mathrm{x}}$ in this kind of systems (Warnatz et al. 1999). It should be noted that the $\mathrm{NO}_{\mathrm{x}}$ values are consistent with the set of experimental data collected during the validation process for one single engine speed ( $900 \mathrm{rpm})$. Without $\mathrm{RG}$ addition, the molar fraction of $\mathrm{NO}_{\mathrm{x}}$ is below $5 \mathrm{ppm}$ at $\mathrm{AF} \geq 40$. Higher engine load presented a large increase in $\mathrm{NO}_{x}$, where thermal $\mathrm{NO}_{\mathrm{x}}$ dominates the $\mathrm{NO}$ production (Warnatz et al. 1999). 
a) Eng. speed $900 \mathrm{rpm}, \mathrm{S}: \mathrm{C}=1: 1$

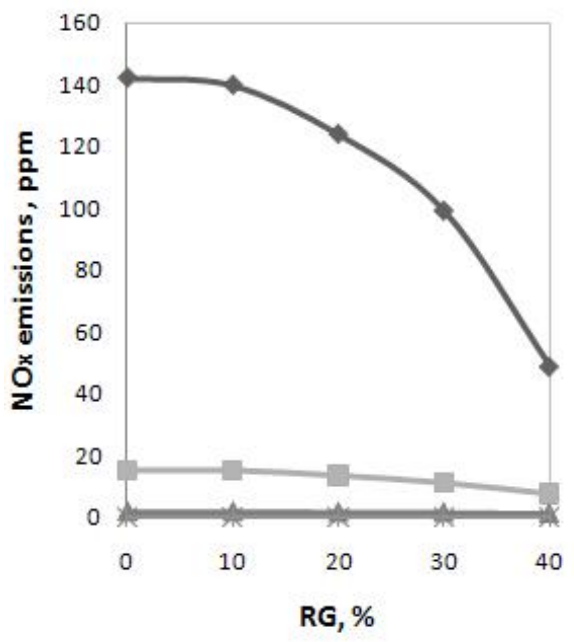

b) Eng. speed $1500 \mathrm{rpm}, \mathrm{S}: \mathrm{C}=1: 1$

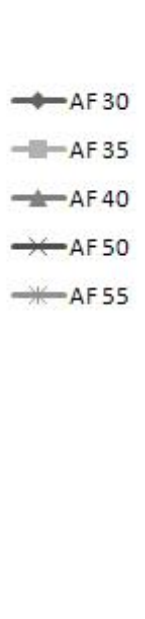

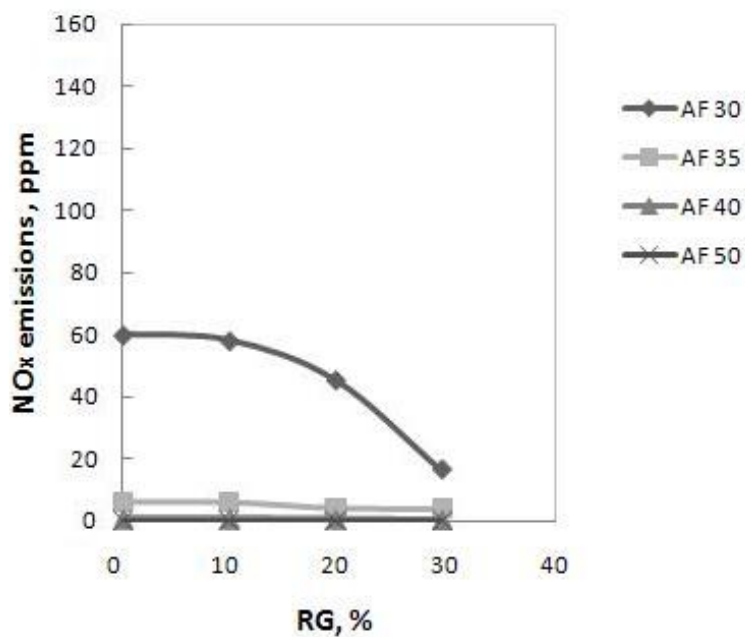

Figure 54. Calculated $N O_{x}$ emissions at different $A F_{\text {syst }}, R G$ and engine speed conditions. a) Engine speed $900 \mathrm{rpm}$ and b) $1500 \mathrm{rpm}$. TCR operating at $S: C=1: 1$ and $T_{\text {ref }}=T_{\text {exh }}$.

$\mathrm{CO}$ emissions are presented in Figure 55. At low speed the effect of RG on CO emissions is negligible. Emission values depend on load $\left(A F_{\text {syst }}\right)$ values and show a behavior that coincides with results published by Guo et al. (2009). Low loads increase the CO emissions probably due to almost misfiring conditions. At high load the relative reduction in available $\mathrm{O}_{2}$ forces a slight increase in $\mathrm{CO}$ emissions. At $1500 \mathrm{rpm}$ the $\mathrm{CO}$ exhaust molar fraction increases considerably due to the effect of combustion delay typical of high speed HCCI operation, which is exacerbated by RG addition. It is also likely that the addition of $\mathrm{CO}$ from $\mathrm{RG}$ replacement increases the emission values for the cases where no ignition was achieved.

a) Eng. speed $=900, S: C=1: 1$

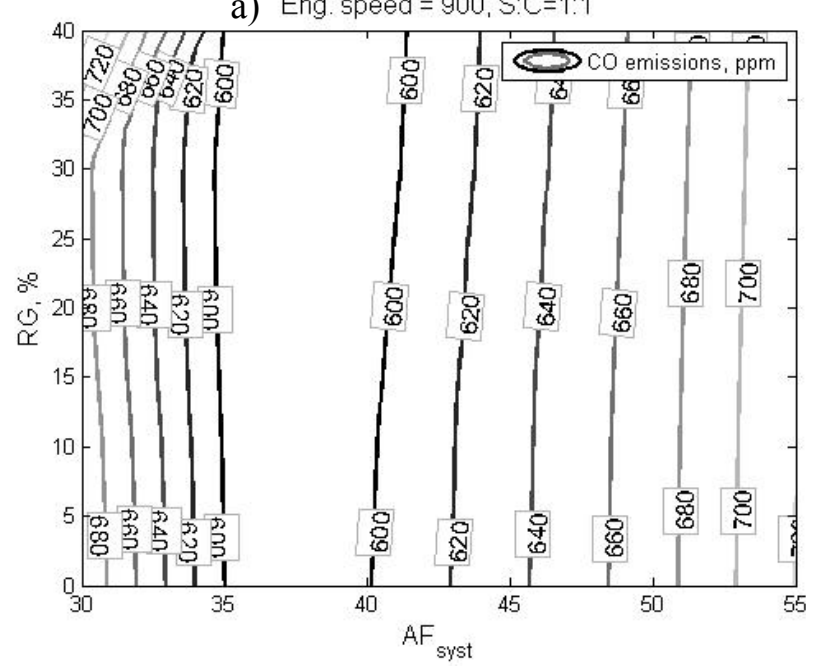

b) Eng. speed $=1500, S: C=1: 1$

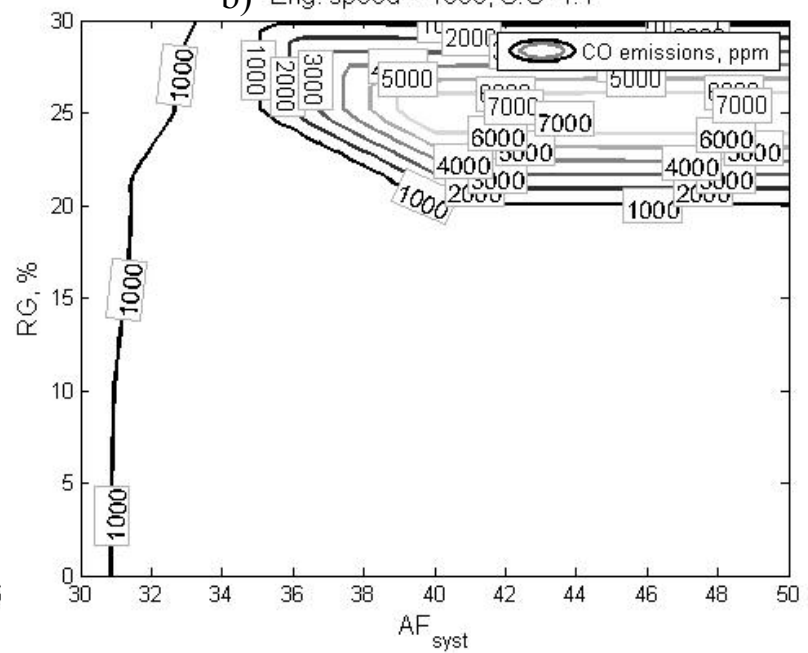

Figure 55. Calculated $C O$ emissions at different $A F_{\text {sys, }} R G$ and engine speed conditions. a) Engine speed $900 \mathrm{rpm}$ and b) $1500 \mathrm{rpm}$. TCR operating at $S: C=1: 1$ and $T_{r e f}=T_{e x h}$. 


\subsubsection{Effects on Ringing and Operational Limits}

The HCCI engine performance limits are defined in the lean limit by misfire and by ringing in the the rich limit. The parameter RI, proposed by Eng (2002), correlates the in-cylinder pressure history with the ringing intensity, which was defined in the section Combustion Parameters Definition. This parameter is recommended for HCCI studies given its independency on boost conditions. Another option to define the HCCI engine performance limits would be using the maximum rate of pressure rise. However the maximum value is dependent on boost conditions (Eng, 2002). Figure 56 shows the calculated RI values for the same engine conditions discussed in this parametric study.

a) Eng. speed $=900 \mathrm{rpm}, \mathrm{S}: \mathrm{C}=1: 1$

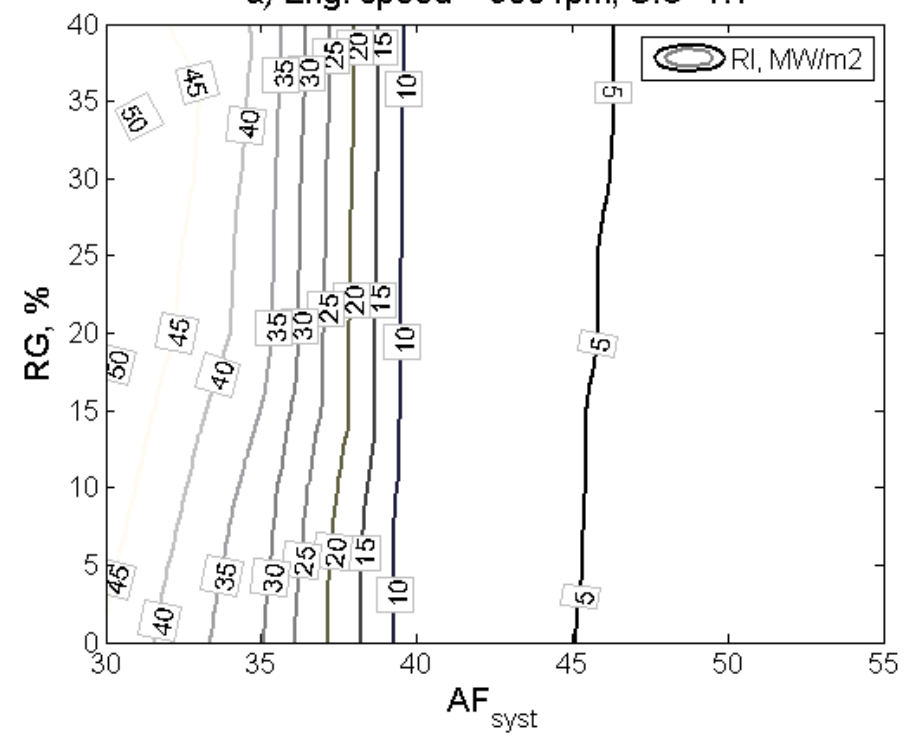

b) Eng. speed $=1500 \mathrm{rpm}, \mathrm{S}: \mathrm{C}=1: 1$

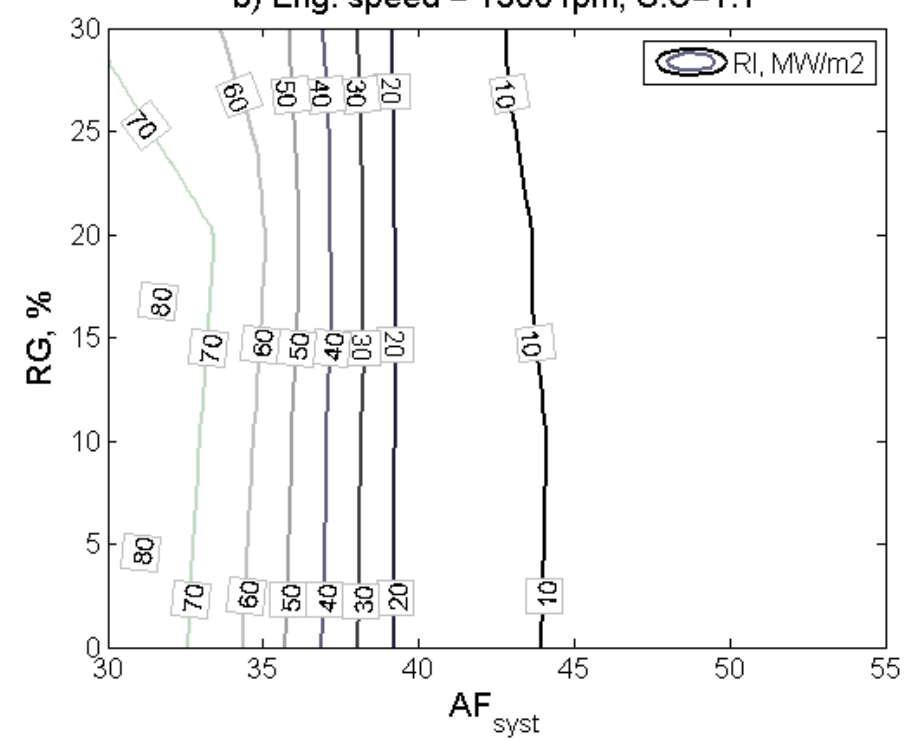

Figure 56. Calculated $R I$ values at different $A F_{\text {syst }}, R G$ and engine speed conditions. a) Engine speed 900 rpm and b) $1500 \mathrm{rpm}$. TCR operating at $S: C=1: 1$ and $T_{r e f}=T_{e x h}$. 
Typical RI conditions of HCCI operation are 2-6 MW/m², as was explained by Eng (2002). The effect of RG on RI is negligible at the limit where the HCCI combustion finds its rich operational limit. The calculated RI values match the experimental data where the rich limit is found at $A F=43$ and $R G=0$, which can be found in Table 4. RG addition does not have a significant effect either at low or high speeds. Higher speeds exacerbate the RI problem, as $P_{\max }$ is reduced with speed, according to the validation results on the HCCI model.

These results suggest that RG might not be capable of improving the engine performance limits. Although calculated RI values are affected by the way the numerical solution is obtained, the solution is consistent regarding the effect of RG. According to the RI map, the HCCI engine can only be operated under acceptable ringing conditions at a maximum AF between 40 and 45 at $900 \mathrm{rpm}$ and below 45 at higher engine speeds.

\subsubsection{TCR Study}

The HCCI and the TCR work in series. The exhaust gases are used by the TCR to produce steam and reform the fuel into a hydrogen rich stream. This rich hydrogen stream provides ignition control capability and improves the engine performance at specific engine conditions. Besides the HCCI engine operation, the TCR operation was also studied. In this section the reforming temperature is mapped first, and then the TCR and RR efficiency are presented.

\subsubsection{Reforming Temperature}

The temperature used in the steam-heptane reformer model was assumed to be equal to the time averaged exhaust gas temperature (Equation 52). Figure 57 shows the exhaust gas temperature for different conditions of $A F_{\text {syst }}$ and RG. Exhaust temperature is highly dependent on AF conditions. The addition of RG has its largest impact in exhaust temperature by delaying CA50. This increases exhaust temperature as the gas has less time to cool down during the expansion stroke. This can be confirmed by observing the CA50 map. The calculated values of exhaust temperature lay on the "sweet spot" for fuel conversion in the steam-heptane reformer (Figure 31). 
a) Eng. speed $900 \mathrm{rpm}, \mathrm{s}: \mathrm{C}=1: 1$

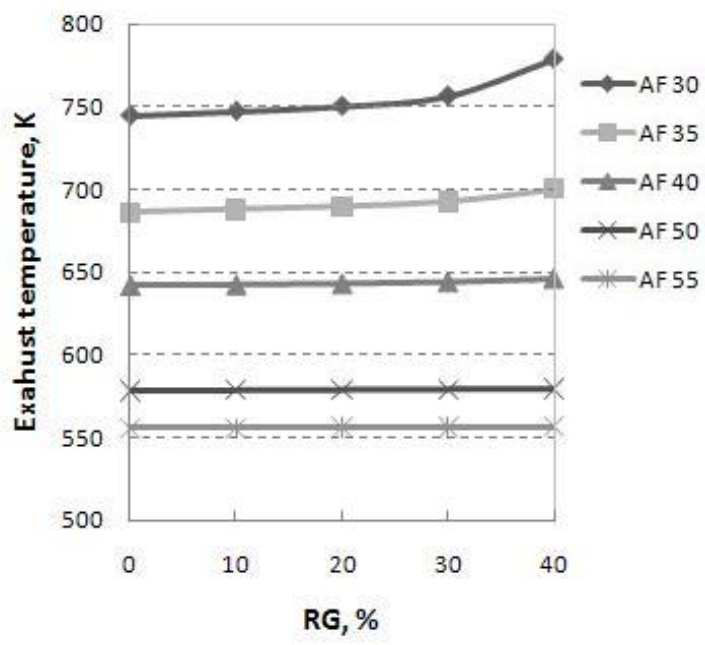

b) Eng. speed $1500 \mathrm{rpm}, \mathrm{S}: \mathrm{C}=1: 1$

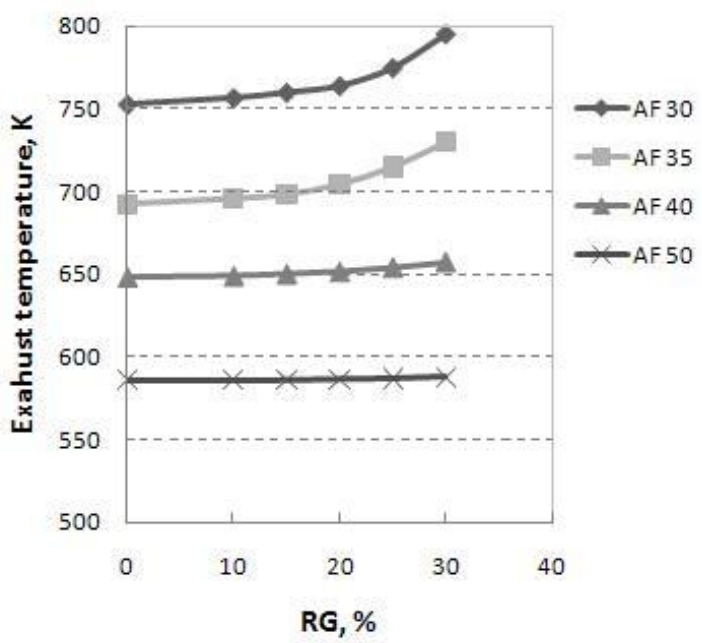

Figure 57. Calculated Exhaust temperature at different $A_{\text {syst }}, R G$ and engine speed conditions. a) Engine speed $900 \mathrm{rpm}$ and b) $1500 \mathrm{rpm}$. TCR operating at $S: C=1: 1$ and $T_{\text {ref }}=T_{\text {exh }}$.

\subsubsection{RR and TCR Performance}

In previous sections the concept of fuel reformer thermal efficiency $\left(\eta_{t h, r e f}\right)$ was introduced which quantifies how much heating value per unit mass of fuel has been gained during the reforming process; and the whole TCR system (RR, EV and SG) efficiency, $\eta_{T C R}$, which describes the ratio of increase in fuel energy content (in the RG stream) with respect to exhaust enthalpy used in the process. Figure 58 presents the calculated values under previously discussed engine conditions.
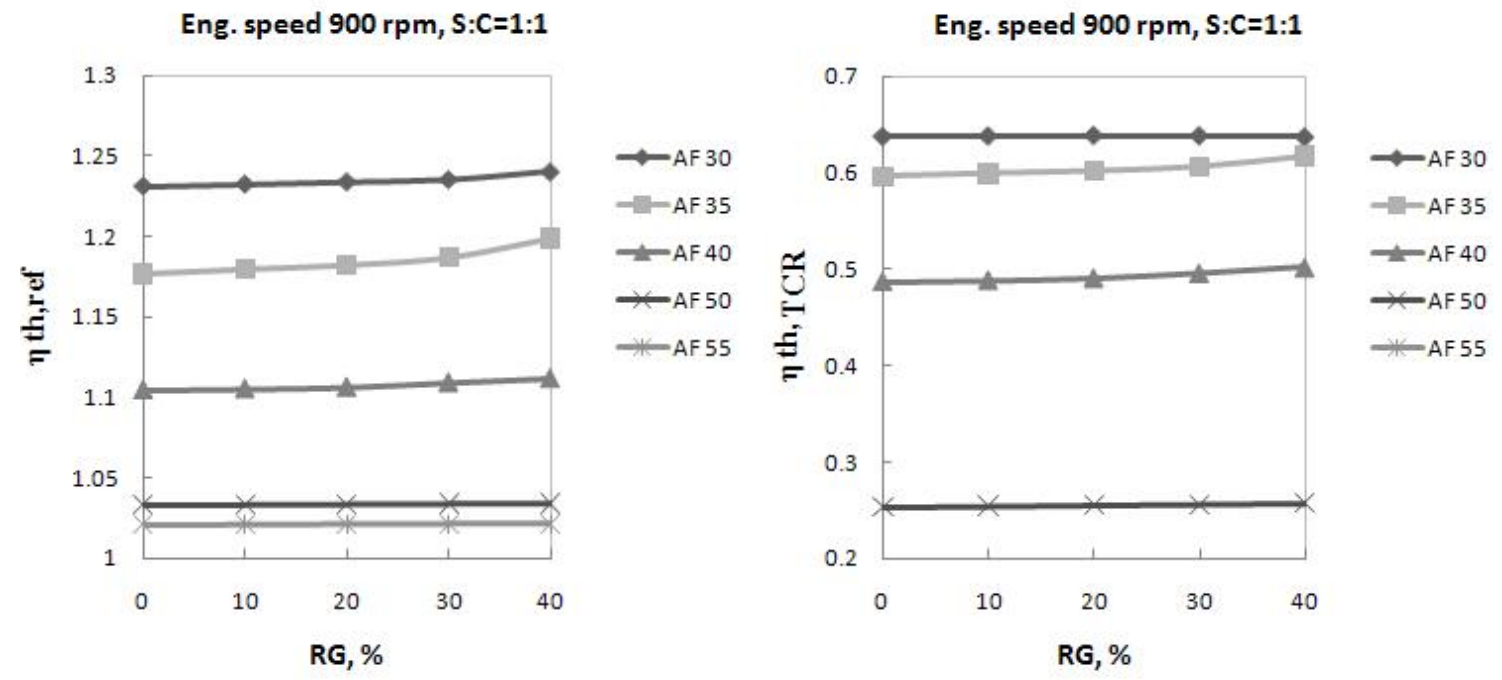

Figure 58. Calculated thermal efficiency of $R R$ and TCR at different $A F_{\text {syst }}, R G$. Engine speed 900 rpm. 
The steam-heptane reformer efficiency depends on exhaust temperature, which depends on AF values. At typical conditions for HCCI operation AF 40, the reformer thermal efficiency is around 1.1, meaning that there is a $10 \%$ increase in the LHV of RG by kilogram of fuel reformed. The TCR system efficiency shows that at typical HCCI operation conditions AF 40, about $50 \%$ of the energy recovered from the exhaust gases is used to increase the LHV of RG. The remaining percentage is used as sensible heat, to produce steam for reforming, and to increase the temperature of feed species and product species during the reforming process. At higher exhaust temperatures, where the fuel conversion is higher, the thermal efficiency of the TCR is highest, at about $64 \%$.

A better understanding of the ability of the TCR to recuperate exhaust energy that otherwise would be lost, is accounted for with $f_{H_{R R}}$ and $f_{H_{T C R}}$, which were defined in section 4.4. Figure 59 shows calculated values for each term. It is obvious that the amount of energy recovered is directly proportional to the amount of RG used by the system. Between $2 \%$ and $18 \%$ of exhaust enthalpy can be recovered during the steam-heptane reforming process at maximum RG use. The fraction of energy recovered in the RR is a fraction of the total enthalpy recovered by the TCR which is presented in Figure 59(b). The trend is the same in both cases. The difference between both fractions is the energy consumed by the whole TCR system in evaporating water and fuel before the mixture enters into the RR. It can be observed that at higher RG use and load most of the energy recuperated is employed in reforming the fuel. At higher $\mathrm{S}: \mathrm{C}$ ratios the trend is the same, but the values are higher due to higher mass flow in the TCR.
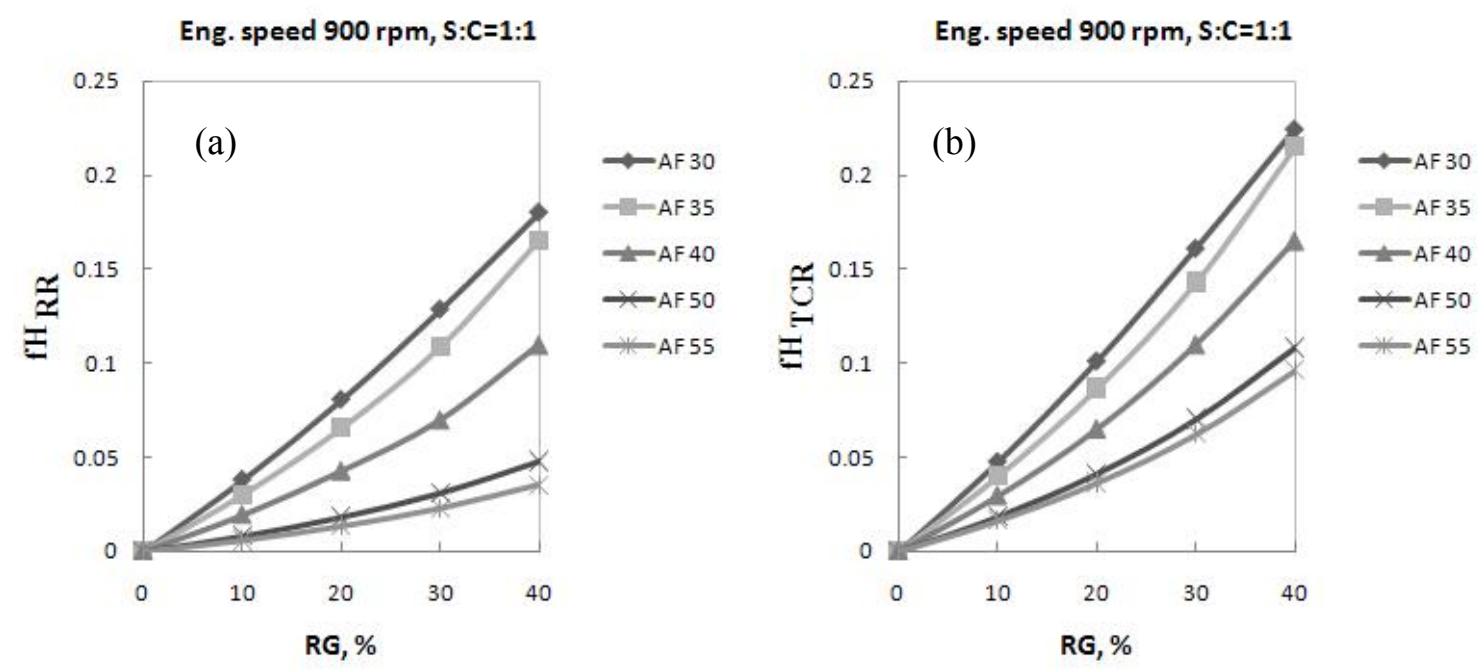

Figure 59. Calculated fraction of enthalpy recuperated at the RR (a) and at the TCR (b) at different AF $F_{\text {syst }}$ $R G$ values. Engine speed 900 rpm 


\section{Chapter 6. Conclusions and Recommendations}

A single-zone and a multi-zone model were developed and validated with experimental data to investigate the HCCI combustion of $n$-heptane. The model includes a gas exchange process model aiming to predict exhaust temperature and flowrate for reforming. The steam-fuel reformer model was developed based on equilibrium conditions. The TCR system model was developed in order to evaluate the ability of the steam-fuel reformer model to recuperate energy from the exhaust gases. A parametric study was used to evaluate the integrated HCCI-TCR model under different engine and reforming conditions.

\subsection{Conclusions}

The Single zone model was found adequate and efficient for analysis of the effect of engine conditions and RG addition on HCCI combustion history. Calculated CA10 values were within $2^{\circ} \mathrm{CA}$ of experimental data. The calculated combustion timing, which is evaluated with CA50, was very well predicted by the SZ model at different conditions of AF and engine speed. Maximum differences on CA50 values $\left(3.2^{\circ} \mathrm{CA}\right)$ were found at the leanest AF conditions. A multi-zone model was also developed to better account for HCCI engine performance (IMEP and RI) and emissions of $\mathrm{NO}_{\mathrm{x}}, \mathrm{CO}$ and $\mathrm{HC} . \mathrm{MZ}$ calculated values for IMPE were about 5-9\% above the experimental data. $\mathrm{NO}_{\mathrm{x}}$ and $\mathrm{CO}$ emission were slightly under-predicted in most cases, but the trend was correctly followed. HC emissions were highly under-predicted and the trend was not in agreement with experimental data.

SR was used as the reforming process for $n$-heptane due to its ability to achieve better reforming efficiency $(+24 \%)$ than PO (-13\%). In addition $\mathrm{H}_{2}$ yield per mole of n-heptane was higher with SR than with PO. Equilibrium model results based on the global reaction of steam and n-heptane produced good results for $\mathrm{H}_{2}$ yield when compared to experimental data. Experimental results from GTI show that steamheptane reformer produced a hydrogen-rich reformer fuel at various exhaust temperatures by steam reforming of n-Heptane. High levels of $\mathrm{H}_{2}(28 \%-52 \%)$ and $\mathrm{CO}(13 \%-24 \%)$ content in the reformed fuel were calculated at relatively low reforming temperature $(550 \mathrm{~K}-700 \mathrm{~K})$. Experimental data show that at $700 \mathrm{~K}$ there was up to $47 \% \mathrm{H}_{2}$ and $13 \% \mathrm{CO}$. According to the model, $90 \%$ conversion of n-heptane occurs at reforming temperatures higher than $650 \mathrm{~K}$. Values obtained from experimental results show a similar trend, with $\mathrm{n}$-heptane conversions higher than $91 \%$ at $\mathrm{T}_{\text {ref }}=658 \mathrm{~K}$.

Energy requirements and temperature conditions for the steam-heptane reforming process to occur were defined. A maximum of exhaust heat recuperation is achieved below the reforming temperature 
where the $\mathrm{H}_{2}$ yield has reached its equilibrium maximum and the heptane conversion has ceased, $833 \mathrm{~K}$ and $719 \mathrm{~K}$ for $\mathrm{S}: \mathrm{C}=1: 1$ and $\mathrm{S}: \mathrm{C}=2: 1$, respectively. The value of $\eta_{\mathrm{TCR}}$ reaches a maximum at the same reforming temperature where $\eta_{\text {th.eff }}$ reaches its maximum. Increasing the exhaust temperature does not increases the LHV gained in the process, but increases the exhaust enthalpy, causing the $\eta_{\mathrm{TCR}}$ to reduce. At its peak value the TCR thermal efficiency reaches $52 \%$ and $63 \%$ at $S: C=1: 1$ and $S: C=2: 1$, respectively.

The first step to develop the integrated model was to study the effect of RG on HCCI combustion of n-heptane. A synthetic blend of $\mathrm{H}_{2}$ and $\mathrm{CO}$ at a molar ratio $\mathrm{H}_{2}: \mathrm{CO}=3: 1$ was used. At constant intake and engine operational conditions, the addition of RG delays and reduces the magnitude of the LTHR stage. The HTHR was delayed in proportion to the reduction on LTHR. $\mathrm{H}_{2}$ was found to be the main species to alter the LTHR regime by changing the temperature range where this event occurred and by reducing the magnitude of the energy released. In consequence, the HTHR was progressively delayed at higher concentrations of $\mathrm{H}_{2}$ in the cylinder charge. $\mathrm{CO}$ did not show a strong influence on the LTHR and its impact on combustion phasing was a very modest advance of CA50 due to changes on mixture specific heat. The model and experimental results showed that RG addition increased IMEP due to delayed CA50 values. RI calculated values varied depending on the crank angle where the combustion occurred.

The integrated HCCI-TCR system was investigated through a parametric study developed with the HCCI engine model. The addition of RG, thanks to its hydrogen content, allowed for tuning the CA50 value. The effect of RG on CA50 at low engine speed depends on load $\left(A F_{\text {syst }}\right)$. At low load, the effect of RG was negligible, while at high load the effect was very significant. At high loads the effect of RG addition was more pronounced, manifested in its ability to delay CA50 values by more than $20^{\circ} \mathrm{CA}$ at the highest RG values. This non-linearity in CA50 was caused by the combined effect of exhaust temperature variations and $\mathrm{RG}$ composition, in terms of $\mathrm{H}_{2}$ and $\mathrm{CO}$ concentration, as function of reforming temperature. The effect of RG addition on IMEP and indicated engine thermal efficiency depended not only on the amount of RG added but on the load and speed conditions that defined the RG composition. At high load and $900 \mathrm{rpm}$, the benefit was estimated as $6 \%$, while at mid-load $\left(A F_{\text {syst }}=40\right)$ the benefit in IMEP was found around 3.5\%. At $1500 \mathrm{rpm}$ the best benefit obtained with RG was calculated below $1.5 \%$, At $A F_{\text {syst }}=30$ and $\mathrm{RG}=20 \%$.

The effect of RG on indicated engine thermal efficiency was twofold. First a reduction in the energy input at IVC; and second, an increase in work during the expansion stroke due to the delaying effect of RG on n-heptane combustion. The effect on emissions also depends on engine conditions. At high load the addition of $\mathrm{RG}$ reduced the amount of $\mathrm{NO}_{\mathrm{x}}$ emitted. At low load calculated $\mathrm{NO}_{\mathrm{x}}$ emissions reduce slightly with RG. Low loads increase the $\mathrm{CO}$ emissions due to near misfiring conditions, and this effect 
was exacerbated at high speeds. At high load the relative reduction in available $\mathrm{O}_{2}$ forces a slight increase in $\mathrm{CO}$ emissions.

RG addition was found not capable of improving the engine performance limits defined by RI. Although calculated RI values were affected by the way the numerical solution was obtained, the solution was consistent regarding the effect of RG. According to the RI map, the HCCI engine can only be operated under acceptable ringing conditions at a maximum AF between 40 and 45 at $900 \mathrm{rpm}$ and below 45 at higher engine speeds. Exhaust temperature is highly dependent on AF conditions. The addition of RG had its largest impact in exhaust temperature by delaying CA50, which increased exhaust temperature as the gas has less time to cool down during the expansion stroke.

Evaluation of the TCR shows that at typical conditions for HCCI operation AF 40, the reformer thermal efficiency was around 1.1, meaning that there was a 10\% increase in the LHV of RG by kilogram of fuel reformed. The TCR system efficiency showed that at typical HCCI operation conditions AF 40, about $50 \%$ of the energy recovered from the exhaust gases was used to increase the LHV of RG. Around $18 \%$ of exhaust enthalpy was recovered during the steam-heptane reforming process at maximum RG use.

\subsection{Recommendations}

Regarding the HCCI MZ combustion modeling, the HC emission modeling would benefit from more zones and specialized crevice zones. It can be inferred that solution of boundary layer problems using MZ models require a MZ model tailored to the engine where experimental data was obtained.

The ability to control ignition timing, without a significant loss of lower heating value associated with EGR (internal or external), suggest that the use of TCR technologies to produce $\mathrm{H}_{2}$ on board can be used to control the ignition timing of HCCI heptane. Other fuels that behave like n-heptane, with LTHR stages and with the tendency to delay the CA50 with higher concentrations of $\mathrm{H}_{2}$ can also be studied to expand the domain of fuels suitable for HCCI-CTR operation.

The ability of the TCR to achieve maximum fuel conversion levels suggest that it can be used in HCCI-SI engines, where the HCCI is used at low load and low speed, avoiding operating conditions where high RI are achieved, while providing the benefits of improved IMEP and improved engine efficiency. 
The HCCI-TCR modeling would benefit from a model where heat transfer processes are studied. This could include the exhaust manifold heat transfer process and the heat transfer process between engine exhaust gases and the recuperative reformer. That consideration would reduce the exhaust temperature and provided a more accurate picture of the integrated HCCI-TCR system. 


\section{References}

Aceves, S. M., Flowers, D., Westbrook, C., Pitz, W., Christensen, M., and Johanson, B., "A Multi-Zone Model for Prediction of HCCI Combustion and Emissions." SAE Paper, no. 2000-01-0327 (2000).

Aceves, S. M., Smith, J. R., Westbrook, C., and Pitz, W., "Compression Ratio Effect on Methane HCCI Combustion." ASME Journal of Gas Turbines and Power Vol. 121, no. 3 (1999).

Aroonsrisopon, T., Sohm, V., Werner, P., and Foster., D., "An Investigation into the Effect of Fuel Composition on HCCI Combustion Characteristics." SAE Paper, no. 2002-01-2830 (2002).

AVL, AVL BOOST User's Guide version 4.0, AVL LIST GmbH., Graz, Austria, 2003.

Beard, C. A., "Inlet and Exhaust Systems." in Diesel Engine Reference Book, by Challen, B., and Baranescu, R., Chap. 9, Society of Automotive Engineers, Inc., Warrendale, PA, 1999.

Bennett, J. P., "Issues in Hydrogen Production Using Gasification." in Materials for the Hydrogen Economy, by Jones, R. H., and Thomas, G. J., Chap 8, CRC Press Taylor and Francis Group, Boca Raton, FL, 2007.

Cairns, A., and Blaxhill, H., "The Effects of Combined Internal and External Exhaust Gas Recirculation on Gasoline Controlled Auto-Ignition.” SAE Paper, no. 2005-01-0133 (2005).

Cao, L., Zhao, H., Jiang, Xi., and Kalian, N., "Investigation into the Effect of Injection Timing on Stoichiometric and Lean CAI Operations in a 4-Stroke GDI Engine." SAE Paper, no. 2006-01-0417 (2006).

Caton, J. A., and Heywood, J. B., "An Experimental and Analytical Study of Heat Transfer in an Engine Exhaust Port.” Int. J. Heat Mass Transfer 24, no. 4 (1981): 581-595.

Chang, J., Guralp, O., Filipi, Z., Najt, P., Rask, R., and Assanis, D., "New heat transfer correlation for an HCCI engine derived from measurements of instantaneous surface heat flux." SAE Paper, no. 2004-012996 (2004).

Chen, Z., Yan, Z., and Elnashaie, S., "Modeling and optimization of a novel membrane reformer for higher hydrocarbons." AIChE J 49, no. 5 (2003): 1250-65.

Christensen, M., and Johansson, B., "Supercharged Homogeneous Charge Compression Ignition (HCCI) with Exhaust Gas Recirculation and Pilot Fuel.” SAE Paper, no. 2000-01-1835 (2000).

Christensen, M., Johansson, B., and Einewall, P., "Homogeneous Charge Compression Ignition (HCCI) using iso-Octane, Ethanol and Natural Gas - A comparison with Spark Ignition Operation." SAE Paper, no. 972874 (1997).

Christensen, M., Johansson, B., Amneus, P., and Mauss F., "Supercharged Homogeneous Charge Compression Ignition." SAE Paper, no. 980787 (1998). 
Christensen, T. S., "Adiabatic Prereforming of Hydrocarbons - an Important Step in Syngas Production." Appl Catal A: Gen, 1996: 138-285.

Curran, H. J., Gaffuri, P., Pitz, W. J., and Westbrook, C. K., "A Comprehensive Modeling Study of nHeptane Oxidation.” Combustion and Flame, no. 114 (1998): 149-177.

Dec, J., and Sjoberg, M., "Isolating the Effects of Fuel Chemistry on Combustion Phasing in an HCCI Engine and the Potential of Fuel Stratification for Ignition Control." SAE Paper, no. 2004-01-0557 (2004).

Easley, W. L., Agarwal, A., and Lavoie, G. A., "Modeling of HCCI Combustion and Emissions Using detailed Chemistry." SAE Paper, no. 2001-01-1029 (2001).

Eng, J. A., "Characterization of Pressure Waves in HCCI Combustion." SAE Paper, no. 2002-01-2859 (2002).

Eng, J. A., Leppard, W. A., and Sloane, T. M., "The Effect of POx on the Autoignition Chemistry of nHeptane and Isooctane in an HCCI Engine.” SAE Paper, no. 2002-01-2861 (2002).

Fish, A., "The Cool Flames of Hydrocarbons." Angewandte Chemie International Edition in English Vol. 7, no. 1 (1968): 45-60.

Fiveland, S., and Assanis, D., "Development of a Two Zone HCCI combustion Model Accounting for Boundary Layer Effects.” SAE Paper, no. 2001-01-1028 (2001).

Fiveland, S., and Assanis, D., "A Four-Stroke Homogeneous Charge Compression Ignition Engine Simulation for Combustion and Performance Studies.” SAE Paper, no. 2000-01-0332 (2000).

Fogler, H. S., Elements of chemical reactor engineering. Prentice-Hall, Inc., Upper Saddle River, NJ, 2006.

Fu, H., Chen, X., Shilling, I., and Richardson, S., “A One-Dimensional Model for Heat Transfer in Engine Exhaust Systems.” SAE Paper, no. 2005-01-0696 (2005).

Glassman, I., Combustion, Academic Press, Inc., London, UK, 1996.

Gray, Allen W., and Thomas W. Ryan. "Homogeneous Charge Compression Ignition (HCCI) of Diesel Fuel." SAE Paper, no. 971676 (1997).

Guo, H., Li, H., and Neil, W. S., "A Study on the performance of Combustion in a HCCI Engine Using nHeptane by a Multizone Model." Proceedings of the ASME Internal Combustion Engine Division 2009 Fall Technical Conference. Lucerne, Switzerland, 2009.

Heywood, J. B., Internal Combustion Engine Fundamentals. McGraw-Hill, Inc., New York City, NY, 1988.

Hoogers, G., "Fuel Cells." in The Engineering Handbook, by Dorf, R. C., Chap. 77, CRC Press LLC., Boca Raton, FL, 2005. 
Hosseini, V., and Checkel, M. D., "Effect of Reformed Gas on HCCI Combustion - Part I: High Octane Fuels." SAE Paper, no. 2007-01-0208 (2007-a).

Hosseini, V., and Checkel, M. D., "Effect of Reformed Gas on HCCI Combustion - Part II: Low Octane Fuels.” SAE Paper, no. 2007-01-0206 (2007-b).

Houseman, J., and Cerini, D., "Onboard Hydrogen Generation for Automobiles." 11th Intersociety Energy Conversion Engineering Conference. Nevada, 1976.

Hu, J., Wang, Y., VanderWeil, D., Chin, C., Palo, D., Rozmiarek, R., Dagle, R., Cao, J., Holladay, J., Baker, E., "Fuel Processing for Portable Power Applications." Chemical Engineering Journal, 93 (2003): 55-60.

Hulkvist, A., Endgar, U., Johanson, B., and Klingmann, J., "Reacting Boundary Layers in a Homogeneous Charge Compression Ignition (HCCI) Engine." SAE Paper, no. 2001-01-1032 (2001).

Hunt, A., and Ewing, R., Percolation Theory for Flow in Porous Media, Lect. Notes Phys. 771, Springer, Berlin Heidelberg, 2009.

Hyvönen, J., Wilhelmsson, C., and Johansson, B., "The Effect of Displacement on Air Diluted MultiCylinder HCCI Engine Performance." SAE Paper, no. 2006-01-0205 (2006).

Jain, S., Adiga, K., and Verkener, V., "A New Approach to Thermodynamic Calculations of Condensed Fuel-Oxidizer Mixtures." Combustion and Flame 40 (1981): 71-79.

Johnson, T. V., "Diesel Emission Control in Review.” SAE Paper, no. 2009-01-0121 (2009).

Jones, M. R., and Wyszynski, M. L., "Exhaust-Gas Reforming of Hydrocarbon Fuels.” SAE Paper, no. 931096 (1993).

Kalghatgi, G. T., Risberg, P., and Ångström, H. E., “A Method of Defining Ignition Quality of Fuels in HCCI Engines.” SAE Paper, no. 2003-01-1816 (2003).

Kelly-Zion, P., and Dec, E. J., "A Computational Study of the Effect of Fuel-Type on Ignition Time in HCCI Engines.” 28th International Combustion Symposium. Edinburgh, 2000.

Kirk, R.E., and Othmer, D. F., Kirk-Othmer Encyclopedia of Chemical Technology. 4th ed., Vol. 13., Wiley, New York City, NY, 2000.

Komninos, N.P., Hountalas, D.T., and Kouremenos, D. A., "Development of a New Multi-zone Model for the Description of Physical Processes in HCCI Engines." SAE Paper, no. 2004-01-0562 (2004).

Kongsereeparp, P., and Checkel, M. D., "Investigating the Effects of Reformed Fuel Blending in a Methane or n-Heptane -HCCI Engine Using a Multizone Model.” SAE Paper, no. 2007-01-0205 (2007).

Kongsereeparp, P., and Checkel, M. D., "Study of Reformer Gas Effects on n-Heptane HCCI combustion using a Chemical Kinetic Mechanism Optimized by Genetic Algorithm." SAE Paper, no. 2008-01-0039 (2008). 
Kulzer, A., Ansgar C., Rausher, M., Sauer, C., Wurfel, G., and Blank, T. "Thermodynamic Analysis and Benchmark of Various Gasoline Combustion Concepts.” SAE Paper, no. 2006-01-0231 (2006).

Lemmon, E. W., McLinden, M. O., and Friend, D. G., "Thermophysical Properties in Fluid Systems in NIST Chemistry WebBook." NIST Standard Reference Database. 2010. http://webbook.nist.gov (accessed June 2010).

Leppard, W. R., “The Chemical Origin of Fuel Octane Sensitivity.” SAE Paper, no. 902137 (1990).

Livengood, J., and Wu, P., "Correlation of Autoignition Phenomenon in Internal Combustion Engines and Rapid Compression Machines.” 5th Symp. (Intern.) on Combust. (1955): 347-356.

Lu, X. C., Chen, W., and Haung Z., "A Fundamental Study on the Control of HCCI Combustion and Emissions by Fuel Design concept Combined With Controllable EGR. Part 1. The Basic Characteristics of HCCI Combustion.” Fuel 84 (2005): 1074-1083.

Milovanovic, N., and Chen, R., “A Review of Experimental and Simulation Studies on Controlled AutoIgnition Combustion.” SAE Paper, no. 2001-01-1890 (2001).

Nah, C. Y., and Palanki, S., "Analysis of Heptane Autothermal Reformer to Generate Hydrogen for Fuel Cell Applications.” Int J Hydrogen Energy 34 (2009): 8566-8573.

Najt, P. M., and Foster D. E., “Compression-Ignited Homogeneous Charge Combustion.” SAE Paper, no. 830264 (1983).

Noda, T., and Foster D. E., "A Numerical Study to Control Combustion Duration of Hydrogen Fueled HCCI by using Multi-Zone Chemical Kinetics Simulation.” SAE Paper, no. 2001-01-0250 (2001).

Noguchi, M., Tanaka, Y., Tanaka, T. and Takeuchi, Y., “A Study on Gasoline Engine Combustion by Observation of Intermediate Reactive Products During Combustion.” SAE Paper, no. 790840 (1979).

Ogawa, H., Miyamoto, N., Kaneko, N., and Ando, H., "Combustion Control and Operation Range Expansion in an HCCI Engine with Selective Use of Fuels with Different Low Temperature Oxidation Characteristics." SAE Paper, no. 2003-01-1827 (2003).

Ogink, R, and Golovitchev, V., "Gasoline HCCI Modeling: An Engine Cycle Simulation Code with a Multizone Combustion Model.” SAE Paper, no. 2002-01-1745 (2002).

Olsson, J., Tunestal, P. Haraldsson, G., and Johansson, B., “A Turbo Charged Dual Fuel HCCI Engine.” SAE Paper, no. 2001-01-1896 (2001).

Olsson, J., Tunestal, P., Ulfvick, J., and Johansson B., "The Effect of Cooled EGR on Emissions and Performance of a Turbocharged HCCI engine.” SAE Paper, no. 2003-01-0743 (2003).

Onishi, S., Jo, S. H., Shoda, K., Jo, P. D., and Kato, S., "Active Thermo-Atmosphere Combustion (ATAC) - A New Combustion Process for Internal Combustion Engines.” SAE Paper, no. 790591 (1979). 
Patel, A., Kong, S., Reitz, R. D., "Development and Validation of a Reduced Reaction Mechanism for HCCI Engine Simulations.” SAE Paper, no. 2004-01-0558 (2004).

Peng, Z., Zhao, H., and Ladommatos, N., "Effect of Air/Fuel Ratios and EGR Rates on HCCI Combustion of n-Heptane, a Diesel Type Fuel.” SAE Paper, no. 2003-01-0747 (2003).

Persson, H., Pfeiffer, R., Hultqvist, A., and Johansson, B., "Cylinder to Cylinder and Cycle to Cycle Variations at HCCI Operation with Trapped Residuals." SAE Paper, no. 2005-01-0130 (2005).

Pollard, R. T., "Hydrocarbons." in Comprehensive Chemical Kinetics: Gas Phase Combustion, by Bamford, C. H., and Tipper, C. F., Vol. 17, (1977): 249-367.

Posada, F., Bedick, C., Clark, N.N., Koslov, A., Linck, M., Boulanov, D., and Pratapas, J., "Low Temperature Combustion with Thermo-Chemical Recuperation." SAE Paper, no. 2007-01-4074 (2007).

Reaction Design. CHEMKIN Software Theory Manual. no. RD00411-C01-004-001, San Diego, CA, 2007.

Ryan, T. W., "Homogeneous Charge Compression Ignition of Diesel Fuel.” SAE Paper, no. 961160 (1996).

Shaver, G. M., Gerdes, J. C., Jain, P., and Caton, P. A., "Modeling for Control of HCCI Engines." Proc. of the Amer. Control Conf. Denver, Colorado (2003): 749-754.

Shibata, G., Oyama, K., Urushijara, T., and Nakano T., "The Effect of Fuel Properties on Low and High Temperature Heat Release and Resulting Performance of an HCCI Engine." SAE Paper, no. 2004-010553 (2004).

Shibata, G., Oyama, K., Urushijara, T., and Nakano, T., "Correlation of Low Temperature Heat Release with Fuel Composition and HCCI Engine Combustion." SAE Paper, no. 2005-01-0138 (2005).

Shudo, T., Ono, Y., and Takahashi, T., "Ignition Control by DM- Reformed Gas in HCCI Combustion of DME.” SAE Paper, no. 2003-01-1824 (2003).

Sjoberg, M., Dec, J. E., Babaimopoulus, A., and Assanis, A., "Comparing Enhanced Natural Thermal Stratification Against Retarded Combustion Phasing for Smoothing of HCCI Heat Release Rates." SAE Paper, no. 2004-01-2994 (2004).

Thring, R. H., "Homogeneous Charge Compression Ignition (HCCI) Engines.” SAE Paper, no. 892068 (1989).

Tottrup, P. B., "Evaluation of Intrinsic Steam Reforming Kinetic Parameters from Rate Measurements on Full Particle Size." Appl Catal 4 (1982): 377-379.

Urushihara, T., Hiraya, K., Kakuhou, A., and Itoh, T., "Expansion of HCCI Operating Region by the Combination of Direct Fuel Injection, Negative Valve Overlap and Internal Fuel Reformation." SAE Paper, no. 2003-01-0749 (2003). 
Waldman, J., Nitz, D., Aroonsrisopon, T., and Foster, D. E., "Experimental Investigation into the Effects of Direct Fuel Injection during the Negative Valve Overlap Period in a Gasoline Fueled HCCI Engine." SAE Paper, no. 2007-01-0219 (2007).

Wang Z., Wang J.X., Tian, G., Shuai, J., Zhang, Z., Yang, J., "Research on Steady and Transient Performance of an HCCI Engine with Gasoline Direct Injection." SAE Paper, no. 2008-01-1723 (2008).

Warnatz, J., Maas, U., and Dibble, W., Combustion Physical and Chemical Fundamentals, Modeling and Simulation, Experiments, Pollutant Formation. 2nd ed., Springer-Verlag, Berlin Heidelberg, New York, 1999.

Westbrook, C. K., "Chemical Kinetics of Hydrocarbon Ignition in Practical Combustion Systems." $28^{\text {th }}$ International Combustion Symposium. Edinburgh (2000): 1563-1577.

Westbrook, C. K., Warnatz, J., and Pitz, W. J., "A Detailed Chemical Kinetic Reaction Mechanism for the oxidation of iso-Octane and n-Heptane Over and Extended Temperature Range and its Application to Analysis of Engine Knock." 22nd International Combustion Symposium. Pittsburgh, PA (1988): 893-901.

Wilhelmsson, C., Tunestal, P., and Johansson, B., "Operation Strategy of a Dual Fuel HCCI Engine with VGT.” SAE Paper, no. 2007-01-1855 (2007).

Willand, J., Nieberding, R. G., Vent, G., and Enderle, C., "The Knocking Syndrome - Its Cure and its Potential." SAE Paper, no. 982483 (1998).

$\mathrm{Xu}$, J., and Froment, J. F., "Methane Steam Reforming, Methanation and Water-Gas Shift: Intrinsic Kinetics." AIChE J. 35, no. 1 (1989): 88-96.

Yang, J., and Martin, J.K., "Approximate Solution One Dimensional Energy Equation for Transient, Compressible, Low Mach Number Turbulent Boundary Layer Flows." Journal of Heat Transfer Vol 11 (1989): 619-624. 


\section{Appendix A. Experimental Data Variability}

Experimental data variability is presented here based on a single case of engine operation conditions assuming steady state operation. The conditions are engine speed of $800 \mathrm{rpm}$ and equivalence ratio $\varphi=0.26$. The in-cylinder pressure data was provided by Dr. Vahid Hosseini of the National Research Council Canada. During steady state conditions, for the condition described here and for each one presented as validation data, the in-cylinder pressure data was recorded as 10 samples per engine crank angle and smoothed through a low pass filter $(<2.5 \mathrm{kHz})$. The mean value and the standard deviation were calculated for 75 engine cycles where recorded and averaged to reduce combustion noise. Figure A1 shows the calculated mean in-cylinder pressure $\mathrm{P}$, and its standard deviation $\sigma$.

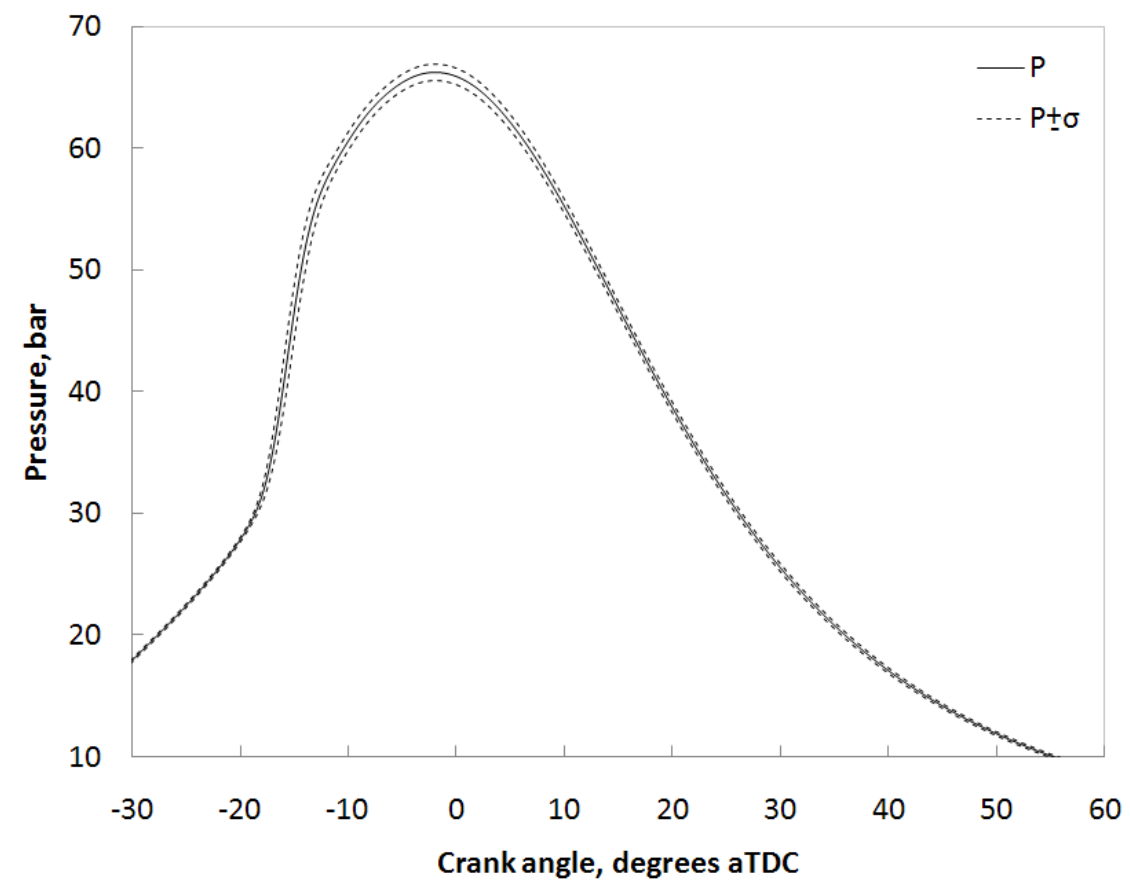

Figure A-1. Experimental in-cylinder pressure $P$, averaged for 75 cycles, and its corresponding standard deviation $\sigma$. Engine speed $800 \mathrm{rpm}, \varphi=0.26, P_{\text {int }}=144 \mathrm{kPa}$ and $T_{\text {int }}=383 \mathrm{~K}$

The standard deviation of the experimental data is presented in Figure A-2. It can be observed that the pressure variability very small during the compression stroke, before the ignition occurs. After ignition occurs, the standard deviation peaks above 1 bar. During the estimated duration of the combustion process (CA10-CA90), the value of standard deviation remains above 0.2 bar. Once the combustion reactions have finished, the standard deviation remains around 0.1 bar. 


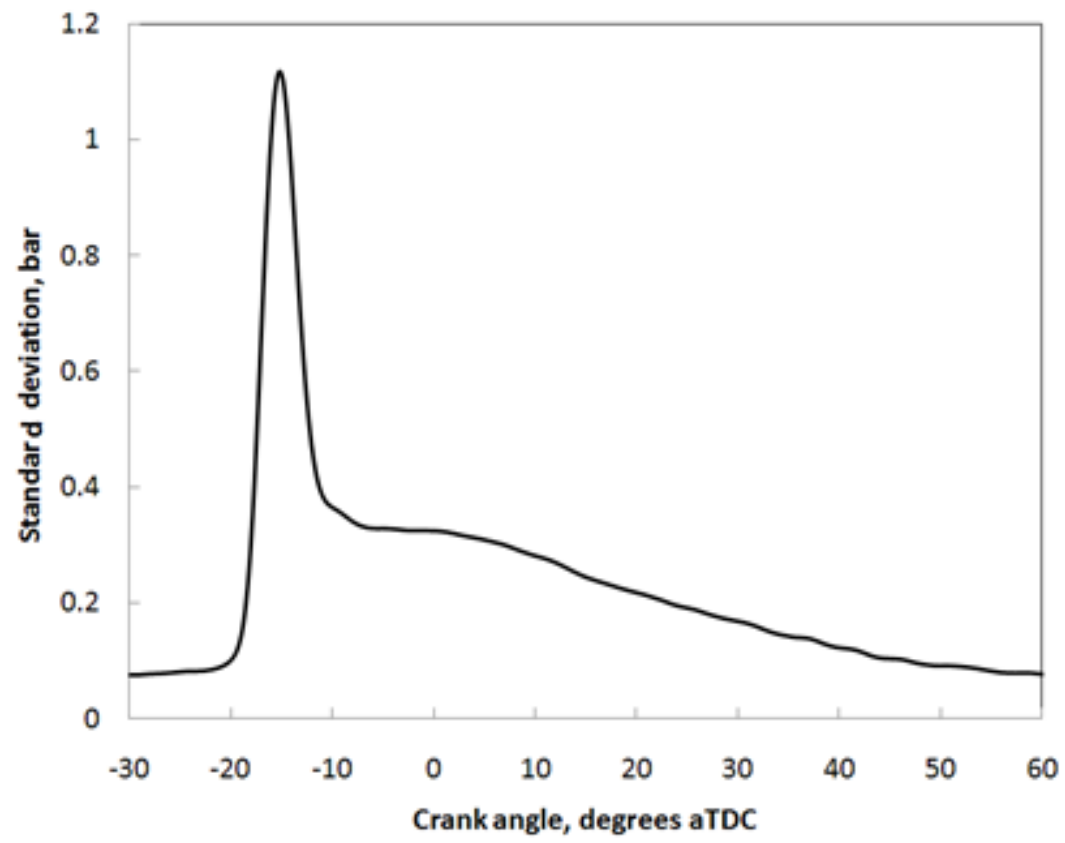

Figure A-2. Standard deviation for experimental in-cylinder pressure. Engine speed $800 \mathrm{rpm}, \varphi=0.26$, $P_{\text {int }}=144 \mathrm{kPa}$ and $T_{\text {int }}=383 \mathrm{~K}$ 